\section{Consejo de Editores (Editors Board)}

Editora Jefe (Editor-in-Chief)

Dra. Rosa García-Ruiz, Universidad de Cantabria, España

Editores Adjuntos (Assistant Editors)

- Jaime Padilla-Verdugo, Universidad Politécnica Salesiana, Ecuador

- Dr. Napoleón Esquivel, Universidad Politécnica Salesiana, Ecuador

Editores temáticos (Thematic Editors)

- Sergio Enrique Hernández Loeza, Universidad Autónoma de México, México

- Álvaro Guaymás, Universidad Nacional de Salta, Argentina

- Dr. Daniel Mato, Universidad Nacional Tres de Febrero, Argentina

Co-Editores internacionales (International Coeditors) Brasil: Dr. Geraldo Caliman, Universidade Católica de Brasília, Brasil

\section{Consejo Científico (Advisory Board)}

- Dr. Alejandro Rodríguez-Martín, Universidad de Oviedo, España

- Dra. Ana Castro Zubizarreta, Universidad de Cantabria, España

- Dra. Ana Rosa Arias Gago, Universidad de León, España

- Dr. Antonio Bautista García-Vera, Universidad Complutense de Madrid, España

- Dra. Armanda Matos, Universidad de Coímbra, Portugal

- Dr. Carlos Paladines Escudero, Pontificia Universidad Católica del Ecuador, Ecuador

- Dra. Carmen Martínez Novo, Universidad de Kentucky, USA

- Dra. Cristina Allemann-Ghionda, Universidad de Colonia, Alemania

- Dr. Daniel Mato, Universidad Nacional Tres de Febrero, Argentina

- Dr. Emilio Álvarez-Arregui, Universidad de Oviedo, España

- Dr. Felipe Trillo Alonso, Universidad de Santiago de Compostela, España

- Dra. Gabriela Borjes, Universidade Federal de Juiz de Fora, Brasil

- Dr. Geraldo Caliman, Universidade Católica de Brasília, Brasil

- Dr. Ignacio Aguaded, Universidad de Huelva, España

- Dr. Javier Loredo Enríquez, Universidad Iberoamericana México

- Dr. José Joaquín Brunner, Universidad Diego Portales, Chile

- Dr. Manuel Area, Universidad de La Laguna, España

- Dr. Mario Óscar Llanos, Università Pontificia Salesiana, Italia

- Dra. Natalia González Fernández, Universidad de Cantabria, España

- Dra. Paula Renés Arellano, Universidad de Cantabria, España

- Dr. Ronaldo Zacharias, Centro Universitario Salesiano de São Paulo, Brasil

- Dra. Rosa García-Ruiz, Universidad de Cantabria, España

- Dra. Soraya Ferreira Vieira, Universidade Federal de Juiz de Fora, Brasil

- Dr. Vicent Gozálvez Pérez, Universidad de Valencia, España

\section{Consejo Internacional de Revisores}

(International Reviewers Board)

- Dra. Adelina de Oliveira Novaes, Universidade Cidade de São Paulo, Brasil

- Dra. Adir Casaro Nascimento, Universidade Catolica Dom Bosco, Brasil

- Dra. Águeda Delgado-Ponce, Universidad de Huelva, España

- Dra. Aleksandra Jablonska, Universidad Pedagógica Nacional, México

- Dr. Alexandre Godoy Dotta, Centro Universitário Autônomo do Brasil, Brasil

- Dra. Alicia Inés Villa, Universidad Nacional de La Plata, Argentina

- Dra. Alma Rosa Hernández Mondragón, Universidad La Salle, México

- Dr. Amauris Laurencio Leyva, Universidad de La Habana, Cuba

- Dra. Amelia Gort Almeida, Universidad de La Habana, Cuba

- Dra. Ana Lupita Chaves, Universidad de Costa Rica, Costa Rica

- Ana Marcela Castellanos Guzmán, Universidad La Salle, México

- Dra. Ana María Eyng, Pontificia Universidad Católica de Paraná, Brasil

- Dra. Ana Pérez-Escoda, Universidad Internacional de La Rioja, España

- Dra. Ángela Santamaría Chavarro, Universidad del Rosario de Bogotá, Colombia

- Dra. Anita Gramigna, Università degli Studi di Ferrara, Italia

- Dra. Annachiara Del Prete, Universidad Autónoma de Chile, Chile

- Anne Köster, European University Viadrina, Alemania

- Dra. Antonella Cagnolati, Università degli Studi di Foggia, Italia

- Dra. Antonia Ramírez García, Universidad de Córdova, España

- Dr. Antonio Hilario Aguilera Urquiza, Universidade Federal de Mato Grosso do Sul, Brasil

- Dr. Antônio Igo Barreto Pereira, Universidade Federal do Acre, Brasil

- Dr. Aristeo Santos López, Universidad Autónoma del Estado de México, México

- Dra. Azucena Ochoa Cervantes, Universidad Autónoma de Querétaro, México

- Dra. Beatriz Celada Scianca, Universidad Nacional del Comahue, Argentina

- Dra. Beatriz Gualdieri, Universidad Nacional de Luján, Argentina

- Dra. Bianca Thoilliez Ruano, Universidad Autónoma de Madrid, España

- Dra. Carla Förster Marín, Pontificia Universidad Católica de Chile, Chile

- Carlos Manuel Crespo Burgos, Universidad Andina "Simón Bolívar”, Ecuador

- Dra. Caterina Benelli, Università degli Studi di Messina, Italia

- Dra. Cecilia Dolores Correa de Molina, Universidad Simón Bolívar, Colombia

- Claudia Cayulef Ojeda, Universidad Católica Silva Henríquez, Chile

- Dra. Claudia del Pilar Vélez De La Calle, Universidad de San Buenaventura de Cali, Colombia 
- Dr. Cristian Desbouts, Università Pontificia Salesiana, Italia

- Dra. Damián Mendoza-Zambrano, Universidad Laica Eloy Alfaro de Manabí, Ecuador

- Dr. Daniel Hugo Suárez, Universidad Metropolitana para la Educación y el Trabajo, Argentina

- Daniel Llanos Erazo, Universidad Politécnica Salesiana, Ecuador

- Dr. Daniel Loncón, Universidad Nacional de la Patagonia San Juan Bosco, Argentina

- Diana Ávila, Universidad Politécnica Salesiana, Ecuador

- Dra. Dora Elena Marín Méndez, Universidad Nacional Autónoma de México, México

- Dr. Eduardo Fabara Garzón, Universidad Andina "Simón Bolívar", Ecuador

- Dr. Eduardo Mercado Cruz, Instituto Superior de Ciencias de la Educación del Estado de México, México

- Elena Guadalupe Rodríguez-Roa, Universidad La Salle, México

- Dra. Elsa Celina Gatti García, Universidad de la República, Uruguay

- Dra. Emiko Saldivar, University of California, Santa Barbara, USA

- Dr. Enrique Arturo Parra Marín, Universidad de Chile, Chile

- Dr. Enrique Sánchez Rivas, Universidad de Málaga, España

- Dr. Ernesto Guerra García, Universidad Autónoma Indígena de México, México

- Dr. Felipe de Jesús Perales Mejía, Universidad Pedagógica Nacional - Unidad Torreón, México

- Dr. Fernando Lara, Pontificia Universidad Católica del Ecuador, Ecuador

- Fernando Paladines Jaramillo, Universidad Politécnica Salesiana, Ecuador

- Dra. Flor Marina Bermúdez-Urbina, Universidad de Ciencias y Artes de Chiapas, México

- Dr. Francisco Javier Merchán Iglesias, Universidad de Sevilla, España

- Dr. Gabriel Alfonso Suárez Medina, Pontificia Universidad Javeriana, Colombia

- Dra. Gema Sáez Rodríguez, Universidad Francisco de Vitoria, España

- Dr. Gersem José dos Santos Luciano, Universidade Federal do Amazonas, Brasil

- Dra. Gina Benavides Llerena, Universidad Andina "Simón Bolívar", Ecuador

- Giovanna Barroca de Moura, Universidade Estadual dal Paraíba, Brasil

- Dr. Greby Uriel Rioja Montaño, Universidad Mayor de San Simón, Bolivia

- Dr. Gunther Dietz, Universidad Veracruzana, México

- Hamlet Santiago González Melo, Universidad Distrital Francisco José de Caldas, Colombia

- Dr. Henry Chero Valdiviezo, Universidad Católica Los Ángeles de Chimbote, Perú

- Dra. Herminia Hernández, Universidad de La Habana, Cuba

- Dra. Irene Melgarejo Moreno, Universidad Católica de Murcia, España

- Dr. Ivar César Oliveira de Vasconcelos, Universidade Católica de Brasília, Brasil

- Dr. Jaime Brito Farías, Universidad Católica Silva Henríquez, Chile

- Dr. Jaime Rivas Castillo, Universidad Don Bosco, El Salvador
- Dr. Jean Carlos García Zacarías, Pontificia Universidad Católica del Ecuador, Ecuador

- Dra. Jennie Brand Barajas, Universidad La Salle, México

- Dr. José Andrés García Méndez, Escuela Nacional de Antropología e Historia, México

- Dr. José Antonio Fernández Bravo, Universidad Camilo José Cela, España

- Dr. José Francisco Alvarado García, Universidad Iberoamericana, México

- Dr. José Guilherme dos Santos Fernandes, Universidade Federal do Pará, Brasil

- Dr. José Luis Guzón Nestar, Universidad Pontificia de Salamanca, España

- Dr. José Luis Moral, Università Pontificia Salesiana, Italia

- Dr. José Manuel Alfonso Sánchez, Universidad Pontificia de Salamanca, España

- Dr. José Manuel del Val Blanco, Universidad Nacional Autónoma de México, México

- Dr. José Raúl Jiménez Ibáñez, Universidad de La Salle, Colombia

- Dr. Juan Vicente Ortiz Franco, Fundación Universitaria Los Libertadores, Colombia

- Dr. Julio Cabero-Almenara, Universidad de Sevilla, España

- Dra. Kathie Njaine, Fundação Oswaldo Cruz, Brasil

- Laura Rosso, Universidad Nacional de Nordeste, Argentina

- Dra. Laura Selene Mateos Cortés, Universidad Veracruzana, México

- Dra. Leonor Buendía Eisman, Universidad de Granada, España

- Dra. Liliana Inés Ávila Garzón, Universidad Pedagógica y Tecnológica de Colombia, Colombia

- Dra. Liliana Mayer, Universidad Metropolitana para la Educación y el Trabajo, Argentina

- Dra. Lisset Coba Mejía, Facultad Latinoamericana de Ciencias Sociales, Ecuador

- Dr. Lorenzo Cantoni, Università della Svizzera Italiana, Suiza

- Dr. Luis Antonio Reyes Ochoa, Universidad Católica Silva Henríquez, Chile

- Dr. Luis Enrique Sime Poma, Pontificia Universidad Católica del Perú, Perú

- Dr. Luis Fernando Cuji Llugna, Universidad Nacional de Tres de Febrero, Argentina

- Luis Fernando García Álvarez, Centro INAH Nuevo león, México

- Dr. Luis Huerta-Charles, New Mexico State University, USA

- Dra. Marcela Rosario Salazar Ibáñez, Universidad La Salle, México

- Dr. Márcio Roberto de Lima, Universidade Federal de São João Del-Rei, Brasil

- Dra. Maria Alfredo Lopes Moreira, Universidade do Minho, Portugal

- Dra. María Bertha Fortoul Ollivier, Universidad La Salle, México

- Dra. María Cristina Rinaudo, Universidad Nacional de Río Cuarto, Argentina

- Dra. Maria de Fátima Pereira, Universidade do Porto, Portugal

- Dra. María del Mar Rodríguez Rosell, Universidad Católica de Murcia, España

- Dra. María Domingo Coscollola, Universitat Internacional de Catalunya, España 
- Dra. María Elena Ortiz, Universidad Politécnica Salesiana, Ecuador

- Dra. María Inés Copello Danzi, Universidad de la República, Uruguay

- Dra. María José Batista Pinto, Universidade Federal de Minas Gerais, Brasil

- Dra. María José Bermeo, Columbia University, USA

- María Margarita Marhx Bracho, Universidad La Salle, México

- Dra. María Sol Villagómez, Universidad Politécnica Salesiana, Ecuador

- Dra. María Teresa Prieto Quezada, Universidad de Guadalajara, México

- Dra. Maria-Carmen Caldeiro-Pedreira, Universidad Pública de Navarra, España

- Dra. Mariana Coralina Carmo, Universidade Estadual de Campinas, Brasil

- Dra. Maribel Enaida Alegre Jara, Universidad Nacional del Santa, Perú

- Dra. Maribel Pinto, Instituto Politécnico de Viseu, Portugal

- Dr. Marlécio Maknamara, Universidade Federal da Bahia, Brasil

- Dra. Mirtes Lira, Universidade de Pernambuco, Brasil

- Dra. Mónica Cecilia Sáenz Amaguaya, Universidad Politécnica Salesiana, Ecuador

- Dra. Mónica Montenegro, Universidad de Buenos Aires, Argentina

- Nelson Rubén Martínez Reyes, Universidad Don Bosco, E Salvador

- Dra. Olga Espinoza Aros, Pontificia Universidad Católica de Chile, Chile

- Pablo Gómez Jiménez, Universidad Juárez Autónoma de Tabasco, México

- Dra. Patricia Carla da Hora Correia, Universidade do Estado da Bahia, Brasil

- Dra. Patricia Muñoz Borja, Universidad Santiago de Cali, Colombia

- Dr. Paulo César Nodari, Universidade de Caxias do Sul, Brasil

- Dr. Pierre André Garcia Pires, Universidade Federal do Acre, Brasi

- Raimundo França, Universidade Federal de Alagoas, Brasil

- Dr. Ramon Luis de Santana Alcântara, Universidade Federal do Maranhão, Brasil

- Dra. Regina Ferreira Barra, Universidade Federal de Juiz de Fora, Brasil

- Dra. Renata Nunes Vasconcelos, Universidade Federal de Alfenas, Brasil

- Dra. Rita Gomes do Nascimento, Ministério da Educação, Brasil

- Dr. Robério Pereira Barreto, Universidade do Estado da Bahia, Brasil

- Roberto López Chila, Universidad Politécnica Salesiana Ecuador

- Dra. Romilda Teodora Ens, Pontifícia Universidade Católica do Paraná, Brasil
- Dra. Ruth Aguilar Feijoo, Universidad Técnica Particular de Loja, Ecuador

- Dra. Ruth Amanda Cortes Salcedo, Instituto para la Investigación Educativa y el Desarrollo Pedagógico - IDEP, Colombia

- Dra. Salomé Sola-Morales, Universidad de Santiago de Chile, Chile

- Dra. Sandra Alves da Silva Santiago, Universidade Federal da Paraíba, Brasil

- Dra. Sandra Liliana Londoño Calero, Pontificia Universidad Javeriana, Colombia

- Dr. Sebastián Granda Merchán, Universidad Politécnica Salesiana, Ecuador

- Dra. Shantal Meseguer Galván, Universidad Veracruzana Intercultural, México

- Dra. Shirlei Rezende Sales, Universidade Federal de Minas Gerais, Brasil

- Silvia Barco, Universidad Nacional del Comahue, Argentina

- Dra. Sílvia Ester Orrú, Universidade de Brasília, Brasil

- Dra. Sonia Liliana Ivanoff, Universidad Nacional de la Patagonia San Juan Bosco, Argentina

- Dra. Sonia Sampaio, Universidad Federal de Bahía, Brasil

- Susana Barco, Universidad Nacional del Comahue, Argentina

- Dra. Suyai Malen García Gualda, Universidad Nacional del Comahue, Argentina

- Dra. Suzana dos Santos Gomes, Universidade Federal de Minas Gerais, Brasil

- Dra.Sylvia Irene Schmelkes del Valle, Universidad Iberoamericana, México

- Dra. Tânia Regina Dantas, Universidade do Estado da Bahia, Brasil

- Dra. Tania Suely Azevedo Brasileiro, Universidade Federal do Oeste do Pará, Brasil

- Dra. Teresa Laura Artieda, Universidad Nacional del Nordeste, Argentina

- Dra. Vanessa Figueiredo, Universidade Federal de Mato Grosso do Sul, Brasil

- Dra. Vania Tanira Biavatti, Universidade Regional de Blumenau, Brasil

- Dra. Victoria Jara, Universidad Politécnica Salesiana, Ecuador

- Dra. Wedja Maria Oliveira Leal, Pontifícia Universidade Católica de São Paulo, Brasil

- Dr. Wellington de Oliveira, Universidade Federal dos Vales do Jequitinhonha e Mucuri, Brasil

- Willy Chambi Zabaleta, Universidad Salesiana de Bolivia, Bolivia

- Yamila Irupé Núñez, Universidad Nacional de Misiones, Argentina

- Dra. Yamirlis Gallar Pérez, Universidad Internacional SEK, Ecuador

- Dra. Yolanda Castro Robles, Pontificia Universidad Javeriana, Colombia 
Edita (Published by)

Universidad Politécnica Salesiana

www.ups.edu.ec

\section{Consejo Técnico (Board of Managment)}

Hernán Hermosa (Coordinación General Editorial Abya-Yala) MSc. Tania X. Barrezueta (Soporte OJS)

Dr. Ángel Torres-Toukoumidis (Soporte OJS)

Wilson Verdugo (Soporte OJS)

Marco Gutiérrez (Soporte OJS)

Paulina Torres (Redacción y estilo)

Raysa Andrade (Maquetación)

Martha Vinueza Manosalvas (Maquetación)

Joaquín Crespo (Traducción)

Editorial Universitaria Abya-Yala (Quito, Ecuador) Av. 12 de Octubre N23-116 y Wilson, Bloque A, UPS Casilla 17-12-7-19

Teléfono: (593-2)3962-800 ext. 2638

E-mail: editorial@ayayala.org

Portal electrónico: http://www.abyayala.org

\section{Consejo de Publicaciones}

(Board of Publication)

Dr. Javier Herrán Gómez, sdb

Dr. Juan Bottasso Boetti, sdb

MSc. Juan Pablo Salgado Guerrero

Dr. José Juncosa Blasco

MSc. Jaime Padilla Verdugo

Dra. Floralba Aguilar Gordón

MSc. Sheila Serrano Vincenti

MSc. Fabricio Freire Morán

MSc. John Calle Sigüecia

MSc. René Unda Lara

MSc. Betty Rodas Soto

MSc. Andrea De Santis

MSc. Mónica Ruiz Vásquez

Editor General UPS (General Editor UPS)

Dr. Luis Álvarez-Rodas 
Editorial

SECCIÓN MONOGRÁFICA

"Educación Superior y Pueblos Indígenas en América Latina"

Higher Education and Indigenous Peoples in Latin America

DRA. ANA VALERIA HANNE.

Estudiantes indígenas y Universidad: realidades y retos ante la diversidad cultural. Caso de la Universidad

Nacional de Salta

Indigenous Students and University: realities and challenges to cultural diversity.

The case of National University of Salta

DRA. MARÍA SOL VILLAGÓMEZ RODRÍGUEZ.

"Otras Pedagogías": La experiencia de la Carrera de Educación Intercultural Bilingüe-UPS

Other pedagogies: The experience of the Bilingual Intercultural Education-UPS

DAVID SILVESTRE DELGADILLO ZERDA.

"Iyambae": en busca de una educación superior emancipadora en la UNIBOL Guaraní y Pueblos de Tierras Bajas "Iyambae": in search of an emancipatory higher education in the UNIBOL Guarani and Lowland Peoples

DR. JURIS TIPA.

¿De qué me sirve la interculturalidad? Evaluación de la Universidad Intercultural de Chiapas por sus estudiantes What is the use of interculturalism? Evaluation of the Intercultural University of Chiapas by its students

VICTORIA RAQUEL ROJAS LOZANO, SERGIO IVÁN NAVARRO MARTÍNEZ

Y AMELIA ESCOBAR POTENCIANO

La educación superior intercultural en Tabasco. Una historia en construcción

Higher Intercultural Education in Tabasco. A history in construction

\section{SECCIÓN MISCELÁNEA}

CARLOS ANTONIO ITURRALDE DURÁN.

La educación superior en las cárceles. Los primeros pasos de Ecuador

The higher education in prisons. The first steps of Ecuador

DR. LAURENTINO LUCAS CAMPO Y MTRA. FANNY CRUZ GARCÍA

Trayectoria de la Universidad Intercultural del Estado de Puebla (UIEP), México

Trajectory of the Intercultural University of the State of Puebla (UIEP in Spanish), Mexico

RAMIRO ANDRÉS ANDINO JARAMILLO

Capacitación docente: Pilar para la identificación y gestión de la violencia escolar

Teacher training: Pillar for the identification and bullying management

RUBI SUREMA PENICHE CETZAL Y CRISTÓBAL CRESCENCIO RAMÓN MAC.

Desempeño académico y experiencias de estudiantes universitarios mayas en Yucatán, México

Performance academic and experiences of Mayan university students on Yucatan, Mexico

LUCIANE SCHULZ.

Juego de Arena y Escrituras de Sí: revelando los itinerarios ecoformativos de una profesora

The Sandplay and the Written of Itself: revealing the eco-formative journey of an teacher

Normas de Publicación en "Alteridad"

Publication guidelines in "Alteridad". 


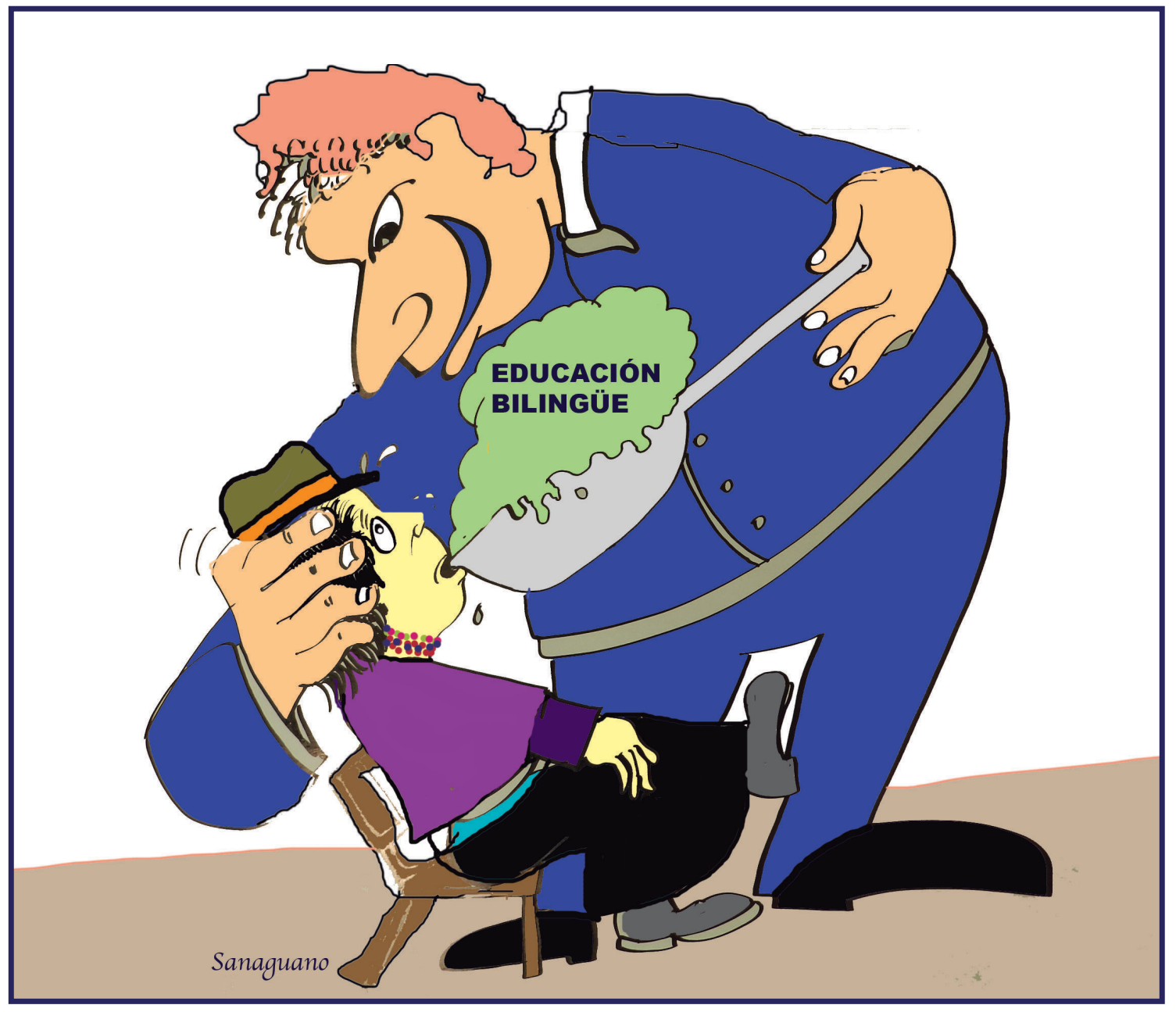

GALERÍA DE ARTE

PABLO SANAGUANO

Artista y teólogo ecuatoriano. Pablo caracteriza a su obra como una práctica artística comunitaria. De hecho, su recorrido privilegia el encuentro. Para lograrlo se esfuerza por estar en una actitud de movimiento cotidiano: salir para buscar, buscar hasta encontrar, encontrar para aprender y aportar, aportar para re-crear. Gracias a esa dinámica continúa aprendiendo; la inspiración le proporciona los encuentros con la gente de las comunidades indígenas y de los barrios; encuentros de todos los "colores" que han ampliado su humanidad, los cuales han sido "traducidos" en creaciones plásticas [dibujos, cuadernos de viaje, caricaturas sociales, modelados en arcilla, ilustraciones de cuentos, pinturas sobre lienzo, fotografías...]. 


\section{Editorial}

En América, la construcción de los Estados poscoloniales estuvo marcada por políticas de homogeneización sociocultural, en las que predominaron proyectos de "blanqueamiento". Las poblaciones de la región que no aceptaron dichos proyectos han sido objeto de embates de los Estados orientados a lograr su exterminio físico o su aculturación forzada, siendo los pueblos indígenas y afrodescendientes los más afectados.

En el caso particular de los pueblos indígenas, su historia ha estado marcada por intensos procesos de imposición y resistencia, dentro de los cuales las políticas llamadas indigenistas han sido centrales. Un ejemplo significativo han sido aquellas que han mantenido las relaciones coloniales al interior de los Estados nacionales latinoamericanos, utilizando a los sistemas educativos como una de sus herramientas fundamentales. En respuesta a ellas, los pueblos indígenas promovieron cambios importantes en la impronta educativa, especialmente durante el siglo XX, dando origen a diversas modalidades como la de educación indígena, educación bilingüe, educación bilingüe bicultural y, más recientemente, educación intercultural.

La emergencia de estas modalidades responde a procesos organizativos diversos, que en algunos casos fueron impulsados y ejecutados desde los gobiernos centrales, y en otros desde las organizaciones indígenas. Un denominador común es que comenzaron a implementarse en la educación básica, dándose pocos desarrollos en la educación media, media superior y superior. Fueron estas circunstancias las que propiciaron que las primeras iniciativas de formación superior para pueblos indígenas estuvieran orientadas a mejorar la calidad de la labor docente, pues era necesario contar con profesionales conocedores de las lenguas y culturas de sus pueblos. A raíz de estos procesos, durante la última década del siglo XX comenzaron a tomar fuerza las demandas de inclusión en educación superior por parte de los pueblos indígenas, pero también de transformación de este nivel educativo para que responda de manera más abierta y apropiada a la diversidad cultural de la región.

Es así que en los últimos años proliferaron experiencias de "Programas de Inclusión de Estudiantes Indígenas" en Universidades y otros tipos de Instituciones de Educación Superior (IES) "convencionales" (denominamos "convencionales" a las universidades e IES que no han sido creadas por/para/con pueblos indígenas), que en líneas generales responden a objetivos de asegurar su ingreso, permanencia y graduación. Asimismo, algunas organizaciones y referentes de los pueblos indígenas crearon instituciones que por lo general denominaron "universidades propias" o "universidades indígenas", las cuales en muchos casos concibieron también como "intercultura-

les". Entre tanto, algunos organismos internacionales, así como gobiernos y organizaciones de la sociedad civil de varios países latinoamericanos crearon universidades y otros tipos de IES, a las que con frecuencia también concibieron como "interculturales". Como resultado de estos diversos tipos de experiencias observamos la emergencia de un creciente número de estudiantes, docentes y profesionales indígenas que se relacionan de diversas formas con sus comunidades de origen 
$\mathrm{u}$ otras de pueblos indígenas, las instituciones educativas (de diverso nivel), otras instituciones gubernamentales o no, y con otros actores sociales, incluso más allá de los respectivos contextos nacionales.

En este marco, la sección monográfica de Alteridad que acá presentamos procura contribuir a analizar avances, retos y dificultades de las experiencias que en el campo de Educación Superior y Pueblos Indígenas han venido desarrollándose en América Latina especialmente desde la década de 1990 en adelante. Con este propósito ofrece estudios de caso que dan cuenta de la diversidad de experiencias que están emergiendo en toda la región, llamando la atención tanto a las innovaciones que se están introduciendo, como a los retos y dificultades que enfrentan.

El primer artículo, de Ana Valeria Hanne, titulado "Estudiantes indígenas y Universidad: realidades y retos ante la diversidad cultural. Caso de la Universidad Nacional de Salta" da cuenta de la experiencia de un programa de inclusión de estudiantes indígenas en una universidad convencional de Argentina. Para ello analiza discursos, acciones y políticas institucionales desplegadas por la Universidad Nacional de Salta (UNSa) creadas con el objeto de favorecer y fortalecer los procesos de inclusión socioeducativa de estudiantes indígenas auto-reconocidos en la misma. La autora concluye afirmando que la UNSa necesita plantearse la necesidad de "interculturalizarse" mediante la transformación de sus objetivos, estructuras, currículas y relaciones sociales, promoviendo genuinas políticas de inclusión socioeducativa, que valoren la diversidad como un verdadero potencial de desarrollo para todos.

Siguiendo esta veta temática, el segundo artículo “'Otras Pedagogías’: La experiencia de la Carrera de Educación Intercultural Bilingüe-UPS”, de María Sol Villagómez, presenta una análisis del surgimiento de pedagogías "otras" en un programa educativo de formación docente de profesores indígenas impulsado desde la Universidad Politécnica Salesiana (UPS), universidad convencional del Ecuador. La autora denomina "otras pedagogías" a aquellas que parten de las necesidades educativas de los sujetos y colectivos que se educan, es decir, que surgen de los contextos, de las luchas, de las resistencias y de la participación. En este programa educativo se posicionan alternativas pedagógicas que se producen en la pluralidad, en el encuentro de personas diversas y en la interrogación de las jerarquías. Son pedagogías alertas a la necesidad permanente de una mirada crítica, y que fomentan el estudio de pedagogías emergentes latinoamericanas e interculturales.

El tercer artículo "Iyambae' en busca de una educación superior emancipadora en la UNIBOL Guaraní y Pueblos de Tierras Bajas”, de David Silvestre Delgadillo Zerda, nos introduce al complejo campo de las Instituciones Interculturales de Educación Superior (IIES) en Bolivia. Dicho proyecto, nos señala el autor, posee dos condiciones básicas: el territorio y la emancipación. Sostiene una crítica al régimen de universidades públicas-convencionales, atrincheradas en la autonomía universitaria, y de su invariable función reproductora de la desigualdad arraigada fuertemente en el pensamiento colonial. Al mismo tiempo afirma que las IES interculturales o indígenas carecen de mecanismos, procesos e instrumentos que les permitan ser congruentes con el fin de construir una educación propia. Ello requiere, primero, de la identificación y determinación de indicadores que especifiquen los constituyentes académicos posibilitando a una determinada IES ser catalogada o no como una IIES, diferenciándolas de cualquier otro régimen de universidades.

Continuando con el análisis de la trayectoria histórica de las IIES, el cuarto artículo "La educación superior intercultural en Tabasco. Una historia en construcción”, de Victoria Raquel Rojas Lozano, Sergio Iván Navarro Martínez y Amelia Escobar Potenciano, presenta un estudio del recorrido de la Universidad Intercultural del Estado de Tabasco (UIET), incluyendo su proceso de creación, las etapas por las que ha pasado y los retos que se enfrentan. A través de una 
revisión documental y del uso de técnicas cualitativas de corte participativo, los autores señalan que entre las dificultades institucionales se encuentran el uso político que se le da a la UIET, la rotación docente, el ser estigmatizada por la población local y las mismas autoridades educativas, y la distancia entre el modelo intercultural y su puesta en práctica. En cuanto a los estudiantes, identifican como principales retos la deserción estudiantil y la baja tasa de titulación. Los autores concluyen que si no se realizan modificaciones, la universidad puede convertirse en un agente más del neoindigenismo.

Cerramos el monográfico con un acercamiento a actores emergentes de vital importancia en el campo de las IIES, y a través de quienes se puede tener una primera aproximación a procesos evaluativos de las experiencias, es decir, a sus estudiantes. El artículo, de Juris Tipa, lleva por título “¿De qué me sirve la interculturalidad? Evaluación de la Universidad Intercultural de Chiapas por sus estudiantes" y nos ofrece un estudio cuantitativo de las opiniones que estudiantes de la Universidad Intercultural de Chiapas (UNICH) tienen sobre el modelo educativo de su universidad, los motivos que les hicieron ingresar y la formación recibida. Entre las principales conclusiones de su estudio, Tipa señala que la adscripción étnica tiene un impacto diferenciado en la forma de evaluar el modelo de universidad intercultural y en las motivaciones para el ingreso a la UNICH; asimismo, señala que las dudas acerca del modelo educativo aumentan conforme avanzan en el cursado de la carrera y se hace más patente entre estudiantes de la licenciatura en Lengua y Cultura. El estudio deja ver las tensiones existentes en la UNICH al tratar de cumplir con el objetivo de construir una interculturalidad simétrica y las dificultades laborales que vislumbran sus estudiantes.

Los cinco artículos que conforman la sección monográfica ponen en evidencia las dificultades que enfrentan estas jóvenes experiencias frente a la institucionalidad propia de la educación superior convencional y los imaginarios sociales vinculados a ella, que limitan la emergencia de modelos educativos que no sólo hagan visible la diversidad cultural, sino que además incidan en la transformación de la educación superior en su totalidad y del lastre colonial que pesa sobre las sociedades latinoamericanas.

Reflexionar sobre estos temas se hace aún más relevante cuando nos encontramos a unos meses de la conmemoración de los 100 años de la Reforma Universitaria de Córdoba. Significativamente, el tema de la diversidad cultural no formó parte de la agenda del movimiento estudiantil de 1918, esperablemente marcado por las limitaciones propias de las visiones ideológicas de aquella época. En cambio, sí lo estará y con fuerza en el mes de junio del próximo 2018 al celebrarse su centenario, toda vez que uno de los siete ejes temáticos de la 3ra. Conferencia Regional de Educación Superior (CRES) está dedicado a "Educación Superior, diversidad cultural e interculturalidad en América Latina"1. Esta inclusión no es sorprendente, porque es consecuencia de la creciente importancia que las experiencias de los tipos de las estudiadas en esta sección monográfica han venido adquiriendo en las últimas décadas, cuyo valor y necesidad ya fue explícitamente reconocido en la Declaración Final de la 2da. CRES, realizada en Cartagena de Indias en junio de 2008. El espacio regional que brindará la 3ra. CRES permitirá perfilar líneas de acción basadas en los avances, retos y dificultades que existen en este campo, siendo insumos fundamentales las experiencias de los propios actores y las publicaciones académicas como la que ahora entregamos al lector.

1 http://wnw.cres2018.org/ 
La Sección Miscelánea inicia con el primer artículo titulado "La Educación Superior en las cárceles. Los primeros pasos del Ecuador” de Carlos Antonio Iturralde Durán quien sostiene que para alcanzar el Buen Vivir es necesario resolver los problemas de exclusión social de los presos, muchos de los cuales antes de delinquir vivieron en un contexto de violencia y pobreza, situación que en la cárcel se reproduce, cuya superación se alcanzaría con una educación superior inclusiva similar a la ofertada en las universidades pero con diseños curriculares y metodológicos específicos que rehabiliten a la persona. En esta dirección, Ecuador inició una primera experiencia facilitando becas de estudios universitarios a un grupo de prisioneros, proyecto que requiriere de un trabajo entre instituciones y del aporte de la sociedad para alcanzar los objetivos planteados, como el convertir los centros carcelarios en ambientes de Rehabilitación Social que promuevan los derechos humanos.

El segundo escrito, "Trayectoria de la Universidad Intercultural del Estado de Puebla (UIEP), México" de Laurentino Lucas Campo y Fanny Cruz García aborda el trabajo impulsado para brindar educación universitaria por medio de la UIEP, quien desde hace diez años trabaja con la población de Totonacapan compuesta por totonacos, nahuas y mestizos. Los objetivos de la investigación son evidenciar cómo funciona la UIEP y analizar si se cumplió el fin para el cual fueron creadas las Universidades Interculturales (UI). El estudio abarca el análisis y la reflexión del tema por parte de los profesores e investigadores de tiempo completo. Los principales hallazgos se relacionan con la docencia, la investigación y la vinculación con la comunidad. Y, se concluye afirmando que los avances, las contradicciones, los conflictos y las perspectivas del futuro abonan al desarrollo de la institución.

El tercer artículo, "Capacitación docente: pilar para la identificación y gestión de la violencia escolar” de Ramiro Andrés Andino Jaramillo expone cómo los docentes de Educación General Básica de la Unidad Educativa "Nicolás Gómez Tobar", de la ciudad de Santo Domingo pueden identificar y gestionar la violencia escolar. Para ello aplicó un módulo donde describe tipos de violencia escolar y modelos de gestión pacífica de conflictos. La metodología fue investigación explicativa, aplicó un pretest, una intervención y un postest a 22 docentes. Los resultados obtenidos muestran que la capacitación ayuda a identificar casos de violencia escolar posibilitando la aplicación de modelos de resolución pacífica de problemas. En las conclusiones, se explica la importancia de la capacitación vista como ayuda para que el docente identifique y gestione la violencia escolar, también se resumen las ventajas de concientizar a los docentes sobre este problema.

El cuarto manuscrito, "Desempeño académico y experiencias de estudiantes universitarios mayas en Yucatán, México" de Rubi Surema Peniche Cetzal y Cristóbal Crescencio Ramón describe las experiencias académicas que han tenido tres estudiantes universitarios con desempeño académico sobresaliente de una universidad pública en Yucatán, enfatizando sus dificultades y las estrategias usadas para superarlas. Para los tres estudiantes el asunto económico es el principal problema que influye en su formación; también la dificultad para usar instrumentos tecnológicos, los prejuicios hacia su imagen, y la falta de apoyo y credibilidad en sus capacidades por parte de sus padres. A pesar de ello, los estudiantes consideran que la organización, la comunicación con los docentes, la autogestión personal, las tutorías y las becas a la excelencia permiten superar las dificultades y obtener buenas notas.

La última investigación, "Juego de Arena y Escrituras de Sí: revelando los itinerarios ecoformativos de una profesora" de Luciane Schulz cierra la sección miscelánea y sustenta que el tema central de los cursos de formación de profesores es lo intelectual/conceptual. Ante ello, sostiene que es necesario que el futuro docente cree un ambiente pedagógico que favorezca la autoría, la 
autoconstrucción y la autorreflexión partiendo del ámbito (auto)biográfico o comprensión de sí mismo y de sus nexos con el saber, siguiendo el itinerario de la ecoformación. La metodología consiste en talleres que se realizaron en el Centro de Educación de la Universidad Federal de Rio Grande do Norte, Brasil, que terminaron con la confección de escenarios imaginarios de los elementos agua, fuego, aire y tierra por medio del Juego de Arena (Sandplay) y de las escrituras de sí. La experiencia permitió darse cuenta que la ecoformación aporta a la trayectoria personal, docente y académica y son recursos metodológicos esenciales para la formación del profesor.

Deseamos que las investigaciones publicadas en este número generen un impacto positivo en nuestros lectores e incentive el deseo de producir y divulgar vuestras investigaciones científicas. También les recordamos que Alteridad. Revista de Educación, asesorados por el Grupo Comunicar de España, continúa ejecutando del Plan Estratégico que le está conduciendo a mejorar la calidad y el impacto de sus artículos con el objetivo de postularse a base de datos como SciELO y Scopus, sin olvidar que la revista ya se encuentra indexada en Latindex y Redalyc entre otros. Finalmente, nos despedimos invitándoles a enviar sus artículos para iniciar el proceso de revisión para publicarlos en la Sección monográfica del Vol. 13 No. 2 (julio-diciembre de 2018) titulado Educación y sexualidad o en la sección Miscelánea que recibe investigaciones que abarcan el tema de la educación.

Cordialmente,

Sergio Enrique Hernández Loeza Coordinador temático

Doctorando en la Universidad Autónoma de México

Álvaro Guaymás

Coordinador temático Universidad Nacional de Salta (Argentina)

Daniel Mato

Coordinador temático

Universidad Nacional Tres de Febrero (Argentina)

Napoleón Esquivel

Editor adjunto

Revista Científica "Alteridad" 



\section{Sección Monográfica}

"Educación Superior y Pueblos Indígenas en América Latina" Higher Education and Indigenous Peoples in Latin America

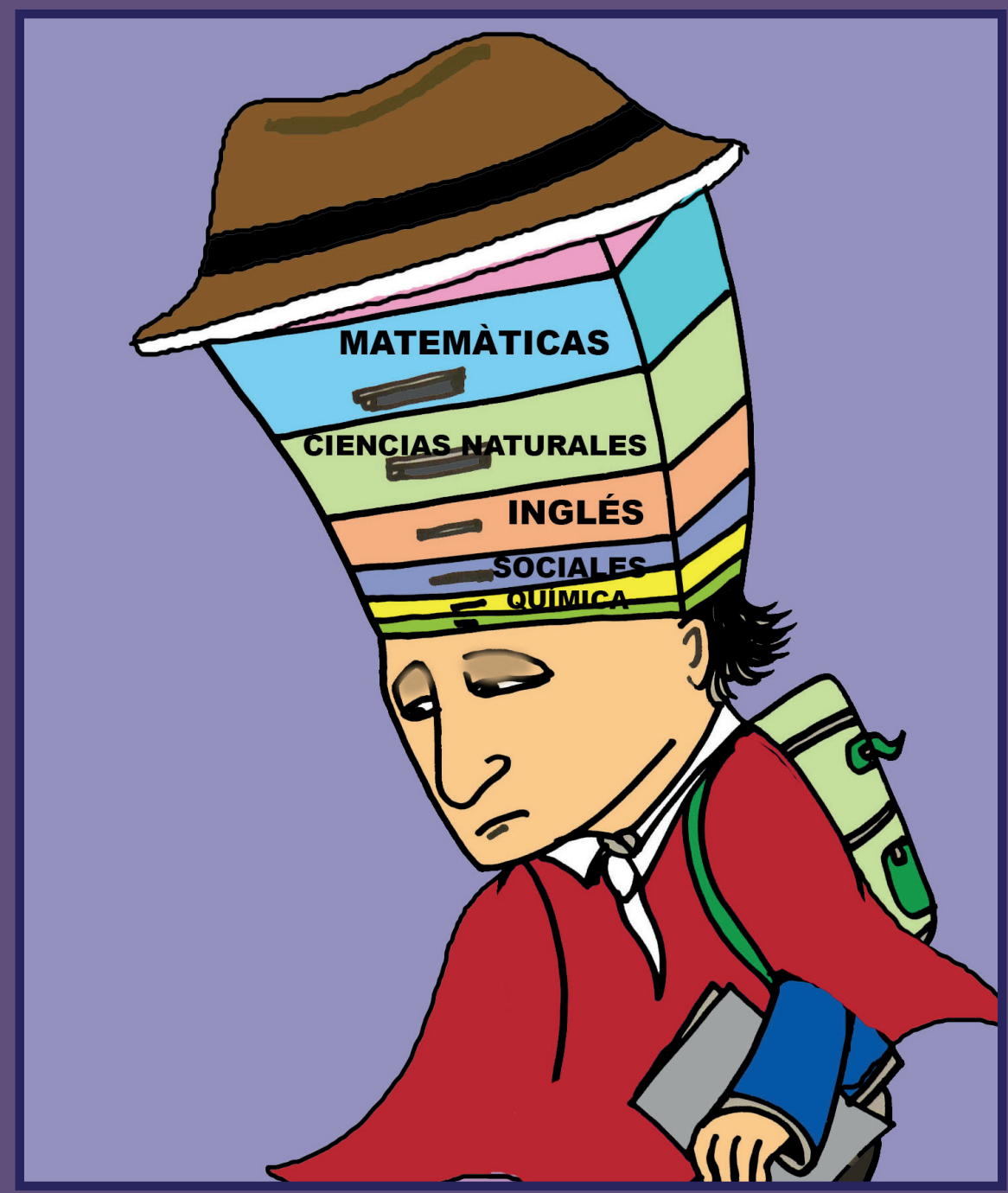




\title{
Estudiantes indígenas y Universidad: realidades y retos ante la diversidad cultural. Caso de la Universidad Nacional de Salta
}

\section{Indigenous Students and University: realities and challenges to cultural diversity. The case of National University of Salta}

\begin{abstract}
Dra. Ana Valeria Hanne es profesora e investigadora de la Universidad Nacional de Salta (Argentina), becaria postdoctoral de CONICET (Consejo Nacional de Investigaciones Científicas y Tecnícas- Argentina), (valehanne @gmail.com) (http://orcid.org/0000-0003-2453-9820)
\end{abstract}

Recibido: 2017-07-28 / Revisado: 2017-01-05 / Aceptado: 2017-11-01 / Publicado: 2018-01-01

\section{Resumen}

El presente artículo identifica, por un lado, los discursos y acciones desplegadas por la Universidad Nacional de Salta (UNSa), en aras a favorecer los procesos de inclusión socioeducativa de estudiantes indígenas autoreconocidos en la misma, apelando al análisis de su política institucional y de las iniciativas desarrolladas (Programas/Proyectos) para atender y promover la diversidad cultural. Por otro, recupera algunas apreciaciones que tales estudiantes expresan, en torno a las debilidades y fortalezas de la UNSa respecto al abordaje de la dimensión étnica. La investigación de la que emana este escrito, supuso un diseño metodológico fundamentalmente cualitativo, apelándose también a descripciones cuantitativas ligadas a perfiles sociodemográficos y culturales. Se empleó un cuestionario semiestructurado, a fin de relevar información sobre aspectos institucionales, psicosociales y étnicos. El mismo contempló la inclusión de herramientas cualitativas: análisis lexicométrico y asociación libre de palabras en torno a núcleos centrales. Asimismo, se consultó a informantes clave y a fuentes secundarias de datos para enriquecer el relevamiento y abordaje de estos tópicos. Los hallazgos posibilitaron advertir la creciente presencia de estudiantes indígenas en la UNSa y sus demandas; el interés y compromiso de grupos institucionales por desplegar estrategias que promuevan accesos y permanencias, como así también la progresiva sensibilización que ha merecido la temática en la academia. Pese a ello, queda mucho camino por desandar en materia de propuestas de atención a la diversidad cultural en orden a la inclusión.

Forma sugerida de citar: Hanne, A. (2018). Estudiantes indígenas y Universidad: realidades y retos ante la diversidad cultural. Caso de la Universidad Nacional de Salta. Alteridad, 13(1), 14-29. https://doi.org/10.17163/alt.v13n1.2018.01. 
Descriptores: Diversidad cultural, universidad estudiantes indígenas, políticas institucionales, inclusión, desafíos.

\begin{abstract}
The present article identifies, on the one hand, speeches and actions deployed by National University of Salta in order to favour the processes of social and educational inclusion of indigenous students that are self-recognized in the university, appealing to the analysis of its institutional policy and others initiatives (programs or projects) developed, to attend and promote cultural diversity. On the other hand, some students' appreciations regarding to the university's ethnic approach and its weaknesses and strengths are recovered.

The research from which this article derives, supposed a methodological design fundamentally qualitative, appealing also to quantitative descriptions linked to
\end{abstract}

\section{Introducción}

La diversidad cultural es una característica constitutiva de la Argentina, y el modo de reconocerla y dar respuesta a ella es uno de los retos más inminentes de la sociedad en general y del sistema educativo en particular. Aunque el carácter pluriétnico y multicultural de la Nación es asumido y proclamado constitucionalmente, sus instituciones precisan acompañar genuinamente dichas decisiones actuando en consecuencia. En este marco, las Universidades, caracterizadas por las históricas resistencias al reconocimiento e inclusión de las diversidades en sus espacios académicos, adquieren hoy un rol trascendental y un compromiso insoslayable. Si bien "siguen concibiéndose como centros neurálgicos de construcción y difusión del conocimiento universal" (Mato, 2008), actualmente son convocadas a repensar sus sentidos, lógicas, posicionamientos, estructuras, valores y saberes, y a reflexionar, además, respecto de los cambios vitales que las mismas precisan gestionar para así construir y sostener espacios verdaderamente acogedores de las pluralidades culturales, entre tantas otras (Dietz y Mateos, 2008). En este social, demographic and cultural profiles. A semi-structured questionnaire was used to provide information on institutional, psychosocial and ethnic aspects. Also, qualitative tools were included: lexicometric analysis and free association of words around central nuclei. Key informants and secondary sources of data were also consulted to enrich the survey and address these topics. The findings made it possible to note the growing presence of indigenous students at National University of Salta and their needs, an interest and commitment from institutional groups to develop strategies to promote indigenous students' access and permanence at the institution, as well as the progressive sensitization that this problematic has deserved in academic environments. Despite of this, there is still a long way to go in terms of proposals for attention to cultural diversity in order to really include indigenous students at universities.

Keywords: Cultural diversity, university, indigenous students, institutional policies, inclusion, challenges.

sentido, el presente artículo se propone identificar los discursos y acciones desplegadas por la Universidad Nacional de Salta (UNSa), en aras a favorecer los procesos de inclusión socioeducativa de estudiantes indígenas autoreconocidos que transitan sus trayectorias académicas en la misma, apelando al análisis de su política institucional y de las iniciativas desarrolladas para atender y promover la diversidad cultural; a la vez que recupera algunas apreciaciones que tales estudiantes expresan, en torno a las debilidades y fortalezas de la UNSa, respecto al abordaje de la dimensión étnica.

La significativa y creciente participación de estudiantes indígenas en los espacios universitarios argentinos evidencia la importancia de reflexionar acerca de las demandas de esos actores y de abordar las nociones de diversidad, acceso e inclusión socioeducativa. Tales presencias no constituyen un hecho reciente, no obstante, en los últimos años, han logrado mayor visibilidad $y$ atención por parte de las instituciones educativas, de las políticas públicas y de los organismos del Estado, producto de incesantes e históricas luchas por la reivindicación de sus postergados y vapuleados derechos, tras una larga historia en el 
país de invisibilidad y exclusión de estos colectivos culturales (Benito Cuéllar, 2009; Zidarich, 2010).

Vale advertir que, aunque las instancias de acceso e inclusión a la universidad suelan concebirse como instancias análogas y simultáneas, resulta medular develar tal eufemismo comprendiendo que constituyen procesos claramente diferenciados, en los cuales, a veces, paradójicamente operan mecanismos excluyentes y con sentidos contrapuestos. Las realidades de los espacios académicos evidencian que dichos accesos no se traducen necesariamente en inclusiones reales, en abordajes "situados" de las trayectorias educativas de los estudiantes indígenas, de sus procesos y pluralidades. Es decir, es menester comprender a la inclusión no sólo como acceso al sistema, no como mera acción aditiva que busca "revelar" presencias omitidas o abordar trayectorias socio-culturales y académicas desde miradas "compensatorias", sino como una auténtica posibilidad de generar y fortalecer mentalidades y actitudes basadas en la equiparación y promoción de derechos (Yarza de los Ríos, 2010).

Sensibilizar a los distintos actores universitarios acerca de la inminente diversidad que existe en la sociedad argentina constituye una imperiosa necesidad, como lo es también el propiciar conocimientos genuinos de los perfiles socioculturales y educativos de los estudiantes indígenas presentes en dichos espacios formativos, quienes demandan a las agendas universitarias el diseño de políticas de inclusión socioeducativas, contextualizadas (Bello, 2009), que favorezcan estructuralmente la equidad en las trayectorias educativas de estos sujetos como una forma posible de democratizar e "interculturalizar” el quehacer universitario (Villasante, 2008).

En este sentido, ahondar en el rol que asumen las universidades frente a la innegable diversidad cultural, con las emergentes y complejas demandas sociales/regionales; las formas de reconocerla, incorporarla y valorarla en sus actores, espacios, currícula, relaciones y procesos; las estrategias institucionales de recepción, inclusión y promoción que se despliegan en relación a los estudiantes indígenas (políticas, programas, proyectos); reparar en sus condiciones de acceso y permanencia; en los aspectos facilitadores y obstaculizadores a lo largo de sus itinerarios formativos; como así también en sus fortalezas y debilidades en el plano socio-cultural-afectivo y académico, resultan aspectos medulares a considerar para el análisis, debate y generación de políticas institucionales inclusivas.

Se sabe que el nivel universitario argentino no cuenta aún con lineamientos ni políticas específicas que respalden la atención a la diversidad cultural (Reynaga, 2011; Paladino, 2008). No obstante, son perceptibles los esfuerzos de algunas universidades, o grupos al interior de ellas, que han hecho manifiesta su intención de favorecer tanto la inclusión socioeducativa como la profesionalización de jóvenes de pueblos indígenas, mediante la generación de diversos tipos de decisiones, proyectos y apoyos. Cada vez resultan más las universidades que, de algún modo, en los últimos años han asumido, desde diversos enfoques, la temática indígena en sus agendas. Las iniciativas y/o programas generados por este tipo de instituciones, en la mayoría de los casos, constituyen experiencias que se traducen en espacios socio-educativos recientemente conquistados. Es loable el compromiso y trabajo de muchos equipos al interior de ellas, ya que "con seguridad que cada una tienen acumuladas problemas, experiencias y aprendizajes que les han dado lineamientos más claros que sólo la buena voluntad para con los indígenas" (Cortés Lombana, 2009, p. 46). Todavía hay mucho camino por recorrer y acciones por desplegar para hacer legítimos los lineamientos jurídicos proclamados a nivel internacional y nacional, los cuales pregonan el desarrollo y ejecución de prácticas sociales y formativas que contemplen las particularidades culturales de los estudiantes indígenas, fortalezcan sus identidades, atenúen las adversidades emergentes en sus respectivas trayectorias y favorezcan el empoderamiento de sus pueblos y comunidades.

En este marco, se presenta el caso de la UNSa, a fin de conocer cuál es el posicionamiento 
que adopta con la temática indígena, partiendo de la consideración que la misma se autodefine como una institución académica "de frontera" (dada la fuerte impronta de su localización geopolítica en sus propósitos y funciones, fundamentalmente al momento de su creación) y que se encuentra situada en la Provincia de Salta, la cual reúne la mayor diversidad cultural y lingüística del país (Buliubasich, 2009). Asimismo, el recuperar algunas apreciaciones de los propios estudiantes indígenas, acerca de las debilidades y fortalezas que ellos identifican en dicha Universidad, pretende movilizar un análisis reflexivo de las demandas y necesidades que aquellos sujetos expresan a la Educación Superior (ES), en tanto portadores de saberes, prácticas y cosmovisiones heterogéneas. Repensar estos aspectos resulta un compromiso ineludible ante el imperioso desafío de promover mayores políticas de inclusión socioeducativa que acojan y valoren la diversidad (Schmelkes, 2012) mediante el desarrollo de legítimos espacios, actitudes y mentalidades interculturales.

\section{Fundamentación teórica}

\subsection{Pueblos indígenas y universidades. Contexto argentino}

La participación de estudiantes indígenas en las universidades, argentinas en particular y latinoamericanas en general, es un fenómeno reciente que tiende a incrementarse y que cobra vital importancia dentro de los procesos de inclusión educativa (Cortés Lombana, 2009). Sin embargo, se sabe que este espacio académico fue vedado para estos sujetos, quienes históricamente estuvieron relegados de la ES.

Argentina narra una historia en la cual las universidades, desde sus orígenes, fueron concebidas como instituciones "monolíticas y homogeneizantes", patrimonio exclusivo de un selecto grupo de la sociedad, caracterizado por su opulento capital social, cultural y económico. Paulatinamente, este escenario fue transformándose, y las crecientes demandas de la sociedad en su conjunto, comenzaron a interpelar a las universidades, demandando mayores niveles de: pertinencia social y cultural, cobertura de la matrícula, extensión y compromiso con las diversas realidades del contexto, en el cual se desempeñaban. Por su parte, los procesos de urbanización indígena, entre otros aspectos, contribuyeron a que algunos jóvenes de los pueblos indígenas accedieran al nivel superior, inscribiéndose en universidades con la intención de profesionalización. Tal incorporación, sin embargo, no siempre supuso visibilidad o reconocimiento, menos aún la toma de conciencia por parte de esas instituciones respecto de la necesidad de ofrecerles contención y una formación con equidad y pertinencia cultural, razón por la cual, en muchos casos, los indígenas optaron por ocultar o negar sus identidades, a fin de evitar situaciones de marginación y menosprecios.

A partir de la década de los noventa, tras las reivindicaciones conquistadas en materia de derechos, los pueblos indígenas comenzaron a explicitar sus presencias en los distintos contextos socio-académicos y a luchar por la concreción de sus aspiraciones personales y comunitarias (Serrudo, 2010). Al respecto, cabe aclarar que tal desafío no estuvo exento de dificultades, por el contrario, fueron y aún continúan siendo muchas las adversidades que deben sortear en sus respectivas trayectorias formativas. Dificultades ligadas a situaciones personales (inseguridades, miedos, desarraigo familiar y comunitario), académicas (formación exigua en los niveles educativos previos, exigencias académicas descontextualizadas), culturales (dominio de códigos culturales significativamente diversos, formas de vinculación, y de desenvolvimiento en la ciudad), económicas (recursos escasos e insuficientes para la subsistencia cotidiana y para afrontar los gastos personales y educativos que implica la vida citadina) (Arce, 2010), entre tantas otras.

Más allá de que en la Argentina este nivel de educación aún no pueda considerarse como un verdadero espacio intercultural y de 
real inclusión, se advierte que uno de los grandes desafíos de las instituciones universitarias reside justamente en acoger genuinamente la diversidad, desplegando en sus espacios y con sus actores algunas "modalidades sostenibles de colaboración intercultural” (Mato, 2016), lo cual invita a desarrollar iniciativas (de formación profesional, investigación y vinculación social) que resulten pertinentes con las diferentes necesidades, culturas, epistemologías y proyectos de los sujetos implicados. No sólo la cuestión de los accesos resulta una dimensión a fortalecer, sino fundamentalmente la relevancia y significatividad con que las acuciantes demandas de los pueblos indígenas son abordadas institucionalmente, en miras a promover ámbitos más democráticos y equitativos.

\subsection{La UNSa y su relación con la temá- tica indígena}

La UNSa, en los últimos años, ha avanzado notablemente en lo que respecta a su vinculación con la temática indígena. El interés por revisitar este tópico en la ES ha ido cobrando fuerza y así, a través de proyectos de vinculación social, de tutorías, del accionar de equipos de cátedra (mediante la incorporación de aspectos alusivos a la diversidad cultural en los programas de las asignaturas; o a través de propuestas de intervención en terreno), del interés de investigadores en plantear indagaciones afines a la diversidad e interculturalidad, o de iniciativas particulares (sumando adeptos y formalizando propuestas enriquecedoras en la materia), la dimensión étnica ha merecido una notable atención, incorporándose paulatinamente en parte de la agenda institucional.

La diversidad cultural ha estado siempre presente en los contextos de la academia (aunque con otros matices y porcentajes), sólo que en muchas ocasiones eran presencias omitidas o excluidas, razón por la cual poco (o nada) se abordaban institucionalmente las singulares realidades culturales de esos estudiantes. Es decir, la UNSa no contaba con políticas de atención e inclusión a la diversidad cultural, ni con medidas específicas que permitieran contener las demandas y necesidades de los sujetos indígenas, que garantizaran su derecho ciudadano a educarse en un marco de igualdad, calidad y equidad.

En los últimos años, ante la inminente y numerosa presencia de universitarios indígenas, se hizo insoslayable la necesidad de diseñar e implementar distintas estrategias que posibilitaran favorecer sus procesos de ingreso, permanencia y graduación. Conforme pasó el tiempo, y con la experiencia acumulada al respecto, puede advertirse que la UNSa ha pasado por etapas, claramente identificables, que transcurren desde la invisibilización/negación de la dimensión étnica en su agenda institucional, pasando por su problematización/ sistematización, hasta llegar, en la actualidad, a la gestión e institucionalización de la atención a las diversidades. Una política institucional genuinamente intercultural todavía supone un desafío para esta Universidad, en tanto aún se están madurando los procesos necesarios para forjar relaciones interculturales con equidad, en el sentido que Mato (2009) lo plantea.

\subsubsection{Algunas referencias a las políticas imple- mentadas por la UNSa}

El reconocimiento de la diversidad de perfiles estudiantiles, junto a los contextos con marcada desigualdad social y económica de los que provienen, demanda una ineludible reflexión acerca del accionar institucional, de las iniciativas y medidas promovidas en pos de una verdadera inclusión al espacio universitario, en particular, y a la sociedad en general, para luego ser traducida en prácticas e intervenciones significativas.

La UNSa refleja la diversidad propia de la provincia en que se sitúa, acusando algunas etnias una representación mayoritaria, según las regiones geográficas en las que se localizan las Sedes académicas. Si bien la presencia de estudiantes pertenecientes a comunidades indígenas en esta Universidad se advierte desde larga data, es recién a partir de 2008 
que la Institución reflexiona acerca de conceptos, discursos y prácticas en torno a la diversidad cultural, en pos de propiciar espacios más inclusivos, que fomenten la democratización de la ES, por sobre todo tipo de diferencia. En este sentido, comenzaron a bosquejarse diversas acciones y proyectos con iniciativas de atención y promoción a la dimensión étnica, los cuales fueron canalizados a través de los correspondientes organismos de la Universidad. En el marco de dichas iniciativas, posteriormente, se aprueba el Programa de Tutorías para Estudiantes de Pueblos Originarios (PTEPO) (Res. CS. N 197/ 10), como una instancia que pretendía ilustrar la efectivización del posicionamiento político, social e institucional adoptado. Hasta entonces, puede decirse que no existía una política institucional que tuviera como destinatarios específicos a los estudiantes indígenas.

El PTEPO es comprendido como un espacio de configuraciones que:

(...) busca acompañar los procesos que realizan los estudiantes a fin de responder a necesidades y problemas situados, abarcando la multiplicidad de dimensiones que convergen: personales, sociales, académicos, culturales, etc. De este modo, el trabajo conjunto que se realiza tiende a desplegar estrategias diversas que posibiliten alcanzar mejores logros académicos y personales. Este acompañamiento resulta indispensable al momento del ingreso. Paulatinamente, al ganar los ingresantes conocimiento y seguridad, los tutores pasan a cumplir más fuertemente la orientación académica y el desarrollo de actividades socioculturales (Bergagna, 2012, p.118).

Importa mencionar que dicho Proyecto no cuenta con economías para otorgar becas integrales a los estudiantes indígenas, por lo que se trabaja con la socialización de la información disponible sobre los distintos beneficios que se ofrecen tanto a nivel nacional, provincial, así como también otras becas o ayudas ofrecidas desde las facultades o la universidad o (para fotocopias, transporte, comedor universitario, etc.) (Ossola, 2014).
Por último, desde la coordinación del Proyecto se proponen diversas actividades extra académicas (talleres participativos sobre temáticas de interés para el grupo; jornadas interculturales de reconocimiento e intercambio de culturas; talleres de escritura y redacción; proyectos de extensión a las comunidades de pertenencia y ferias Interculturales), a fin de propiciar instancias de producción e intercambio cultural; fomentar una actitud de empoderamiento $y$ reafirmación identitaria en los estudiantes indígenas; construir lazos solidarios y vinculaciones interculturales entre los distintos miembros de la comunidad universitaria, y además, de favorecer en ellos un sentimiento de posibilidad e igualdad.

\section{Fundamentación metodológica}

En el presente estudio, por la particularidad de la temática abordada, los perfiles de los participantes y los propósitos que lo orientan, se optó por un diseño de abordaje metodológico fundamentalmente cualitativo, contemplando asimismo una aproximación cuantitativa, de carácter descriptiva (fase exploratoria, vinculada a dimensiones de base y a perfiles sociodemográficos-culturales), a los fines de recuperar otros datos que posibiliten enriquecer la lectura y el análisis cualitativo. Dado el complejo entramado de aspectos involucrados se promueve un diseño metodológico flexible e integral que posibilite abordar la multiplicidad de dimensiones emergentes.

En efecto, la metodología adoptada para el presente estudio resulta particularista, descriptiva y heurística, en tanto se indaga a un acotado número de sujetos, enfatizando un análisis intensivo y comprensivo de algunos núcleos centrales que posibiliten instancias posteriores de teorización.

El diseño cualitativo tiene como preocupación comprender los significados de las acciones humanas y de la vida social en sus contextos naturales, a partir de los propios marcos referenciales y puntos de vistas de los sujetos involucrados 
en las problemáticas investigadas. Parafraseando a Vasilachis (2006), este tipo de investigación supone un abordaje que intenta dar cuenta de la forma en que la realidad social es comprendida, vivenciada y producida. Por ello, en este estudio, a través de la utilización de los instrumentos diseñados se buscó recuperar toda información que posibilitara dichos propósitos, concediendo especial interés a los contextos y procesos socioacadémicos, a la perspectiva de los universitarios indígenas, a sus sentidos, conocimientos y representaciones, mediante la construcción de posibles categorías analíticas (Abric, 2001).

La acción de indagación cualitativa:

[...] se mueve de manera dinámica en ambos sentidos: entre los hechos y su interpretación, y resulta un proceso más bien "circular" y no siempre la secuencia es la misma, varía de acuerdo con cada estudio en particular (Hernández Sampieri, R. et al., 2010, p. 7).

Participaron en el estudio universitarios indígenas "autoreconocidos"2 (Convenio OIT 169, 1989; INDEC 2001; INDEC-ECPI 2004/2005; Censabella, 2010) que iniciaron sus trayectos formativos en la UNSa. (considerando la Sede Central-SC- junto a las Sedes Regionales de OránSRO-y Tartagal-SRT-), inscriptos en diferentes carreras de las instituciones referenciadas, tomando como criterio de selección la cohorte de sujetos comprendidos en el período 2008-2010 (dado que es a partir de 2008 que se encuentra ya sistematizado el trabajo para con estos jóvenes). Dentro de esta cohorte se identificaron 61 alumnos indígenas ( 25 en la SC; 10 en la SRO y 26 en la SRT), de los cuales sólo 26 aceptaron participar de la investigación.

Para la selección de la muestra se consideraron criterios teóricos intencionales (muestreo intencional), que tuvieron en cuenta los propósitos esbozados y la relevancia teórica del universo seleccionado, en función de los interrogantes planteados en la investigación. Se trata de una muestra no probabilística, que adopta el criterio de selección "por conveniencia" en donde se consideraron todos aquellos casos que resultaron accesibles al investigador en las instancias contempladas de abordaje.

Para la obtención de la información se construyó un dispositivo de relevamiento integrado por diferentes herramientas metodológicas, diseñado en función de la literatura consultada y en base a las problemáticas manifestadas por algunos informantes claves. En tal sentido, se elaboró un cuestionario semiestructurado, en tanto no se encontraron antecedentes en el abordaje metodológico de los tópicos abordados en este estudio que pudieran ser readaptados a las realidades investigadas en esta oportunidad.

En el proceso de relevamiento de información se trabajó con herramientas cualitativas, tales como: la Asociación Libre de Palabras y el Análisis Lexicométrico, a fin de generar un espacio que recupere "la voz de los participantes" y que posibilite indagar con mayor profundidad sobre algunos núcleos centrales. Ambas técnicas permiten cuantificar datos originalmente cualitativos, mediante la construcción a posteriori de categorías explicativas que permiten reorganizar y dar sentido a las expresiones vertidas por los participantes. Específicamente, la asociación libre de palabras permite trabajar con las asociaciones conceptuales espontáneas a partir de una frase o término inductor, lo que pone en descubierto las representaciones compartidas por los participantes del estudio (Wagner y Hayes, 2011).

En el proceso de relevamiento se apeló también a fuentes secundarias de datos sobre las temáticas abordadas, consultándose diversos documentos: informes estadísticos sobre el acceso a la universidad por parte de la población estudiada, normativas acerca de la ES y su relación con la cuestión indígena, marcos legislativos afines, escritos elaborados por diversos organismos sobre políticas y programas promulgados e implementados, estatutos y estudios académicos vinculados, informes específicos diseñados por los programas destinados a los estudiantes originarios, entre otros. Asimismo, se mantuvieron reuniones y conversaciones informales con algu- 
nas autoridades/ responsables que contribuyeron o que aún se encuentran comprometidos activamente con tales iniciativas inclusivas.

\section{Análisis y resultados}

\subsection{Dimensiones inclusivas}

Se apeló a las apreciaciones que los estudiantes indígenas manifestaron en torno a la actuación institucional respecto de la diversidad cultural y la inclusión socioeducativa. A los fines del presente trabajo se presenta solo el siguiente nodo. Nodo a: La Universidad y la diversidad cultural

Aquí se buscó conocer las representaciones que los estudiantes indígenas presentaban respecto a la Universidad y su capacidad inclusiva, de atención a la diversidad. Se planteó a dichos sujetos la siguiente pregunta “ ¿Consideras que la Universidad es un ámbito que atiende $y$ valora la diversidad cultural?" Las categorías propuestas como opciones de respuestas fueron: Definitivamente sí (b1); A veces (b2); Casi nunca (b3) y Definitivamente no (b4). Los resultados arrojados en las respuestas evidenciaron que un porcentaje muy reducido de los estudiantes indígenas participantes en el estudio (3\%) considera que la Universidad definitivamente no valora ni atiende la diversidad cultural, en tanto un 23\% del grupo total de encuestados adujo en sentido contrario, es decir confirmando que definitivamente sí lo hace. La mayor concentración de frecuencias en las respuestas la obtuvieron las categorías a veces (39\%) y casi nunca (36\%), lo cual permite inferir entonces que, desde la perspectiva de los propios sujetos involucrados, la atención a la diversidad cultural en la Universidad abordada no representa una política instituida, o en caso de serlo no resulta compatible lo declamado con lo actuado.

\section{Gráfico 1. La universidad como ámbito de atención y valoración de la diversidad cultural}

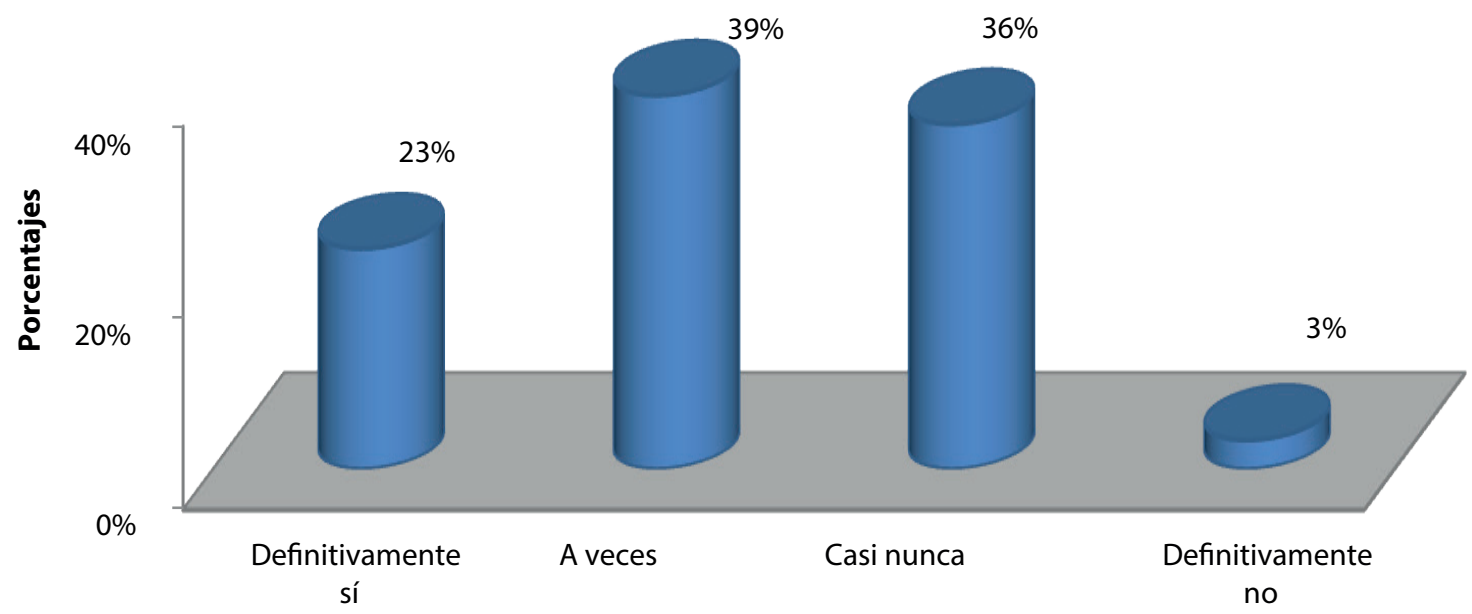

Fuente: elaboración propia

\subsection{Aspectos facilitadores/ obstaculizadores}

En el análisis de los nodos siguientes se exponen aquellos aspectos institucionales y extra-institu- cionales que, según las vivencias y referencias de los estudiantes de pueblos originarios, actuaron como aspectos facilitadores y obstaculizadores, tanto para el acceso, como para la permanencia en la UNSa. 
Nodo a: Aspectos obstaculizadores en el acceso a la Universidad

Se abordaron aquí aspectos de la comunidad universitaria que, según el criterio de los sujetos encuestados, actúan como obstáculos y suponen importantes limitaciones para el acceso a la UNSa. Se recuperaron las respuestas vertidas por ellos ante la consigna de mencionar hasta cinco nociones que asociaran espontáneamente, a partir de la frase inductora "Aspectos que obstaculizaron/ dificultaron su acceso a la Universidad". Analizadas las mismas, se construyeron a posteriori categorías explicativas de tal diversidad de palabras recabadas.

Según los resultados, el mayor obstáculo al momento de acceder a la Universidad fueron las dificultades económicas (e.g.: "recursos económicos"; "necesidad económica"; "no tener un trabajo para solventar gastos"), registrando esta categoría el porcentaje más alto (27\%). El resto de categorías presentaron porcentajes similares. Así, algunos estudiantes (15\%) mencionaron aspectos de índole familiar/afectiva (situaciones afectivas y vinculares que obstaculizaron el acceso al espacio universitario: "desarraigo familiar"; "distancia con la familia"; "hijos"; "amigos"; "miedo a dejar mi familia"), mientras que otro grupo, de equivalente frecuencia (15\%) adujeron cuestiones personales (aspectos actitudinales relacionados con sentimientos negativos sobre sí mismos, limitantes: "miedos"; "indecisión", "falta de motivación"; "mi edad"; "autoestima"; "incapacidad", "no sentirme preparada para comenzar la universidad"; "vagancia"; "desconocimiento"; "otras responsabilidades"), entre las mayores dificultades que se le presentaron al momento del acceso a la UNSa. Asimismo, por su parte, se identificaron dos grupos de participantes (13\% respectivamente), que manifestaron como limitaciones relevantes en los recorridos iniciales en la Universidad, cuestiones relacionadas con aspectos formativos - académicos previos (e.g.: "formación del nivel medio"; "los contenidos nuevos"; "formación previa -(escuela albergue)"; "el hecho de no tener el secundario aprobado"; "falta de acompañamiento institucional"; "modo de aprendizaje"; "comprensión textual"; "rendimiento académico"; "bibliografía"; "falta de información de las carreras"), y a dimensiones de índole cultural que evidencian dificultades de socialización y desconocimiento de códigos culturales (e.g.: "idiomas"; "diferencias de cultura"; "costumbres"; "personas nuevas"; "marginación"; "convivencia"; "adaptación"; "ignorancia"; "desconocimiento de la vida en la ciudad"). Finalmente, un 10\% referenció restricciones asociadas a cuestiones tempo-espaciales (e.g.: dificultades en cuanto a "alojamiento"; "hospedaje"; "el tiempo insuficiente que tenía"; "tiempo (no conseguía trabajo de medio tiempo)"; "Falta de organización de los tiempos personales"; "no tenía tiempo por el trabajo"); mientras que un 7\% mencionó dificultades de distancia y traslado (e.g.: "distancia"; "lejanía de la universidad"; "transporte por las distancias"; "los caminos (son muy difíciles para llegar)"; "no poder viajar todos los días").

\section{Gráfico 2. Aspectos obstaculizadores en el acceso a la Universidad}

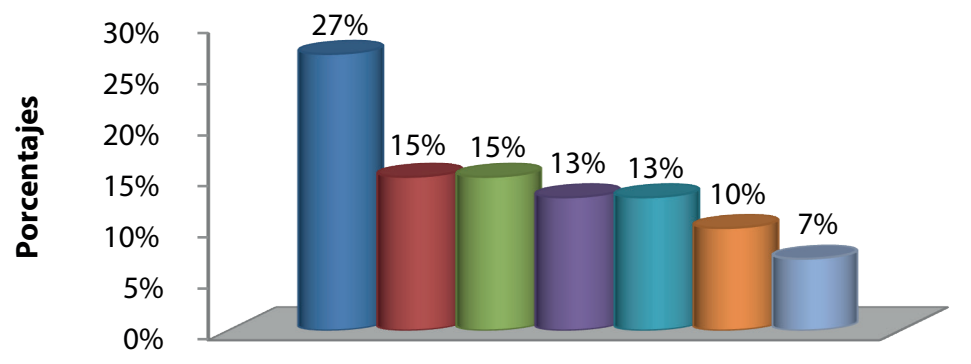

Fuente: elaboración propia

\author{
- Aspectos económicos \\ - Aspectos Fliares/ afectivos \\ - Aspectos personales \\ - Aspectos formativos/académicos \\ - Aspectos culturales \\ - Aspectos tempo-espaciales \\ - Distancia/traslado
}


Nodo b: Aspectos facilitadores en la permanencia en la Universidad

Las respuestas brindadas a la consigna de referenciar aspectos que, según sus apreciaciones, facilitaron la permanencia en el espacio universitario, permitió la construcción a posteriori de las siguientes categorías representativas.

Los estudiantes encuestados reconocieron que las cuestiones que más facilitaron su permanencia en la Universidad fueron las personales, es decir, aquellas relacionadas con aspectos actitudinales o características individuales (24\%), (e.g.: "capacidad"; "carácter"; "compromiso"; "conocer mis derechos"; "el deseo de tener nuevos conocimientos"; "esfuerzo"; "esmero propio"; "esperanza”; "estabilidad (emocional, física, económica)"; "la fuerza y voluntad de mi parte"; "ganas de salir adelante"; "meta"); asimismo, y con un porcentaje equivalente $(24 \%)$, identificaron la presencia de los otros significativos, aludiendo a la presencia de personas que desempeñaron un papel importante y facilitaron sus permanencias en la universidad como otro aspecto medular que permitió sostener sus permanencias (e.g.: "acompañamiento docente"; "agentes sanitarios"; "apoyo de los integrantes del programa de beca"; "apoyo personal de algunas figuras de la universidad"; "personas del programas de la universidad"). Se conjugan entonces, con el mismo grado de frecuencia e importancia, dimensiones personales y sociales, es decir, ellos revelan que sus permanencias en la Universidad suponen la consideración de diversas dimensiones intervinientes. Un $22 \%$ del total de los participantes declaró a los afectos y a la familia como aspectos que favorecieron su permanencia en la Universidad (e.g.: "acompañamiento familiar"; "afectos"; "amigos", "apoyo de los compañeros que vinieron de las comunidades"; "ánimos de compañeros para salir adelante"; "ayuda familiar", entre otras). Un 16\% de los estudiantes reconocieron a las dimensiones académicas y formativas destacando aspectos positivos de sus trayectorias académicas que facilitaron su continuidad en la Universidad ( e.g.: "accesibilidad de cursar las materias"; "apoyo por parte del programa de tutorías"; "aprendizaje"; "capacitación"; "clases nivelación"; "estudio"; "escuela secundaria"; "poder inscribirme en un proyecto universitario"). Por último, la categoría alusiva a los aspectos materiales representó un 14\% (e.g.: "alojamiento"; "ароуо económico"; "beca de estudio"; "beca de fotocopia"; "la universidad es gratuita"; "residencia universitaria"; "trabajo"). Este dato resulta coherente con lo expresado en el nodo anterior, en el cual la dimensión económica/material constituyó la principal limitación y debilidad en las trayectorias formativas de los estudiantes indígenas.

\section{Gráfico 3. Aspectos facilitadores en la permanencia en la Universidad}

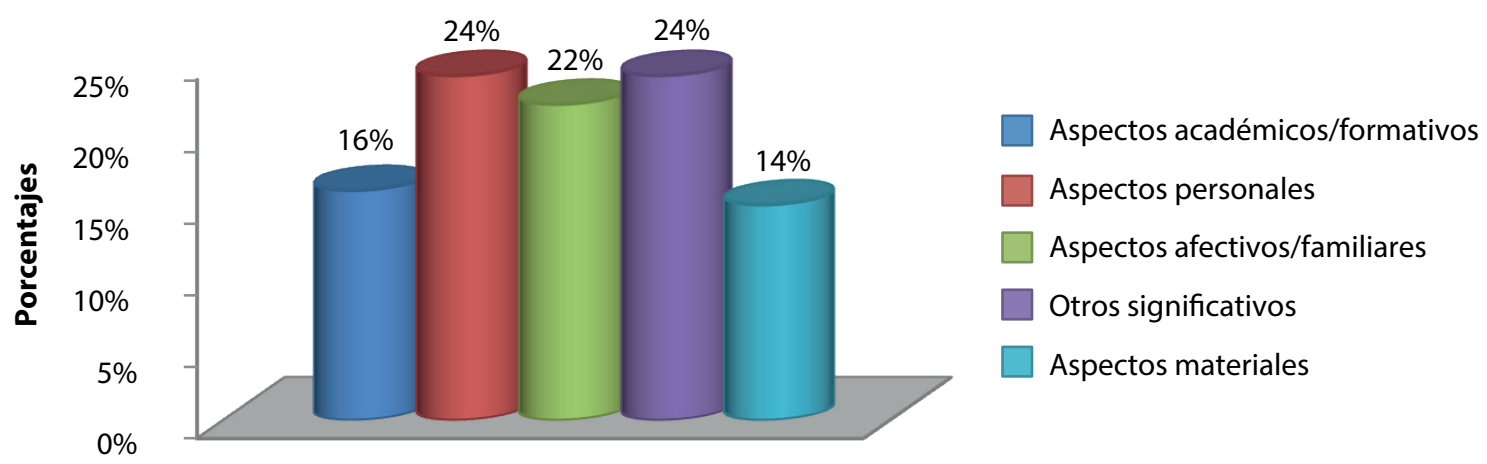

Fuente: elaboración propia 


\subsection{Dimensiones institucionales/ organizacionales}

Nodo a: Dificultades de la comunidad universitaria que condicionan las trayectorias académicas de los estudiantes indígenas

De las categorías emergentes, observamos un grupo mayoritario (26\%) que reconoció como mayor limitación de la comunidad universitaria los aspectos vinculares y relacionales, ligados al trato y convivencia entre los distintos actores institucionales (e.g.: "Falta de ayuda"; "competencia"; "incomprensión"; "ausencia de diálogo"; "falta de apoyo en la adaptación”; "falta de comunicación"; "falta de integración"; "mala convivencia"; "prejuicios"). Seguidamente, un $22 \%$ registró a los recursos materiales de UNSa como segundo aspecto que resulta una clara restricción en el logro de los propósitos formativos y personales (e.g.: "aulas "; "comedor"; "falta de bibliografía"; "infraestructura"; "falta de libros nuevos"; "no acceder a tecnologías"; "los recursos materiales solicitados no están al alcance de todos"), Por su parte, con porcentajes equivalentes $(17 \%)$ se erigieron las categorías correspondientes a profesores (e.g.: "Falta de dedicación de algunos docentes"; "falta de compromiso de docentes"; "desánimo de los profesores"; "falta de ayuda de los profesores"; "falta de docentes (deben venir de otros lugares)"; "desconsideración de las realidades económicas de los estudiantes"; "algunos docentes generan temor"), a aspectos académicos formativos (e.g.: "bibliografía incomprensible"; "contenidos de las materias"; "exámenes de ingreso"; "exigencias académicas"; "falta de prácticas profesionales"; "falta de talleres o cursos en relación a la carrera"; "trabajos en grupo o en terreno"; "sistema de regularidades") $y$, por último, a aspectos administrativos y organizativos de la Institución (e.g.: "Desorganización"; "horas de cursado"; "inflexibilidad en los horarios"; "la universidad no está preparada para los estudiantes que necesitan trabajar para estudiar"; "lo burocrático de la institución"; "no se cumple el cronograma”).

\section{Gráfico 4. Dificultades de la comunidad universitaria en las trayectorias académicas}

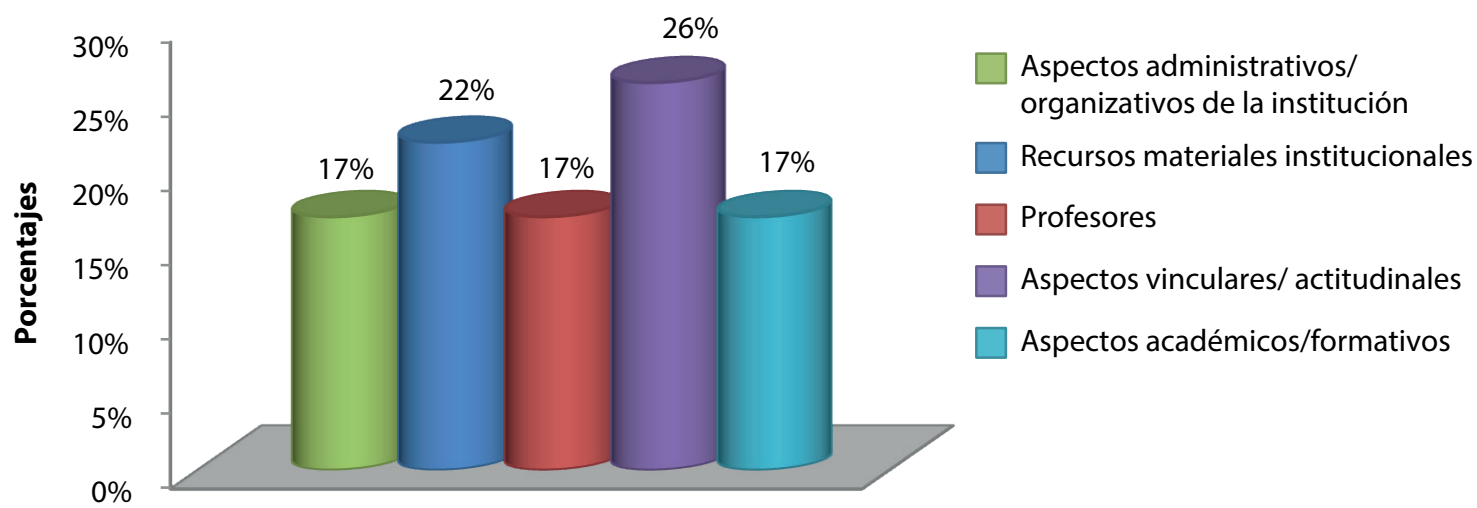

Fuente: elaboración propia

Nodo b: Modificaciones sugeridas para los servicios universitarios

Casi la mitad de estudiantes encuestados (45\%) sugirió cambios para el servicio universitario, en materia de políticas inclusivas (es decir, demandan mayores niveles de adecuación a las realidades contextuales, difusión e inclusión del estudiantado general y de comunidades originarias en particular. Reconocen la necesidad de repen- 
sar políticas y acciones que resulten inclusivas a los distintos servicios universitarios). El tópico de la inclusión evidencia ser una acuciante demanda a abordar con mayor detenimiento y atención institucional. Un $16 \%$ de los encuestados solicitaron, como cuestiones necesarias a contemplar, modificaciones en lo que respecta a los servicios de biblioteca y afines (tales como actualización de materiales, provisión de mayores unidades bibliográficas, modificaciones y ampliación de espacios y horarios destinados a la consulta de material de lectura). Asimismo, un $11 \%$ reconoció que los aspectos administrativos merecen sustantivos cambios, a fin de optimizar las trayectorias de los estudiantes (destacaron cuestiones administrativas relacionadas al funcionamiento de tales servicios. En este marco, se resalta la importancia de la identidad, eficiencia y eficacia en el ejercicio de las funciones, como así también se resignifica la flexibilidad, difusión, gestión y facilitación de los diversos servicios que desde la Universidad se promueven). El $10 \%$ de los encuestados destacó que los servicios tutoriales $y$ de orientación también requieren repensarse a fin de introducir transformaciones que puedan traducirse en mejoras para los estudiantes indígenas en particular y el estudiantado en general (entienden que para poder mejorar genuinamente sus trayectos formativos se torna medular disponer de mayores apoyos y asesoramientos, tanto académicos como de otra índole). Finalmente, un $8 \%$ de los participantes mencionó la imprescindible necesidad de generar modificaciones que favorezcan cuestiones de infraestructura y de recursos materiales (tales como la provisión, acondicionamiento, disponibilidad y ampliación de diferentes recursos materiales, propios y necesarios para el desempeño como estudiante universitario -becas, ampliación de espacios físicos, funcionamiento de residencias estudiantiles, etc.). El 5\% restante planteó consideraciones relacionadas con propuestas de extensión y prácticas extracurriculares (modificaciones a nivel de actividades extracurriculares, es decir mediante la implementación de otras actividades no propiamente académicas, que posibiliten la realización de diversos talleres y el despliegue de distintas actuaciones con el medio social).

\section{Gráfico 5. Modificaciones sugeridas para los servicios universitarios}

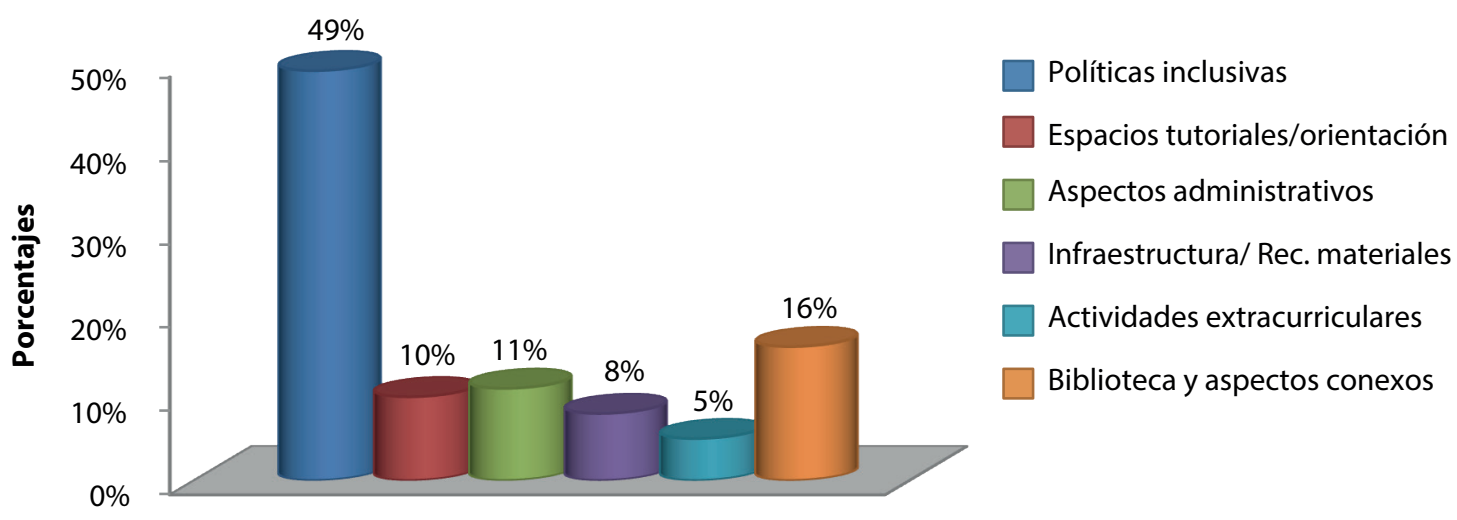

Fuente: elaboración propia

\section{Discusión y conclusiones}

La lectura de los documentos institucionales consultados posibilitó apreciar que la UNSa, según lo declarado, encuadra sus principios y propuestas institucionales dentro de políticas de atención a la diversidad cultural, buscando impulsar la generación de prácticas y mentalidades inclusivas 
mediante diferentes tipos de programas, proyectos y espacios de tutorías. En este sentido, la temática de la diversidad cultural ha sido contemplada en su agenda institucional mediante la generación de algunas iniciativas que fundamentan su accionar en el marco legal nacional y provincial vigente, en pos de materializar los derechos indígenas, específicamente.

Tal como fue planteado oportunamente, la UNSa despliega estrategias específicas direccionadas a promover el acceso de estudiantes indígenas (como ser el programa de acompañamiento socio-académico y contención afectiva). La propuesta implementada por el PTEPO pretende instaurarse como una sólida estructura institucional de apoyo pedagógico, afectivo y sociocultural, principalmente, que posibilite acompañar las trayectorias académicas de aquellos sujetos, conteniendo sus inquietudes y contribuyendo al desarrollo de competencias diversas y al despliegue de sus potencialidades. Se destaca que las instancias de contención, de acompañamiento en los procesos de adaptación a la vida universitaria y citadina, de apoyo educativo ante las dificultades halladas en el cursado académico, como así también de andamiaje ante incomprensiones culturales (alusivas al dominio de códigos lingüísticos y no lingüísticos, representaciones sociales, estilos de vida, etc., marcadamente distintos), promovidas desde dicho espacio, fueron apreciadas de manera muy positiva por los estudiantes encuestados, resaltando el valor sustantivo que las mismas revisten a lo largo de sus trayectos universitarios, no sólo en el plano formativo, sino fundamentalmente en el personal/emocional.

Pese al desarrollo de tales iniciativas, según pudo constatarse en el análisis de la información recabada, no puede hablarse aún de propuestas legítimas de interculturalidad. Es decir, se reconocen y valoran las diferentes acciones gestadas en dicha dirección, como así también la sensibilización progresiva que ha merecido la temática en tales espacios académicos, sin embargo, todavía queda mucho camino por desandar en materia de acciones interculturales y de genuinas inclusiones.

Resulta oportuno contemplar que no basta con la promoción de los accesos, mayor difusión de la oferta educativa en las comunidades originarias, ni con disipar los obstáculos emergentes al momento del ingreso, para propiciar la inclusión de la diversidad cultural en la ES. Indudablemente, éstas son acciones loables, que merecen ser sostenidas y alentadas, complementándose además con políticas y prácticas concretas que apuntalen la permanencia y graduación ulterior. Problematizar sobre estos aspectos posibilita comprender que la inclusividad de la ES supone la apertura a la diversidad, el acogimiento de la misma a través de lo declamado y lo actuado.

La UNSa precisa plantearse la necesidad de "interculturalizarse" mediante la transformación de sus objetivos, estructuras, currículas y relaciones sociales, promoviendo genuinas políticas de inclusión socioeducativa, que valoren la diversidad como un verdadero potencial de desarrollo para todos. Desde la perspectiva de los sujetos encuestados, esto supone un desafío a concretar. Los obtenidos permitieron apreciar que la mayoría de ellos considera que dicha Institución "a veces" y "casi nunca" atienden a la diversidad cultural presente en sus espacios académicos. Estas declaraciones invitan a repensar mandatos esbozados a la luz de las acciones y políticas impulsadas, en tanto no se confirman con las representaciones de los sujetos implicados.

Es posible advertir que sus principales demandas por una ES inclusiva se expresan en 3 dimensiones: la académica/curricular, la afectiva/vincular y la de accesibilidad.

En la académica, los sujetos demandan a la ES la consideración e integración de temáticas culturales diversas, de contenidos y prácticas de sus contextos de pertenencia, propias de sus realidades, tanto en el diseño de los planes de estudios, como en la planificación y abordaje de las clases, instando al intercambio de saberes y experiencias culturales, en un marco de derecho 
e igualdad. Otra cuestión implicada dentro de esta dimensión es la alusiva a las formas y metodologías adoptadas en los procesos de enseñanza y evaluación de los aspectos curriculares. En este sentido, muchos estudiantes han referenciado no sólo el sentimiento de ajenidad de los contenidos brindados, sino también la poca accesibilidad (a nivel comprensivo) de los mismos y de las bibliografías sugeridas.

Lo afectivo/vincular resalta la importancia de forjar vínculos y promover interrelaciones entre los jóvenes indígenas y los diferentes actores institucionales, desde la afectividad, de fomentar el encuentro, la escucha, el diálogo, la confianza y el respeto entre ellos. Estas ideas cobran sustento en tanto, según las respuestas de aquéllos, "los otros significativos" han sido valorados como aspectos favorecedores de sus permanencias en la UNSa. Es menester comprender que las trayectorias educativas de aquellos universitarios indígenas, como las de cualquier estudiante, involucran aspectos no sólo académicos, sino que en ellas se entrecruzan también una multiplicidad de otros aspectos como son los afectivos, familiares, culturales, económicos, etc.

La dimensión de la accesibilidad que referenciaron los propios estudiantes originarios se liga a las posibilidades genuinas de acceso y permanencia en la UNSa. Esto compete desde la promoción y apertura al momento del ingreso, como así también su sostenimiento a lo largo del itinerario formativo. Uno de los mayores obstáculos encontrados por estos sujetos en sus trayectorias han sido los de carácter económico y material.

A modo de cierre, y en relación a la Institución bajo estudio, se resalta la importancia de problematizar tales aportes de manera reflexiva y situada, en vistas a promover estrategias de mejora en dicho espacio académico, en las currículas y en las dinámicas vinculares que se generan al interior de la misma. En tal sentido, se sugiere que la promoción de la inclusión de jóvenes indígenas a la ES sea entendida no sólo como posibilidades de acceso al sistema, como propuesta institucional tendiente a "revelar" presencias omitidas históricamente, sino como un auténtico posicionamiento direccionado a "interculturalizar" los espacios universitarios, los planes de estudios y relaciones interpersonales, fortaleciendo de esta manera el desarrollo de mentalidades, actitudes y políticas basadas en la equiparación de derechos y en la promoción del principio de igualdad, el cual no supone la supresión de las diferencias, sino su celebración en un marco de posibilidades y oportunidades.

Los hallazgos de este estudio pretenden ser un aporte al campo de la educación inclusiva y una contribución al abordaje de la diversidad cultural en los espacios de la ES, presentando perspectivas y reflexiones sobre realidades que interpelan no sólo a la academia, sino también a la sociedad en su conjunto, animando a cobrar protagonismos y compromisos activos en la construcción e implementación de políticas y estrategias interculturales, para lograr no sólo Universidades sino también sociedades más justas, inclusivas y reflexivas de sus procesos.

\section{Notas}

1. Localizada en la ciudad capital de la Provincia de Salta, Argentina.

2. El Censo Nacional de Población de Hogares y Viviendas del año 2001 incorpora por primera vez dicha variable en el marco de un censo poblacional general. El "autoreconocimiento" fue el criterio de identificación que se empleó para el relevamiento de la población indígena.

\section{Referencias bibliográficas}

Abric, J. C. (2001). Prácticas sociales y representaciones. México: Coyoacán.

Arce,H. (2010).Educación superiorindígena en Misiones. Mecanismos de inclusión-exclusión del sistema educativo formal. En Kirsch, S. y Serrudo, A. (Comps.), La Educación Intercultural Bilingüe en Argentina. Identidades lenguas y protagonistas (255-272). Buenos Aires: Noveduc.

Bello, A. (2009). Diversidad cultural y políticas públicas para una educación superior inclusiva en Chile y América Latina. ISEES: Inclusión 
Social y Equidad en la Educación Superior, (5), 13-27. Recuperado de https://goo.gl/xrUz8A

Benito Cuéllar, C. (2009). Programas universitarios para estudiantes indígenas: Universidades en Bogotá. En Miguel Rocha Vivas (Ed.), Interacciones multiculturales. Los estudiantes indígenas en la Universidad (182-187). Bogotá: Universidad Externado de Colombia.

Bergagna, A. (2012). Estudiantes de Pueblos Originarios en la Universidad: La experiencia de la Universidad Nacional de Salta. En M. Aparicio (Coord.), Interculturalidad y Universidad (3554). Mendoza: Editorial Zeta.

Buliubasich, Catalina (2009). "Derechos indígenas: la agenda urgente”. Info-UNSa (periódico mensual de la Universidad Nacional de Salta), $\mathrm{N}^{\circ}$ 2. Salta-Argentina: Editorial Universidad Nacional de Salta.

Censabella, M. (2010). Lenguas y pueblos indígenas en la Argentina. En D. Quilaqueo Rapimán, C. Fernández, y S. Quintriqueo Millán (Eds.), Interculturalidad en contexto mapuche (4160). Neuquén: EDUCO.

Convenio OIT 169 (1989). Sobre Pueblos Indígenas y Tribales en países independientes. Ginebra.

Cortés Lombana, P. (2009). Indígenas universitarios en Bogotá. En Miguel Rocha Vivas (Ed.), Interacciones multiculturales. Los estudiantes indígenas en la Universidad (42-48). Bogotá: Universidad Externado de Colombia.

Dietz, G. y Mateos, L. (2008). Prólogo. Cuadernos Interculturales, 6(10), 11-14. 6. Centro de Estudios Interculturales y del Patrimonio (CEIP). Recuperado de: https://goo.gl//zNFoK7

Hernández Sampieri, R., Fernández Collado, C., y Baptista Lucio, P. (2010). Metodología de la investigación. México: Mc Graw Hill.

Instituto Nacional de Estadística y Censos (INDEC) (2001).Censo Nacional de Población, Hogares y Viviendas 2001. República Argentina.

Instituto Nacional de Estadística y Censos (INDEC) (2004-2005). Encuesta Complementaria de Pueblos Indígenas 2004-2005 (ECPI). Censo Nacional de Población, Hogares y Viviendas 2001. República Argentina.

Mato, D. (Coord.) (2008). Diversidad cultural $e$ interculturalidad en Educación Superior. Experiencias en América Latina. Caracas: IESALC-UNESCO.
Mato, D. (2009). Instituciones interculturales de Educación Superior en América Latina procesos de construcción, logros, innovaciones y desafíos. Caracas: IESALC-UNESCO.

Mato, D. (2016). Educación Superior y Pueblos Indígenas en América Latina: del "Diálogo de Saberes" a la construcción de "modalidades sostenibles de Colaboración Intercultural". Tramas/Maepova, 4(2), 71-94. Recuperado de https://goo.gl/Krnov4

Ossola, M. (2014). Los jóvenes wichí: voces emergentes en la educación superior. Revista Novedades Educativas, 26(284), 43-46.

Paladino, M. (2008). Pueblos indígenas y educación superior en la Argentina. Datos para el debate. ISEE: Inclusión Social y Equidad en la Educación Superior (6), 81-122. Recuperado de https://goo.gl/QmZU2p

Reynaga F., G. (2011). Inclusión social y equidad en la educación superior: el rol de las universidades en el siglo XXI. "Reflexiones sobre acción afirmativa en la educación superior". En C. Del Valle, Ma. Del C. Feijoo, G. Williamson, Fundación EQUITAS (Coords.), Inclusión social, interculturalidad y equidad en la Educación Superior (149-163). Santiago: Fundación Equitas.

Schmelkes, S. (2012). Multiculturalismo, educación intercultural y universidades. En F. Tubino y K. Mansilla (Eds.) Universidad e interculturalidad: Desafíos para América Latina (55-86). Lima: RIDEI - PUCP.

Serrudo, A. (2010). Indígenas en la escuela: representaciones y tensiones acerca de los docentes indígenas bilingües en Argentina. En S. Kirsch y A. Serrudo (Comps.) La Educación Intercultural Bilingüe en Argentina. Identidades lenguas y protagonistas (255-272). Buenos Aires: Noveduc.

UNSa (1996). Estatuto de la Universidad Nacional de Salta. Salta.

UNSa (2010). Resolución Consejo Superior No 197/2010. Vasilachis, I. (Coord.) (2006) Estrategias de Investigación Cualitativa. Barcelona: Gedisa.

Villasante, M. (2008). Los estudiantes indígenas en la universidad peruana: La experiencia de la Universidad del Cusco. ISEES: Inclusión Social y Equidad en la Educación Superior (3), 45-68. Recuperado de https://goo.gl/mdwhwk 
Wagner, W. y Hayes, N. (2011). El discurso de lo cotidiano y el sentido común. La teoría de las representaciones sociales. Barcelona: Anthropos.

Yarza de los Ríos, A. (2010). Educación superior, exclusiones e inclusiones: algunas lecciones aprendidas y perspectivas de análisis en Colombia. En M. Vergara Fregoso, y J. Ríos Gil (Comps.) Diversidad cultural: un reto para las instituciones educativas. México,
Colombia, Argentina, Perú y Guatemala (117126). México: Universidad de Guadalajara.

Zidarich, M. (2010). Pareja vulnerable, si las hay: docente originario y docente no originario En S. Kirsch, y A. Serrudo (Comps.) La Educación Intercultural Bilingüe en Argentina. Identidades lenguas y protagonistas (223254). Buenos Aires: Noveduc. 


\section{"Otras Pedagogías": La experiencia de la Carrera de Educación Intercultural Bilingüe-UPS}

\section{Other pedagogies: The experience of the Bilingual Intercultural Education-UPS}

Dra. María Sol Villagómez Rodríguez, es profesora e investigadora de la Universidad Politécnica Salesiana (Ecuador) (mvillagomez@ups.edu.ec) (http://orcid.org/0000-0002-7510-6198)

Recibido: 2017-07-13 / Revisado: 2017-11-16 / Aceptado: 2017-11-20 / Publicado: 2018-01-01

\section{Resumen}

Muchas de las experiencias de la educación superior indígena de América Latina surgen como respuesta a las luchas históricas de los pueblos indígenas por su derecho a la educación. Las primeras de ellas atienden a la necesidad de formación de profesorado para la educación propia y la Educación Intercultural Bilingüe (EIB), tal como es el caso de la Carrera de EIB de la Universidad Politécnica Salesiana del Ecuador (UPS), que cuenta con una trayectoria de más de veinte años en la formación de docentes para la EIB del pueblo kichwa y achuar. En la experiencia educativa de la Carrera de EIB de la UPS, se configuran "Otras Pedagogías", que parten de las necesidades educativas de los sujetos y colectivos que se educan, por ello, surgen de los contextos, de las luchas, de las resistencias y de la participación. Son pedagogías dinámicas y en construcción que emergen de las prácticas y se configuran como respuestas pedagógicas alternativas a las pedagogías convencionales y a la educación hegemónica. El objetivo de este trabajo es explicitar las Pedagogías "Otras" que se delinean en la experiencia de la Carrera de EIB en particular. Para ello, desde la reflexión a partir del testimonio de los actores, se categorizan cuatro pedagogías: I. de reafirmación identitaria; 2. del "ir para volver"; 3. del "entre culturas" y 4. de "concientización de la opresión.

Descriptores: Educación intercultural, "otras pedagogías", formación docente, Educación superior indígena, interculturalidad, pedagogía intercultural.

\begin{abstract}
Many of the experiences of Latin American indigenous higher education have a trajectory that arises as a response to the historical struggles of indigenous peoples for their right to education. The first ones address the need for teacher training for self-education and Intercultural Bilingual Education (EIB), as is the case of the EIB Career at the Salesian Polytechnic University of Ecuador (UPS), which has a track record of over of twenty years in the training
\end{abstract}

Forma sugerida de citar: Villagómez Rodríguez, M. S. (2018). "Otras Pedagogías": La experiencia de la Carrera de Educación Intercultural Bilingüe-UPS. Alteridad, 13(1), 30-41. https://doi.org/10.17163/alt.v13n1.2018.02. 
of teachers of the Kichwa and Achuar people. In the educational experience of the UPS EIB Career, "Other Pedagogies" are configured, based on the educational needs of the subjects and groups that are educated. For this reason, they emerge from contexts, struggles, resistances and participation. They are dynamic and under construction pedagogies that emerge from the practices and are configured as alternative pedagogical responses to conventional pedagogies. The objective of

\section{Introducción}

La educación superior indígena de América Latina surge en muchos casos como respuesta a las demandas por el derecho a la educación de los pueblos indígenas de la región; varias de estas demandas se relacionan con la necesidad de contar con instituciones de educación superior destinadas a la formación del profesorado de los propios pueblos.

Este estudio toma el caso de la Carrera de Educación Intercultural Bilingüe (EIB) de la Universidad Politécnica Salesiana (UPS), institución de formación inicial docente para la EIB del Ecuador. A partir de la voz de los actores se analiza cómo en la experiencia de este programa académico emergen "otras pedagogías" que parten de las necesidades de los sujetos y colectivos que se educan, dando lugar a respuestas pedagógicas alternativas a las convencionales y hegemónicas.

El texto inicia con un mapeo de la educación superior indígena de América Latina (López, Moya, y Hamel, 2009; Mato, 2016) entre las cuales se ubica la Carrera de EIB de la UPS. A continuación se analiza las condicionantes sociohistóricas que propiciaron su surgimiento y su aporte en la continuidad del proyecto educativo del pueblo indígena de la provincia de Cotopaxi inicialmente y, posterior ampliación de su oferta a otras provincias del Ecuador (Farfán, 2008; Castro et al., 2009; Villagómez, 2016).

Finalmente, a partir del análisis de los datos obtenidos mediante entrevistas en el tra- this work is to make explicit the "Other" pedagogies that are delineated in the EIB Career experience in particular. For this, the reflection from the testimony of the actors, are categorized four pedagogies: I. identity reaffirmation; 2. "go to return"; 3. "between cultures" and 4. "awareness of oppression".

Keywords: Intercultural education, teacher training, indigenous higher education, "other pedagogies", interculturality, intercultural pedagogy.

bajo empírico de tipo cualitativo, realizado en el marco de la tesis doctoral "Práctica de la Interculturalidad, descolonización y formación docente: El caso del Programa Académico Cotopaxi del Ecuador" (Villagómez, 2016), se exponen cuatro Pedagogías "Otras" que emergen en la experiencia de la Carrera de EIB de la UPS: 1. de reafirmación y recomposición identitaria; 2. del "ir para volver"; 3. interculturales y 4. de "concientización de la opresión.

Los principales referenciales teóricos utilizados para argumentar la emergencia de estas pedagogías "Otras", tienen que ver con las categorías: "alternativa pedagógica” (Puiggrós y Gómez, 1992; Rodríguez, 2015) que entiende a la educación como una "práctica social sobredeterminada", por lo que es posible analizar dimensiones pedagógicas en otros planos de lo social, que se hacen internas a los procesos educativos particulares (Rodríguez, 2015, p. 7). Desde esta comprensión es posible reconocer la emergencia de "Otras pedagogías", categoría utilizada por (Arroyo, 2012; Medina, 2015) refiriéndose a las respuestas pedagógicas que se construyen en los procesos educativos y movimientos sociales; que en el caso de este análisis nacen de los contextos y las luchas, del pueblo indígena por una educación que responda a sus necesidades y a la vez esté vinculada y sea parte de su propio proyecto político.

El documento deja explícita la necesidad de la atención analítica del pedagogo en la comprensión crítica de las "Otras pedagogías" emergentes. 


\section{Fundamentación teórica y metodológica}

En lo que refiere a las herramientas teóricas, se recurre a las contribuciones de la Pedagogía Crítica latinoamericana que coloca central atención en los aportes de la educación a la transformación social. Utilizamos las categorías "alternativas pedagógicas" (Rodríguez, 2015) y "otras pedagogías" (Arroyo, 2012) que nos ayudan a la comprensión de la educación como práctica social en la cual emergen en la experiencia respuestas pedagógicas “insumisas” (Medina, 2015), transformadoras y descolonizadoras; son pedagogías "que resisten y en esa resistencia son capaces de constituirse como sujetos con opciones de futuro posibles desde el derecho al presente" (Medina, 2015, p. 43).

Para la recolección de información, se trabaja desde el testimonio de los actores (informantes clave seleccionados en múltiples y continuos acercamientos al contexto del estudio), a partir de entrevistas realizadas durante el trabajo de campo de la tesis doctoral: "Práctica de la Interculturalidad, descolonización y formación docente. El caso del Programa Académico Cotopaxi del Ecuador" (Villagómez, 2016). Para el análisis, los diálogos sobre las experiencias y reflexiones de los actuantes fueron transcritos; los datos se organizaron en categorías que concentran ideas y temas similares (Fernández, 2006, p. 4), así como creencias y eventos que se analizaron de manera inductiva, crítica e interpretativa en "relación dialéctica con el marco teórico y metodológico" (Ripamonti, 2015, p. 13), constituyéndose en los insumos fundamentales para la comprensión del sentido que los actores le otorgan a la educación y de las pedagogías que emergen de la experiencia de la Carrera de EIB de la UPS. Los datos obtenidos se completaron con la revisión de los documentos académicos y curriculares.

\section{Análisis y resultados}

\subsection{Educación superior indígena y for- mación de docentes para la EIB en América Latina}

De acuerdo con López et al. (2009), desde la década de 1990 la región "ha venido experimentando un desplazamiento de la demanda indígena, desde el nivel de educación básica, hacia el nivel de educación superior, incluida la universidad" (p. 246); las primeras experiencias de educación superior indígena de la región, surgen para atender a las necesidad de formación de profesores para la EIB, como es el caso del Programa Académico Cotopaxi (PAC) en 1994, actualmente Carrera de EIB de la UPS.

En la actualidad existen en Latinoamérica una enorme diversidad de programas de educación superior indígena, llegando a constituirse en un "campo heterogéneo de experiencias" (Mato, 2016, p. 215) determinadas por la intencionalidad de los programas educativos y el grado de participación de los destinatarios en su creación y en el desarrollo del proyecto educativo. A continuación, se expone la taxonomía de los programas de educación superior indígena de América Latina, elaborada por Mato (2016):

1) Programas de inclusión individual de estudiantes indígenas en universidades 'convencionales';

2) Programas de grado y otros tipos de certificación establecidos por universidades convencionales;

3) Programas de enseñanza, investigación y servicios sociales desarrollados por universidades 'convencionales' con la participación de comunidades de pueblos indígenas;

4) Asociaciones de organizaciones indígenas y universidades 'convencionales' o educación superior indígena;

5) Universidades interculturales y educación superior indígena; 
6) Universidades indígenas y educación superior indígena;

7) Universidad Autónoma Indígena e Intercultural.

De acuerdo con el mismo autor, el PAC de la UPS se ubicaría en el segundo tipo por ser un programa dirigido a población indígena, establecido en una universidad convencional (Mato, 2016 , p. 217); además de ser incluida en el sexto tipo, entre las universidades indígenas (p. 220). Como sostiene el mismo autor, de acuerdo con los intelectuales y organizaciones indígenas insisten en nominar como Universidades Indígenas aquellas que reúnen algunas de las siguientes características. Varias de las cuales posee la Carrera de EIB de la UPS, como lo destacaremos más adelante.

Haber sido establecidas y son gobernadas por ellos, o sus organizaciones y comunidades. Garantizan la continuidad de sus formas de idiomas, los sistemas de conocimiento, los valores y el cumplimiento de sus proyectos futuro. Prevén la posibilidad de siendo interculturales propiciar la inclusión de las cosmovisiones y los intereses de varios pueblos indígenas y, en algunos casos, también de los pueblos afrodescendientes...

Ponen en relieve la importancia de garantizar la perdurabilidad de los conocimientos en sus currículos... (Mato, 2016, p. 219, traducción propia).

Como tal, la Carrera de EIB de la UPS, es un proyecto académico que es parte de una institución de educación superior de corte convencional, dirigido particularmente a la educación superior indígena, pues la oferta académica de la UPS tiene carreras que atienden de manera prioritaria a población indígena, tales como EIB y Gestión local para el desarrollo (Vázquez et al., 2012, p. 655) y otras más convencionales que incluyen estudiantes de las minorías étnicas, apoyadas en el proyecto de la Residencia Intercultural (Di Caudo, 2014). Como Carrera de EIB, busca dar respuesta a las demandas edu- cativas, específicamente de formación docente para la educación intercultural bilingüe de los pueblos y nacionalidades indígenas del Ecuador.

A continuación se analiza la experiencia de la Carrera de EIB, como programa de educación superior indígena de carácter intercultural, centrando particular atención en la intencionalidad y agencia educativa y pedagógica que se lleva adelante en este programa académico dedicado a la formación inicial de docentes para la EIB.

\subsection{La Carrera de Educación Intercultural Bilingüe de la UPS}

Como resultado de las luchas y resistencias de la organización indígena CONAIE (Confederación de Nacionalidades Indígenas del Ecuador), la EIB se institucionaliza en el país en el año de 1988 (Vélez, 2008) con la oficialización de la Dirección Nacional de Educación Intercultural Bilingüe (DINEIB) (Decreto Ejecutivo 203, 1988, p. 03). Varias décadas antes de que esto ocurra el país contó con importantes experiencias de educación para los pueblos indígenas, algunas de ellas promovidas por el Estado central generalmente de carácter integracionista y homogeneizador, en concordancia con el proyecto del Estado nacional único, homogéneo y mestizo; otras en cambio, fueron experiencias de educación indígena impulsadas por los propios pueblos que nacen como "iniciativa comunitaria de educación indígena” (Torres, 1992, p. 13) y son parte fundamental de su propio proyecto político constituyéndose en espacio de organización comunitaria.

Las escuelas indígenas como escuelas propias e interculturales bilingües, se caracterizan por ser alternativas como "desafío al poder del Estado hegemónico y homogéneo" (González, 2011, p. 5), único, monolingüe y monocultural. Requieren de docentes propios, es decir que pertenezcan a la misma comunidad y que hablen la lengua propia. Para Molina y Tabares (2014) "La educación propia representa la posibilidad histórica de resistir al proyecto sistemático 
de desaparición al que han sido sometidas las comunidades indígenas...". (p. 2) en el cual se da un proceso de apropiación social y comunitario, fáctico o simbólico de la institución escolar como estrategia reivindicativa.

Entre estas experiencias de educación propia, se encuentra el Sistema de Escuelas Indígenas de Cotopaxi (SEIC) que nace en la década de 1970 (Granda, 2016) con el proyecto Quilotoa de la Misión Salesiana de Zumbagua que inicia con la alfabetización y que luego, "cuando muchos adultos ya estaban alfabetizados y cada vez más niños acudían a los centros de alfabetización, las comunidades tomaron la decisión de transformar dichos centros en escuelas" (Ramírez et al., 2007, p. 123). El SEIC llegó a contar con todos los niveles de escolaridad, desde la alfabetización Runakunapak Yachana Wasi, la educación infantil Wawakunapak Yachana Wasi, la educación básica Yachana Wasi, (Baltazar et al., 1992, p. 65), la secundaria o bachillerato con el Colegio Jatari Unancha.

Con el crecimiento del SEIC, la demanda de educación superior se vinculaba a la necesidad de mejorar la práctica profesional de los docentes de las escuelas, lo que se sumaba a las exigencias de la institucionalidad de Ministerio de Educación que colocó sobre los docentes mayores requerimientos de formación formal, profesionalización y titulación para su ejercicio en las instituciones interculturales bilingües, que para 1990 ya estaban reconocidas por el Estado central.

Aunque durante este período se crean los Institutos Pedagógicos (IPED) e Institutos Pedagógicos Interculturales Bilingües (IPIB) "para atender las demandas de docentes de manera sectorizada, existen uno por provincia y dos o más en las provincias de mayor concentración poblacional, en tanto que los IPIB están ubicados en lugares de mayor población indígena" (Fabara, 2004, p. 32) que funcionaron en todo el país (25 IPED para la formación de docentes para la educación hispana y ocho IPIB para la formación de docentes para la EIB), sin embargo, en la zona geográfica de injerencia del SEIC, se encontraba únicamente el IPED del cantón Pujilí que formaba docentes para la educación hispana y no específicamente para la EIB, como era la necesidad del contexto.

Finalmente, la necesidad de contar con un programa de educación superior para la formación de docentes para las escuelas propias culminó con la creación del PAC de la UPS, esta última también en proceso de formación. Así, de acuerdo con los testimonios de los actores la creación del PAC en 1994, denominada desde 2003 Carrera de EIB "es el punto de llegada de un proceso educativo liberador de educación propia” (Salesiano, entrevista, 2014, en Villagómez, 2016, p. 131) que permitía dar continuidad al proceso educativo que llevaba adelante el SEIC, ofreciendo una Licenciatura en Ciencias de la Educación y en modalidad de estudios semipresencial, atendiendo a estudiantes indígenas y mestizos vinculados a la organización indígena (Farfán, 2008, p. 28).

La propuesta de la creación de la Universidad en el Páramo se analizó desde el año 1993, conjuntamente con comunidades, organizaciones de segundo grado. Según acta número 01 del primero de septiembre de 1994, realizada una reunión para analizar la opinión de varias instancias de la organización indígena, como es la DINEIB, CONAIE, se define el apoyo a la creación de una propuesta de educación superior en el ámbito de la Educación Intercultural Bilingüe (Castro et al., 2009, p. 27).

Desde 2003, la Carrera de EIB, se extiende a las provincias de la sierra: Imbabura con centro de apoyo en Otavalo; Pichincha en Cayambe, Cotopaxi en Latacunga; Chimborazo en Riobamba y Bolívar en Simiatug; y en la Amazonía, la provincia de Morona Santiago en Wasak-entza.

La revisión de la documentación curricular de la Carrera de EIB, plantea una estrecha relación con las especificidades para la formación de docentes que atañen a la DINEIB, como son, entre otras:

"Formar y capacitar profesores y demás recursos humanos para la educación indígena en las diferentes lenguas del país; Organizar programas acelerados de formación de maestros 
indígenas de acuerdo con las características y necesidades de las diversas comunidades indígenas; Dirigir, organizar y orientar la educación de los normales bilingües" (Ecuador, Decreto ejecutivo, 203, 15 de noviembre de 1988, p. 03). En esta misma línea se construyen los objetivos del PAC:

1. Formar, capacitar, profesionalizar docentes identificados con la realidad socioeconómica, política y cultural de las nacionalidades indígenas, que dominen los conocimientos y técnicas en los campos educativo y productivo del proyecto histórico de los pueblos, especialmente indígena.

2. Sistematizar, dinamizar y actualizar la sabiduría, la ciencia y la tecnología en función de la dignificación del hombre, especialmente de las nacionalidades indígenas.

3. Desarrollar un proceso educativo paraescolar a nivel superior que esté al servicio de las comunidades, organizaciones, instituciones y dirigentes y que se caracterice por responder permanente, sistemática y progresivamente a los requerimientos de formación socio-política de la población indígena (UPS, 2005, consulta SNA, 2016).

Los lineamientos pedagógicos descritos en el documento prevén procesos formativos de corte liberador, comunitario y político que partan de la realidad sociolingüística y el bilingüismo, la búsqueda de la identificación cultural, perspectiva intercultural y la cosmovisión del pueblo andino (UPS, 2005, s/p).

En la actualidad la Carrera de EIB, tiene una amplia cobertura con 424 estudiantes y más de mil graduados hasta la fecha (UPS, 2017), funciona en modalidad semipresencial y con apoyo de entornos virtuales de aprendizaje, con encuentros presenciales que se realizan en territorio, en los denominados centros de apoyo.

\section{3. “Otras Pedagogías" se delinean en la experiencia educativa}

En el Ecuador el SEIB parte de considerar la necesidad de pensar otra educación -diferen- ciada de la hispana- y otra escuela alineada a las necesidades educativas propias de las comunidades y los pueblos indígenas. Estas necesidades educativas van a marcar las exigencias para otra formación docente a las que la Carrera de EIB deberá responder.

Frente a estas exigencias, la Carrera de EIB de la UPS hace posible otra realidad, que tiene que ver con la factibilidad de acceso a la educación superior de población históricamente excluida, en un proyecto educativo que intentará desde la lectura del contexto y las demandas de la propia población, dotar de especificidad a la formación de profesores de EIB.

En la revisión de la experiencia de la carrera, situamos varios hallazgos que permiten sostener la idea central de este este artículo en que se afirma que los procesos de formación docente, propician la emergencia de "Otras pedagogías". Se trata de alternativas pedagógicas porque ofrecen una opción diferente y tienen un carácter prospectivo.

Se hace uso de la categoría, "alternativa" porque esta "se vincula con el trabajo de construir la realidad como campo problemático, de modo que pueda ser abordada como objeto de conocimiento... (Rodríguez, 2015, p. 3), además de ser "un concepto ordenador en la medida en contribuye a delimitar campos de observación" (p. 3). Por otro lado, exige como lo señala la misma autora, comprender lo pedagógico sin reduccionismos, al definirse la educación como "sobredeterminada" (Puiggrós, 1984).

Para Arroyo, (2012) se trata de Otras pedagogías que "surgen de los contextos, de las luchas, de la toma de conciencia... se hacen presentes en acciones, en movimientos... Interrogan la docencia, el pensamiento pedagógico, las prácticas educativas..." (p. 9); interrogan la pedagogía moderna que "ha participado del pensamiento moderno, inclusive en su carácter abismal y sacrificial en la subalternización de los Otros" (p. 17).

Así, una concepción amplia de la pedagogía permite vislumbrar más allá de metodologías y propuestas didácticas. Se trata como lo plantea 
Arroyo (2012), refiriéndose a la obra de Paulo Freire, "no inventa metodologías para educar a los adultos campesinos... reeduca la sensibilidad pedagógica para captar a los oprimidos, como oprimidos, como sujetos de su educación, de construcción de saberes, valores y cultura" (p. 27, traducción propia). Constituyen otras respuestas pedagógicas que se construyen en el mismo proceso educativo por eso son pedagogías en movimiento, en construcción donde todos se educan entre sí, con la mediación del mundo (Freire, 1987).

Como se indica al inicio de este trabajo, de acuerdo con lo expuesto por Mato (2016) la Carrera de EIB es un programa de educación superior indígena de carácter intercultural ofertado por una universidad convencional. El programa está dirigido principalmente a población indígena y mestiza, comprometida con la EIB. Si bien el proyecto académico curricular declara una opción educativa intercultural, es en la misma experiencia de la Carrera en que se perfilan otras pedagogías que se construyen en los procesos, su estudio como alternativas permite problematizar su emergencia para propiciar su comprensión, no sin considerar la complejidad y los conflictos del entramado social donde las prácticas educativas se producen. Como pedagogías en emergencia, son vistas más como procesos en construcción que como productos finales; por ello se asumen en este análisis como desafíos que exigen reflexión constante y de una mirada crítica del proyecto educativo y de las prácticas.

Se esbozan a continuación cuatro "Pedagogías Otras" que se delinean desde la experiencia de los actores y que emergen y se recrean en la misma práctica del proyecto educativo.

\subsubsection{Pedagogías de reafirmación y recomposi- ción identitaria}

En programas académicos dirigidos prioritariamente a población históricamente excluida como el caso analizado en este documento, la tensión entre blanqueamiento y etnogénesis es constante. La vergüenza étnica y lingüística, como resultado de la experiencia de violencia colonial y el racismo por parte de la sociedad blanco-mestiza provoca en los indígenas sentimientos de autodesvalorización que se contraponen a "sentimientos de justicia que pugnan frente a un modelo sociocultural que desconoce otros conocimientos, sujetos y sus historias (González, 2011,p. 182) generando así la tensión "entre la imposición occidental y la resistencia y búsqueda de reafirmación cultural y lingüística" (Villagómez, 2016, p. 172).

Consiente de esta tensión la propuesta educativa, constituye también un proyecto de intervención en el que entran en juego acciones de resistencia y de lucha en la que la reafirmación identitaria es una respuesta pedagógica que busca favorecer la etnogénesis y sentimientos de autovaloración, como lo menciona uno de los actores:

Son gente con identidades muy devaluadas, tanto individuales como colectivas. Muchas veces esconden su identidad indígena. Entones el gran reto... si no trabajas en la línea de autovaloración en términos individuales y colectivos, muy poco vas hacer... en ese marco la entrada de hablar de nosotros, de lo propio de recuperar la propia historia... para ese trabajo más formativo (Académico, entrevista, 2016 en Villagómez, 2016, p.174).

En coherencia con los postulados de la EIB del país el trabajo que se realiza en la Carrera se dirige a "fortalecer la identidad cultural, las lenguas y la organización de los pueblos y nacionalidades" (MINEDUC, 2014, p. 29) posibilitando así el surgimiento de pedagogías tendientes a la reafirmación cultural. Algunos testimonios de estudiantes y exalumnos, ayudan a situar lo expuesto:

Antes era el puesto sombrero, el que menos sabe. El que habla kichwa no es inteligente. De esa manera. Eso se ha superado poco a poco (Líder indígena, entrevista 2014, en Villagómez, 2016, p. 172).

...he cambiado de vestimenta, quizás... Pero, lo de indígena se lleva en la mente, se lleva en 
el corazón, se lleva en la sangre. Y si es que la mente no logra perder sigue siendo indígena. Eso es lo mío... (Profesora indígena, graduada del PAC, entrevista, 2014, en Villagómez, 2016).

\subsubsection{Pedagogías del "ir para volver"}

El "Ir para volver", como diría Segato, (2015) significa "ir, aprender la lengua del colonizador, comprender la forma de pensar y de vivir del mundo blanco y también las armas y las formas que utiliza el opresor para oprimir, pero para volver", como ilustran los versos de Neto, (s.f., traducción propia)

Desde que salí de casa,

traje el viaje de vuelta gravado en mi mano, enterrado en el ombligo,

dentro y fuera, así conmigo,

mi propia orientación (s. p).

Se trata de pedagogías que marcan en la experiencia del educando la ruta de la ida -el acercarse al conocimiento del otro-, pero para retornar empoderado a partir de procesos educativos que siendo coherentes con las necesidades de los sujetos individuales y colectivos que se educan lo acercan al conocimiento de la ciencia y lengua occidental y del conocimiento y valoración de la cultura propia. Tal como de manera simbólica se manifiesta en uno de testimonios (Líder indígena, entrevista 2014, en Villagómez, 2016, p. 179) quien refiriéndose a su experiencia como estudiante sostiene que su trayectoria en la carrera "es como entrar en una casa, pero de allí salir formado, con ideas, más apropiado", como la posibilidad de aprender para retornar a la comunidad, como se lee en el testimonio que sigue, "para mí, más principalmente, mi anhelo es llevar la profesión y trabajar con las gentes indígenas" (Estudiante, entrevista, 2015, en Villagómez 2016, p. 180).

El ir para retornar cobra sentido en la alteridad. Ya otros autores como Segato (2015) ilustran el sentido del ir para volver sirviéndose del texto "No soy un aculturado" de Arguedas (1968) en el que exalta la posibilidad de transitar en el mundo del blanco y del indio: “... Yo no soy un aculturado; yo soy un peruano que orgullosamente, como un demonio feliz habla en cristiano y en indio, en español y en quechua".

Se trata de pedagogías que se construyen en el deseo de retornar a la propia cultura y a la propia comunidad, pero para aportar, pedagogías que a través de experiencias que propician el conocimiento de lo propio y de occidente, ayudan a interrogar la jerarquía entre la ciencia occidental y las epistemologías y saberes ancestrales y que, además exigen su inclusión y vitalización y uso cotidiano en los espacios académicos y escolares, tal como lo manifiesta uno de los profesores de la Carrera de EIB, son pedagogías que se construyen en la tensión de la valoración de la lengua y la cultura propia y de la necesidad de conocer la ciencia y occidental y la cultural mestiza.

Está bien hacerles conocer las teorías occidentales... pero hay que hacerles conocer contrastando con la metodología propia... partir de lo que ya tenemos..., por otros caminos.... Hay varias ciencias (Académico, intelectual y líder indígena, entrevista, 2015 en Villagómez, 2016).

\subsubsection{Pedagogías interculturales: "entre culturas"}

Las pedagogías interculturales, son pedagogías inconclusas, siempre en construcción, por tanto, las pedagogías del "entre culturas" son pedagogías de la esperanza, como tales tienen un profundo componente utópico, se erigen en el camino, en la práctica en la necesidad de construir el "entre culturas" y la alteridad; emergen en el reto que requiere la construcción de aprendizajes mutuos, de la valoración de lo propio y el reconocimiento del otro. La interculturalidad en este marco, "más que un simple concepto de interrelación, significa el proceso de construcción de una sociedad 'otra" (Walsh, 2009, p. 232). Así, la interculturalidad debe ser vista como una práctica y no como algo concluido..

Las pedagogías interculturales emergen en ese camino, donde se dan las relaciones interculturales, en los espacios cotidianos, la comunidad, 
las manifestaciones culturales, las tradiciones, la familia. En las acciones de resistencia, pero también de colaboración.

Como pedagogías del "entre culturas" insisten en la necesidad del encuentro de diversos, de grupos plurales (mestizos e indígenas). No desconocen los conflictos, las dificultades, los tropiezos, las jerarquías y las herencias coloniales, a la vez reconocen lo andado, las solidaridades y sororidades, los esfuerzos. Como concluye Cuji, (2011) en un estudio realizado sobre Carrera de EIB "no todas las diferencias o encuentros son necesariamente conflictivos" (p. 75). Así mismo lo expresan los actores:

Al principio, si había como decir desigualdad, porque por una parte éramos, como decir la gente de abajo, como decían y otros eran la gente de arriba, que es indígena. $\mathrm{Al}$ principio, era así, pero no, después ya íbamos llevándonos bien. Y así salimos adelante... (Estudiante, entrevista, 2014 en Villagómez, 2016, p. 177).

...el primer día de encuentro entre indígenas y mestizos es un mundo diferente, que estamos los dos mundos, que estamos uniendo, encontrando. Si es un poco difícil la situación hasta acoplar, hasta conocer. Hemos estado educándonos y educamos también y hemos mostrado respeto mutuo (Estudiante, entrevista, 2014 en Villagómez, 2016, p. 176).

Nosotros somos indígenas, mezclados con otros compañeros, con los mestizos, hemos conocido, aprendido de parte de allá y hemos compartido de nosotros también hacia allá... (Graduado, entrevista, 2014 en Villagómez, 2016, p. 176).

Las pedagogías interculturales desarrollan en los individuos la capacidad de comprender la diferencia y de aprender de esta. De colaborar con los diferentes y de ser solidarios. Propician finalmente la posibilidad construir una historia común para finalmente, como lo refieren los líderes indígenas "compartir el poder".

\subsubsection{Pedagogías de "concientización de la opresión"}

El concepto "Pedagogías de concientización de la opresión y de los procesos de deshumanización" es empleado por Arroyo (2012) refiriéndose a otras pedagogías

Al buscar esas Otras pedagogías en los Otros sujetos en acciones colectivas y movimientos está reconociendo que estos son sujetos de otras experiencias sociales y de otras concepciones, epistemologías y de otras prácticas de emancipación (p. 28, traducción propia).

En el caso de la Carrera de EIB, las pedagogías de la "concientización de la opresión" tienen que ver con la formación de un profesorado comprometido con la lucha indígena que permita a los sujetos de la educación, "asumirse como colectivos sociohistóricos con su propia identidad, la misma que se convierte en un recurso de la lucha social" (Moya, 2007, p. 239). Tal como señala Freire (2012) solo por la educación "nos volvemos capaces de intervenir en la realidad, tarea incomparablemente más compleja y generadora de nuevos saberes que la simple función de adaptarnos a ella" (p. 100).

Son pedagogías que propician una conciencia de su rol histórico como representantes de una comunidad, de un pueblo en el afán de un mejor futuro basado en la confianza en uno mismo y en la posibilidad de seguir peleando en la seguridad de que "luchando se pueden cambiar las cosas" (Segato, 2015).

De acuerdo con uno de los docentes de la Carrera de EIB, (2015), la intencionalidad del proyecto educativo centra su esfuerzo en la formación de profesores que "apoyen ese proceso de reconstrucción de lo que sería un colectivo indígena que el día de mañana pueda integrarse de manera más equitativa al estado nación". Lo que implica el desafío que exige una formación política del profesorado. Para Farfán en (Mato, 2008, p. 289), "la formación de líderes indígenas que están aportando en los gobiernos locales” es una de las contribuciones más importantes de la Carrera de EIB al proyecto político del pueblo indígena y a su lucha por la transformación de una realidad de inequidad y exclusión. Se transcribe seguidamente un fragmento del discurso de 
graduación de la estudiante del Centro de Apoyo Latacunga y profesora indígena, Simaluisa (2015 en Villagómez, 2016, p. 204).

En esta mañana llena de luz, de felicidad, sobre todo de esperanza por una vida más digna para nuestras familias; hoy estamos aquí de las diferentes nacionalidades y pueblos indígenas, negros y mestizos; venimos desde los más altos paramos de la sierra y de las diferentes ciudades de nuestro Ecuador querido.

Pareciera común lograr el título de tercer nivel, en realidad no lo es así; en el Ecuador hay una brecha muy distante entre pobres y ricos, analfabetos por niveles, pueblos indígenas arrinconados, tanto en el campo, como en las grandes urbes que no tienen el pan del día peor para comprar un esfero, un lápiz o un papel, que decir de las mujeres en particular del sector indígena y negro; sin embargo hemos empezado a salir pero estamos lejos de tener la igualdad que tanto se habla, seguiremos adelante y hoy estamos aquí en busca de la construcción de una nueva sociedad más justa y humana, para así alcanzar el Sumak kawsay que han soñado nuestros pueblos.

Son en definitiva pedagogías liberadoras y de la esperanza de una vida más digna, para la construcción de una sociedad más justa. Como se colige del testimonio de (Simaluisa, 2015) propician la "toma de conciencia" de la situación de exclusión para forjar el anhelo de "salir... seguir adelante" para la construcción de una sociedad "más justa y humana" y para alcanzar el "sumak kawsay".

\section{Discusión y conclusiones}

La Carrera de EIB de la UPS, como programa educativo de formación docente de profesores indígenas se suma a los esfuerzos de otras propuestas latinoamericanas de educación superior indígena, para responder a sus demandas por una educación superior pertinente y contextualizada.

La Carrera es un programa académico en ejecución dirigido prioritariamente a población indígena. Se diferencia de los programas conven- cionales de formación docente al incluir como ejes la interculturalidad y el bilingüismo.

La revisión de la experiencia de la Carrera de EIB que en este artículo se centra en la dimensión pedagógica aporta a un campo de estudio más amplio, el de la educación superior intercultural.

La experiencia de la Carrera de EIB, en los procesos de formación docente, a decir de los actores, propicia la emergencia de "Otras Pedagogías" que surgen de los contextos, de las realidades, de las luchas de los mismos estudiantes como miembros de su comunidad y como parte de un proyecto político colectivo.

Estas "Otras Pedagogías", son siempre en construcción, inacabadas, constituyen desafíos porque interrogan las prácticas pedagógicas convencionales y delinean otras posibilidades para la formación de los docentes para la EIB. Son pedagogías que se gestan en la tensión entre la negación, el blanqueamiento y la valoración y vitalización de la cultura, la lengua y los conocimientos propios, conducen a la reafirmación identitaria.

Son alternativas pedagógicas que se producen en la pluralidad, en el encuentro de diversos y en la interrogación de las jerarquías. Propician la concientización de la opresión por eso llevan a la formación política de los sujetos individuales y colectivos para la transformación de las realidades y la construcción de otra historia.

Alertamos además sobre la necesidad de mantener siempre una mirada crítica en la experiencia educativa y en el proceso pedagógico porque al ser la pedagogía intercultural un campo emergente hay que tener en cuenta el riesgo de caer en el discurso hegemónico de la tolerancia y la armonía. Se requiere considerar la complejidad de los contextos sociales y económicos en los que se dan las relaciones interculturales.

Finalmente, es importante dejar sentada la necesidad de profundizar el estudio de las pedagogías emergentes latinoamericanas e interculturales. Es imprescindible contar con evidencia empírica que permita comprender los requerimientos educativos, pedagógicos y de la 
formación de profesorado, desde la actuación de los propios sujetos que se educan en la construcción de su propia educación. A la vez, es necesario atender al desafío de la educación en los ámbitos curriculares y didácticos, así como la producción y sistematización de materiales educativos y recursos didácticos propios.

\section{Referencias bibliográficas}

Arguedas, J. (1968). Pura Letra. No soy un aculturado, Palabras en el acto de entrega del premio "Inca Garcilaso de la Vega”, Lima, Recuperado de https://goo.gl/4v21RN.

Arroyo, M. (2012). Outros sujeitos outras pedagogías. Belo Horizonte: Editorial Vozes.

Baltazar, E., Manangón, J. y Trávez, P. (1992). Sistema de Escuelas Indígenas de Cotopaxi. En: Torres, V. (Ed.), La escuela india: Integración o afirmación étnica (61-85). Quito: COMUNIDEC.

Castro, G., Cóndor, N., Conejo, A., Iza, A., Laso, P., \& Puente, T. (2009). La Universidad en el páramo. El Programa Académico Cotopaxi. Quito: Abya-Yala.

Cuji, L. (2011). Educación superior e interculturalidad (Tesis de Maestría). Quito: FLACSO.

Decreto Ejecutivo 203. Reforma al Reglamento General de la Ley de Educación. Quito: s/e, 15 de noviembre de 1988.

Di Caudo, V. (2014). Estudiantes interculturales en la Universidad. Un relato colectivo desde Ecuador. Quito: Abya-Yala.

Fabara, E. (2004). Situación de la formación inicial docente $y$ en servicio en Colombia, Ecuador $y$ Venezuela. Santiago: OREALC-UNESCO.

Farfán, M. (2008). Experiencia del Programa Académico Cotopaxi, Formación en Educación Intercultural Bilingüe de la Universidad Politécnica Salesiana (Ecuador). En D. Mato (Coord.), Diversidad cultural e interculturalidad en educación superior. Experiencias en América Latina (285-296). Caracas: IESALC-UNESCO.

Fernández, L. (2006) ¿Cómo analizar datos cualitativos? Butlletí LaRecerca, 1-13. Barcelona: Universidad de Barcelona.

Freire, P. (1987). Pedagogía do Oprimido. São Paulo: Paz e Terra.
Freire, P. (2012). Pedagogía de la Indignación. Cartas Pedagógicas en un mundo revuelto. Buenos Aires: S. XXI.

González, M. (2011). Movimiento indígena y educación intercultural en el Ecuador. México: Universidad Autónoma de México- CLACSO.

Granda, S. (2016). Estado, educación y pueblos indígenas en los Andes ecuatorianos. Alteridad, 11(2), 221-230. DOI: http://dx.doi.org/10.17163/alt.v11n2.2016.07.

López, E., Moya, R., \& Hamel, R. (2009). Pueblos indígenas y educación superior en América Latina. En E. López, Interculturalidad, educación y ciudadanía perspectivas latinoamericanas (221-290). La Paz: FUNPROEIB Andes.

Mato, D. (2016). Indigenous People in Latin America: Movements and Universities. Achievements, Challenges, and Intercultural Conflicts. Journal of Intercultural Studies, 37(3), 211-233. https://doi.org/10.1080/07256868.2016.1163536

Medina, P. (2015). Presentación. En P. Medina (Coord), Pedagogías insumisas. Movimientos político-pedagógicos y memorias colectivas de educaciones otras en América Latina. México: Universidad de Ciencias y Artes de ChiapasCentro de Estudios Superiores de México y Centroamérica-Educación para las Ciencias en Chiapas- Juan Pablos Editor.

Ministerio de Educación (2014). Modelo del Sistema de Educación Intercultural Bilingüe (MOSEIB). Quito: MINEDUC. Recuperado de https://goo.gl/heEfJo

Molina, V. y Tabares, J. (2014). Educación propia. Resistencia al modelo homogeneizador de los pueblos indígenas de Colombia. Polis Revista Latinoamericana, 13(38), 149-172.

Moya, R. (2007). Formación de maestros e interculturalidad. En R. Cuenca, N. Nucinkis y V. Zavala (2007), Nuevos maestros para América Latina (229-258). Madrid: Ediciones Morata.

Neto, T. (s.f). Todo o dia D. Recuperado de: https://goo.gl/Zc1P2w

Puiggrós, A., \& Gómez, M. (1992). Alternativas pedagógicas, sujetos y perspectiva de la educación latinoamericana. México: UNAM.

Puiggrós, A. (1984). La educación popular en América Latina. México: Nueva Imagen.

Ramírez, A., Unda, F., Zavala, V., \& Moya, R. (2007). La educación intercultural bilingüe en el Ecuador. 
En V. Zavala, Avances y desafíos de la Educación Intercultural Bilingüe en Bolivia, Ecuador $y$ Perú (117-136). Lima: IBIS CARE.

Ripamonti, P. (2015). La historia oral o historizar la memoria. En Cátedra Fals Borda de CLACSO, Metodología de la investigación social (1-18). Buenos Aires: CLACSO.

Rodríguez, L. (2015). Alternativas pedagógicas y prospectivas educativas en América Latina. Cuestiones teórico, analíticas y metodológicas. CLACSO. Recuperado de https://goo.gl/vqDrHX

Segato, R. (2015) Brasil: Colonialidad, élites y universidad. Ponencia en Seminario internacional: Educación superior latinoamericana y la geopolítica del conocimiento. Quito: Universidad Andina Simón Bolívar. Recuperado de https://goo.gl/qq8f4L

Torres, V. (1992). La escuela india: integración o afirmación étnica. Quito: COMUNIDEC, Abya-Yala.
UPS (2005). Proyecto Académico de la Carrera de Educación Intercultural Bilingüe. Quito: UPS. UPS (2017). Sistema Gestión Académica. Cuenca: UPS. Vázquez, V., Regalado, J., Garzón, B., Torres, V., \& Juncosa, J. (2012). La presencia salesiana en Ecuador. Perspectivas históricas y sociales. Quito: Abya-Yala.

Vélez, C. (2008) Trayectoria de la Educación Intercultural Bilingüe en el Ecuador. Revista Educación y Pedagogía, 20(52), 103-112.

Villagómez, M.S. (2016). Práctica de la interculturalidad, descolonización y formación docente: el Programa Académico Cotopaxi del Ecuador. (Tesis de Doctorado). Belo Horizonte: Universidade Federal de Minas Gerais.

Walsh, C. (2009). Interculturalidad, Estado, sociedad. Luchas (de) coloniales de nuestra época. Quito: Universidad Andina Simón Bolívar, Abya-Yala. 


\section{"Iyambae": en busca de una educación superior emancipadora en la UNIBOL Guaraní y Pueblos de Tierras Bajas}

\section{"Iyambae": in search of an emancipatory higher education in the UNIBOL Guarani and Lowland Peoples}

David Silvestre Delgadillo Zerda es profesor e investigador de la UIEP Universidad Intercultural del Estado de Puebla (México); candidato a doctor por la UNAM (México) (david.delgadillo@uiep.edu.mx) (http://orcid. org/0000-0002-5461-8450)

Recibido: 2017-08-12 / Revisado: 2017-11-17 / Aceptado: 2017-11-29 / Publicado: 2018-01-01

\section{Resumen}

En Latinoamérica (LA), hablar de las condiciones de posibilidad que den muestra de la construcción de una Educación propia en la educación superior como alternativa al proyecto pedagógico de la modernidad y del capitalismo hegemónico es referirse a experiencias educativas localizadas y concretas en la región. El contexto de diversidad corresponde al de las etnias indígenas de tierras bajas de Bolivia. Ahora bien, ¿Cuáles son los alcances y limitaciones que particularizan el abordaje de la diversidad étnica, cultural y lingüística del modelo de Universidad Indígena Boliviana (UNIBOL) Guaraní y de Pueblos de Tierras Bajas "Apiaguaki Tüpa" que permite hablar de la construcción de una educación propia orientada al posicionamiento de una pedagogía latinoamericana? Los pueblos indígena, originario, ancestrales (PIOAs) han impreso a esta institución las siguientes características: subversión de la configuración jerárquica herencia del modelo de universidad colonial (Weinberg, 1995), establecimiento de relaciones horizontales en un contexto de verticalidad de la educación superior (ES). Así como, la transformación de la función jerarquizante, monocultural y hegemonizante en una práctica pluralizadora y preservadora de la diversidad destinada a la superación de las desigualdades a través de su valoración rescate y fortalecimiento de elementos étnicos, culturales y lingüísticos propios. Además del tránsito de la suplantación de la presencia, voz y accionar de los PIOAs a un activo y efectivo protagonismo en la construcción de un modelo de ES constituido y constituyente de la visión histórica, política e identitaría de los pueblos indígenas de tierras bajas desempeñando una función emancipadora.

Descriptores: Educación propia, educación superior, pueblos indígenas, lenguas indígenas, emancipación, reivindicación política.

Forma sugerida de citar: Delgadillo, D. S. (2018). "Iyambae": en busca de una educación superior emancipadora en la UNIBOL Guaraní y Pueblos de Tierras Bajas. Alteridad, 13(1), 42-55. https://doi.org/10.17163/alt.v13n1.2018.03. 


\begin{abstract}
In Latin America (LA), to speak of the conditions of possibility that show the construction of an own education in higher education as an alternative to the pedagogical project of modernity and hegemonic capitalism is to refer to localized and concrete educational experiences in the region. The context of diversity corresponds to that of the indigenous lowland ethnics of Bolivia. Now, what are the scope and limitations that particularize the approach of the ethnic, cultural and linguistic diversity of the model of the Bolivian Indigenous University (UNIBOL) Guaran and of the Low Lands Peoples "Apiaguaki Tüpa" that allows to speak of the construction of an own education oriented to the positioning of a Latin American pedagogy? The indigenous, original, ancestral peoples (IOAPs) have printed to this institution the following characteristics:
\end{abstract}

\section{Introducción 1}

Actualmente, gran parte de la pedagogía que sustenta el accionar educativo en los países latinoamericanos adolece no solo de una fundamentación esencializada en el axioma de la desigualdad (Rancière, 2003). Modelo asumido y perfeccionado por el proyecto pedagógico de la modernidad y el capitalismo hegemónico (Laclau y Mouffe, 1985) sino también, instituye el sistema al cual representa, reproduce y disemina imponiéndola como el paradigma a emular en educación. Esquema que mantiene a los demás sistemas educativos en una situación de sometimiento, al modelo hegemónico, obligándolos a reproducir y perpetuar dicha desigualdad.

En educación quienes más han experimentado procesos de inferiorización y minorización, han sido los pueblos indígenas, concebidos, desde lógicas indigenistas (Castañeda, 2006) como incapaces para poder decidir sus destinos por sí mismos y más aún concebir, construir y llevar adelante sus propios sistemas educativos (Sarango, 2013). Proceder que ha encontrado en la educación superior, heredera de la colonia, el perfecto mecanismo de reproducción y naturalización de la relación de subalternización política, subversion of the hierarchical configuration, inheritance of the colonial university model; establishment of horizontal relationships in a context of verticality of higher education $(\mathrm{HE})$. As well as, the transformation of the hierarchical, monocultural and hegemonic function into a pluralizing and preserving practice of diversity destined to overcoming inequalities through its valuation, rescue and strengthening of own ethnic, cultural and linguistic elements. In addition to the transit of the supplanting of the presence, voice and actions of the IOAPs to an active and effective role in the construction of a model of HE constituted and constituent of the historical, political and identitarian vision of the indigenous peoples of the low lands performing an emancipatory function.

Keywords: Own education, higher education, indigenous peoples, indigenous languages, emancipation, political vindication.

económica, cultural, epistémica y lingüística de los pueblos indígenas.

En Bolivia la administración de Estado, arraigada en la colonialidad del poder (Quijano, y Wallerstein, 1992), negó históricamente el reconocimiento de dos elementos constituyentes e instituyentes de las naciones indígenas; sus territorios ancestrales y su libre determinación (Aparicio, 2009). Empero la lucha indígena, particularmente de tierras bajas, obtuvieron, en décadas recientes, logros importantes en la consecución de ambas reivindicaciones. Avance que configuró un espacio propicio para la concreción de las principales propuestas de la vía indígena erigiéndose como un proyecto social alterno.

La condición de mayoría es la que le permite a la sociedad indígena brindar su esquema interpretativo, su esquema de conocimiento y su posicionamiento político, como una posibilidad hegemónica que sea atractiva y que cuestione a los mestizos nuestra identidad. Para mí, lo más interesante políticamente del fenómeno de la insurgencia india, es que le plantea por primera vez al conjunto de la sociedad boliviana la posibilidad de indianizarse y de superar las visiones externas, esencialistas y cosificadoras de lo étnico (Rivera, 2008). 
En el ámbito de la educación superior la creación del régimen de universidades indígenas, particularmente la UNIBOL "Apiaguaki Tüpa" es la propuesta de los pueblos indígenas de tierras bajas. La trascendencia del proyecto educativo radica en la correlación entre el proyecto educativo y la visión política e ideológica propia de los pueblos indígenas de tierras bajas fundada en la reconstitución de los territorios ancestrales, la autodeterminación y la retoma de la historicidad propia. En este marco la experiencia desarrolla importantes elementos enmarcados en la construcción de una educación propia.

\section{Metodología}

Desde finales de los ochenta del siglo pasado, el accionar del movimiento indígena, además de otros factores confluyentes suscitaron cambios importantes en los países de la región; las respuestas oficiales del Estado-Nación involucraron procesos de institucionalización de la diversidad en la ES. Propuestas que van desde una lógica de inclusión, integración de población indígena (Mato, 2014, p. 43) hasta aquellas, procedentes de los mismos PIOAs consistentes en experiencias autogestivas. La diferencia entre ambas permite dilucidar el problema de investigación. Cuando el proyecto es planteado por no indígenas, entonces, el estudio se centraría en la pertinencia; pero, cuando la propuesta emerge de los mismos indígenas, el presente caso, el objetivo es evidenciar las posibilidades y limitaciones en el proceso de materializar y consolidar la proyección de la visión política, ideológica y cultural de estos pueblos en la ES.

La necesidad de conocer las particularidades que hacen de esta universidad una propuesta de los pueblos indígenas, instó adoptar la investigación cualitativa de corte etnográfico. La estrategia exploratoria implementó las siguientes técnicas: a) La revisión documental permitió acceder y analizar información relevante de la universidad. b) La entrevista fue de tipo no estructurada, en profundidad, y se aplicó bajo el criterio de mayor incidencia en la materiali- zación de la propuesta educativa. c) La observación no participante resultó vital para analizar los sucesos cotidianos; actitudes de detractores y/o partidarios del modelo. Los instrumentos utilizados fueron: el diario de campo, guías de entrevista; así como, el registro fotográfico y voz.

\section{Resultados}

\subsection{Contextualización de las naciona- lidades indígenas y las universi- dades interculturales en el Estado Plurinacional de Bolivia}

Bolivia es uno de los países más biodiversos del mundo, la profusión encarna también en la variedad étnica, cultural y lingüística. Una clasificación básica de la composición geográfica distribuye su territorio en "tierras altas" (puna, altiplano y valles) y "tierras bajas" (Amazonía, chaco y llanos orientales). Comparando ambas extensiones, el 60\% del territorio corresponde a la región de la Amazonía (Rivero, 2014), por tanto más que país andino debe ser considerado amazónico. La población total del país asciende a 10457329 habitantes, de los cuales el 44\% es indígena (INE, 2011), porcentaje cuestionado por la reducción drástica respecto del censo 2001 donde el $62 \%$ se auto-identificaba como indígena. Bolivia reconoce 36 nacionalidades indígenas, cinco habitan ancestralmente en tierras altas: El resto, 31 están localizados en tierras bajas. Esto indica una mayor concentración de la diversidad étnica, cultural y lingüística en tierras bajas

La instrumentalización de la educación originada en la colonia y proseguida en la época republicana busco siempre la desestructuración étnica, política, territorial y simbólica de PIOAs imponiéndoles una política educativa homogeneizadora, minorizadora e inferiorizante (Choque, 2015) denominada Indigenismo (Fabre, 1998). A contracorriente, la subalternización provocó en los indígenas la necesidad de apropiarse de la educación. Para el movimiento indígena la paradoja expuso connotaciones subversivas sobre la educación asumiéndosela cómo 
una más de sus demandas (Rojas, 2003). En este sentido, la lucha de los pueblos indígenas por sus reivindicaciones generó en las últimas cuatro décadas cambios importantes. Transformaciones que alcanzaron su punto más alto con la aprobación de una Nueva Constitución Política del Estado (NCPE) en 2009. Acuerdo social donde la participación activa de los pueblos indígenas fijó las bases del nuevo modelo de Estado fundadas en el reconocimiento de la plurinacionalidad que lo obliga a atender las demandas, necesidades y expectativas de los pueblos que la conforman.

Con la creación del régimen de universidades indígenas bolivianas en 2008 el escenario de la educación superior experimenta cambios significativos que impulsa la explicitación de la obligatoriedad del Estado a garantizar a las nacionalidades indígenas el rescate, mantenimiento y desarrollo de la diversidad étnica, cultural y lingüística queda establecida en la NCPE:

La educación superior es intracultural, intercultural y plurilingüe, y tiene por misión la formación integral de recursos humanos con alta calificación y competencia profesional; desarrollar procesos de investigación científica para resolver problemas de la base productiva y de su entorno social; promover políticas de extensión e interacción social para fortalecer la diversidad científica, cultural y lingüística; participar junto a su pueblo en todos los procesos de liberación social, para construir una sociedad con mayor equidad y justicia social (Gaceta oficial del Estado Plurinacional de Bolivia, 2009, p. 25).

Asimismo, desde 2011 entra en vigencia, la Ley de Educación "Avelino Siñani, Elizardo Pérez" incorporando nuevos elementos tendientes a preservar y fortalecer el patrimonio cultural de los PIOAS. El artículo $5^{\circ}$ fija principios que regirán la educación acorde al nuevo modelo de país establecido por la constitución señalando; "Las naciones y pueblos indígena originario campesinos tienen derecho a una educación intracultural, intercultural y plurilingüe en todo el sistema educativo." Con esto se busca que todo el sistema educativo contribuya al fortalecimiento de la unidad e identidad de los pueblos indígenas como parte del Estado Plurinacional, así como a la identidad y desarrollo cultural de sus miembros.

UNIBOL Guaraní y de Pueblos de Tierras Bajas "Apiaguaiki Tüpa"

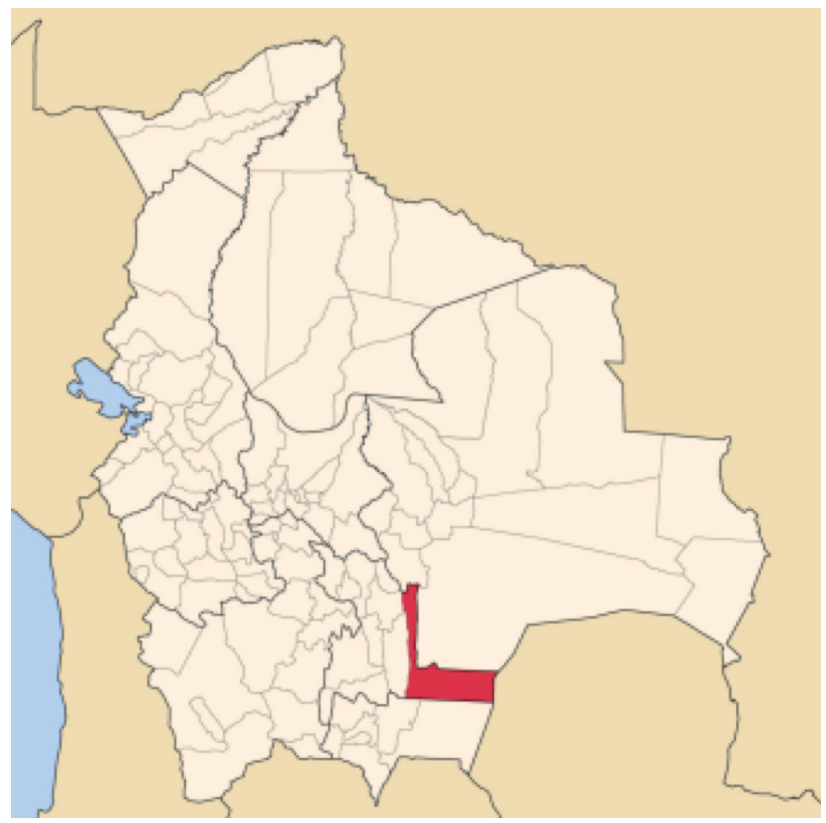


Enclavada en la comunidad de Ivo, provincia Luis Calvo del Departamento de Chuquisaca, en el territorio indígena originario (TIO) Guaraní, se encuentra el campus de la UNIBOL "Apiaguaiki Tüpa”. Desde su fundación esta universidad mostró avances importantes, remitiéndonos a la posibilidad de construcción de una educación insumisa (Medina, 2015) y con ella una pedagogía alterna. En este sentido, la visualización del proyecto político de los pueblos indígenas está esencializada en dos condiciones básicas de vida para la población indígena: el territorio y la emancipación. El carácter vital de estos elementos se tradujo para los pueblos indígenas en dos imperativos; el primero, "la reconstitución de los territorios indígenas" y el segundo "la autodeterminación de estos pueblos". Ambos preceptos enmarcados en la retoma de la historicidad propia (Cusicanqui, 2010, p. 54).

Bajo estos dos principios ordenadores la población indígena generó numerosas y diversas estrategias de resistencia y lucha para enfrentar las condiciones brutales de desestructuración sociocomunitaria cultural impuestas por el sistema colonial (Golte, 1980) que significó la usurpación y despojo de los territorios indígenas ancestrales y la explotación de sus recursos naturales. Además del sometimiento de la población indígena a trabajos forzados bajo modalidades de servidumbre y esclavitud que duró casi tres siglos, desde la llegada de los españoles hasta 1825 (Canedo, 2011). La independencia, reafirmando su herencia colonial, no puso fin al despojo y la explotación, intensificándola. Situación que afirmo la reconstitución territorial y la autodeterminación como reivindicaciones inequívocas de los PIOAs. Para los indígenas de tierras bajas de Bolivia, los movimientos milenaristas (Wachtel, 1973) como el Ivi Marae "tierra sin mal" para los guaraníes; o el Kandire "La Búsqueda de la Loma Santa" para los moxeños constituyen la estrategia relacionada con la reconstitución de los territorios indígenas (Lehm, 1991).

Los territorios son espacios sagrados donde las personas o las familias guaraníes tienen que cuidar y formar parte de ella... entonces esas tres categorías es, para nosotros, es que necesariamente tiene que tener un territorio ¿no? y si no cumple esos tres componentes el territorio está en conflicto, si solo es un pequeño lotecito para la casa, le falta algo ¿no?, le falta tener un sembradío. Pero si tengo casa y luego un sembradío, resulta que me está faltando algo que es más importante ¿no? que es el espacio mayor que es el lugar sagrado, lugar para la caza, lugar para la espiritualidad, para el desplazamiento de las personas y el contacto también con otros seres, entonces ese es el espacio mayor, entonces en esas tres dimensiones se entiende el territorio y bueno desde tiempos muy antiguos hemos estado siempre buscando territorio así ¿no? la palabra buscar, la búsqueda del Ivi Marae o "Tierra sin Mal” no significa que no lo teníamos ¿no? sino que era un permanente estar en ese espacio de la tierra sin mal. En otro momento si requería, cuando ya el territorio era desgastado, el territorio ya no tenía esos tres elementos era necesario un desplazamiento o el uso espacial dentro el dominio espacial sobre sus territorios. Entonces esa es la visión de la tierra sin mal ¿no? para nosotros (E. Camargo, entrevista, 18/11/2014).

En el mismo sentido el Iyambae o Iyaambae cuyo significado más cercano refiere a un ser humano libre "el sin dueño" se establece como estrategia que insta a la búsqueda de autodeterminación de los pueblos indígenas. Ambos preceptos impulsan y orientan históricamente el accionar y vida de la población indígena hacia la consecución de estos ideales.

Iyambae es una condición, es una condición humana, no solo del guaraní sino lo que decimos es que el guaraní es libre, sin dueño, autónomo, libre para decidir su futuro libremente. Ese es el ser Iyambae no tendría que haber patrón, no tendría que haber alguien que dirija. Entonces esa es también la dignidad de las personas ¿no? Porque el mundo ahora ha entrado hay unos que explotan y otros que...un explotador y otros que son explotados. Entonces en la visión guaraní no es eso ¿no? sino el ser soberano en sí, la persona. Por eso es que antes no teníamos... una confede- 
ración, de los guaraníes antes, no había un... alguien que mande a toda la nación guaraní, sino que cada sector, cada comunidad, cada persona, cada capitanía era libre ¿no? claro en el momento de defender el territorio se unían toditos pero después cada quien a desarrollar de manera autónoma su propia vida ¿no? entonces esa es una de las cuestiones más importantes que nosotros cuidamos ¿no? (E. Camargo, entrevista personal, 18/11/2014).

Impulsados y direccionados por estas utopías movilizadoras los PIOAs han obtenido, en las tres últimas décadas, importantes resultados en la consecución de sus reivindicaciones fundamentales. Entre los logros perceptibles para los pueblos indígenas encontramos: 1) Obtienen la titulación colectiva de 20715 950,3 hectáreas desde 1990 hasta 2010 en calidad de Territorios Indígena Originario Campesinos (TICOs), Fundación Tierra (2011). 2) La elección del primer presidente indígena en 2006. 3) En 1985 Proponen se convoque a la asamblea constituyente. 4) Participan junto a otras organizaciones indígenas y de la sociedad civil en la realización de Asamblea Constituyente de 2006 a 2009. 5) Logran el reconocimiento de la composición étnica, cultural y lingüística diversa del país cambiando la denominación de República de Bolivia por el de Estado Plurinacional de Bolivia (EPB). 6) Consiguen la constitucionalización de sus demandas históricas como el reconocimiento del "territorio indígena originario campesino” y la autonomía indígena. 7) Obtienen la representación política directa en el órgano legislativo. 8) Constitucionalizan la consulta previa en la carta magna.

Dada la existencia precolonial de las naciones y pueblos indígena originario campesinos $\mathrm{y}$ su dominio ancestral sobre sus territorios, se garantiza su libre determinación en el marco de la unidad del Estado, que consiste en su derecho a la autonomía, al autogobierno, a su cultura, al reconocimiento de sus instituciones y a la consolidación de sus entidades territoriales, conforme a esta Constitución y la ley (Gaceta del Estado Plurinacional de Bolivia, 2009.17).
Así el movimiento indígena habría avanzado, tanto en la reconstitución de los territorios ancestrales como en la autodeterminación de los pueblos. En este sentido los logros han redundado en el reconocimiento y revalorización de la diversidad étnica, cultural y lingüística de las nacionalidades indígenas por el conjunto de la sociedad boliviana en sus diferentes estamentos sociales. Hecho que permitió acordar un nuevo pacto social bajo la consigna "nunca más sin los pueblos indígenas." De este modo los pueblos indígenas han incrementado su visibilización y participación en diferentes ámbitos político, jurídico, económico y social en Bolivia. Asimismo, la elección del primer presidente indígena de Bolivia en 2006 marca un continuo en las concreciones de varias demandas históricas sujetas siempre a las utopías movilizadoras (Ivi marae e Iyambae). Configuración propicia para la instauración de las principales propuestas de la vía indígena en diferentes esferas sociales.

En el ámbito de la educación superior en 2008 se crean tres universidades indígenas: la UNIBOL aimara “Tupak Katari”, la UNIBOL quechua "Casimiro Huanca" y la UNIBOL Guaraní y de Pueblos de Tierras Bajas "Apiaguaki Tüpa". La creación de estas IES se inscribe en la visión política amplia de los pueblos indígenas orientados siempre a la reconstitución ancestral de los territorios ancestrales, la autodeterminación de las naciones indígenas y la retoma de la historicidad de los pueblos indígenas. La creación de este nuevo régimen de universidades ${ }^{2}$ alternas a las universidades clásicas, convencionales ya existentes se justifica en la experiencia de gran parte de la población indígena que tuvo que lidiar con procesos de alienación, pérdida de identidad cultural, priorización de intereses individuales y una visión predominantemente comercial del conocimiento, bajo un principio monocultural (Díaz-Polanco, 2006) que invisibilizó y descalifico el conocimiento y comprensión de la realidad producido por los pueblos indígenas.

La crítica al régimen de universidades públicas-convencionales, atrincherada en la 
autonomía universitaria, deviene no solo de su invariable función reproductora de la desigualdad arraigada fuertemente en el pensamiento colonial (Tünnermann, 2010). Sino también del inexistente aporte en los procesos de transformación emprendidos por los sectores sociales mayoritarios desde 2004 que culminaron con la aprobación de la NCPE en 2009, más aún prevalece la actitud reticente a los cambios propugnados por sectores sociales mayoritario. Negativa que repercutió en la necesidad de crear IES (no convencionales) indígenas correlacionadas a los requerimientos educativos del ser, actuar y pensar propio de la alteridad indígena.

Con la puesta en marcha de la UNIBOL "Apiaguaiki Tüpa" se expone la tensión existente entre dos modelos de universidad que pugnan por imponerse al interior de la institución. Por un lado está el modelo de universidad convencional moderna de corte occidental, con el que vienen funcionando las universidades públicas y privadas, desde la fundación de la primera universidad en Bolivia. Por otro lado está el "modelo de universidad indígena no convencional" que podría describirse como el intento de concreción de la idea de educación superior propia que tienen los pueblos indígenas, en este caso los pueblos indígenas de tierras bajas de Bolivia.

Al no haber un modelo preestablecido de universidad indígena, sino que está en construcción, la consolidación en la experiencia de la UNIBOL se enfrenta a la influencia que ejerce el modelo convencional preestablecido. En este sentido la convergencia de ambos modelos al interior de esta IES indígena expresa sus múltiples tensiones y conflictos en distintas dimensiones, niveles y actores universitarios impactando en el desarrollo constitutivo de la educación propia en el nivel superior de la educación consignada bajo esta IES. Tal coyuntura configura los alcances y límites de dicha experiencia afectando diferentes componentes constitutivos, estos son: a) Participación de los pueblos indígenas en la estructura de gobierno universitario y funcionamiento actual de la universidad, b) El diálogo y articulación del conocimiento universal de corte occidental con los saberes y conocimientos propios, c) Dinámica sociolingüística y abordaje institucional de las lenguas indígenas; y d) la vinculación universitaria con las comunidades, organizaciones y población indígena.

\subsection{Participación de los pueblos indí- genas en la estructura de gobierno y funcionamiento actual de la uni- versidad de la UNIBOL Guaraní y de pueblos de Tierras Bajas}

Uno de los rasgos más visibles de la UNIBOL Guaraní desde su creación hasta el momento, es la implicación de la población indígena en el proyecto. Actualmente alberga a 732 estudiantes y 62 docentes. La evidencia constata una participación cualitativa en cuanto plantea y materializa una propuesta académica posicionada en la visión política e ideológica de los pueblos de tierras bajas. Cuantitativamente la participación de los PIOAs se efectiviza, en cuanto el planteamiento educativo es vehiculizado en instancias de proposición, decisión y ejecución donde la participación de los pueblos indígenas es mayoritaria definiendo el curso de acción institucional. La propuesta educativa ciertamente está a cargo de los pueblos indígenas de tierras bajas; tanto en la estructura de gobierno como la administración de recursos, la gestión institucional y académica. Los mismos actores indígenas visualizan a la universidad como una institucionalidad creada por ellos. Igualmente, la población no indígena reconoce a esta IES como una institucionalidad propiamente indígena.

La máxima instancia de decisión en la UNIBOL “Apiaguaki Tüpa”, en la estructura organizacional, está dada por la Junta Comunitaria. Esta instancia está conformada por los representantes de cada uno de los pueblos indígenas de donde provienen los estudiantes. Si hay 12 nacionalidades indígenas presentes en la universidad, serán 12 representantes indígenas en el consejo, los directores de cada las cuatro 
carreras; Ingeniería en Petróleo y Gas Natural IPGN, Ingeniería Forestal (IF), Ingeniería en Eco-piscicultura (IEP) y Medicina Veterinaria (MV). Un representante docente por carrera (4 docentes), un representante estudiante también por carreras (4 estudiantes indígenas) y el Rector o Rectora, indígena. Esta composición señala que la tuición de la universidad recae mayoritariamente en la población indígena haciendo de la participación indígena deliberativa y decisoria.

\subsubsection{La UNIBOL Guaraní de Tierras Bajas está} en directa vinculación con las demandas mediatas, inmediatas y posteriores de los pueblos indígenas del oriente boliviano

Bajo el lema "por el territorio y la dignidad" en 1990 en Bolivia, el movimiento indígena de tierras bajas convocó a una marcha reivindicando el derecho de los pueblos indígenas al territorio. Con esta marcha los pueblos originarios lograron que el gobierno les titulara en calidad de TCO (Tierras Comunitarias de Origen) tres extensiones territoriales (Lehm, 1991). Desde entonces se han reconocido en Bolivia más veinte TCOs a diferentes nacionalidades indígenas.

En esta coyuntura la creación de las universidades indígenas constituye una respuesta a las necesidades educativas de los PIOAs vinculadas esencialmente a la ocupación y aprovechamiento de recursos naturales en sus territorios ancestrales. En este sentido, la creación de los cuatro programas educativos convencionales responde a la exigencia constitucional de impulsar la productividad a través de la ES. Igualmente, corresponden con los recursos naturales existentes en los territorios: Ingeniería del Petróleo y Gas Natural, vinculadas al aprovechamiento de los hidrocarburos cuyos yacimientos importantes se encuentran ubicados en los territorios indígenas de la nación Guaraní. Ingeniería Forestal, relacionada al aprovechamiento de los recursos forestales existentes en los bosques de la Amazonía. Ingeniería en Ecopiscicultura relacionada con el aprovechamiento de los recursos hídricos abundantes en el oriente boliviano. Y Medicina Veterinaria previendo la potencialidad de cría de animales.

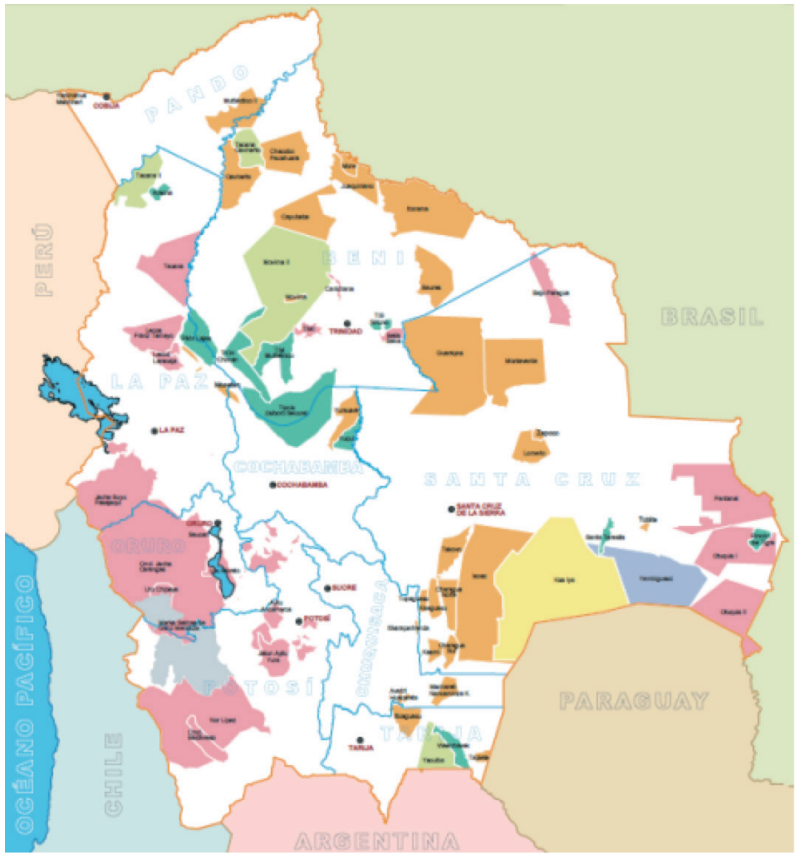




\subsubsection{Los sabios indígenas en la UNIBOL Guarani y de Tierras Bajas}

Un rasgo a destacar de la experiencia educativa es la emergencia, en el ámbito académico, de los sabios indígenas, actualmente en la universidad están trabajando bajo esta función cuatro sabios que corresponden a las naciones indígenas: guaraní, moxeño, bésiro y guarayu. En cuanto a sus funciones son varias; orientador para los estudiantes, educador, experto en lengua indígena, desempeñándose también como asesores académicos y políticos que guían a los órganos de gobierno y de administración institucional. De entre todas las funciones realizadas por los sabios indígenas sobresalen dos: la primera relacionada con el rol de depositarios de los saberes y conocimientos de los pueblos indígenas y mediadores en los procesos de articulación entre el conocimiento universal de corte occidental y los saberes y conocimientos propios. En este sentido la importancia de la función pedagógica del sabio indígena para la UNIBOL radica en su potencialidad como agente intraculturizador en procesos académicos de diseño y restructuración curricular de planes y programas académicos. Intervención indispensable en la tarea de promover un pluralismo epistemológico (Prada, 2015) en un contexto adverso, por tratarse de carreras convencionales cuyos campos de conocimiento están conformados por la ciencia estructural, los métodos explicativos basados en la totalidad, y el método científico de corte occidental como medio de validación.

La segunda función está relacionada con su papel de guía y consejero político en la conducción de la UNIBOL, allí se constituye en vigilante de la junta comunitaria. Precautelando que los procesos académicas, administrativos, sociales, culturales no contravengan a la propuesta educativa indígena establecida por la institución. En este sentido aboga en diferentes instancias, especialmente en los diferendos académicos entre docentes técnicos (anclados en formatos académicos convencionales), docentes de len- guas indígenas (posicionados en la propuesta indígena). $Y$ docentes transversales (custodios de la propuesta) cuidando que la consolidación del modelo mantenga las características que la hacen indígena.

\subsubsection{Dinámica sociolingüística y abordaje ins- titucional de las lenguas indígenas en la UNIBOL "Apiaguaiki Tüpa"}

De las tres universidades indígenas creadas en Bolivia la UNIBOL "Apiaguaiki Tüpa" es la que más diversidad étnica, cultural, lingüística atiende. Esto le significa a la institución una gran dificultad y un verdadero desafío referido al rescate y fortalecimiento de las lenguas indígenas de tierras bajas. Actualmente en la Universidad podemos encontrar estudiantes provenientes de 17 naciones indígenas, incluidos algunos estudiantes provenientes de tierras altas, de lengua aimara y quechua.

No obstante, la complejidad que involucra revitalizar el uso de las lenguas indígenas la UNIBOL ha asumido este reto, estableciendo la asignatura de lengua originaria (indígena) como trocal en las cuatro carreras; con el objetivo de producir investigaciones, ciencia y teoría desde la lengua indígena. Así los estudiantes puedan elaborar y teorizar desde su propio código lingüístico, además de construir representaciones del contexto productivo, ambiental, tomando en cuenta su propia forma de ver el mundo vehiculizado por su lengua como instrumento principal (UNIBOL, 2012).

El abordaje de la lengua indígena en la institución muestra dificultades y limitaciones referidas principalmente a la imposibilidad de atender adecuadamente la gran diversidad de lenguas presentes en la UNIBOL. Si bien la intención es consolidar un modelo de revitalización de las lenguas de tierras bajas, materialmente esto no es posible porque implica la contratación de por lo menos una treintena de docentes sólo para este eje curricular. Por esta razón la institución optó por atender gradualmente a las lenguas en la formación profesional. Inicialmente trabaja 
cuatro lenguas indígenas de uso mayoritario en los estudiantes: el guaraní, el moxeño, el bésiro y el guarayu. Las demás lenguas se irán abordando en los subsiguientes años de forma gradual.

Numéricamente los estudiantes bilingües (Appel y Muysken, 1997) son pocos en comparación con los estudiantes monolingües en castellano en la UNIBOL. La estrategia adoptada consiste en agrupar a los estudiantes en bilingües castellano-lengua indígena y en monolingües en castellano. Los primeros llegan a la universidad con todas las habilidades lingüísticas en castellano y ciertas competencias en lengua indígena. En cambios los segundos vienen solo con el dominio de las competencias en castellano (entienden, hablan, escriben y leen). Ambos grupos abordan la lengua con diferentes finalidades los dos primeros semestres; los bilingües buscan consolidar las cuatro habilidades lingüísticas y los monolingües inician el aprendizaje de la lengua, esto supone inicialmente la elección de una de las cuatro lenguas ofertadas por la institución. En tercer semestre, se fusionan ambos y conforman grupos de cooperación para la consolidación de las competencias en lengua indígena, ahí los estudiantes bilingües asumen un rol importante como apoyo en la formación de sus compañeros monolingües. Pese al tiempo dedicado y la estrategia adoptada para favorecer el aprendizaje de las lenguas, los resultados aún son muy limitados, al terminar su profesionalización los estudiantes (monolingües) aún no han logrado consolidar las capacidades lingüística en lengua indígena.

\subsubsection{Tendencia de los docentes a replicar la función docente convencional de su propia formación profesional}

Todos los docentes de los cuatro programas de la UNIBOL "Apiaguaiki Tüpa” se formaron en universidades públicas convencionales, su práctica docente actual refleja mucho de su experiencia de formación profesional caracterizado por la función de maestro explicador reproductora de la desigualdad de inteligencias (Ranciére,
2003). Donde el rol activo estaba centrado en la enseñanza del docente, sus conocimientos, su método, etc. el modelo de universidad indígena proporciona a estos docentes el espacio para transformar su experiencia docente subordinadora de inteligencias a una práctica educativa emancipadora.

Al momento la UNIBOL presenta tres tipos de docencia de acuerdo a las áreas curriculares: docentes técnicos, docentes de lenguas indígenas y docentes transversales. Debido a la formación de los docentes en universidades convencionales, el modelo explicador estuvo presente en todos pero con diferenciadas intensidades. Así los docentes de las ingenierías parecen haber experimentado, acentuadamente, procesos de atontamiento pedagógico (Ranciére, 2003). La razón remite a los contenidos del área de las ciencias naturales fuertemente estructurados en los métodos de comprobación científica. De ahí la reticencia a concebir otros sistemas de conocimientos cómo válidos, principio transformador de la práctica educativa. En cambio los docentes el área transversal parecen haber sido menos afectados por la experiencia educativa del maestro explicador, debido en parte a la naturaleza de los contenidos que corresponden con el área de las humanidades y las ciencias sociales. Su práctica actual como docentes muestra una mayor apertura a la emancipación de la educación, en muchos casos, promueve abiertamente e instan a los docentes del área técnica a transitar de una metodología de enseñanza fundada en la desigualdad de inteligencias a una metodología de la igualdad de voluntades. Por su parte los docentes de lengua indígena, fortalecidos en su identidad cultural se constituyen en promotores del modelo indígena.

Las negociaciones entre estos tipos de docentes perfilan una determinada articulación de saberes, conocimientos y lenguas producto no siempre del diálogo sino como resultado de la pugna por asignar un porcentaje de la calificación distributiva que refleje no solo el dominio de conocimientos del área disciplinar técnica, 
sino también, el uso académico de la lengua indígena, la fundamentación cultural que recupera la propia historicidad, además de la recuperación de algún saber o conocimiento propio.

\subsubsection{Los contenidos de algunas asignaturas se prestan más al método explicador}

En cuanto a los contenidos de las diferentes asignaturas de la carrera de ingeniería forestal de la UNIBOL cabe señalar la presencia de contenidos en áreas curriculares que justificarían prácticas docentes tradicionales. Dichos contenidos corresponden al área de las ciencias naturales. Disciplinas como dendrología, edafología, botánica general, fisiología vegetal y otras propias del área forestal, así como las materias de física, química y cálculo cuyos contenidos están cimentados en métodos rígidos de comprobación y clasificación científica. Por tanto, el peso de estas asignaturas en la formación profesional viene revestido por un estatus de ciencia indiscutible frente a otros saberes y conocimientos en particular, los indígenas. En este sentido los docentes técnicos muchas veces descalifican los conocimientos provenientes del patrimonio cultural de los estudiantes negándose a considerarlos como conocimientos, especialmente en trabajos de investigación de grado. Asimismo la concepción de superioridad de los conocimientos "científicos" de estas las asignaturas es transmitida a los estudiantes, en este sentido se replica la jerarquización "desigualdad del conocimiento". Dicho sea de paso, en estas asignaturas el porcentaje de aprobación del curso por tradición, es menor al de otras.

Por otro lado, en los estudiantes se puede observar también, el peso de una trayectoria educativa, en los niveles escolarizados, caracterizada por la práctica pedagógica explicadora que ha trastocado el modo de concebir el proceso de aprendizaje. Las repercusiones de esta experiencia se pueden percibir en la inseguridad que los estudiantes muestran a la hora de enfrentarse a tareas académicas donde la intervención del docente se reduce. Al respecto López (2009) señala que el peor empobrecimiento es que hemos formado a la población indígena o de ancestro indígena como gente insegura de sí misma, y un sujeto inseguro no puede contribuir al desarrollo de un país. Asimismo, otra implicación de la experiencia educativa escolarizada, es que para gran parte de los estudiantes su aprendizaje deviene de la explicación de un docente quien tiene consolidado un gran cúmulo de conocimientos en el área que enseña. Especialmente cuando se trata de las materias del área técnica.

Cuando se les pregunta ¿cuáles son las características de los maestros que enseñan bien? Muchos responden que son aquellos quiénes explican mejor, adjudicando su aprendizaje no a sí mismos sino al rol explicador del maestro; así como a su cúmulo de conocimientos del área y que están en permanente actualización. La concepción misma del aprendizaje de los estudiantes alude a ese proceso de vaciamiento del conocimiento del docente hacia los estudiantes, elementos que refuerzan y mantienen el rol explicador del maestro.

\section{Discusión}

No obstante los cambios del Estado logrados por los movimientos sociales, especialmente, el movimiento indígena. La transformación de la educación superior en Bolivia ha encontrado en el modelo de universidad convencional, tradicional, autónoma, de origen colonial un obstáculo infranqueable para concretar la visión educativa propia. De ahí que la reconfiguración de la educación superior haya buscado otros derroteros, como la creación de otros regímenes de universidades entre las que se encuentran las universidades indígenas. La institucionalidad de las IES Indígenas trasciende la tradicional autonomía universitaria, enmarcándose en una autonomía más amplia la "autonomía indígena".

En el proyecto de educación superior indígena no hay interpretación de los requerimientos educativos de los pueblos indígenas de tierras bajas. Tampoco existe una intermediación agen- 
tiva, pues son los mismos indígenas los ideólogos, propulsores e interlocutores quienes, a través de sus organizaciones, transmiten, negocian con el Estado sus demandas, necesidades y expectativas educativas. Actuar que les ha permitido llevar adelante sus propias propuestas de educación superior. En este sentido, la participación de la población indígena fue decisiva desde el inicio, en la gestación la idea y creación de la UNIBOL "Apiaguaiki Tüpa" y su actual desarrollo.

Los actores indígenas universitarios tienen claro y asumen la diferencia con las universidades públicas convencionales, las cuales constituyen el referente inicial para la construcción de una propia identidad institucional. Sin embargo, se observa una resistencia al cambio por parte de algunos docentes, quienes, debido a su formación en IES convencionales, no asumen aun el enfoque indígena propugnado por la institución y las organizaciones indígenas desarrollando sus actividades académicas en un marco aun tradicionalconvencional de educación superior. Ello dificulta la consolidación de un modelo propio en la ES.

La elección explícita de la propuesta educativa superior por la vía indígena permite a los actores involucrados, desde el inicio, Identificar las demandas, necesidades y expectativas que los PIOAs confieren a la educación superior. Hecho que faculta a los participantes posicionarse críticamente, identificándose con la visión política ideológica de los pueblos indígenas a la que responde la propuesta educativa de esta universidad. Asimismo, ello repercute en el involucramiento y compromiso de los actores universitarios en el proyecto educativo.

La atención exclusiva de la población indígena en la ES, a través del modelo indígena, reditúa en la claridad de los involucrados, organizaciones indígenas, docentes, comunidad, estudiantes, autoridades de su accionar político, pedagógico y epistemológico porque los fines, objetivos y propósitos están directamente vinculados a la consecución de las reivindicaciones históricas de los pueblos indígenas y la proyección de los horizontes ontológicos semióticos
(De Alba, 2009) de los 31 pueblos indígenas de tierras bajas.

\section{Conclusiones}

Desde la época colonial, la educación indígena en Bolivia ha sido negada y perseguida; no es sino, en las últimas cuatro décadas que la lucha del movimiento indígena concretó avances importantes en varios ámbitos sociales. La consolidación de la propuesta de educación superior indígena, evidencia de este avance en el ámbito educativo, muestra elementos significativos en cuanto los rasgos que la particularizan corresponden al locus de enunciación de los PIOAs, identificar estos elementos y su lógica de articulación. Permite conocer el curso en la construcción de una educación propia cuya teorización aporte a la emancipación pedagógica Latinoamericana.

Como se observa, la emergencia de la UNIBOL Guaraní de Pueblos de Tierras Bajas se opone a la función suplantadora anclada en la desigualdad, y apuesta más bien por una práctica pedagógica sustentada en la valoración de los saberes y conocimientos de los pueblos indígenas. Este posicionamiento implica un cambio que orienta a la institución en su accionar pedagógico hacia la búsqueda del establecimiento de vínculos con las comunidades y la población indígena de las diferentes nacionalidades indígenas de tierras bajas valorándolas como poseedoras de un legado cultural traducido en saberes, conocimientos y tecnologías ancestrales. Patrimonio cultural que corresponde a cada uno de los pueblos indígenas de los cuales provienen los estudiantes de esta universidad, convirtiéndolos en sus portadores. Por lo tanto los protagonistas de los procesos de formación profesional (autoridades, docentes y alumnos) deben aspirar a establecer una metodología de aprendizaje que suscite la emancipación política, intelectual, cultural y lingüística de los estudiantes.

Cabe resaltar que este fin pedagógico constituye una parte importante del proyecto educativo de los pueblos indígenas, quienes lle- 
van construyendo en Bolivia y otros países de Latinoamérica proyectos referidos a la educación propia: la de los pueblos indígenas-originarios. Asimismo, como se puede observar la educación propia no implica una esencialización de las culturas indígenas ancestrales que represente un retorno al pasado. Se trata más bien de resignificar la presencia viva de los pueblos indígenas en el mundo actual dotándola de sentido propio mediante la retoma de su historicidad. Ello implica, una necesaria interrelación con otras visiones de mundo, incluso hegemónicas que están modelando las formas actuales de vida, buscando establecer una interculturalidad crítica (Walsh, 2002) que les permita emanciparse del dominio cultural, ideológico, político y lingüístico impuesto históricamente.

La elección explícita de la propuesta educativa superior por la vía indígena permite a los actores involucrados, identificar claramente las demandas, necesidades y expectativas que los pueblos indígenas le confieren a la educación superior en el marco de su historicidad. Hecho que faculta a los participantes posicionarse críticamente, posicionándose desde la visión política ideológica a la que responde la propuesta educativa de esta universidad. Ello repercute en el involucramiento y compromiso de los actores universitarios en el proyecto educativo.

\section{Notas}

1 Proyecto subvencionado por el Consejo Nacional de Ciencia y Tecnología (CONACYT) de México, dentro del proyecto “Construcción de la educación propia en las IES: un estudio comparativo de dos universidades: La Universidad Indígena Boliviana Guaraní y de Pueblos de Tierras Bajas “Apiaguaiki Tüpa” (Bolivia) y La Universidad Veracruzana Intercultural (México)".

2 Artículo $1^{\circ}$ del decreto supremo № 29664 de creación de las tres universidades indígenas bolivianas de fecha 2 de agosto de 2008 “Créase tres (3) Universidades Indígenas Bolivianas Comunitarias Interculturales Productivas-UNIBOL "Aymara", "Quechua" y "Guaraní y Pueblos de Tierras Bajas" como entidades descentralizadas de educación pública superior, bajo Régimen Especial y tuición del Ministerio de Educación y Culturas. Gaceta oficial del Estado Plurinacional de Bolivia.

\section{Bibliografía}

Aparicio, M. (2009). La libre determinación y la autonomía de los pueblos indígenas. El caso de México. Boletín Méxicano de Derecho Comparado, 42(124), 13-38. Recuperado de https://goo.gl/zMzuJ1

Appel R. y Muysken P. (1997). Bilingüismo y contacto de lenguas. Córcega- Barcelona: Ariel.

Canedo, G. (2011). La loma santa: una utopía cercada. Territorio, cultura y estado en la amazonía boliviana. La Paz: IBIS-Plural.

Castañeda, E. (2006). La educación indígena en México. Ciudad de México: Universidad Nacional Autónoma de México.

Choque, María E. (2015). La estructura universitaria vigente, resabio del colonialismo, te contradice y te anula como ser humano. En: Daniel Mato (Coord.), Educación Superior y Pueblos Indígenas en América Latina. Buenos Aires: EDUNTREF.

De Alba, A. (2009). Horizonte ontológico semiótico en la relación espacio epistémico-teoría. Recuperado de https://goo.gl/gCJzKR

Díaz-Polanco, H. (2006). Elogio a la diversidad. Globalización, multiculturalismo y etnofagía. México: Siglo XXI Editores.

Gaceta Oficial del Estado Plurinacional de Bolivia (2008). Decreto 29664 de creación de tres universidades indígenas bolivianas. La Paz-Bolivia.

Gaceta Oficial del Estado Plurinacional de Bolivia (2009). Constitución Política del Estado Plurinacional de Bolivia. La Paz-Bolivia.

Golte, J. (1980). Protesta contra los repartimientos mercantiles en sus repartos y rebeliones. Tupac Amaru y las contradicciones de la economía colonial. Lima: IEP.

Laclau, E. y Mouffe, Ch. (1985). Hegemony and Socialist Strategy: Towards a Radical Democratic Politics. London: Verso.

López, LE. (2009). Pueblos indígenas y educación superior en América Latina y El Caribe. En: Interculturalidad, educación y ciudadanía. La Paz-Bolivia: Plural Editores.

Lehm, Z. (1991). Loma santa: procesos de reducción, dispersión y reocupación del espacio de los pueblos indígenas mojeños. Tesis. La PazBolivia: UMSA. 
Ministerio de Educación (2010). Ley de la educación "Avelino Siñani- Elizardo Pérez" Nº70.

Mato, D. (2014). Universidades Indígenas en América Latina. Experiencias, logros, problemas, conflictos y desafíos. ISEES Inclusión Social y Equidad en la Educación Superior, (14), 17-45. Recuperado de https://goo.gl/4raZ3o

Medina, P. (2015) Pedagogías insumisas: movimientos político-pedagógicos y memorias colectivas de educaciones otras en América Latina. México: Universidad de Ciencias y Artes de Chiapas.

Ministerio de Educación (2012). Plan de Estudios de la Carrera de Ingeniería Forestal Universidad Indígena Boliviana (UNIBOL) Guaraní y Pueblos de Tierras Bajas "Apiaguaki Tüpa". Chuquisaca-Bolivia.

Prada, R. (2015). Epistemología, pluralismo y descolonización. Cochabamba: FUNPROEIB Andes.

Quijano, A. y Wallerstein, I. (1992). Americanity as a concept or the Americas in the modern world-system. International Social Science Journal, (134), 549-557.

Rancière, J. (2003). El maestro ignorante. Cinco lecciones sobre la emancipación intelectual. Barcelona: Editorial Laertes.

Rojas, A. (2003). La etnoeducación y construcción de sentidos sociales. Memorias. Popayan: Instituto Caro y Cuervo, CCELA, PROEIB Andes.

Rivera, S. (2008).Violencia e interculturalidad. Paradojas de la etnicidad en la Bolivia de hoy. Recuperado de https://goo.gl/EhsLXK

Sarango, L.F. (2013). La universidad comunitaria intercultural de las nacionalidades y pueblos indí- genas "Amawtay Wasi" hacia un nuevo paradigma de educación superior en Educación intercultural a nivel superior. México: UIEP, UCIRED, UPEL.

Tünnermann, B.C. (2010). Universidad y sociedad: balance histórico y perspectivas desde Latinoamérica. Caracas: Universidad Central de Venezuela.

UNIBOL Guaraní y Pueblos de Tierras Bajas “Apiaguaiki Tüpa” (2009). Documento de organización curricular. Ministerio de Educación del Estado Plurinacional de Bolivia. La Paz-Bolivia: Área Académica UNIBOL.

Wachtel, N. (1973). Rebeliones y milenarismo. En: Juan M.Ossio (Ed.), Ideología mesiánica del mundo andino (118-123). Lima: Edición de Ignacio Prado Pastor.

Walsh, C. (2002). (De) construir la interculturalidad. Consideraciones críticas desde la política, la colonialidad y los movimientos indígenas y negros en el Ecuador. En: Norma Fuller (Ed.), Interculturalidad y política. Lima: Red de Apoyo de las Ciencias Sociales.

Weinberg, G. (1995). “Educación Prehispánica”. En su Modelos educativos en la historia de América latina. Buenos Aires: UNESCO/ CEPAL/PNUD.

Zambrana, A. (Ed.) (2014). Pluralismo epistemológico. Reflexiones sobre la educación superior en el Estado Plurinacional de Bolivia. Cochabamba: FUNPROEIB Andes - SAIH. 


\section{¿De qué me sirve la interculturalidad? Evaluación de la Universidad Intercultural de Chiapas por sus estudiantes}

\section{What is the use of interculturality? Evaluation of the Intercultural University of Chiapas by its students}

Dr. Juris Tipa es Docente en la Universidad Iberoamericana. Ciudad de México (México) (juris.tipa@gmail. com) (http://orcid.org/0000-0001-5213-5757)

Recibido: 2017-07-25 / Revisado: 2017-10-03 / Aceptado: 2017-10-24 / Publicado: 2018-01-01

\section{Resumen}

El modelo intercultural en la educación superior en México hasta el momento ha sido la única propuesta hecha realidad para una educación inclusiva hacía los conocimientos y saberes "no occidentales", integrados en un currículo educativo oficial-estatal. No obstante, este modelo hasta ahora ha recibido muchas críticas desde distintos campos académicos, aunque la información sobre los puntos de vista de los estudiantes de las universidades interculturales es limitada. El objetivo del presente artículo es explorar las opiniones de la población estudiantil de la Universidad Intercultural de Chiapas (México) sobre el modelo intercultural, sus motivaciones de entrar en esta universidad y la aplicabilidad práctica de sus estudios. Esto con el fin de conocer algunos aspectos funcionales de este modelo de educación y su valoración "desde abajo", por parte de las y los estudiantes. Utilizando metodología cuantitativa se concluye que existen diferencias étnicas en la evaluación del modelo intercultural y las motivaciones de cursar en la universidad intercultural. Además se muestra que el nivel de escepticismo expresado por los estudiantes sobre dicho modelo y las distintas formas de su aplicabilidad práctica está relacionado con la cantidad de tiempo que el alumno ha pasado estudiando en la universidad. Basándose en estos datos se propone revisar algunos puntos críticos para mejorar el funcionamiento de las universidades interculturales.

Descriptores: Interculturalidad, multiculturalidad, educación superior intercultural, estudiantes, Universidad Intercultural de Chiapas.

Forma sugerida de citar: Tipa, J. (2018). ¿De qué me sirve la interculturalidad? Evaluación de la Universidad Intercultural de Chiapas por sus estudiantes. Alteridad, 13(1), 56-71. https://doi.org/10.17163/alt.v13n1.2018.04. 


\section{Summary}

The intercultural model in higher education in Mexico has so far been the only proposal made a reality for an inclusive education towards the "nonwestern" knowledge integrated in an official-state educational curriculum. However, this model has so far received much criticism from different academic fields, although information on the views of students of intercultural universities is limited. This article explores the opinions of the student population of the Intercultural University of Chiapas (Mexico) on the intercultural model, their motivations to enter this university and the practical applicability of their studies. With a use

\section{Introducción}

La introducción de la interculturalidad en las políticas públicas del gobierno de México en el campo de la educación superior es un importante giro hacia la inclusión educativa y cultural que hace dos décadas aún era algo poco probable, aunque igual de necesario como hoy en día. La desigualdad en acceso a la educación superior en México es bien documentada y lo que resalta en prácticamente todos los estudios al respecto es la situación de exclusión que están viviendo las y los jóvenes de las etnias mexicanas (Bertely Busquets, 2011; Casillas Alvarado et al., 2012; Chávez, 2008; Gallart Nocetti y Henríquez Bremer, 2006). Las razones porque existe tal exclusión son varias, pero las principales siguen siendo la marginalización socioeconómica de ese sector de población, la discriminación anti-étnica y la distribución geográfica de las universidades que usualmente están ubicadas en las urbes, bastante lejos de las numerosas comunidades rurales.

En gran medida gracias a las movilizaciones y los movimientos de los grupos étnicos, la educación superior intercultural fue implementada al nivel estatal en el siglo XXI (Dietz y Cortés, 2011). En este modelo de educación la interculturalidad implica una comunicación comprensiva entre las distintas culturas que conviven en un mismo espacio, con la meta de estimular el enriquecimiento mutuo, el reconocimiento y la of quantitative methods it concludes that there are ethnic differences in the evaluation of the intercultural model and the motivations to study in the intercultural university. It is also shown that the level of skepticism expressed by students about this model and the different forms of its practical applicability is related to the amount of time that the student has spent studying in the university. Based on these data it is proposed to review some critical points to improve the functioning of intercultural universities.

Keywords: Interculturality, multiculturalism, intercultural higher education, students, Intercultural University of Chiapas.

valoración de cada una de ellas dentro del marco de igualdad (Hidalgo Hernández, 2005, p. 78). En México, al igual que en algunos otros países latinoamericanos, este modelo de interacción ha sido implementado de forma institucional en las Universidades Interculturales (UI) que son multiétnicas y en sus contenidos educativos intentan integrar tanto los saberes "modernos-científicos", como los "tradicionales", propios a las etnias. De ahí proviene el permanente debate si este modelo es funcional en el sentido de estar cumpliendo con sus metas y de qué forma.

El proceso de aprendizaje siempre involucra un intercambio de conocimientos e ideas, no sólo entre los maestros y los alumnos en el aula, sino también entre los estudiantes. Considerando que la interculturalidad es un concepto polisémico y, simultáneamente, una práctica en constante construcción, es indispensable interrogar cómo está percibida, valorada y practicada por los estudiantes de las UI, porque estos jóvenes están siendo preparados profesionalmente dentro de un modelo educativo donde la interculturalidad es la base ideológica. De ahí proviene el objetivo principal del presente estudio: analizar las opiniones de los alumnos activos de la Universidad Intercultural de Chiapas (UNICH) sobre el modelo intercultural y describir cómo ellos y ellas evalúan la aplicabilidad práctica de lo aprendido, tanto en el mercado laboral como en sus vidas cotidianas. 


\subsection{Multiculturalidad e interculturali- dad: ¿conceptos nuevos para proce- sos viejos?}

Como paradigmas explicativos, tanto la multiculturalidad como la interculturalidad son utilizados para entender, explicar y "manejar" la diversidad y el pluralismo cultural. Ambos conceptos surgen en las sociedades del occidente de Europa y los Estados Unidos, logrando tener un gran desarrollo analítico con la aparición de la migración como un fenómeno social de larga escala y el consecuente debate acerca de la inclusión de las minorías étnicas en los territorios nacionales.

El concepto clave en el multiculturalismo es la tolerancia como una virtud ética de lo público: la capacidad y la disposición de respetar las diferencias y no colocar las creencias propias como condición absoluta de la convivencia con el otro. Sin embargo, aquí se puede distinguir dos modalidades de tolerancia: la negativa y la positiva. La primera se refiere a la capacidad de soportar la diferencia de modo que se tolera aunque no se comparte. La tolerancia positiva, en cambio, consiste en intentar situarse en el lugar del otro para compartir sus creencias y valoraciones "desde dentro" (Pérez Ruiz, 2014, pp. 100-101).

A diferencia de la multiculturalidad, la interculturalidad aparece como un término analítico y multidimensional para entender las relaciones interétnicas y/o entre-culturales. En lugar de un manejo de "foto fija" cultural -como el hecho de que en una sociedad o país coexistan distintas culturas- el interculturalismo se centra en la relación entre culturas desde la diferencia entre ellas $y$, al mismo tiempo, partiendo del principio de igualdad de las culturas para la interacción positiva dentro de la diversidad (Malgesini y Giménez, 2000, pp. 253-259).

Durante la década de los años noventa, los discursos transnacionales de la multiculturalidad e interculturalidad migraron no sólo entre los países anglosajones y los europeos del continente, sino entre éstos y la América Latina, que vivía un post-indigenismo y post-colonialis- mo, resultando en una versión propia de dicho concepto. Como lo observa Peréz Ruiz (2014, pp. 102-105), en lugar de la tolerancia positiva, el interculturalismo latinoamericano no buscó establecer medidas que faciliten la asimilación de las minorías étnicas, sino que apuntó a cambiar las condiciones y las modalidades en las que se dan las relaciones e intercambios asimétricos. De esta forma, lo intercultural en Latinoamérica se discute, se resignifica y se apropia bajo una mirada "descolonial", problematizado los procesos históricos de las relaciones entre colonizadores y colonizados, y los efectos que han producido siglos de discriminación (Mato, 2014; Tirzo Gómez y Hernández, 2010, pp. 25-26).

Actualmente la interculturalidad está abordada al menos desde cuatro campos del pensamiento social: la educación, la comunicación, la mediación intercultural y desde el campo sociopolítico donde la interculturalidad aparece como un ideal societario. La interculturalidad como una utopía social, el tipo ideal de comunicación y, al mismo tiempo, un programa político institucionalizado se muestra con mayor claridad en el campo de la educación. La interculturalidad según los estatutos de las UI se refiere a relaciones mutuas entre distintas culturas y la participación mutua equilibrada. El intercambio cultural, según sus estatutos, suele tener un rasgo "controlado" porque procura evitar relaciones de dominación-imposición cultural, favoreciendo una comunicación e intercambio simétrico. Sin embargo, cómo la premisa intercultural institucionalizada en forma de un ideal societario y, a la vez, una política concreta está llevada a cabo en la vida real, desafortunadamente, es un tema lleno de problemas y contradicciones internas.

\subsection{Los logros y las contradicciones de la Educación Superior Intercultural}

Unos de los objetivos principales de las UI es crear alumnos comprometidos con el desarrollo de sus pueblos y sus regiones. En el centro de la institución se encuentra la investigación 
sobre las culturas y las lenguas de los pueblos a los que sirve. La docencia, la investigación y la vinculación con las comunidades debe ser respetadas y todos los docentes y alumnos deben participar en los tres áreas (Sartorello, 2016). De ahí provienen varios logros de las UI como (1) mejoramiento de las posibilidades de que las y los jóvenes de las etnias accedan a la educación superior; (2) mayor distribución geográfica de las universidades; (3) la integración de diversos tipos de saberes y modos de producción de conocimiento; (4) valorización y reivindicación de los idiomas y conocimientos de las etnias; (5) el desarrollo de docencia e investigación orientadas por criterios de valoración de la diversidad cultural; (6) generación de proyectos concretos de "desarrollo local" y (7) formación de egresados provenientes de las comunidades a las que se proponen servir (Casillas Muñoz, 2012; Mato, 2014). Últimamente también se ha discutido si la educación intercultural puede aportar directamente a la creación de un "capital intercultural" como una forma particular del capital cultural de la persona (Pöllmann, 2014). Si las formas del capital cultural ${ }^{1}$ existen "en relación a" y "a través de" diferentes culturas, entonces en un mundo cada vez más "conectado" e interdependiente el "capital intercultural" está emergiendo como una cualidad humana con gran importancia sociocultural ${ }^{2}$, sobre todo en países tan culturalmente diversos como México.

A pesar de ciertos logros y el enorme potencial de la educación intercultural en el mejoramiento del "diálogo cultural", el presente estado de la implementación de este modelo ha causado fuertes críticas tanto administrativas y prácticas, como teóricas y epistemológicas. Además de los problemas económicos, existen ciertos problemas administrativos-educativos de las UI en forma de acreditaciones que derivan de la premisa intercultural de juntar "saberes modernos" y "saberes tradicionales" en un contexto institucional, estatal y burocrático (Mato, 2014; Vargas Moreno, 2014). Por siguiente en las UI no sería pertinente aplicar sistemas rígidos de criterios de validez supuestamente "universales" (pues, no existe un "saber universal"), sino sistemas "flexibles". Desafortunadamente, esta "flexibilidad" muchas veces suele malinterpretarse como de "baja calidad".

Para evitar segregaciones las UI no se plantean como exclusivas para los provenientes de los grupos étnicos, sino que están abiertas a estudiantes de cualquier grupo y adscripción sociocultural. Al mismo tiempo, está enfatizada la presencia de jóvenes de las etnias, al igual que la "comunidad" y "ruralidad" como los temas principales de los proyectos de investigación en las carreras ofrecidas por las UI. Este punto aún sigue siendo algo confuso, ya que en el imaginario común las UI se convierten en "universidades (para) indígenas". Sólo basta con observar cuántas UI en México y América Latina llevan en su nombre la palabra "indígena" o de alguna etnia en particular. Por lo tanto, esta demostración del "empoderamiento étnico" resulta ser contradictorio con la premisa de evitar separaciones étnicas y estar abiertos no exclusivamente a ese sector de población.

Continuando con el punto anterior, se puede percibir un hilo neo-indigenista en el funcionamiento y las premisas de las UI (Kaltmeier, 2010). Como el marco de las políticas educativas están construidas sin la participación de las etnias, nada más se convierten en una "nuevas imposiciones simuladas" con los discursos de respeto a la diversidad cultural (Gómez Lara, 2011; Llanes Ortiz, 2008). El supuesto "diálogo de saberes" no logra ocultar ni el carácter asimétrico, ni la conflictividad inherente de tal diálogo (Corona Berkin y Pérez Daniel, 2010, pp. 22-23; Sartorello, 2016). Los saberes pueden ser complementarios en la práctica campesina, cotidiana, pero a menudo no son fácilmente subsumibles o incorporables al saber canónicocientífico. Al mismo tiempo, promover un diálogo entre saberes y culturas implica dicotomizar nuevamente determinados saberes y culturas (indígenas-mestizos, rurales-urbanos, etc.) y, de nuevo, enfrentarse con obstáculos para lograr un 
diálogo de conocimientos heterogéneos (Dietz y Cortés, 2011, pp. 120-138). De esta manera, el actual papel de la interculturalidad educativa como una forma de "descolonizar el saber" resulta ser sobrevaluada (Cuji Llugna, 2012). Además de estos problemas epistemológicos, existen otras problemáticas internas, propias de las UI que tienen que ver tanto con los contenidos de la oferta intercultural, como la comunicación dentro de las instituciones (Bastiani y Moguel Viveros, 2011).

En México las UI están sujetas a cambios políticos en los Estados donde se instalan y, por lo tanto, carecen de estabilidad. Debido a los recurrentes cambios es las administraciones institucionales, se rompe la continuidad de la formación de docentes e investigadores al no estar el mismo personal académico desde el inicio por su constante movilidad hacia otros espacios profesionales. $\mathrm{Al}$ igual existen disputas internas entre los "teóricos" y los "prácticos" o docentes que enfatizan de forma exclusiva el lado teórico de la interculturalidad y los que valoran sólo la dimensión práctica (Tipa y Zebadúa, 2014, pp. 38-39). En este tenor también ha sido cuestionada la utilidad de los proyectos, porque, al contrario de como lo postulan las UI, estos no le suelen corresponder a las necesidades de las comunidades y los conocimiento adquiridos en las UI tampoco resultan útiles para muchos estudiantes a la hora de su implicación en la vida cotidiana (Cruz Salazar y Moreno, 2013; Sartorello, 2016).

Otro problema que comparten las UI es la interpretación del "enfoque intercultural" que varía entre los docentes. El análisis de los discursos de las UI sobre la interculturalidad revela que éste es un concepto polisémico, con múltiples significados, interpretaciones y definiciones. Incluso su conceptualización puede variar de un periodo a otro y de acuerdo con los diferentes contextos e intereses que se pretendan a lograr. En general, se puede distinguir diversas dimensiones o contextos donde la interculturalidad es utilizada y problematizada: en términos ontológicos, epistemológicos, educativos, socia- les, intra-culturales y político-institucionales (Sandoval et al., 2010).

$\mathrm{Al}$ parecer, los logros de las UI y el modelo actual de la educación superior intercultural aún no son suficientes para poder disminuir y ensombrecer los problemas y las criticas sustanciales. Aunque la existencia de estas universidades ya de por sí podría ser considerada como un gran logro, en este balance entre los logros y las críticas podemos observar una tendencia muy peligrosa: mientras los logros suelen tener cualidades más teóricas y abstractas, casi del nivel especulativo ${ }^{3}$, las críticas son concretas y de nivel cotidiano.

\section{Metodología}

Para lograr el objetivo del presente estudio -describir y analizar las opiniones de los alumnos de la UNICH sobre el modelo intercultural y la aplicabilidad de sus estudios- fue elegido un método poco común, una encuesta. Esta elección se debe a varias razones. La primera es la ausencia de métodos cuantitativos a la hora de estudiar las poblaciones estudiantiles de las universidades interculturales, pues en este tipo de acercamientos casi siempre prevalece el uso de metodología cualitativa, mientras los instrumentos cuantitativos son más comunes en los estudios donde se analizan las poblaciones estudiantiles de las universidades "convencionales". La segunda razón es volver a mostrar que el uso de los instrumentos cuantitativos siempre tiene la ventaja de poder describir las opiniones de forma general, es decir, captar las tendencias "globales" lo que sirve como un suelo fructífero para nuevos acercamientos cualitativos. Resumiendo, el uso de instrumento cuantitativo en este tipo de estudios es novedoso y necesario, tomando en cuenta que existe una explícita ausencia de datos más generales de índole cuantitativa sobre las poblaciones estudiantiles de las UI.

La base empírica para este estudio proviene de una encuesta aplicada a la población estudiantil de la UNICH, sede San Cristóbal de Las Casas. La encuesta fue hecha con base en una muestra 
representativa $(n=204)$ estratificada según el idioma materno de la persona, el sexo y la carrera cursada en la universidad. Estos tres elementos para hacer la muestra fueron elegidos por la disponibilidad de la información que existe por parte de la UNICH sobre sus estudiantes. Asimismo, estos elementos sirven como el enfoque principal al correlacionar y describir los datos obtenidos. En el cuestionario los jóvenes fueron invitados a expresar su opinión sobre la interculturalidad como modelo de educación superior, sus motivaciones de entrar en la UNICH y la utilidad práctica de sus estudios. Posteriormente, utilizando estadísticos descriptivos, tablas de frecuencias y de contingencia, estas opiniones fueron analizadas en el contexto de la pertenencia etnolingüística de la persona, su sexo y la carrera cursada en la universidad. En los próximos apartados serán presentados los datos más llamativos que aparecieron en los resultados de dicha encuesta.

\section{La evaluación de la oferta educativa y el modelo intercultural por parte de los alumnos de la UNICH}

La UNICH como la segunda institución de educación superior intercultural en México fue fundada el primero de diciembre del 2004 y abierta a los estudiantes desde agosto de 2005. Actualmente en esta universidad pueden ser cursadas seis carreras de licenciatura, distribuidas entre cinco unidades académicas. La sede principal (San Cristóbal de Las Casas) ofrece cinco carreras y es la más numerosa en términos de alumnos, siempre contando con más de mitad de todos los alumnos inscritos en la UNICH. En el semestre enero-junio de 2015 la sede San Cristóbal de Las Casas contaba con 1 088 alumnos, de los cuales 39\% eran hablantes nativos del castellano, mientras el restante $61 \%$ eran hablantes de uno de los idiomas regionales de Chiapas (tsotsil, tsletal, ch'ol, zoque o alguna otra). La distribución por el sexo era bastante equilibrada con $49 \%$ mujeres y $51 \%$ hombres. En el 2015 la sede principal estaba ofreciendo cinco carreras de licenciatura: "Medicina con enfoque intercultural" (con 18\% de alumnos inscritos), "Turismo Alternativo" (con 15\% de alumnos), "Desarrollo Sustentable" (con 18\% de alumnos), "Comunicación Intercultural" (con 14\% de alumnos) y "Lengua y Cultura" (con 35\% de alumnos).

La satisfacción general con la carrera que las personas cursan en la UNICH presenta un panorama bastante positivo, pues tres cuartas partes de los alumnos afirman que "es lo que querían" (Gráfico 1). Sólo 10\% de los encuestados expresaron insatisfacción, de los cuales $5 \%$ lo hicieron de forma explícita, es decir, queriendo cambiar de carrera y/o de la universidad. También las razones de por qué los jóvenes han elegido la UNICH por lo general muestra un paisaje positivo: la cuarta parte de los alumnos ya querían estudiar en esta universidad antes de haber entrado, mientras la mayoría (43\%) eligió la UNICH después de haber conocido su oferta educativa (Gráfico 2). No obstante, para $22 \%$ de los estudiantes la UNICH fue la segunda opción o la única universidad donde lograron entrar.

Aunque este dato es llamativo, sería muy arriesgado hacer generalizaciones sobre la UNICH como universidad "de segunda", pues para la mayoría de los alumnos el hecho de no poder entrar en otra universidad no fue la razón principal para su elección de la UNICH y no existen datos de otras universidades con los cuales se podría comparar las motivaciones de los jóvenes a la hora de elegir la universidad donde cursar. Asimismo, considerando que la UNICH aún es una universidad “joven”, es poco sorprendente que la mayoría de los estudiantes eligió a favor de ella después de haber conocido su oferta.

La educación superior a menudo es una estrategia para la movilidad social ascendente y una inserción más favorable en el mercado laboral. En este sentido más de la mitad de los alumnos (64\%) expresan dudas sobre sus estudios en la UNICH como un elemento que les vaya a facilitar encontrar el trabajo (Gráfico 3 ). Esto significa que la universidad que está ofre- 
ciendo educación como un cierto tipo de capital en el sentido bourdiano no está informando a sus alumnos de forma eficiente sobre la aplicabilidad de su oferta en el mercado laboral.

\section{Gráfico 1. Satisfacción sobre la elección de la carrera en la UNICH}

¿Te sientes satisfecha/o con la elección de tu carrera en la UNICH? ( $n=204)$

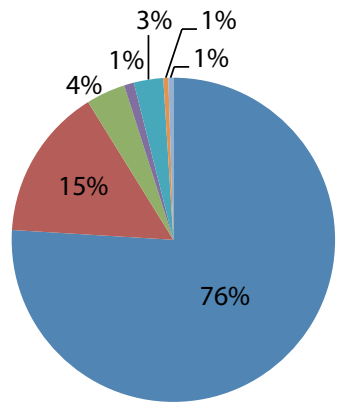

- Si, es lo que quería

- Más o menos, no estoy segura(o) si me va a servir para conseguir trabajo

Me gustaba al inicio, pero ya no tanto

- No, quiero cambiar de carrera

- No, quiero cambiar de universidad, pero seguir en una carrera similar

no, quiero cambiar de carrera y de universidad

- Me da igual, estudio sólo para obtener el diploma

Fuente: elaboración propia

Gráfico 2. Las razones de elegir la UNICH

¿Por qué elegiste la UNICH? $(n=204)$

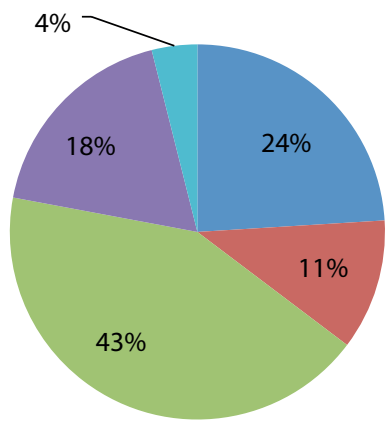

Antes de entrar ya quería estudiar en la UNICH

- Me aconsejaron que debiera estudiar en la UNICH

Me llamó la atención la oferta de la UNICH

Fue mi segunda opción, no pasé el examen en otra universidad

Fue la única universidad donde logré entrar

Fuente: elaboración propia

\section{Gráfico 3. Evaluación de los estudios en el contexto del mercado laboral}

¿Crees que los estudios en la UNICH te facilitarán encontrar trabajo? ( $n=204)$

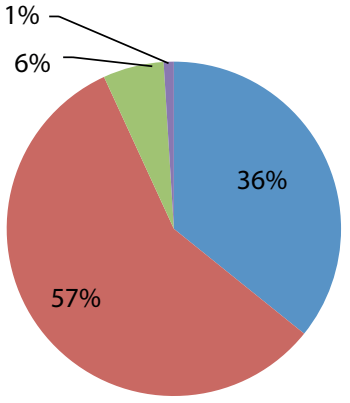

$\mathrm{Si}$

No estoy seguro(a), pero creo que sí

Muchas veces lo dudo

No

Fuente: elaboración propia 


\section{Gráfico 4. Evaluación de los estudios en el contexto cotidiano}

¿Crees que lo aprendido en la UNICH podrán aplicar en tu vida cotidiana? (n=204)

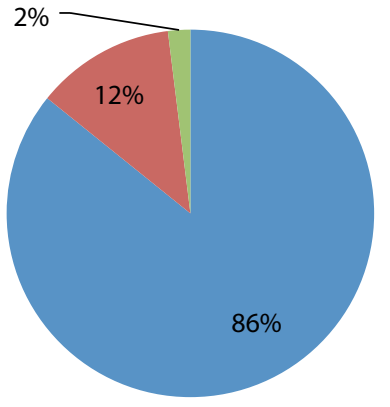

Fuente: elaboración propia

Por otro lado, la mayoría de los estudiantes $(86 \%)$ opinan afirmativamente que lo aprendido en la UNICH les va a servir en sus vidas cotidianas (Gráfico 4). Un aparente desequilibrio entre la "recompensa utilitaria" y la "recompensa humana" que existe en el imaginario de los alumnos es una situación peculiar en el contexto de la educación superior. Esta lleva a considerar que, utilizando la terminología bourdiana, el llamado "capital intercultural" en términos generales sería más convertible al capital social que al capital económico. En cierto sentido esto concuerda con la premisa humanista original de la interculturalidad en lugar de ser una idea mercantilizable. Simultáneamente, lo anterior indica que son indispensables futuros estudios sobre los egresados de las UI y sus trayectorias laborales.

Estos datos son particularmente llamativos cuando vemos que para la mayoría de la población estudiantil de la UNICH (70\%) los planes al terminar la universidad es justamente encontrar empleo que tenga que ver con sus carreras, mientras la cuarta parte de los alumnos quieren continuar con estudios en el posgrado (Gráfico 5). En otras palabras, la motivación basada en la mercantilidad de la educación superior no es segundaria para estos jóvenes aunque ellos y ellas tampoco están seguras si es algo que se cumplirá al terminar los estudios en la UNICH.

\section{Gráfico 5. Planes después de haber terminado los estudios}

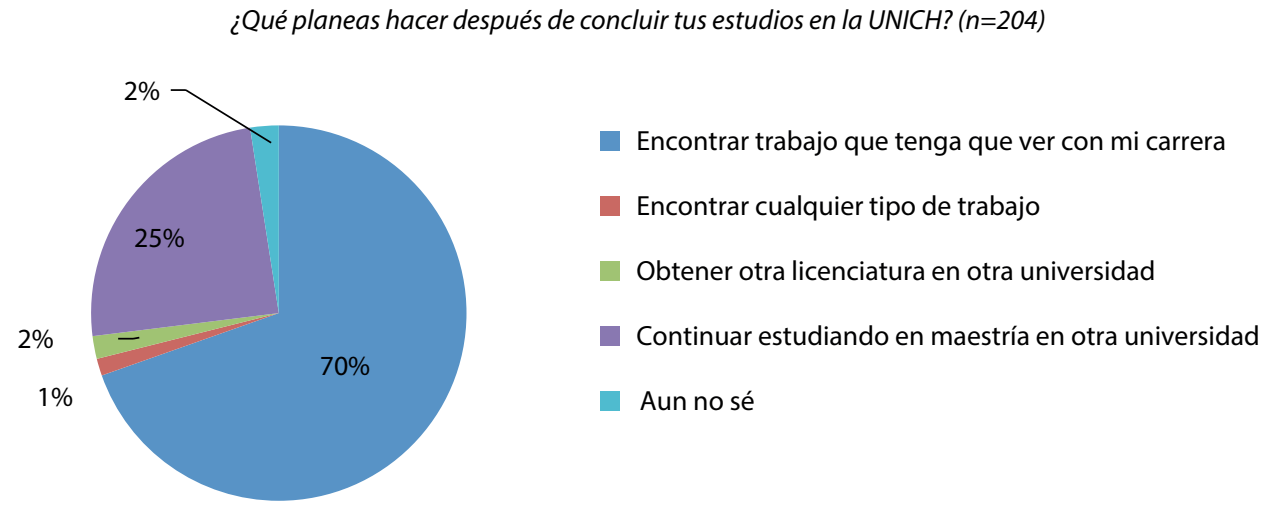

Fuente: elaboración propia 
La evaluación general del modelo intercultural implementado en la UNICH es bastante positiva, pues $77 \%$ de los alumnos opinan que los contenidos educativos cumplen con dicho modelo, aunque la cuarta parte de los jóvenes no concuerdan con esta afirmación en distintos grados (Gráfico 6).

\section{Gráfico 6. Evaluación general del modelo intercultural}

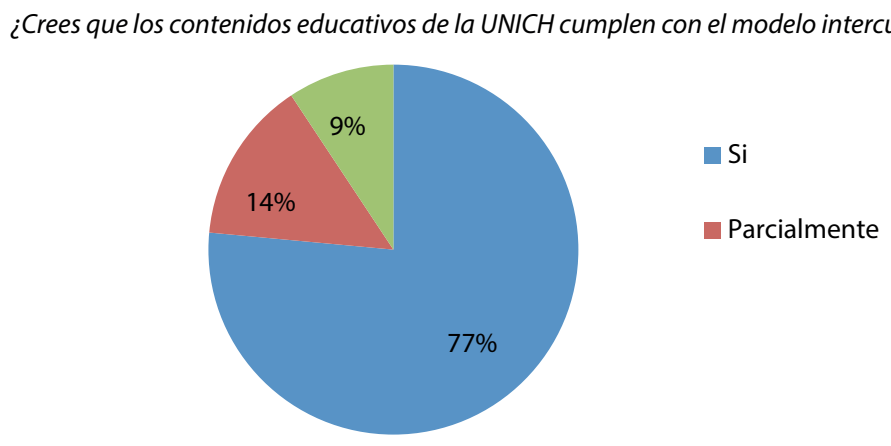

\section{Fuente: elaboración propia}

Lo que es verdaderamente alarmante es el hecho que existe una relación entre la evaluación de los contenidos educativos y el semestre en el cual la persona está cursando: mientras más tiempo la persona ha pasado en la UNICH, más escéptica se vuelve sobre la pertenencia de los contenidos educativos al modelo intercultural (Gráfico 7). Al mismo tiempo, la satisfacción sobre la elección de la carrera en la UNICH no presentó una distribución de respuestas tan diferenciada según el semestre. Resumiendo, lo que los estudiantes ponen en duda no es tanto la oferta educativa (los contenidos de las carreras), sino qué tanto ésta le corresponde a la premisa intercultural bajo la cual supuestamente se define la oferta educativa.

\section{Gráfico 7. Evaluación general del modelo intercultural según el semestre}

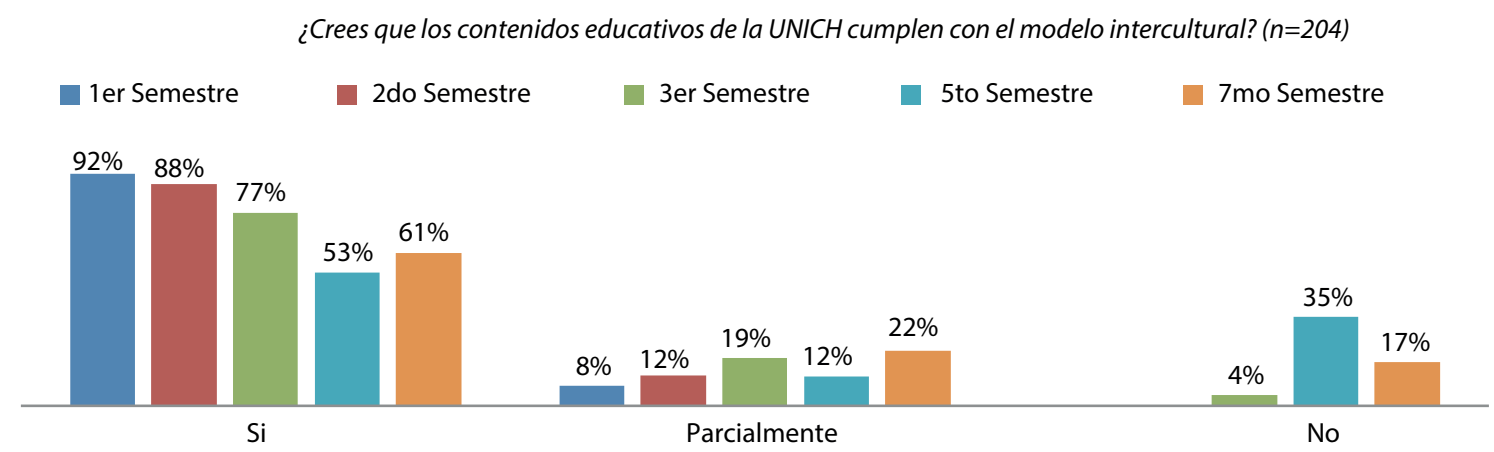

\section{Fuente: elaboración propia}

Aquí cabe recordar que la muestra para la presente encuesta no fue hecha con base en el semestre en el cual la persona se encuentra. De ahí para los futuros estudios de esta índole se vislumbra la importancia de considerar el perio- do de tiempo que la persona ha pasado en la UI, como un aspecto que luego puede reflejarse en su mayor o menor satisfacción con la universidad y sus contenidos educativos. 
3.1. La evaluación de la oferta educativa y el modelo intercultural de la UNICH en el contexto etnolingüístico

Regresando a las tres variables-base de la muestra, se presentarán los datos donde se pudo observar diferencias en la evaluación de la oferta educativa de la UNICH según la lengua materna, el sexo y la carrera elegida por la persona. Ante de todo hay que indicar que no se observaron diferencias significativas (mayores a 5\%) en las respuestas entre hombres y mujeres a excepción de que un ligero mayor porcentaje de las mujeres (en comparación con los hombres) planean continuar con estudios del posgrado al terminar la UNICH. No obstante, existen diferencias más pronunciadas si observamos las respuestas de los alumnos según la variable "lengua materna".

Para mayor operacionalidad de esta variable, los estudiantes fueron agrupados en dos categorías según su idioma materno: (1) las personas cuya lengua materna es castellano y (2) las que son hablantes nativos de algún idioma que no es el castellano, sino propio a las etnias regionales (tsotsil, tseltal, ch'ol, zoque y otras). Aunque el idioma materno 4 no es el único elemento que determina la pertenencia a un grupo sociocultural y/o un etnia, es una de las columnas vertebrales de la cultura como el principal sistema de pensamiento (Fábregas Puig, 2012). Por el carácter específico de las UI hasta se podría afirmar que justamente el idioma es uno de los principales diferenciadores y estructuradores entre los alumnos (Sartorello, 2016, pp. 739-740).

Existe una segmentación etnolingüística entre las cinco carreras de licenciatura impartidas en la sede San Cristóbal de Las Casas de la UNICH (Gráfico 8). El caso más agudo de esta segmentación es la carrera "Lengua y cultura" que también es la más numerosa por los alumnos inscritos: entre los estudiantes de esta carrera $86 \%$ son hablantes de algún idioma regional y los contenidos de esta materia están directamente vinculados con la reivindicación étnica y la diversidad cultural. Asimismo en la carrera "Desarrollo sustentable" ligeramente prevalecen alumnos cuyo primer idioma es uno de los idiomas regionales, mientras en las carreras como "Comunicación intercultural” y "Turismo alternativo", al contrario, prevalecen los hablantes nativos de castellano.

\section{Gráfico 8. Segmentación de alumnos por el idioma materno según las carreras}

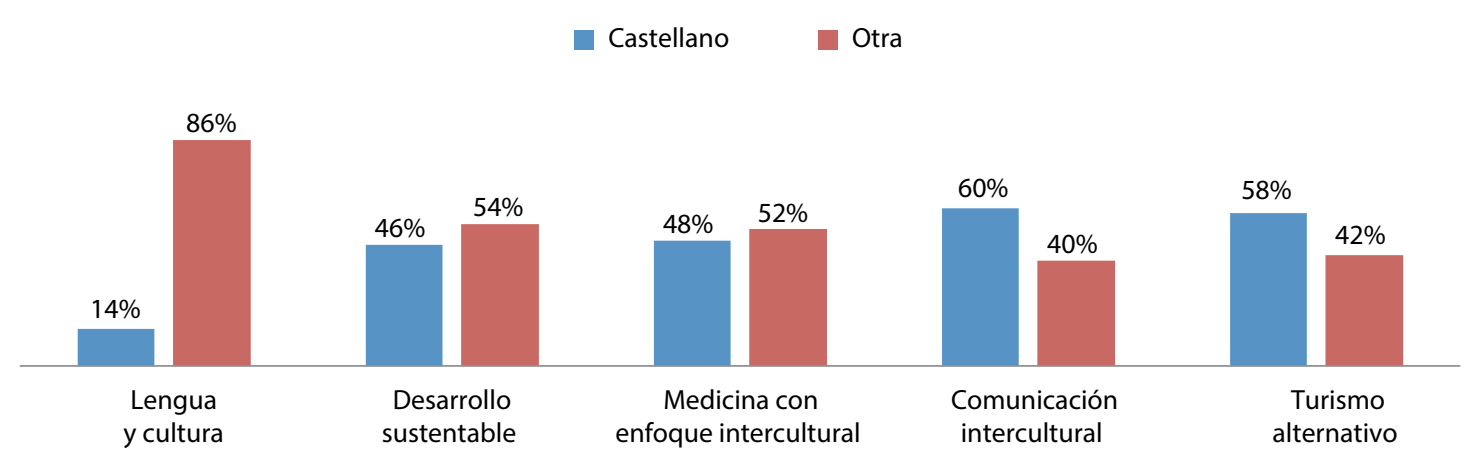

Fuente: elaboración propia

Lo llamativo de esta segmentación no sólo es el hecho de cómo se distribuyen los alumnos según su lengua materna entre carreras que están enfocadas en la reivindicación cultural y la vinculación comunitaria y, por otro lado, carreras que le corresponden más directamente a las exigencias de la globalización (comunicación, turismo), sino también la evaluación del modelo intercultural según los alumnos de cada carrera. 


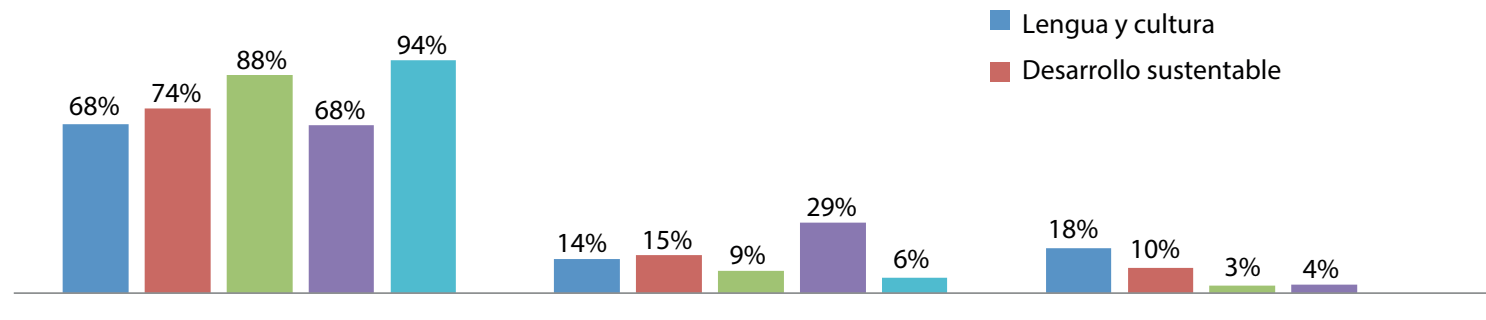

$\mathrm{Si}$

Parcialmente

No

\section{Fuente: elaboración propia}

Mientras los estudiantes de "Lengua y cultura", "Desarrollo sustentable" y "Comunicación intercultural” son los más escépticos en afirmar que los contenidos educativos de la UNICH le corresponden al modelo intercultural, los mayores porcentajes de respuestas negativas se concentran dentro de las carreras donde prevalecen los hablantes de idiomas regionales, sobre todo, de "Lengua y cultura" (Gráfico 9). Curiosamente, no se mostraron diferencias significativas en esta evaluación según la lengua materna en general dentro de la población estudiantil de la UNICH. Este dato lleva a considerar que probable existen distintos discursos sobre la interculturalidad y los materiales didácticos utilizados entre las diferentes carreras de la UNICH y, probablemente, esté ausente una consolidación entre ellos. Es decir, las diferencias teóricas, didácticas y prácticas de los contenidos educativos de las carreras le corresponden de forma diferenciada al modelo intercultural y es algo que se refleja en las diferencias de las opiniones de los estudiantes.

\section{Gráfico 10. Satisfacción con la carrera según el idioma materno}

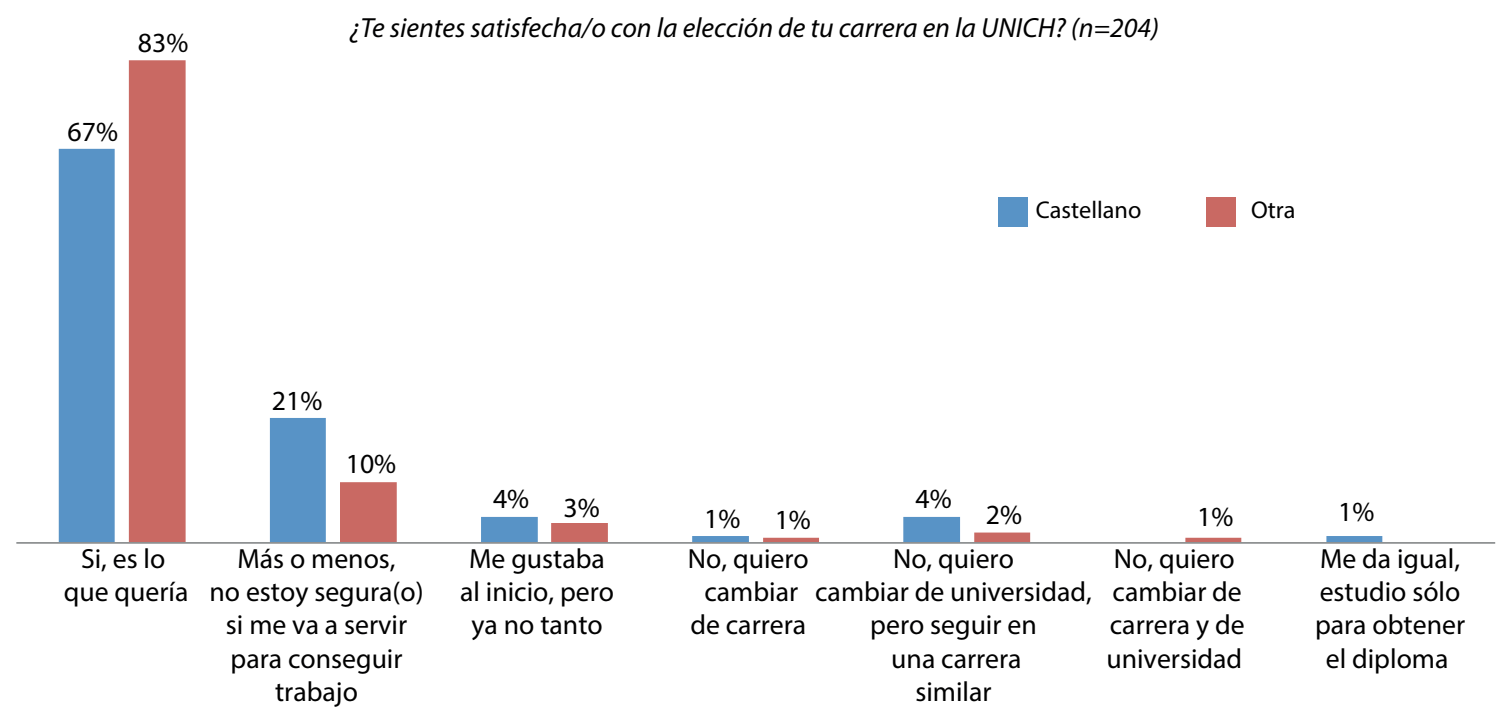

Fuente: elaboración propia 
Los alumnos cuya lengua materna es el castellano suelen estar menos satisfechos con su elección de la carrera en la UNICH, sobre todo, enfatizando el lado mercantil de ella: la quinta parte de los alumnos se siente "más o menos" satisfecha con la elección de sus carrera en la UNICH porque duda que esta les va a servir para encontrar trabajo (Gráfico 10).

\section{Gráfico 11 . Evaluación de los estudios en el contexto del mercado laboral según el idioma materno}

¿Crees que los estudios en la UNICH te facilitarán encontrar trabajo? ( $n=204)$

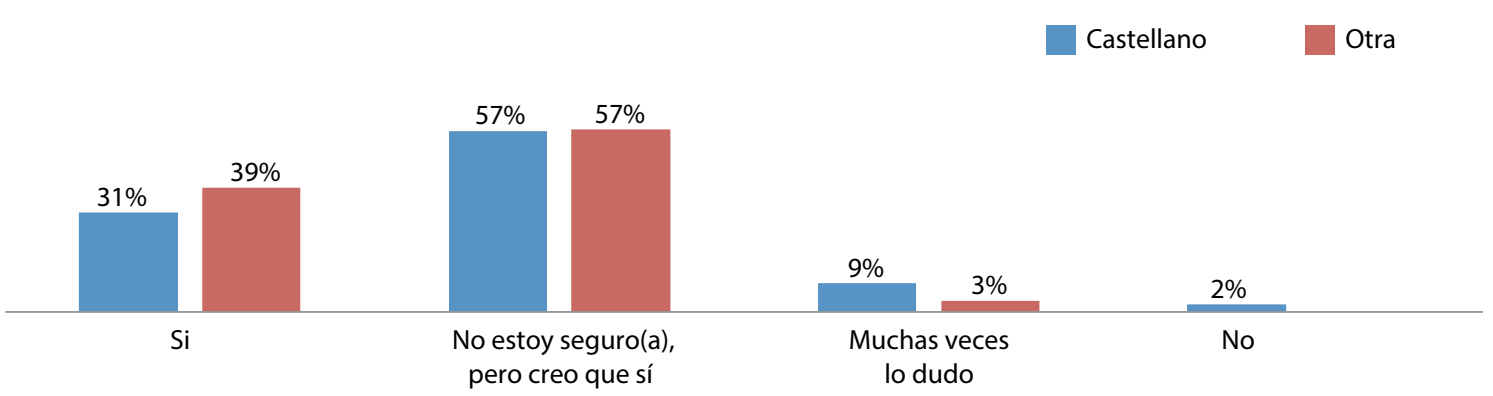

Fuente: elaboración propia

Alumnos cuya lengua materna no es castellana son un poco más "optimistas" sobre sus oportunidades en el mercado laboral ya contando con estudios en la UNICH, aunque el porcentaje de "duda ligera" sobrepasa la mitad de los alumnos en ambos grupos lingüísticos (Gráfico 11). Al mismo tiempo, la expectativa sobre la aplicabilidad en la vida cotidiana de lo aprendido en la UNICH es alta en ambos grupos y no presentó diferencias significativas. Esto reafirma la situación general entre la población estudiantil de la UNICH: no existen tantas dudas sobre la aplicabilidad de lo aprendido en la dimensión "humanista" o "social", sino que este panorama cambia hablando de la educación superior intercultural en términos mercantiles, es decir, como algo que va a elevar las oportunidades en el mercado laboral.

\section{Gráfico 12. Las razones de elegir la UNICH según el idioma materno}

¿Por qué elegiste la UNICH? ( $n=204)$

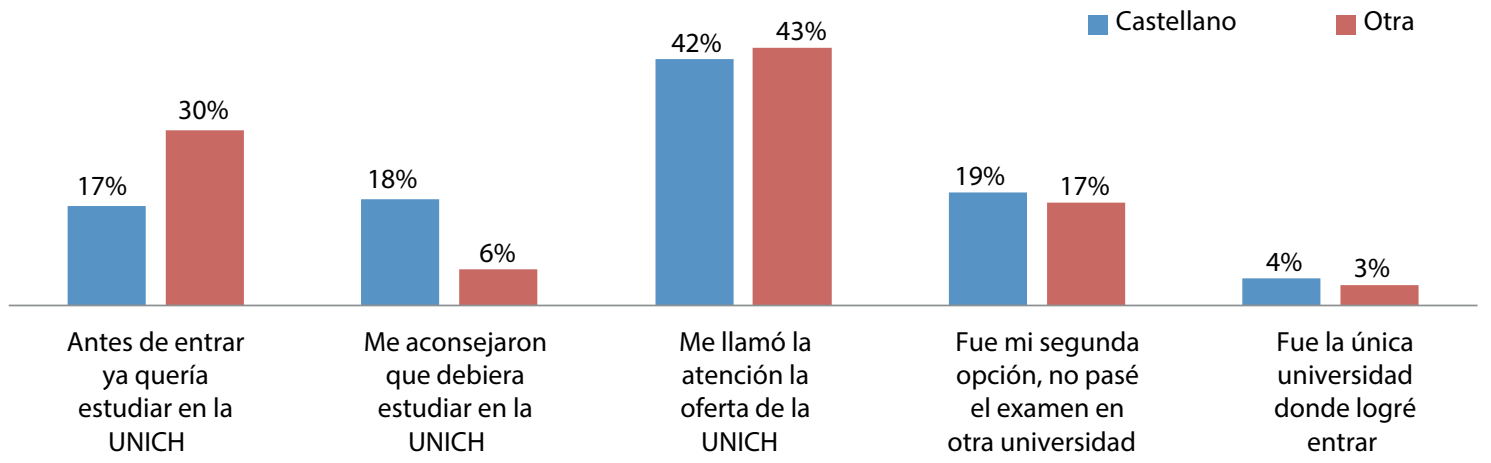

Fuente: elaboración propia 
Las diferencias con base en lengua materna de la persona también se manifiestan en la motivación de elegir la UNICH. La tercera parte de los alumnos cuya lengua materna no es castellana antes de entrar en esta universidad ya querían estudiar ahí, mientras la quinta parte del otro grupo lingüístico siguieron a los consejos de alguien para ir a conocerla (Gráfico 12). Esto confirma que las "relaciones públicas" de la UNICH y, probablemente las UI en general, son orientadas y/o se perciben como orientadas hacia los jóvenes de las etnias.

Cabe indicar que no existe una diferencia significativa según la lengua materna entre los alumnos para los cuales la UNICH fue la segunda opción o la única universidad donde lograron entrar. Este dato pone en duda que la UNICH sea una universidad de una explícita prioridad entre los alumnos cuya lengua materna es uno de los idiomas regionales y la "segunda opción” sólo para el otro grupo lingüístico de alumnos. En otras palabras, independientemente de cómo los futuros alumnos se enteraron de la UNICH, esta fue la primera opción ${ }^{5}$ para $77 \%$ de los encuestados de habla castellana y $80 \%$ de los hablantes nativos de otros idiomas.

A pesar de las dudas que los alumnos de la UNICH tienen sobre su inserción en el mercado laboral, no existen diferencias basadas en la lengua materna de la persona sobre los planes que tienen después de haber concluido sus estudios: casi tres cuartas partes de los alumnos quieren encontrar trabajo que tenga que ver con sus carreras, mientras la cuarta parte de los alumnos de ambos grupos lingüísticos quieren continuar con sus estudios universitarios al nivel de posgrado. Esta también fue la única pregunta donde se observaron ligeras diferencias por el sexo de la persona: mientras hombres y mujeres en proporciones iguales quieren encontrar empleo al terminar sus estudios, son las mujeres que más frecuentemente indicaron que desean continuar con los estudios en el posgrado.

\section{Conclusiones}

A diferencia de los acercamientos cualitativos o del nivel micro, una encuesta permite observar las opiniones de forma más general o del nivel macro. En el presente estudio las opiniones de la población estudiantil de la UNICH fueron descritas desde un posicionamiento general y analizadas según distintas variables como la pertenencia étnica, el sexo y la carrera de la persona. Consecuentemente se pudo detectar las distintas relaciones entre estas variables y la evaluación del modelo intercultural impartido en la UNICH, al igual que las motivaciones para cursar en esta universidad y la satisfacción con la carrera elegi$\mathrm{da}$, entre otros.

Las UI no intentan presentarse como instituciones cerradas y excluyentes, sino se presentan como portadoras de un carácter intercultural: abiertas a todas las personas interesadas, aunque la interculturalidad en estas universidades es pensada y expresada en los planes de estudio y en las estrategias de aprendizaje a partir de las concepciones de las minorías étnicas. Esto también se mostró en los resultados de la encuesta aplicada: los estudiantes cuya lengua materna no es castellano ya de antemano querían estudiar en la UNICH, mientras un elevado porcentaje de los alumnos que son hablantes nativos del castellano seguían a los consejos de conocer esta universidad para hacer su elección final. Aunque las UI se presenten como universidades abiertas a todos, son asociadas con lo indígena. Esto conlleva el peligro que también la interculturalidad pueda ser interpretada como un "asunto de indígenas" y no como algo que le debe concernir a toda la sociedad en conjunto.

A pesar de que la evaluación general sobre los contenidos educativos y el modelo intercultural impartido en la UNICH es positiva, existen diferencias según la carrera, mientras entre las carreras existe una segmentación etnolingüística. Esto indica que posiblemente exista una insuficiente consolidación del discurso intercultural 
entre las carreras, los docentes y la administración académica, algo que aparece como un problema común en las UI. Lo alarmante en este sentido es el hecho que una evaluación negativa del modelo intercultural es más frecuente entre los alumnos de en los semestres avanzados así que mientras más tiempo la persona pasa en la universidad, más escéptica se vuelve. Además, los alumnos de las carreras donde prevalecen hablantes de los idiomas regionales, expresan mayor escepticismo sobre dicho modelo. Por siguiente, es algo que la administración académica debería de atender, por ejemplo, en forma de cursos de capacitación de los docentes y talleres sobre la interculturalidad y su aplicación epistémica y práctica.

Otro problema alarmante es el nivel de escepticismo que los alumnos expresan sobre su inserción laboral contando con los estudios en la UNICH. También este tema debería de ser atendido por la administración de la universidad. Posiblemente los alumnos son informados de forma insuficiente sobre sus competencias y las oportunidades en el mercado laboral. Simultáneamente es de gran importancia informar a los posibles empleadores y la sociedad en general sobre el potencial profesional de los egresados de las UI. Por supuesto, este tipo de campañas involucrarían más gastos y como las UI a menudo se enfrentan con problemas económicos, sería difícil resolver un problema de forma separada de los demás obstáculos. Paralelamente esto subraya la importancia de los futuros estudios sobre las trayectorias laborales de los egresados de las UI para mejorar la detección del nicho que los alumnos de estas universidades tienen en el mercado de trabajo.

Efectivamente, la UNICH y las UI en general aún tienen mucho camino que recorrer para poder acercarse un poco más a sus metas interculturales en forma funcional. Así que cambios tanto en el funcionamiento de las UI, como en sus contenidos son necesarios, al igual que realizar estudios que no sólo sean críticos, sino también propositivos. Qué tan eficiente y fructí- fero es el actual giro intercultural, es una discusión que no podemos resolver teóricamente, sino sólo observando y viviendo los consecuentes cambios en la sociedad, y es algo que tampoco puede ser observado a corto plazo. El presente estudio es pionero en la forma de cómo acercarse a la evaluación de las UI en México y sirve como el punto de partida y comparación con las demás UI no sólo en el territorio mexicano, sino en la demás Latinoamérica. Estudios comparativos de esta índole sería una de las maneras adecuadas para crear una base de conocimiento que en el futuro próximo pueda ser utilizada para mejorar el funcionamiento de las UI. Si las minorías étnicas que son nativas de este continente comparten una situación desventajosa en la estructura de las sociedades latinoamericanas y las UI aparecen como un elemento que en este sentido pueda generar cambios estructurales, entonces mejor funcionamiento de las UI debería de ser construido colectivamente desde lo local hacia lo regional y lo continental.

\section{Notas}

1. Basándose en la clásica teoría de Pierre Bourdieu (2001, pp. 131164) sobre las formas del capital.

2. Por ejemplo, "competencia intercultural”, "habilidades de comunicación intercultural" o "sensibilidad intercultural" que pueden realizarse en toma de conciencia, adquisición y aplicación práctica de dichas virtudes en distintas esferas laborales y sociales (Pöllmann, 2014).

3. Por ejemplo, el supuesto hecho que se mejora la calidad de vida en las comunidades a partir de los proyectos desarrollados en las Ul podría ser cuestionado. No cabe duda que los proyectos están orientados hacía el mejoramiento, pero ¿en cuántos casos han sido verdaderamente eficaces y productivos?

4. $\mathrm{O}$ el primer idioma

5. "Fue la única universidad donde logré entrar" significa que la persona ya había intentado pasar el examen de admisión en otras universidades.

\section{Referencias bibliográficas}

Bastiani, G. J., \& Moguel Viveros, R. (2011). Exclusión e inclusión en el modelo de educación superior intercultural: el caso de la Universidad Intercultural de Chiapas. Signos Lingüísticos, 
6/7(12/13), 23-56. Recuperado de https://goo.gl/httEo8

Bertely Busquets, M. (2011). Educación superior intercultural en México. Perfiles Educativos, 33, 66-77. Recuperado de https://goo.gl/xMRhHL

Bourdieu, P. (2001). Poder, derecho y clases sociales. España: Desclée de Brouwer.

Casillas Alvarado, M. Á. (2012). La diversidad cultural en la universidad. Los estudiantes indígenas y afrodescendientes en la educación superior, necesidad de visibilización y reconocimiento. En Casillas Alvarado, M. Á. et al. (Coords.), Educación superior para indígenas y afrodescendientes en América Latina (89-105). México: Universidad Veracruzana.

Casillas Muñoz, M. (2012). Políticas públicas de atención a la diversidad cultural y lingüística en la educación superior en México. En Casillas Alvarado, M. Á. et al. (Coords.), Educación superior para indígenas y afrodescendientes en América Latina (21-42). México: Universidad Veracruzana.

Chávez, M. E. (2008). Ser indígena en la educación superior ¿desventajas reales o asignadas? Revista de la Educación Superior, 37(4), 31-55. Recuperado de https:// goo.gl/Uo5MRU

Corona Berkin, S., \& Pérez Daniel, M. R. (2010). Cinco desaciertos de la educación intercultural y una estrategia indígena. En StröbeleGregor, J. et al. (Eds.), Construyendo interculturalidad: Pueblos Indígenas, Educación y Políticas de Identidad en América Latina (20-25). Alemania: GIZ.

Cruz Salazar, T., \& Moreno, A. O. (2013). Juventudes interculturales. Voces y visiones estudiantiles en la UNICH. En Cruz Salazar, T., \& Sartorello S. C. (Eds.), Voces y visiones juveniles en torno a diversidad, diálogo y conflicto intercultural en la UNICH (65-91). México: Fray Bartolomé de Las Casas.

Cuji Llugna, L. F. (2012). Una paradoja de la interculturalidad como descolonización de la educación superior. Diversidad, 0, 40-53.

Dietz, G., \& Mateos Cortés, L. S. (2011). Interculturalidad y Educación Intercultural en México. Un análisis de los discursos nacionales e internacionales en su impacto en los modelos educativos mexicanos. México: SEP-CGEIB.
Fábregas Puig,A.(2012).Dela Teoría de la Aculturación a la Teoría de la Interculturalidad. Educación y Asimilación: El caso mexicano. Intercultural Communication Studies, 1(21), 13-23. Recuperado de https://goo.gl/QumUoL

Gallart Nocetti, M.A., \& Bremer, C. H. (2006). Indígenas y educación superior: algunas reflexiones. Universidades, 32, 27-37. Recuperado de https:// goo.gl/tmpNcc

Gómez Lara, H. (2011). La educación intercultural y las identidades de género, clase y etnia. Revista Pueblos y Fronteras Digital, 6(11), 273-298. Recuperado de https://goo.gl/Wdvue2

Hidalgo Hernández, V. (2005). Cultura, multiculturalidad, interculturalidad y transculturalidad evolución de un término. Revista de ciències de l'educació, 1, 75-85. Recuperado de https://goo.gl/9iubxZ

Kaltmeier, O. (2010). Educación Intercultural y políticas de Ströbele-Gregor, J. et al. (Eds.), Construyendo interculturalidad: Pueblos indígenas, educación y políticas de identidad en América Latina (3-8). Alemania: GIZ.

Llanes Ortiz, G. (2008). Interculturalización fallida: Desarrollismo, neoindigenismo y universidad intercultural en Yucatán, México. Trace, 6(53), 49-63. Recuperado de https://goo.gl/G5TwBd

Malgesini, G., y Giménez, C. (2000). Guía de conceptos sobre migraciones, racismo e interculturalidad. España: Catarata.

Mato, D. (2014). Universidades Indígenas en América Latina. Experiencias, logros, problemas, conflictos y desafíos. ISEES: Inclusión social y Equidad en la Educación Superior, 14, 17-45.

Pérez Ruiz, M. L. (2014). Sobre la hibridación y la interculturalidad en el postdesarrollo. Para un diálogo con Arturo Escobar. Cultura y representaciones sociales, 9(17), 74-109. Recuperado de https://goo.gl/HFGd24

Pöllmann, A. (2014). Capital intercultural: hacia la conceptualización, operacionalización e investigación empírica de un marcador de distinción sociocultural en ascenso. Cultura $y$ representaciones sociales, 9(17), 54-73. Recuperado de https://goo.gl/RdYUyy

Sandoval Forero, E.A., Guerra García, E., \& y Contreras Soto, R. (2010). Las dimensiones de la interculturalidad: el discurso de los 
rectores de las Universidades Interculturales. En Sandoval, E. A. et al. (Coords.), Políticas públicas de educación superior intercultural $y$ experiencias de diseños educativos (36-59). Recuperado de https://goo.gl/nuDRxH

Sartorello, S. C. (2016). Convivencia y conflicto intercultural: jóvenes universitarios indígenas y mestizos en la Universidad Intercultural de Chiapas. Revista Mexicana de Investigación Educativa, 21(70), 719-757. Recuperado de https://goo.gl/W7r6Ur

Tipa, J., \& Zebadúa, J. P. (2014). Juventudes, identidades e interculturalidad. Consumos y gustos musicales entre estudiantes de la Universidad Intercultural de Chiapas. México: UNACH.

Tirzo Gómez, J., \& Hernández, J. G. (2010). Relaciones interculturales, interculturalidad y multiculturalismo; teorías, conceptos, actores y referencias. Cuicuilco, 48, 11-34. Recuperado de https://goo.gl/4uPJ3w

Vargas Moreno, P. (2014). Educación Superior Intercultural en disputa. Trayectorias de la Universidad Intercultural Amawtay Wasi Polis. Revista de la Universidad Bolivariana, 13(38), 269-300. Recuperado de https://goo.gl/82jY8Y 


\title{
La educación superior intercultural en Tabasco. Una historia en construcción
}

\section{Higher Intercultural Education in Tabasco. A history in construction}

\begin{abstract}
Victoria Raquel Rojas Lozano es doctoranda en Ciencias en Salud Colectiva por la Universidad Autónoma Metropolitana (México) (vicra.rojas08@gmail.com) (http://orcid.org/0000-0001-6053-9655)

Dr. Sergio Iván Navarro Martínez es docente en el Instituto en Educación Superior en Desarrollo Humano Sustentable. Es Candidato al Sistema Nacional de Investigadores (México) (s-navarro@hotmail.com) (http://orcid.org/0000-0001-5157-0394).
\end{abstract}

Amelia Escobar Potenciano es docente en la Universidad del Grijalva (México) (amescop215@gmail.com) (http://orcid.org/0000-000 1-9608-7822)

Recibido: 2017-07-25 / Revisado: 2017-09-16 / Aceptado: 2017-11-01 / Publicado: 2018-01-01

\section{Resumen}

En el escrito se expone la experiencia educativa denominada: Universidad Intercultural del Estado de Tabasco (UIET) y los datos referidos abarcan un periodo de diez años (2005-20I5).' El texto refleja, desde una mirada crítica, el devenir histórico de la Universidad y las diversas maneras en la que se entiende a la educación intercultural en esta Institución de Educación Superior (IES). Se analiza el proceso de formación de la uiet y los actores que en ella se han involucrado, las diferentes etapas de construcción por las que ha atravesado, los obstáculos y retos a los que se ha enfrentado. La selección de fuentes se orientó bajo la búsqueda de dos tipos de insumos: documentos oficiales de la Universidad y mediante el uso de diversos métodos y técnicas de investigación en las que se reconoció, a partir de experiencias de profesores y estudiantes, la visión de los actores al respecto del devenir de la UIET.
Descriptores: Enseñanza superior, investigación empírica, historia, políica cultural, relaciones interétnicas y práctica pedagógica.

\begin{abstract}
This paper presents the educative experience called: Universidad Intercultural del Estado de Tabasco (UIET) and data comprehends a period of ten years (2005 to 2015). Text shows, from a critical view, the University's historical development and the diverse kinds in which intercultural education is conceived in this Higher Education Institution (IES for its Spanish acronym). The process of UIET's formation is analyzed here as well as the actors who have been involved, the different building steps in the process, complications and challenges faced. Selection of sources was addressed to two kinds of data, one referred to official documents in this university and another related to
\end{abstract}

Forma sugerida de citar: Rojas Lozano, V. R., Navarro Martínez, S. I., \& Escobar Potenciano, A. (2018). La educación superior intercultural en Tabasco. Una historia en construcción. Alteridad, 13(1), 72-82. https://doi.org/10.17163/alt.v13n1.2018.05. 
the use of searching methodology and techniques to identify, through the teachers and students experience, the position of these actors about development and future at UIET.

\section{Introducción}

El discurso intercultural no puede ni debe erigirse descontexualizado de la diversidad cultural que lo sustenta, desligado de las desigualdades e inequidades sociales que se reproducen a su interior, ni de las estructuras políticas y económicas que las condicionan. Un estudio de esta naturaleza requiere evidenciar los conflictos que surgen en este contexto (aculturación, marginación social, relaciones de poder, crisis sociales, entre otros) y, por lo tanto, analizar el proceso histórico de reflexión teórica en torno al concepto y lo que ello ha propiciado en el campo de las acciones concretas (Navarro y Rojas, 2015; Navarro, 2016).

Por ejemplo, las Universidades Interculturales (UI) han sido creadas en Latinoamérica $y$, en el caso que nos ocupa, en México, a partir de numerosas reflexiones político-pedagógicas surgidas en recientes épocas y a causa de procesos socioculturales que distinguen a esta región. Entre estas reflexiones, se encuentran las declaratorias internacionales que favorecieron la institucionalización de políticas interculturales en la educación superior -entre las que está el Convenio 169 de la Organización Internacional del Trabajo- (Bello, 2011; Bermúdez, 2015; Rojas-Cortés y GonzálezApodaca, 2016).

En el caso latinoamericano se presentan dos tipos de educación intercultural: una, "desde abajo" conformada por la labor y esfuerzo de los pueblos indios y organizaciones sociales que han superado las clásicas escuelas y facultades de antropología (Jablonska, 2015; Velasco, 2015; Baronnet, 2012, 2013; Mato, 2008, 2009a y 2009b, Sandoval, 2004); y, el segundo, instituciones de educación para indios creadas por los Estados de manera obligada como respuesta a las presiones y movilizaciones sociales; a diferencia
Keywords: Higher education, empirical researching, history, cultural policy, interethnic relations, pedagogical practice.

de las primeras, éstas últimas son controladas y administradas por mestizos (Sandoval, 2004; Dietz y Mateos, 2011).

De manera particular en los países de Latinoamérica sobresalen ejemplos de UI creadas por los esfuerzos de las comunidades indígenas que responden a sus necesidades y conocimientos. En México, el origen de las UI responde de igual manera, a movilizaciones de grupos sociales históricamente marginados (Rojas-Cortés y González-Apodaca, 2016, Navarro, 2016). Y por el otro, están los proyectos más institucionales que nacieron de iniciativas públicas específicas, cuya función social es la de representar "una propuesta que ofrece espacios de formación alternativos a las culturas minoritarias, con el propósito de dotar a sus integrantes de las herramientas adecuadas para enfrentar los embates del proyecto globalizador que tiende a privilegiar la consolidación de una sociedad monocultural" (Casillas y Santini, 2007, pp. 39-40).

Para Casillas y Santini (2007), es a consecuencia de movimientos sociales y políticos que se abren espacios institucionales con pertinencia intercultural, en los que se retoma el entorno local de los estudiantes, e integra contenidos multiculturales. En México, aunado al reconocimiento constitucional del carácter pluricultural del país y los acuerdos internacionales, se crean a partir de 2003 distintas UI en toda la República sumando, hasta 2015, once Instituciones de Educación Superior (IES) con enfoque intercultural.

El discurso inherente a dicha acción política retomó las reflexiones académicas al respecto, señalando al paradigma intercultural como una contribución más para la inclusión de sectores históricamente marginados y, en consecuencia, a la democratización de la Nación. Sin embargo, las IES son administradas por el modelo occi- 
dental de educación, que responde más a una propuesta de educación intercultural institucionalizada (Dietz y Mateos, 2011). En este contexto, la mayoría de las UI en México no surgen como producto de un auténtico esfuerzo organizativo "desde abajo" proveniente de las comunidades indígenas rurales de la región. La dirección principal del rumbo que lleva este modelo educativo recae en sujetos no indígenas formados en universidades clásicas tradicionales. Dichos actores, en su mayoría, ignoran el carácter epistemológico del saber ancestral de las culturas regionales, propiciando que éstos queden relegados a segundo plano (Sandoval, 2004; Navarro, 2016; Galán y Navarro, 2016; Rojas, Navarro y Escobar, 2016). ${ }^{2}$

La misión de las UI ha sido desde entonces: "Formar profesionistas-intelectuales que contribuyan a elevar el nivel de desarrollo humano de su región mediante la generación y gestión de proyectos auto-gestivos que promuevan la conservación y difusión de su patrimonio cultural y natural, respetando la diversidad cultural y su entorno" (Estudio de Factibilidad, 2004). Misión que tiene que ver con lograr el equilibrio geográfico del desarrollo y responder a las demandas históricas de las poblaciones en situación de vulnerabilidad mediante el desarrollo comunitario y regional. El presente texto tiene por objetivo entonces, caracterizar el proceso intercultural por el que atraviesa la Universidad haciendo algunas anotaciones sobre su estado actual, retos y obstáculos.

En el caso que nos atañe hubo experiencias previas de Educación Superior Intercultural "instituyentes" antes de la creación de la UIET, como es el caso de la Universidad Indígena Latinoamericana en Tabasco (UIL),

a la que se le negó la validación durante dos periodos gubernamentales, y con ello se vio forzada a cerrar. Pocos meses después, según las crónicas periodísticas, se inauguró la UIET, y en marzo de 2015 el gobernador anunció la reapertura de la UIL, ahora como una sede de la UIET (Rojas-Cortes y González-Apodaca, 2016, p. 84).
Otro caso es el citado por Galán (2016), donde además de la UIL, señala la creación y sostenimiento de la Universidad Popular de la Chontalpa (UPCH), la cual se dio por los movimientos en pro de una educación popular en los noventa y principios de 2000 , el autor señala que en la UPCH se formaron

\begin{abstract}
algunos de los líderes que participaron en la creación de la UIET en Oxolotán, como es el caso de quien fue Director académico entre 2005 y 2012 y posteriormente el segundo rector, el maestro Hugo Martín Cabrera Hernández, además de que algunos de los profesores fundadores también provenían de la UPCH (p. 296).
\end{abstract}

Bajo ese antecedente, la UIET inicia operaciones en agosto de 2005 en el Poblado Oxolotán, Tacotalpa, municipio serrano que colinda con el vecino estado de Chiapas. ${ }^{3} \mathrm{Y}$ por acuerdo de creación, que se firma el 5 de abril de 2006, se concibe como organismo público descentralizado, de carácter estatal, con personalidad jurídica y patrimonio propio.

\section{Metodología}

La metodología que guía la presente investigación se realizó desde una perspectiva intercultural, la cual implica reflexionar qué significa hacer investigación de, para y desde dicho enfoque ( $\mathrm{cfr}$. Navarro y Rojas, 2015). Este artículo se generó desde la Línea de Investigación: "Educación para la Interculturalidad", cuyo propósito fue profundizar sobre el significado e influencia del paradigma intercultural en los estudiantes de la UIET, y en lo que respecta a este escrito (que hace parte de dicha investigación) retoma dos variables fundamentales: génesis y procesos interculturales que permitieron dar cuenta de los retos y obstáculos que enfrenta la UIET a diez años de creación. Se retoma los planteamientos del construccionismo social (Guba y Lincoln, 2000), y la teoría crítica (Wiesenfeld, 2001), para abordar la problemática propuesta. 
Metodológicamente desde la perspectiva de la teoría crítica, se privilegia el diálogo -al igual que el construccionismo social- en el que el investigador intenta cambiar los discursos posibles a partir de las experiencias socialmente construidas de los actores sociales que no tienen acceso a las estructuras del poder dominante (Guba, 1990, Guba y Lincoln, 2000). El criterio que priva para la construcción del conocimiento no es el del especialista, sino el de los informantes entre los que se encuentra el investigador (Wiesenfeld, 2001).

La construcción del dato se orientó bajo una muestra de casos-tipo, en la que participaron estudiantes, profesores y administrativos de la Universidad en diversos momentos. Se trabajó con dos tipos de insumos, primero, a partir de documentos oficiales de la Universidad: informes de Gestión de Rectoría, base de datos históricos de la matrícula y de docentes de la Institución; y segundo, mediante un muestreo utilizando las siguientes técnicas de investigación:

a) Foros. Se realizaron dos foros (con duración de tres días cada uno) para reflexionar $\mathrm{y}$ analizar en torno a las diversas interpretaciones que existen sobre la interculturalidad y la implementación del proyecto educativo en Tabasco. El primero fue en noviembre de 2010 se recibieron 44 ponencias, de las cuales 9 fueron de docentes y 35 de estudiantes. El segundo fue en noviembre de 2011, se aceptaron un total de 69 trabajos, 9 ponencias de docentes, 50 de estudiantes; y 10 materiales audiovisuales.

b) Entrevistas semi-estructuradas. Se aplicaron 42 entrevistas a estudiantes, docentes y directivos para conocer las experiencias y saberes sobre la interculturalidad en su vida cotidiana $y$ de igual manera para conocer el proceso de creación de la UIET.

c) Encuestas. Se aplicaron 126 encuestas, con la escala de Likert para conocer la influencia e implementación de la educación intercultural en la UIET.

d) Grupos de discusión. Se hicieron 5 grupos de discusión (de aproximadamente 10 participantes cada uno, en los que participaron estu- diantes, profesores y administrativos), con ellos se buscó promover la construcción colectiva del conocimiento al discutir los resultados de la encuesta.

e) Observación participante. Se realizó en diferentes etapas durante tres años que duró el proyecto, ésta sobre todo se hizo por los integrantes del equipo de investigación en las aulas de clase. Se buscó observar actitudes y prácticas que cobran relevancia en el contraste entre discursos y realidades.

En lo referente a la integración y análisis de datos cualitativos, básicamente se siguió la propuesta de Strauss, Corbin y Zimmmerman (2002) para la investigación cualitativa además de utilizar el método de comparación constante. Lo que se presenta a continuación son los resultados concernientes únicamente a la implementación y consolidación del proyecto educativo de la UIET durante sus primeros años.

\section{Resultados}

La UIET nace, según el Estudio de factibilidad realizado en 2004, como respuesta a

una demanda real y legítima de los jóvenes habitantes de zonas rurales e indígenas que han sido sometidos a una preparación homogeneizadora, sin condiciones de equidad con un modelo educativo impuesto, al cual sólo acceden grupos con mejores índices de desarrollo (Estudio de Factibilidad, 2004, p. 1).

Se argumentó legalmente la apertura de la UIET, primero, mediante leyes, estatutos y reglamentos, ${ }^{4}$ segundo, a partir de la demanda potencial de aspirantes a la educación superior; tercero, a través de la oferta educativa de la región Chol. En cuarto lugar, para justificar la puesta en marcha de la UIET se tomó en cuenta las necesidades del mercado laboral en municipios con presencia indígena. Finalmente, se analizó la ubicación específica de la Universidad a través de una matriz FODA que evidenció al municipio de Tacotalpa como lugar ideal. Esto último debido a que ostenta un porcentaje importante de Choles, 
ya que $40 \%$ de las comunidades del municipio al menos poseen el 10\% de Población Hablante de Lengua Indígena (INEGI, 2010).

Los acuerdos estatales y federales a partir de los cuales se creó la Universidad, estuvieron a cargo de la Coordinación General de Educación Intercultural Bilingüe (CGEIB), pues ésta dependencia, como instancia normativa y operativa de la Secretaría de Educación Pública (SEP), tenía la obligación de cumplir las metas señaladas en el Programa Nacional de Educación.

Inicialmente las actividades de la UIET se gestaron en la Escuela Secundaria Técnica Número 13, donde operaban tres licenciaturas en el turno vespertino (Lengua y Cultura, Desarrollo Rural Sustentable y Desarrollo Turístico). Actualmente posee cuatro terrenos ubicados en Oxolotán (de 3,99 ha, y 14,56 ha respectivamente), uno en Centla (de 5 ha) y el último en Tamulté de las Sabanas. De los cuales sólo existe infraestructura propia en la Unidad Académica de Oxolotán $y$ un edificio en construcción en Villa Vicente Guerrero, Centla. Con estos tres espacios se cubre la atención para las dos regiones étnicas importantes de Tabasco: la Chontalpa, donde se ubica el pueblo Yokot'an, y la Sierra, donde está el pueblo Chol migrante del Norte de Chiapas.

Los programas educativos de la UIET se organizaron para ser cursados en un periodo de cinco años, es decir, diez semestres que estuvieron constituidos por tres áreas: Área de Formación Básica, Área de Formación Técnica y el Área de Formación Profesional. A partir de 2014, los mapas curriculares y los programas de estudios fueron modificados a fin de reducir los años de formación. Con un nuevo modelo flexible de estudio, se espera que el estudiante logre culminar su licenciatura hasta en tres años y medio.

Según el Estudio de Factibilidad (2004) las carreras innovadoras y tradicionales que se propusieron para la apertura de la Universidad, fueron: Atención y promoción de la salud (Medicina Sanitaria), Atención educativa intercultural en todos los niveles (Escuela Normal Intercultural Bilingüe) y Desarrollo sustentable regional y comunitario (Agronegocio). Finalmente, se ofertó Desarrollo Rural Sustentable, Desarrollo Turístico y Lengua y Cultura (que también se brindan en otras IES con enfoque interculturales de México).

La Institución ha ampliado su oferta educativa ofreciendo cuatro licenciaturas más: Comunicación Intercultural (2008), Salud Intercultural (2011), Enfermería Intercultural (2012) y Derecho Intercultural (2014). Como estrategia para aumentar la matrícula universitaria, se abrió la modalidad de semi-escolarizado en el año 2012 con la licenciatura en Desarrollo Rural Sustentable. Para el 2013, se suma en la misma modalidad la licenciatura en Comunicación Intercultural (esas son las únicas dos generaciones bajo esa circunstancia).

De acuerdo a datos obtenidos del Departamento de Información, Estadística y Evaluación de la UIET, en 2005 la matrícula estudiantil fue de 217 estudiantes, se obtuvo un aumentó a 971 en 2014 divididos en 476 para la sede de Oxolotán, 323 para Villa Vicente Guerrero y 173 para Tamulté de las Sabanas. El promedio anual de crecimiento, hasta 2014, fue de 90 estudiantes lo que representa una cifra poco significativa. En ese año, se apertura la sede de Tamulté y se registró el periodo de mayor incremento con el 78,79\%. El periodo más alarmante que enfrentó la UIET fue en 2012 cuando la matricula descendió el 17,75\%.

En relación al género, ha existido un porcentaje equitativo de ingreso de hombres y mujeres a la Universidad. De 2009 a 2013 hubo un número ligeramente mayor de mujeres proveyendo una alentadora cifra sobre la cada vez mayor incursión de la mujer rural e indígena a la educación superior. En el ciclo escolar 20142015 la cifra alcanzó su máximo rango al poseer un $73 \%$ de la matrícula total, es decir, hubo una inscripción de 596 mujeres y 376 hombres.

En lo que respecta a la variable lingüística, a lo largo de la puesta en marcha de la Universidad siempre habían existido una mayoría de estudiantes hablantes de lengua chol. ${ }^{5}$ Para el ciclo 2014-2015, se inscribieron 127 choles, 62 yokotanes, 26 zoques, 10 tsotsiles, 5 tseltales 
y un maya que sumaban en total 231 hablantes, el 23\% de Hablantes de Lengua Indígena (HLI) con respecto del total de la matrícula estudiantil. En estas últimas cifras se observó una relevante diferencia pues en 2005 los HLI representaban el $55.7 \%$ del total de la matrícula disminuyendo en 2006 a $48.3 \%$, en 2007 a $42.9 \%$, en 2008 a 40.7\%, en 2009 a $41.4 \%$, en 2010 a $42.9 \%$, en 2011 a $37 \%$, en 2012 el $38 \%$ y en el último periodo (2014) se visualizó un descenso drástico al contar tan sólo con el 23\% del total de los estudiantes.

Esto no significa que estas Universidades sólo den cabida a los indígenas y el que ahora representen una minoría sea un retroceso. Más bien, lo que debemos cuestionar es, ¿qué está pasando con las expectativas educativas de esta población? lo que seguramente nos llevará a reflexionar sobre la génesis de estas universidades.

Como se mencionó, la Universidad ofrece siete licenciaturas. Durante los primeros seis años, la carrera con mayor demanda fue Desarrollo Turístico (DT). Sin embargo, a partir de la creación de la Licenciatura en Enfermería Intercultural, ésta se constituyó como la de mayor demanda entre la población, desplazando a DT a un cuarto plano. El segundo lugar lo ocupó la licenciatura en Salud Intercultural seguido por Lengua y Cultura. En los puestos consecutivos se encontraron Desarrollo Rural Sustentable, Comunicación Intercultural y Derecho Intercultural.

De estas siete, en su mayoría, los hablantes de lengua originaria están inscritos a la carrera de
Lengua y Cultura. Para el 2014, ellos constituían el $47,5 \%$ del total de HLI de la Universidad. Las licenciaturas que desde su apertura han tenido poca demanda de población indígena fueron la de Comunicación Intercultural y Salud Intercultural. Los lugares de origen de los estudiantes han sido variados. En 2005, se inscribieron en su mayoría jóvenes de Tacotalpa (de sus diferentes localidades), aunque también hubo ingresos de jóvenes provenientes de Chiapas, Nacajuca, Villahermosa, Teapa, Jalapa, Centla, Balancán y Huimangillo.

En lo que respecta a los recursos humanos de la Universidad, la primera contratación de personal se hizo en septiembre 2005 a través del Proceso de Selección del Personal Docente (PSPD), ${ }^{6}$ donde apenas sumaban diez profesores no HLI (seis de tiempo completo, dos de medio tiempo y dos de hora-semana-mes) y dos profesores hablantes de lengua chol, quienes hablan, traducen y escriben esta lengua. Después se agregaron en el primer semestre de 2006, dos profesores más de hora-semana-mes. Con lo que en el primer año de trabajo en la Universidad eran un total de catorce profesores que atendían siete grupos existentes en ese momento (Base de datos de plantilla docente de la UIET, 2011a).

A un poco más de diez años de la Universidad, la planta docente está conformada por 79 profesores agrupados bajo las siguientes categorías:

Tabla 1. Plantilla docente laborando en la UIET en 2015

\begin{tabular}{|c|c|c|c|c|}
\hline Grados académicos & $\begin{array}{c}\text { Profesor de tiempo } \\
\text { completo (PTC) }\end{array}$ & $\begin{array}{c}\text { Profesor de medio } \\
\text { tiempo (PMT) }\end{array}$ & $\begin{array}{c}\text { Profesor de horas, semana, } \\
\text { mes (HSM) }\end{array}$ & TOTAL \\
\hline Técnico & 4 & 0 & 1 & 0 \\
\hline Pasante licenciatura & 0 & 2 & 7 & 22 \\
\hline Licenciatura & 33 & 10 & 0 & 19 \\
\hline Especialidad & 1 & 0 & 0 & 0 \\
\hline Maestría & 18 & 2 & 0 & 79 \\
\hline Doctorado & 1 & 0 & 8 & \\
\hline Total & 57 & 14 & & \\
\hline
\end{tabular}

Fuente: elaboración propia a partir del banco de datos del Departamento de Recursos Humanos UIET 
Quienes han dejado de laborar en la UIET han expresado que su salida ha estado determinada entre otras cosas por: la falta de servicios educativos óptimos para sus hijos en el pueblo de Oxolotán, la falta de adaptabilidad al lugar o a la Universidad, y/o tener otros compromisos laborales.

En los inicios de la Universidad, una de las principales problemáticas que se enfrentó fue el diseño de los Programas de Estudio dado que no existía ningún material previo del cual echar mano. Esto, más que el simple diseño, exigía la comprensión del modelo intercultural en un contexto único y sin precedentes en el país. Pero lo que fue y sigue siendo apremiante, tiene que ver con la propia comprensión de lo que el docente entiende y ejercita como modelo intercultural. Ninguno había estado relacionado con este modelo, ni educado ni trabajado en él (Galán y Navarro, 2016).

Una primera solución se encontró con la asesoría externa de Etel Garrido Cruz, quien acompañó la construcción de los Planes de Estudio de las cinco primeras licenciaturas y el Programa de Formación Docente (PFD) en el que se plasmaron las necesidades de formación con relación al enfoque intercultural: el desarrollo de competencias, evaluación de los aprendizajes, de herramientas constructivistas y tutoría. (Informe de Gestión de la UIET, 2005).

Existía la premura de encontrar una nueva forma de generar conocimiento $y$, por tanto, también de construir una diferente forma de manejar a los grupos culturalmente diversos. Es aquí, donde las necesidades formativas de los docentes reclamaban atención académica inmediata (Galán y Navarro, 2016).

\section{Discusión}

El principal reto que tiene el modelo intercultural, y que es exógeno a él, es su carga segregacionista. Dadas las implicaciones que tiene la interculturalidad, este enfoque debería ser más incluyente y extenso, situación que compete no sólo a las poblaciones indígenas del país. Uno de los retos que existen y que corresponden no sólo a la UIET, es ampliar el proyecto de interculturalidad más allá de las UI, trabajo que incumbe a otras instituciones, a otros actores y al mismo Estado (Aguilar, 2011; Bertely, 2011; Navarro y Saldívar, 2011, Navarro, 2016).

De manera endógena los retos a los que se ha enfrentado la Universidad a lo largo de estos diez años han sido variados e inician con el trabajo constante al respecto de la estigmatización que estas universidades tienen a nivel nacional de autoridades, instituciones gubernamentales incluidas la misma SEP, como lo menciona Schmelkes (2008, p. 230); hasta la producida y trasmitida de boca en boca en los lugares en los que tiene influencia la UIET. Y si se suma a ello que el número de estudiantes con los que se cuenta actualmente no son los esperados, la Universidad se enfrenta al mayor reto de todos, hacerse de jóvenes que quieran estudiar el Nivel Superior.

Aunado al problema que tienen las UI sobre la aplicación del modelo de interculturalidad como política segregacionista, existe una reproducción al interior de la UIET en la que urge trabajar, pues pareciera ser que es sólo durante el año de Formación Básica (cuando éste existía) y en las licenciaturas de Lengua y Cultura y Desarrollo Rural Sustentable, donde existe un mayor énfasis en el fortalecimiento de las competencias para la interculturalidad y trabajo comunitario.

En lo estudiantil el reto constante ha sido motivar algunos jóvenes, que debido a sus escasos recursos han presentado intenciones de abandonar sus estudios. La deserción escolar es una problemática constante entre los jóvenes que está dada por dificultades económicas, la falta de interés y el desconocimiento por cursar alguna de las carreras ofertadas por la UIET. En el primer semestre 2005 sólo se registraron 18 deserciones, con un índice de reprobación nulo índice de reprobación fue nulo, y en el último periodo escolar analizado para esta investigación 
(2014-2015) las deserciones sumaron un total de 144 de 971 estudiantes. De estos, 93 fueron mujeres y 51 hombres.

En cuanto a las sedes, Oxolotán presentó 66 deserciones, Villa Vicente Guerrero enfrentó 48 y Tamulté de las Sabanas sólo 30. Debe considerarse que las dos últimas sedes son de reciente creación (2013 y 2014) por lo que hay ausencia de los últimos semestres y esto influye en la cantidad de deserciones que presenta. Es natural, por tanto, que el índice de deserción sea mayor con respecto a sus homólogas.

Entre las causas que influyeron para que los estudiantes abandonaran sus estudios encontramos que 112 de ellos presentaron problemas de tipo académico. Este dato evoca la presencia de un indicador alarmante en cuanto a deserciones ya que uno de los objetivos del Programa Institucional de Tutorías es, precisamente, evitar este fenómeno. Por tanto, aunque existan otros aspectos que escapan al control de la Institución, el de tipo académico no debiera ser tan frecuente entre las causas del abandono escolar. Otras razones que se encontraron fueron: 31 estudiantes que presentaron problemas de tipo económico y sólo uno con respecto a asuntos familiares.

La mayor incidencia de deserción se presentó en estudiantes que provenían de lugares cercanos a las sedes correspondientes (Tacotalpa, Teapa, Centla y Centro respectivamente a cada sede). Los años escolares en los que existió un mayor índice de deserciones fueron entre 2007 y 2008 donde ascendieron a 48 y 42 respectivamente. Estas ausencias escolares estuvieron dadas en su mayoría por estudiantes no indígenas, sólo fue en el periodo 2010-2011 en el que se dieron las mayores deserciones de HLI.

Otro problema que se enfrenta con el estudiantado es la baja titulación de éstos, pues hasta junio de 2015 había 171 titulados de un total de 445 estudiantes egresados de las cinco generaciones. De ellos, 45 de 105 estudiantes provenientes de la licenciatura en Desarrollo Rural Sustentable, 64 de 150 jóvenes de Desarrollo Turístico, 49 de 135 egresados de Lengua y Cultura y 13 de 55 de Comunicación Intercultural. Esto indica que únicamente el 38\% ha culminado su trámite de titulación (Base de Datos de la Plantilla docente que ha laborado en la UIET, 2011b).

Además de estudiantes, "desde sus inicios la Universidad se enfrentó con los obstáculos de que los recursos humanos del área administrativa esperaban ingresar bajo esquemas tradicionales de estructuras gubernamentales, es decir, entrar por recomendaciones o por compadrazgo" (Informe de Gestión de la UIET, 2005). Así que es imperiosa la necesidad de que este personal reciba una adecuada instrucción en el modelo intercultural, pues recordemos que la labor de éste, no sólo está en el espacio áulico de la Universidad.

Siguiendo lo expresado por Vivar (2014), es necesario dejar de considerar a estas universidades como capital político para los gobiernos. La dirección de estas instituciones debe recaer en personas que poseen las habilidades y actitudes necesarias para la administración y la gestión por lo que el nombramiento de rectores no debiera dejarse a merced de los intereses políticos del gobierno.

Una de las principales dificultades que enfrenta la Universidad, tiene que ver con la contratación de profesores, toda vez que las convocatorias para participar en el proceso de selección docente no han tenido la respuesta esperada. Situación que ha dificultado que éstos cuenten con un nivel superior a la licenciatura. La ubicación de las instalaciones, las características del mismo espacio y del trabajo en la Institución hacen que la estancia de los profesores sea tan incierta y móvil.

\section{Conclusiones}

La situación actual de la Universidad sigue demandando mayores transformaciones, y una de las más apremiantes es llevar el discurso intercultural hacia la práctica. Es necesario llegar a más espacios y a más población para concientizar no sólo sobre la diversidad cultural existen- 
te en el país, sino para buscar los diálogos que permitan la construcción de un verdadero país democrático, eliminando así las relaciones estratificadas por el poder.

Es preciso trascender en el sentido de la comprensión y de la transformación social, sino las UI no serán más que una política dirigida a la población diferenciada. Y quienes laboran en ellas, como en la época de Gamio y de Vasconcelos, terminarán siendo agentes de un neo-indigenismo condenados a repetir los errores del pasado por haber vaciado de su contenido histórico un proceso que en México es ya añejo.

Existe la necesidad imperante de tener la capacidad de trabajar en los dos espacios, en el interno y en el externo. Adentro, preparando a recursos humanos con herramientas necesarias para su labor. Afuera, para cumplir con las demandas de una sociedad compleja en constante mutación, en este caso, en el contexto de la región sierra de Tabasco, evitando caer en un simplismo cultural o en folclorismo.

Lo presentado, nos da elementos para leer el desdibujamiento de lo local, incorporándose la cultura indígena tan sólo como elemento esencialista y no como parte fundamental del desarrollo cognoscitivo y económico-social de los sujetos. De lo anterior se deriva que los estudiantes se encuentren supeditados a otras prioridades y que el personal docente no sea una verdadera veta de inversión para la Institución -de allí la falta de capacitación y formación en torno a la interculturalidad-que no logra consolidar el modelo educativo intercultural.

\section{Notas}

1 El texto forma parte del proyecto "Significación e influencia de la educación intercultural en la vida cotidiana de los estudiantes de la UIET", realizado entre 2009 y 2011.

2 Sandoval (2004), señala que en las IES interculturales, los indios serán aceptados en tanto reconfiguren sus prácticas y se adapten a la institución cuyo fin es el mestizaje (cfr. Llanes, 2008; Dietz y Mateos, 2011; Aguilar, 2011; Hernández, 2012; RojasCortés y González-Apodaca, 2016). La falta de poder directivo de los beneficiarios y la implementación de conocimientos predominantemente occidentales, permiten reproducir la lógica dominador-dominado que, paradójicamente, el paradigma inter- cultural busca erradicar (Navarro, 2016); es decir, que el binomio “dominación/sumisión”, en palabras de Gasché (2008), no se retoma como parte de la reflexión y análisis que sin lugar a dudas limita la consolidación de la "interculturalidad para todos" (López, 2001; Schmelkes, 2003).

3 El poblado de Oxolotán, donde se ubica la matriz universitaria, se Iocaliza a 103 kilómetros de Villahermosa, Tabasco y se encuentra enclavado en región Sierra.

4 El argumento más sólido y fundamental de la creación de la UIET, se encuentra en el artículo 4to. de la Carta Magna que plantea “la Nación Mexicana tiene una composición pluricultural sustentada en la existencia de sus pueblos indígenas", en la Ley General de Educación, vigente desde 1993 se explicita la exigencia de lograr los requisitos de equidad en el sistema educativo actual, y finalmente, en el Programa Nacional de Educación 2001-2006 que sostiene que "se ampliará la cobertura con equidad a través de la diversificación de la oferta del sistema de educación superior y creando nuevos servicios e instituciones públicas" (Estudio de factibilidad, 2004).

5 El Departamento de Estadística de la UIET retoma el criterio lingüístico para saber cuántos son los estudiantes indígenas inscritos en la escuela, más no considera el criterio de autoadscripción a un grupo indígena.

6 Desde un inicio se propusieron cuatro fases a desarrollar en el PSPD, la primera relativa al curriculum vitae de los aspirantes, la carta de exposición de motivos y un ensayo sobre la importancia de la educación intercultural para el desarrollo humano. La segunda fase se refiere a la evaluación psicológica, la tercera la evaluación del diseño de una unidad didáctica y la exposición en aula y por último la fase de entrevista (Informe de Gestión de la UIET, 2006).

\section{Referencias bibliográficas}

Aguilar, M. (2011). Universidades interculturales, adjetivo o sustantivo. El reto de una educación para y en la diversidad. Ponencia presentada en el XI Congreso Nacional de Investigación Educativa, COMIE. México.

Baronnet, B. (2012). Autonomía y educación indígena. Las escuelas zapatistas de la Selva Lacandona de Chiapas. Quito: Abya-Yala.

Baronnet, B. (2013). La autonomía como condición para la educación intercultural. En S. Hernández, M. Ramírez, Y. Manjarrez y A. Flores, Educación intercultural a nivel Superior: reflexiones desde diversas realidades latinoamericanas. México: UIEP/UCIRED/UPEL, México.

Bello, J. (2011). De la educación bilingüe bicultural, a las universidades interculturales de México. En E. Sandoval, E. Guerra y R. Contreras, Políticas Públicas de Educación Superior 
Intercultural y experiencias de diseños educativos. España: Universidad de Málaga.

Bermúdez, F. (2015). Interculturalidad, etnicidad e intermediación cultural en la formación de profesionales indígenas. Concepciones y prácticas en la Universidad Intercultural de Chiapas. En Patricia Medina (Coord.), Sujetos y conocimientos situados, políticas del lugar en educación. Trayectos y experiencias pedagógicas de investigación en la construcción de interculturalidades activas. Oaxaca, México; UNACH, UABJO, UNICH, UPN.

Bertely, M. (2011). Educación superior intercultural. Perfiles Educativos, 33, 66-77.

Casillas Muñoz, M. de L., \& Santini Villar, L. (2007). Universidad intercultural. Modelo educativo. México: CGEIB-SEP.

Dietz, G., \& Mateos, L. (2011). Interculturalidad y educación intercultural en México: Un análisis de los discursos nacionales e internacionales en su impacto en los modelos educativos mexicanos. México: SEP-CGEIB.

Estudio de Factibilidad de la Universidad Intercultural del Estado de Tabasco (2004). Tabasco, México: UIET.

Galán, F. (2016). Procesos de construcción sobre las identidades indígenas a través de las políticas educativas: el caso Oxolotán, Tabasco. (Tesis de doctorado). Xalapa. Universidad Veracruzana.

Galán, F., \& Navarro, S. (2016). Indigenismo y educación intercultural: una discusión necesaria. La experiencia en la Universidad Intercultural del Estado de Tabasco. Desacatos, 52, 144-159.

Gasché, J. (2008). La motivación política de la educación intercultural indígena y sus exigencias pedagógicas. ¿Hasta dónde abarca la interculturalidad? En M. Bertely, J. Gasché y R. Podestá, Educando en la Diversidad. Investigaciones $y$ experiencias educativas interculturales y bilingües. Quito: Abya-Yala.

Guba, E. (1990). The paradigm dialog. Newbury Park: Sage.

Guba, E., \& Lincoln, Y. (2000). Paradigmas en competencia en la investigación cualitativa. En Denman y Haro (Comps.), Por los rincones. Antología de Métodos cualitativos en la investigación social. Sonora, México: El Colegio de Sonora.
Hernández, S. (2012). Experiencias en la generación de un modelo de investigación intercultural en la Universidad Intercultural del Estado de Puebla. Ponencia presentada en el Congreso Desafíos y horizontes de Cambio. Ciudad de México: México en el Siglo XXI.

Instituto Nacional de Estadística y Geografía, Censo de Población y Vivienda (2010). México.

Jablonska, A. (2015). La Universidad Comunal Intercultural de Cempoaltépetl: Un proyecto político, cultural y pedagógico. En P. Medina Melgarejo, Pedagogías insumisas. Movimientos politico-pedagógicos y memorias colectivas de educaciones otras en América Latina. México: Universidad de Ciencias y Artes de Chiapas, Centro de Estudios Superiores de México y Centroamérica, Educación para las Ciencias en Chiapas, Juan Pablos Editor.

López, L. (2001). La cuestión de la interculturalidad y la educación latinoamericana. Documento de apoyo de la Séptima Reunión del Comité Regional Intergubernamental del Proyecto Principal de Educación en América Latina y el Caribe. Santiago: UNESCO.

Mato, D. (Coord.) (2008). Diversidad cultural e interculturalidad en educación superior: experiencias en América Latina. Caracas: IESALC.

Mato, D. (Coord.) (2009a). Educación Superior, Colaboración Intercultural y Desarrollo Sostenible/Buen Vivir. Experiencias en América. Caracas: IESALC.

Mato, D. (Coord.) (2009b). Instituciones Interculturales de Educación Superior en América Latina. Procesos de construcción, logros, innovaciones $y$ desafíos. Caracas: IESALC.

Navarro, S., \& Saldívar, A. (2011). Construcción y significado de la educación intercultural en la escuela normal indígena intercultural bilingüe "Jacinto Canek". Revista digital Pueblos y Fronteras, 6(12), 67-104.

Navarro, S., \& Rojas, V. (2015). Reflexión teórica-práctica del quehacer de la investigación en la Universidad Intercultural del Estado de Tabasco. Revista electrónica Ruta Antropológica, 2, 19-28.

Navarro, S. (2016). Discursos y prácticas de la educación intercultural. Análisis de la formación de jóvenes en el nivel superior de Chiapas. (Tesis 
de doctorado). San Cristóbal de Las Casas. Universidad de Ciencias y Artes de Chiapas.

Rojas-Cortés, A., \& González-Apodaca, E. (2016). El carácter interactoral en la educación superior con enfoque intercultural en México. LiminaR Estudios Sociales y humanísticos, XIV (1), 73-91.

Rojas, V., Navarro, S., \& Escobar, A. (2016). Historia de la UIET, su génesis y situación actual. Saberes de los pueblos, 1(1), 15-29.

Sandoval, E. (2004). Universidades interculturales. Modelo del indigenismo en la globalización. En S. Corona y R. Barriga, Educación Indígena. En torno a la interculturalidad. Guadalajara: Universidad de Guadalajara.

Schmelkes, S. (2003). Educación superior intercultural: el caso de México. Conferencia dictada en el Encuentro Internacional Intercambio de Experiencias Educativas, Vincular los Caminos a la Educación Superior, organizado por la Ford Foundation, la Unidad de Apoyo a las Comunidades Indígenas de la Universidad de Guadalajara y la ANUIES. México

Schmelkes, S. (2008). Creación y desarrollo inicial de las universidades interculturales en México: problemas, oportunidades y retos. En D. Mato (Ed), Diversidad cultural e interculturalidad en Educación Superior. Experiencias en América Latina (329-338). Caracas: IESALC.

Strauss, A. L., Corbin, J., \& Zimmerman, E. (2002). Bases de la investigación cualitativa: técnicas $y$ procedimientos para desarrollar la teoría fundamentada. Medellín: Universidad de Antioquia.

Universidad Intercultural del Estado de Tabasco (2006). Informe de Gestión de la Universidad Intercultural del Estado de Tabasco, México.

Universidad Intercultural del Estado de Tabasco (2011a). Base de Datos del Histórico de la matrícula de la UIET (2005-2011), Departamento de Información, Estadística y Evaluación de la UIET. Tabasco, México.

Universidad Intercultural del Estado de Tabasco (2011b), Base de Datos de la Plantilla docente que ha laborado en la UIET, Departamento de Capital Humano de la UIET. Tabasco, México.

Velasco, S. (2015). Movimiento indígena en México y educación alternativa. En Medina Melgarejo (Coord.), Pedagogías insumisas. Movimientos político-pedagógicos y memorias colectivas de educaciones otras en América Latina. México: Universidad de Ciencias y Artes de Chiapas, Centro de Estudios Superiores de México y Centroamérica, Educación para las Ciencias en Chiapas, Juan Pablos Editor.

Vivar, K. (2014). Trayectoria y desplazamiento de modelos teóricos e ideológicos de la educación indígena en México. Una crítica antropológica (Tesis doctoral). México: CIESAS Occidente. Wiesenfeld, E. (2001). La autoconstrucción, un estudio psicosocial del significado de la vivienda. Caracas: Universidad Central de Venezuela. 


\section{Sección Miscelánea}
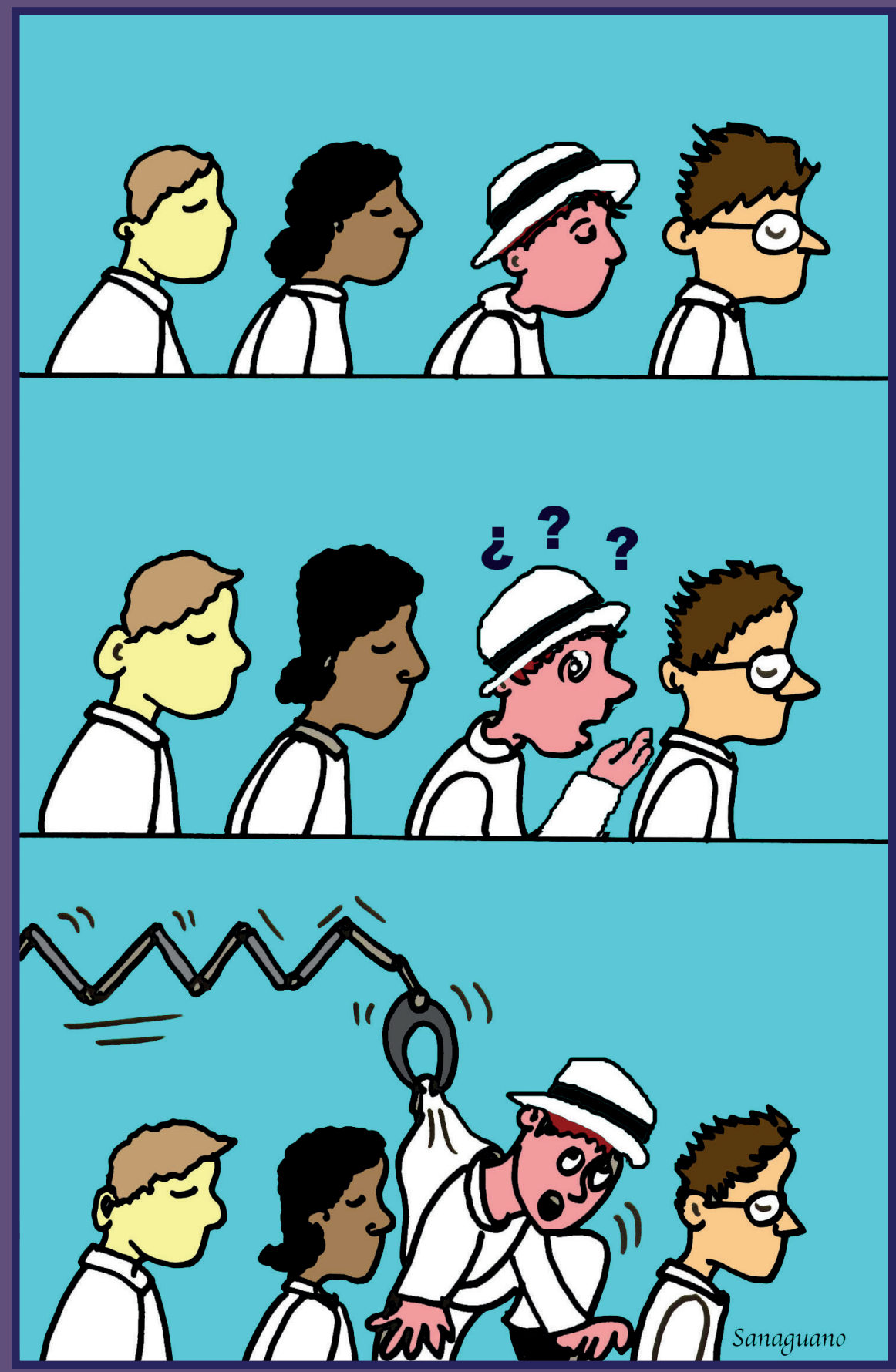


\section{La educación superior en las cárceles. Los primeros pasos de Ecuador}

\section{The higher education in prisons. The first steps of Ecuador}

Carlos Antonio Iturralde Durán, (carlos.iturralde@hotmail.com) (http://orcid.org/0000-0002-0300-7748)

Recibido: 2016-12-08 / Revisado: 2017-04-24 / Aceptado: 2017-08-28 / Publicado: 2018-01-01

\section{Resumen}

Alcanzar el Buen Vivir no es posible sin solucionar los problemas de exclusión social que requieren de la expansión de las libertades de grupos históricamente marginados, como lo son las personas privadas de libertad, muchas de las cuales antes de cometer actos delictivos vivieron en un entorno de violencia y pobreza, situación que en la cárcel punitiva concebida como una institución de castigo y denigración, se intensifica, acentuando conductas antisociales que crean círculos viciosos cuya ruptura se logra, entre otras cosas, proporcionándoles nuevos funcionamientos y capacidades, por lo cual la educación inclusiva en igual calidad que la ofertada en la vida libre pero con diseños curriculares y metodológicos específicos que garanticen la transferencia efectiva de conocimientos hacia este grupo, es clave, constituyéndose en el ejercicio de un derecho humano que dignifica a la vez que rehabilita, siendo la educación superior la de mayor impacto transformador. Ecuador inició un primer pilotaje otorgando becas a un grupo de presos para acceder a estudios universitarios en contexto de encierro, plan que debe superar diversos obstáculos requiriendo de la coordinación interinstitucional y del compromiso de la sociedad para que rinda los resultados deseados, contribuyendo a convertir a las prisiones en verdaderos Centros de Rehabilitación Social y al Sistema de Rehabilitación Social en un promotor de los derechos humanos y el Bien Vivir.

Descriptores: Buen Vivir, capacidades, libertades, educación superior, derechos humanos, cárcel.

\begin{abstract}
Achieving Good Living is not possible without solving the social exclusion problems that require the expansion of the freedoms of historically marginalized groups, such as the people deprived of liberty, many of them, before committing criminal acts, they lived in an environment of violence and poverty, situation that in punitive jail is conceived as an institution of punishment and denigration, intensifies, accentuating antisocial behaviors that create vicious circles which rupture is achieved, among other things, by providing them new functions and capabilities, so that inclusive education in the same quality as offered in free life but with specific curricular and methodological designs that guarantee the effective transfer of knowledge to this group, it is key, constituting itself in the exercise of a human right that dignifies at the same time that it rehabilitates, being the higher education the one with the greatest transformer impact. Ecuador began a
\end{abstract}

Forma sugerida de citar: Iturralde, C. A. (2018). La educación superior en las cárceles. Los primeros pasos de Ecuador. Alteridad, 13(1), 84-95. https://doi.org/10.17163/alt.v13n1.2018.06. 
first pilot giving scholarships to a group of prisoners to access to university studies in the context of confinement, a plan that must overcome various obstacles requiring interinstitutional coordination and the commitment of society in order to yield the desired results, contribut-

\section{Introducción}

Es reconocido que la educación incrementa la capacidad para funcionar, expandiendo la libertad de los individuos para alcanzar la vida que valoran, acercando a las personas y a la sociedad a la consecución del Buen Vivir (London y Formichella, 2006).

Sus beneficios son múltiples abarcando la dimensión económica, creando capital humano, mejorando las rentas individuales y nacionales; política, fomentando la participación ciudadana y la expresión pública en democracia; y social, formando la conciencia colectiva, la cohesión social y mejorando el acceso a servicios fundamentales como la salud y la instrucción formal; por lo cual se considera un activo intangible que contribuye a la reducción del traspaso intergeneracional de la desigualdad, y aún más importante, un derecho humano fundamental cuya exclusión deja a la persona al margen del desarrollo y la sociedad (Iturralde, 2005).

Por su importancia, la UNESCO en 1990 planteó el reto de otorgar educación de calidad para todos, el cual fue bien recibido por los países miembros quienes han diseñado estrategias en cooperación con actores públicos y privados, nacionales e internacionales, para ampliar la cobertura hacia grupos marginados que no han podido ejercer este derecho, y aunque los resultados entre los años 2000-2015 muestran avances, se advierte que aún falta mucho por hacer (UNESCO, 2015).

Entre los grupos excluidos se encuentran las personas privadas de la libertad (PPL), quienes están recluidos en centros de rehabilitación social (CRS), y aunque han perdido su derecho ambulatorio, aún mantienen la mayoría de sus ing to convert the prisons in real Social Rehabilitation Centers and to the Social Rehabilitation System in a promoter of the human rights and Good Living.

Keywords: Good Living, capabilities, freedoms, higher education, human rights, jail.

derechos, como lo es el acceso a educación de calidad (Scarfó, 2003).

En Ecuador, la Constitución reconoce a la educación como un derecho fundamental, y la educación de calidad para todos se cristaliza en los objetivos de desarrollo del Plan Nacional para el Buen Vivir (PNBV), pues es una condición necesaria para alcanzar la visión de desarrollo nacional, esta es "la consecución del buen vivir de todas y todos; la expansión de sus libertades y potencialidades en paz y armonía con la naturaleza; y la prolongación indefinida de las culturas humanas" (Correa, 2008, p. 43).

Estas directrices han permitido que instituciones como el Ministerio de Justicia, Derechos Humanos y Cultos (MJDHC), la Secretaría Nacional de Educación Superior, Ciencia, Tecnología e Innovación (SENESCYT), entre otras, en cooperación con instituciones educativas de diferentes niveles, creen espacios para que las PPL ejerzan su derecho a la educación e incrementen sus capacidades en miras de efectivizar su futura reinserción social.

Este artículo invita a reflexionar sobre la importancia constitutiva e instrumental que tiene la educación superior en la expansión de capacidades y libertades de grupos excluidos, específicamente de PPL; temática que se aborda desde la perspectiva de la equidad y la justicia social y que requiere considerar los principios éticos y de solidaridad que se ajustan al espíritu de los derechos humanos y a la visión del Buen Vivir.

\section{Buen vivir, capacidades y educación}

Buen Vivir, capacidades y educación son tres conceptos tan profundamente relacionados que 
no se puede concebir la existencia de uno sin la de los otros.

Se entiende por Buen Vivir a la "satisfacción de las necesidades, la consecución de una calidad de vida y muerte digna, el amar y ser amado, y el florecimiento saludable de todos y todas, en paz y armonía con la naturaleza y la prolongación indefinida de las culturas humanas" (Ramírez, 2008, p. 387), visión que se contempla en las Constituciones de Ecuador y Bolivia, y que coloca al Estado como promotor del desarrollo, encargado de dirigir el constructo social hacia la ampliación de capacidades y funcionamientos de la población, diseñando políticas que consideren la justicia distributiva para mitigar los graves problemas de exclusión (Celis y Sepúlveda, 2012).

El segundo término nace del enfoque de capacidades de Amartya Sen, Premio Nobel en Economía, quien sostiene que la capacidad de una persona se refleja en la libertad de alcanzar funcionamientos valiosos, y el conjunto de capacidades representa su libertad para conseguir aquello que valora; constituyéndose en determinantes de la calidad de vida a partir de la ampliación o restricción de libertades (Urquijo, 2014). Para comprender este enfoque, es necesario tener claro los siguientes conceptos:

- Funcionamiento. Hace referencia al estado de una persona y las acciones que logra realizar durante su existencia, por lo que el bienestar no se puede medir por la posesión de un bien o el nivel de renta, sino por el estilo de vida que se lleva con ellos lo cual depende del estado del individuo (Sen, 2000). Para ilustrar lo indicado se supondrán dos personas, A y $\mathrm{B}$, quienes obtienen una beca para estudiar en el exterior. Lamentablemente B es acusado de un delito y le imponen prisión preventiva. Para estos agentes, la beca es valiosa por lo que pueden ser o hacer con ella, por tal motivo, en la fecha del viaje, aunque ambos tienen el ticket aéreo y los fondos que financian el estudio, sólo es útil para A.
- Capacidades. Es el conjunto de funcionamientos, es decir, las habilidades físicas, legales e intelectuales que les dan la posibilidad de realizar actos para conseguir la vida que valoran, esto es, el bienestar potencial (Flores, 2005). Siguiendo el ejemplo anterior, se asume que ha pasado un año, B ha resuelto su problema legal y ahora lucha contra las secuelas físicas, psicológicas, económicas y sociales ocasionadas por encierro, teniendo menos opciones que antes de perder su libertad. B se ha empobrecido. Simultáneamente, A regresó de sus estudios con más conocimientos que han incrementado sus opciones laborales, económicas, políticas, culturales y sociales, ya que sus nuevos funcionamientos le dan mayores capacidades y libertades para crear la vida que desea. A se ha desarrollado.

La filosofía del Buen Vivir recoge la propuesta de Sen reconociendo que no se puede concebir el desarrollo sin la expansión de las capacidades y oportunidades, agregando que la libertad, entendida como la realización de las capacidades humanas, está condicionada a la realización de las potencialidades de la sociedad (Ramírez, 2008).

La justicia social demanda que la libertad de las personas no dependa de las condiciones en que nacieron ni de las circunstancias desfavorables de su entorno, siendo el Estado responsable de crear un entorno equitativo a favor de los menos favorecidos, donde la educación juega un rol relevante.

La educación, como condición necesaria para el desarrollo, requiere la intervención pública para garantizar tanto su calidad en todos los niveles: primaria, secundaria y superior, como su cobertura universal, incluyendo a grupos históricamente discriminados, como las PPL, permitiéndoles ser verdaderos actores de su propio progreso, otorgándoles voz, un pensamiento crítico y la capacidad de transformar la realidad que 
los rodea en algo constructivo; y la educación superior, mediante el proceso de transferencia de conocimientos, destrezas y habilidades que derivan en funcionamientos especializados, es el nivel educativo que mayores aportes realiza para el desarrollo integral, contribuyendo a la ruptura del lazo que mantiene a los excluidos atados con la pobreza.

\section{Rompiendo el círculo de violencia}

Las políticas neoliberales implementadas en América Latina entre los años 80 y 90, resquebrajaron el Estado del Bienestar creando desigualdad y pobreza sobre grandes grupos humanos quienes quedaron excluidos de los beneficios del progreso, de la democracia y del goce íntegro de sus derechos, obligándolos a vivir debajo del umbral de la dignidad e incrementando los índices delictivos, ya que sin equidad no puede haber ni eficiencia ni seguridad (SENPLADES, 2012).

Los obstáculos para el desarrollo se correlacionan con la violencia de tal forma que la delincuencia se puede explicar por factores económicos (bajo crecimiento, concentración de la riqueza, desocupación, pobreza), demográficos (discriminaciones por raza, género, urbanidad, migración), educacionales (analfabetismo, baja escolaridad), de capital social (individualismo, poca solidaridad, desconfianza) complementados por factores de carácter disuasivo (Obando y Ruiz, 2007).

Parte de estos marginados que en libertad vivieron en el umbral de la pobreza caracterizada por el desempleo, falta de habilidades sociales, escaso acceso a la educación, entre otras violaciones de sus derechos, agravados en ocasiones por problemas mentales no tratados como ansiedad, depresión, etc., en muchos casos asociados a traumas de la infancia por provenir de hogares disfuncionales donde sufrieron abusos físicos, psicológicos e incluso sexuales; al cometer actos delictivos, fueron capturados y aglutinados en las cárceles, desapareciéndolos virtualmente de la sociedad, y de esta manera, ocultando par- cialmente los deplorable resultados sociales del modelo (INEA, 2013).

En prisión, el campo de tensión "más delirante y violento del aparato de poder" (Parchuc, 2015, p. 20), se agravan las condiciones de estos marginados expuestos al choque físico y psicológico del encierro, la convivencia forzada y la intensificación de la violación de sus derechos. Esta población "no deseada" inicia un proceso de desocialización, aislamiento, fractura familiar, restricción emocional y un brutal empobrecimiento que incrementa sus miedos, ansiedades, agresividad y consumo de drogas reduciendo aún más su autoestima y sus capacidades (Scarfó, 2008).

Cumplida la pena, la cárcel regresa a la sociedad a un ser en peor estado que el inicial, con marcadas tendencias antisociales, quien sufrirá por sus antecedentes delictivos de mayor marginación reproduciéndose el círculo: víctima (social) -victimario (delincuente)- víctima (de la cárcel), el cual no es concebible desde la perspectiva de los Derechos Humanos ni desde la filosofía del Buen Vivir.

La ruptura de este ciclo, que inicia con un déficit del derecho humano seguido de un déficit de seguridad humana, requiere de tres condicionantes necesarias (aunque pueden ser insuficientes):

- Dotar de nuevos funcionamientos a los excluidos, incrementando sus capacidades y libertades, lo cual se logra con Educación, pues su valor intrínseco e instrumental es la clave para todas las capacidades humanas (Nussbaum, 2006). La metodología para la transferencia de conocimientos debe diseñarse "a la medida", reconociendo las particularidades de esta población.

- Acompañar con asistencia y apoyo institucional a las ex-PPL que se reinsertan a la sociedad; pues enfrentan retos personales de índole social, económico y psicológico que motivan a la reincidencia delictiva, como lo son: cambiar círculos sociales para alejarse del mundo delictivo, pagar deudas adquiridas para su defensa jurí- 
dica además de asumir las multas que el Estado les impone por el delito; retornar a un hogar disfuncional, haber perdido su hogar e incluso no tener un lugar físico al cual volver; entre otros.

- Modificar la cultura vigente que crea estereotipos que devalúan a las PPL y ex-PPL ante la sociedad, estigmatizándolos (Pérez, 2013).

La reintegración de las PPL a la sociedad, sin concederles un umbral mínimo de capacidades y funcionamientos que les permitan ejercer la agencia y superar las causales que las impulsaron hacia la delincuencia, no es ética ni justa socialmente, pues volverían a ser excluidos y la probabilidad de fracaso del sistema sería casi una certeza.

El acceso a educación en las cárceles es clave, no sólo por su carácter terapéutico como elemento reinsertador, resocializador y rehabilitador, sino por ser el ejercicio de un derecho que reduce la situación de vulnerabilidad, debiendo abordarse desde dos perspectivas: la inclusiva, para que las PPL ingresen a un proceso que les permita alcanzar igualdad; y social, para democratizar conocimientos fomentando la participación ciudadana cuando recuperen la libertad.

Considerada un servicio no-negociable, pues debe ser inclusivo sin importar los recursos ni estado de los beneficiarios (Dias, 2008), la educación como derecho está consagrada en diferentes instrumentos políticos y jurídicos, entre los cuales se encuentran:

- La Declaración Americana de los Derechos y Deberes del Hombre, señala que toda persona tiene derecho a la educación bajo los principios de libertad, moralidad y solidaridad (OAS, 1948).

- La Convención Relativa a la Lucha Contra las Discriminaciones en la Esfera de la Enseñanza, manifestó que el acceso universal a la educación es responsabilidad prioritaria del Estado (UNESCO, 1960).

- El Pacto Internacional de Derechos Económicos, Sociales y Culturales adoptado por las Naciones Unidas, comprometió a los Estados a asegurar la disponibilidad, accesibilidad, aceptabilidad y adaptabilidad de la educación, sin discriminación (PIDESC, 1976).

- La Convención Americana sobre Derechos Humanos, conocida como Pacto de San José de Costa Rica, entró en vigencia en 1978 obligando al Estado a crear la normativa necesaria para el ejercicio de los derechos humanos, entre ellos, la Educación; complementada con el Protocolo de San Salvador (1988) donde se agregó que el Estado debe garantizar el ejercicio del derecho a la educación para todos (OEA, 1988).

- La Segunda Reunión de la Declaración Mundial sobre la Educación para Todos de la UNESCO (1990), indica que los excluidos son quienes más necesitan apoyo para superar su desventaja educativa y social, tornándose necesaria la acción del Estado.

- Los Estados participante del Proyecto Regional de Educación para América Latina y el Caribe (PRELAC), aceptaron ser garantes y reguladores del derecho a la educación de calidad para todos, reconociéndolo como un bien público que debe orientarse con mayor intensidad a los excluidos (UNESCO, 2007).

- La Declaración Universal de Derechos Humanos reza por el acceso a la educación de calidad para todos, sin exclusión por condición social, raza, género u otros. (UNESCO, 2008).

- La Conferencia Mundial sobre la Educación Superior (UNESCO, 2009) destacó que la ampliación del acceso a educación superior es responsabilidad de todos, en particular de los gobiernos; debiendo responder a objetivos de equidad, pertinencia y calidad; procurando la inclusión de los menos favorecidos.

Por lo expuesto, las PPL deben gozar de la misma educación que una persona en libertad, en igualdad sustantiva y sin discrimina- 
ción, entendiendo como no-discriminación a la garantía de que todos, con énfasis en los marginados, puedan acceder bajo estándares similares de calidad, a cualquier nivel educativo, incluyendo la educación superior.

Educar a los más necesitados para que aprendan a conocer, a hacer, a vivir juntos y a ser, es tal vez una de las misiones más relegadas en la sociedad pese a ser una de las más valiosas debido a las externalidades positivas que genera, como: crecimiento, profundización de la democracia, incremento de la productividad y los ingresos familiares, mayor cohesión social, desarrollo de ciencia y tecnología, beneficios intergeneracionales, reducción de la fertilidad, mejora de los estándares de nutrición y salud, etc.; empero también contribuye a la mitigación de externalidades negativas, como: reducción de la contaminación, reducción de la morbimortalidad infantil, reducción de la desocupación y la pobreza, reducción de la criminalidad, entre otros (Iturralde, 2005).

Los múltiples beneficios de la educación no se limitan al individuo, sino que se expanden hacia la comunidad, por lo que es deseable que todos, incluyendo las PPL, accedan a una educación de calidad de tal manera que los conocimientos y valores que se transmitan en las instituciones educativas fuera de la cárcel, se transfieran también dentro de sus muros.

Brindar educación superior a las presos es una forma de romper el círculo víctima-victimario-víctima en una estrategia ganar-ganar, a favor de las PPL y de la sociedad, ya que las nuevas capacidades generarían oportunidades futuras, mejorarían la participación democrática y los enriquecería como personas, creándoles un compromiso con la construcción de la paz, el desarrollo comunal y el respeto de los derechos humanos (Valenciano, 2009).

\section{Ecuador da sus primeros pasos}

La Constitución del 2008 marca un cambio de modelo, que requirió de reformas estructurales que intentan crear una sociedad más justa y soli- daria, recuperando el rol del Estado como promotor del desarrollo y promoviendo la planificación participativa desde la visión del Buen Vivir.

En ella se reconoce a la Educación como un derecho a lo largo de toda la vida, un deber ineludible e inexcusable del Estado y un área prioritaria de la política pública y la inversión estatal, garantizando la inclusión y la igualdad en acceso y calidad siendo uno de los ámbitos que conforman al Sistema Nacional de Inclusión y Equidad Social, lo cual incluye a la Educación Superior que se considera indispensable para la construcción del derecho del Buen Vivir (LOES, 2010).

La Carta Magna, en los artículos 5, 203 y 341, reconoce el derecho a la educación de las PPL y ordena la ejecución de planes educativos en los CRS, señalando al Estado como el actor responsable de la reinserción social y económica de este grupo vulnerable.

Los criterios de inclusión, justicia social $y$ equidad que priman en la normativa vigente, crean el marco para desarrollar políticas inclusivas que aborden la rehabilitación y reinserción social con una visión superior a la punitiva, siguiendo los lineamientos de la Convención Interamericana de Derechos Humanos, el Conjunto de Principios para la Protección de Todas las Personas Sometidas a Cualquier Forma de Detención o Prisión y el Pacto Internacional de Derechos Civiles y Políticos, que resaltan la importancia de readaptar socialmente a los internos.

El Código Orgánico Integral Penal, en el Artículo 704, agrega que el Sistema de Rehabilitación Social (SRS) debe promover la Educación Superior suscribiendo convenios con institutos o universidades; estrategia que procura efectivizar los pilares que constituyen al modelo penitenciario: privación de libertad-tratamiento-libertad (Messuti, y otros, 2014).

Consecuentes con la visión del Buen Vivir, el PNBV esboza objetivos de desarrollo que direccionan el accionar público, en el ámbito penitenciario, hacia la construcción de capacidades de las PPL y al robustecimiento del SRS, señalando como responsable y corresponsables, 
entre otros actores, al MJDHC y la SENESCYT, estando la Universidad en calidad de observancia. Entre los objetivos de desarrollo, políticas y lineamientos estratégicos que persiguen este propósito, destacan los siguientes:

Tabla 1. Objetivos de desarrollo, políticas y lineamientos para dar capacidades a las PPL

\begin{tabular}{|c|c|c|}
\hline Objetivo de Desarrollo & Política & Lineamiento estratégico \\
\hline \multirow{2}{*}{$\begin{array}{l}\text { Consolidar la transformación de } \\
\text { la justicia y fortalecer la seguridad } \\
\text { integral, en estricto respeto a los } \\
\text { derechos humanos }\end{array}$} & \multirow[b]{2}{*}{ Consolidar la transformación del SRS } & $\begin{array}{l}\text { b. Proteger los derechos de las } \\
\text { PPL... }\end{array}$ \\
\hline & & $\begin{array}{l}\text { e. Promover acciones de reinserción } \\
\text { social para las personas puestas en } \\
\text { libertad }\end{array}$ \\
\hline $\begin{array}{l}\text { Auspiciar la igualdad, la cohesión, } \\
\text { la inclusión y la equidad social y } \\
\text { territorial, en la diversidad }\end{array}$ & $\begin{array}{l}\text { Garantizar la igualdad en el acceso a ser- } \\
\text { vicios de salud y educación de calidad a } \\
\text { personas y grupos que requieren especial } \\
\text { consideración, por la persistencia de des- } \\
\text { igualdades, exclusión y discriminación }\end{array}$ & \\
\hline \multirow{2}{*}{$\begin{array}{l}\text { Fortalecer las capacidades y po- } \\
\text { tencialidades de la ciudadanía }\end{array}$} & $\begin{array}{l}\text { Alcanzar la universalización en el acceso a } \\
\text { la educación inicial, básica y bachillerato, } \\
\text { y democratizar el acceso a la educación } \\
\text { superior }\end{array}$ & $\begin{array}{l}\text { f. Generar mecanismos de acceso al } \\
\text { sistema educativo para la población } \\
\text { históricamente excluida... PPL... } \\
\text { mediante acciones afirmativas }\end{array}$ \\
\hline & $\begin{array}{l}\text { Promover la culminación de los estudios } \\
\text { en todos los niveles educativos }\end{array}$ & $\begin{array}{l}\text { h. Impulsar los programas de be- } \\
\text { cas... para promover el acceso, per- } \\
\text { manencia y reinserción de la pobla- } \\
\text { ción prioritaria y/o en condición de } \\
\text { vulnerabilidad. }\end{array}$ \\
\hline
\end{tabular}

Fuente: (SENPLADES, 2013)

Elaboración: el autor

Siete años después de haber creado el marco normativo para brindar Educación Superior a las PPL, inició el plan piloto para ofertar estudios universitarios dentro de las cárceles otorgando 435 becas, equivalente a menos del $2 \%$ de la población carcelaria, y cuya distribución no respondió a criterios de equidad entre CRS.

Este pilotaje es un esfuerzo interinstitucional entre el MJDHC, quien administra los CRS facilitando la logística, infraestructura y tecnologías, la SENESCYT que gestiona el proceso de capacitación y rendición de la prueba ENES además que asigna las becas a las PPL, y las Instituciones de Educación Superior (IES) encargadas de la docencia, asignando profesores, diseñando metodologías de enseñanza y evaluando conocimientos.

Las PPL, para acceder a las becas, debían ser bachilleres y aprobar el examen ENES. Cuando el número de PPL que cumplen ambos criterios sobrepasó la oferta de becas, se dio preferencia a quienes obtuvieron mayor calificación en el ENES permitiéndoles escoger primero la carrera. Por ello, existieron PPL que escogieron una carrera que no era su primera opción pues no había cupos en la que querían, mientras que otras no pudieron acceder a la universidad por la insuficiencia de becas.

Las PPL beneficiarias, al recobrar su libertad, mantienen la beca pudiendo continuar sus carreras en la IES donde fueron asignadas cuando estuvieron privadas de la libertad, estas son: la Escuela Superior Politécnica del Ejército (ESPE), la Universidad Politécnica Salesiana (UPS), la Universidad Católica de Santiago de Guayaquil (UCSG), y el Instituto Superior Tecnológico Simón Bolívar (ISTSB), como se observa en la tabla dos.

El modelo de gestión penitenciaria que se intenta implementar, tiene una concepción 
diferente del modelo punitivo, reorientando al sistema hacia la rehabilitación, siendo el acceso a educación de calidad uno de los pilares fundamentales del proceso.

Tabla 2. Carreras, año de inicio de clases y número de becas por Universidad y CRS

\begin{tabular}{|c|l|l|l|l|}
\hline Institución & \multicolumn{1}{|c|}{ Carreras } & \multicolumn{1}{c|}{ CRS } & \multicolumn{1}{c|}{ Año inicio } & \multicolumn{1}{c|}{ Becas } \\
\hline ESPE & Telemática, Logística y transporte & CRS Cotopaxi y CRS Latacunga & 2014 & 168 \\
\hline \multirow{2}{*}{ UPS } & $\begin{array}{l}\text { Administración de empresas, Contabili- } \\
\text { dad y auditoría }\end{array}$ & CRS Guayaquil No 1 & 2015 & 75 \\
\cline { 2 - 5 } & Administración de empresas & CRS Turi & 2016 & 64 \\
\hline \multirow{2}{*}{ UCSG } & $\begin{array}{l}\text { Administración, Derecho, Administra- } \\
\text { ción de empresas turísticas y hoteleras, } \\
\text { Contabilidad y auditoría, Marketing, Tra- } \\
\text { bajo social y desarrollo humano }\end{array}$ & CRS Regional Guayas & 2015 & 102 \\
\hline ISTSB & Mecánica industrial & CRS Regional Guayas & 2015 & 26 \\
\hline
\end{tabular}

Fuente: MJDHC, 2015

Elaboración: el autor

\section{Reflexiones finales}

La delincuencia es un problema social que erróneamente se ha intentado solucionar con la simple privación de la libertad de quien delinque, acción que a veces es socialmente aceptada, pese a ser una forma de violencia contra las PPL que desemboca en la extensión y empeoramiento de la situación negativa (Lutz, 2005).

Concebir las cárceles como cajas de Pandora que concentran los males de la humanidad, no sólo es incorrecto, sino también incompatible con los Derechos Humanos y la visión del Buen Vivir. Cambiar el nombre de la cárcel al de CRS no es algo simplemente discursivo, sino que entraña un profundo cambio institucional para crear un valor agregado social real en vez de convertirse en un ente reproductor de males.

Es aceptado que la exclusión social limita el desarrollo de capacidades que permiten el ejercicio de derechos, vulnerando las libertades individuales, por lo cual es una variable relevante al estudiar la delincuencia, no obstante, por sí sola resulta insuficiente dado que las personas que sufren de exclusión no deben ser consideradas delincuentes ipso-facto.
Colocar a una persona en la cárcel punitiva es exponerlo a un aislamiento social agresivo, sumándolo a una comunidad de marginados con culturas muy diversas en una convivencia forzada donde no predominan los valores socialmente aceptados, motivándolo al consumo de drogas, sin que tenga acceso a tratamientos reales de los desórdenes psicológicos o enfermedades psiquiátricas que pueda padecer, obligándolo a subsistir en un medio donde el saneamiento ambiental es escaso y las enfermedades abundantes, fragmentando el hogar de donde proviene; en fin, sometiéndolo a un nivel de violencia que erosiona sus capacidades, indiferentemente de lo desarrolladas que sean, entorpeciendo aún más el ejercicio de sus libertades que son flageladas desde la "formalidad de una institución", y seguramente lo continuarán siendo en libertad.

Respecto al último punto, se debe tener en cuenta que las PPL realizan fuertes gastos para su defensa, y si son declarados culpables, deben pagar multas e indemnizaciones cuando alcancen su libertad, periodo en que le imposibilitan el acceso al trabajo o les dan acceso sin remuneración, generando presiones económicas sobre su hogar, pues aún existen los costos por 
la educación de sus hijos, la alimentación de su familia, etc., conllevando en muchos casos a un sobreendeudamiento que deberá afrontar al salir de prisión, regresando a un hogar que ha cambiado durante su encierro, e intentando reinsertarse en una comunidad que lo rechaza por sus antecedentes penales.

Frecuentemente, para enfrentar la delincuencia se ha incurrido a una especie de venganza social que se cristaliza en la cárcel punitiva, que erróneamente intenta modificar el comportamiento delictivo basándose en la imagen de personas motivadas por el temor en lugar de factores constructivos, derivando en el fomento de la reincidencia delictiva (Larrauri, 1998); desconociendo que los victimarios fueron inicialmente víctimas, centrándose en la acción directa del delito a través de un inexorable sistema judicial, muchas veces carente de credibilidad, y no en los antecedentes que lo llevaron a realizar dichos actos que son y deben seguir siendo rechazados

Rechazar el acto, y no al ser humano que lo comete, es fundamental al momento de ejercer justicia, pues no se desea destruir a quien delinque (por eso en Ecuador no se acepta la pena de muerte) sino que se desea que esos actos delictivos se minimicen hasta llegar a anularse, debiendo eliminarse las motivaciones que influenciaron a su cometimiento, y paralelamente, otorgarle al interno nuevas capacidades y funcionamientos que hagan factible tal misión, lo que fue expresado por Nelson Mandela de esta manera: "Nadie nace odiando... La gente tiene que aprender a odiar, y si ellos pueden aprender a odiar, también se les puede enseñar a amar, el amor llega más naturalmente al corazón humano que su contrario" (1995, p. 144)

Entonces, las cárceles deben propender a la inclusión social a través del ejercicio de derechos y al desarrollo de capacidades, perspectiva que intenta plasmarse en el modelo de gestión penitenciaria donde la educación inclusiva tiene un rol protagónico y abarca a la Educación Superior.

Respecto a la oferta de Educación Superior en las cárceles, el MJDHC inició un plan piloto que consistió en otorgar 435 becas a internos de diferentes CRS del país quienes, siendo bachilleres, debieron obtener más de 600 puntos en el examen ENES, pero muchos de ellos, pese a que cumplieron ambos requisitos, quedaron excluidos porque el número de becas fue insuficiente y se privilegió a los mejores puntuados.

El proyecto es conceptualmente correcto, ajustándose a los objetivos de desarrollo y a la visión del Buen Vivir, pretendiendo potencializar las capacidades de los beneficiarios, y de tener éxito, incrementará sus libertades reduciendo la reincidencia; pero su implementación no es tarea fácil, pues requiere de la acción comprometida de varios actores en el largo plazo para poder superar las enraizadas barreras del entorno, entre ellas, las diferencias de misiones y visiones que derivan en el enfrentamiento: seguridad vs derechos, y castigo vs rehabilitación, que son producto de la inercia del antiguo modelo que se contrapone al que se desea instaurar.

Aunque no se creó una línea de base, se conoce que los beneficiarios del plan son un grupo heterogéneo que presenta diferentes dificultades, encontrándose PPL con maestría y otros que no han estudiado en años, muchos sin hábitos eficientes de estudio y sin conocer todos los beneficios que brinda la educación superior, todos agobiados por el estrés del encierro, lo que podría reducir su participación en el proceso. Por ello, la metodología de enseñanzaaprendizaje es clave y debería ser evaluada continuamente. La conformación de grupos de apoyo entre estudiantes PPL, como se realizó en el CRS Guayaquil Varones durante el proceso previo a la rendición del examen ENES que le permitió ser la cárcel con mayor cantidad de internos que aprobaron el test, fue una estrategia con buenos resultados por lo que su reactivación, para fomentar la cultura de estudio, es pertinente.

La dotación de materiales didácticos no ha sido del todo superada, provocando dificultades ya que las PPL no pueden realizar actos tan básicos como comprar un esferográfico, y son dependientes de que se los proporcionen; 
además que persiste una diferencia marcada en la infraestructura y tecnología de la oferta universitaria dentro de la cárcel con respecto a la existente fuera de ella, pero también existen diferencias entre Centros, dificultando la transferencia igualitaria de conocimientos.

No se ha realizado un seguimiento profundo de los problemas que enfrentan los becarios en temas relacionados a la drogadicción, alimentación, salud, entre otros; ni tampoco se ha estudiado los motivos de deserción tanto en el contexto de encierro, como de aquellos que obtuvieron su libertad pero desistieron de la beca; impidiendo tomar los correctivos pertinentes para que no continúe esta grave ineficiencia.

Para poner en contexto la complejidad que puede tener el proporcionar educación en las cárceles, se asumirá el caso hipotético de un preso que no ha estudiado hace más de 20 años, tiene hábitos poco beneficiosos para el estudio, es adicto a las drogas y carece de buena salud, además padece de psicopatía no tratada, está mal alimentado y no duerme bien porque está perdiendo a su familia; pero la institución educativa le demanda que se concentre y haga deberes aunque carece de cuadernos porque los intercambio por drogas, y si le dan nuevos, seguramente lo volvería a hacer.

Basta con que ocurra uno de estos eventos para que la implementación del plan sea un desafío, pero cuando son más de dos y en distintos estudiantes con diferente combinación de estos y otros factores negativos, su efectividad se vuelve imposible sin el acompañamiento de otros actores como el Ministerio de Salud, la Policía Nacional, ONG, familiares del interno, etc.; es decir, que se requiere de toda la comunidad penitenciaria y no solamente de los profesores universitarios o de varios funcionarios del Ministerio de Justicia, quienes pueden tener las mejores intenciones y estar empoderados del proyecto, pero aún sus mayores esfuerzos serían insuficientes ante tan magna tarea caracterizada por un contexto cambiante y hostil, donde los avances pueden ser lentos pero los retrocesos agresivos.
El cumplimiento íntegro de los derechos humanos de las PPL, tanto en aspectos físicos como la correcta alimentación, el cuidado de la salud, la eliminación de la insalubridad y hacinamiento, etc.; y aspectos emocionales como el apoyo de sus seres queridos, el trato digno, entre otros; es una condición necesaria más no suficiente para que el SRS funcione, y con él, los proyectos emblemáticos como la provisión de Educación Superior en las cárceles.

La iniciativa, nueva en Ecuador pero no en América Latina, es teóricamente consistente, y aunque la cobertura es limitada, ha generado expectativas positivas sobre sus posibles productos. Vencer los múltiples obstáculos es imposible sin un monitoreo objetivo y multidisciplinario, que preferentemente debe ser realizado por agentes exógenos pero generando espacios para que los actores directos, no sólo agentes públicos sino también las PPL y sus familias debidamente representadas, tengan voz; permitiendo la identificación oportuna de desvíos así como la generación de correctivos, constituyéndose en un mecanismo relevante para el éxito del plan.

Ergo, el diseño participativo y la co-implementación de herramientas de seguimiento y evaluación, pueden ser ejecutadas no sólo por el Ministerio rector, sino también por un Observatorio Penitenciario que surgiría como una alternativa pertinente para medir los resultados, tanto de este proyecto como de la implementación global del SRS, abordando la etapa de encierro de las PPL y su posterior reinserción, evaluando los resultados e impactos, esto es, el cambio en la vida de los beneficiarios y la comunidad una vez que los internos recuperen su libertad, revelando en qué medida el sistema cumple su propósito aportando a la visión del Buen Vivir.

Las leyes y los discursos no cambian realidades, sino la acción directa de los actores, direccionados por un objetivo compartido cuyo resultado es deseado por todos. Aceptando el reto, Ecuador ha creado el marco, constituido por las normas que legitiman la acción, el lienzo se ha colocado a través de la planificación central 
y los objetivos de desarrollo, y se han dado los primeros trazos con el plan piloto que comprende al MJDHC, la SENESCYT y la Universidad; no obstante el cuadro final aún no está culminado.

Los costos económicos de estos programas difícilmente serán mayores a los costos sociales de la delincuencia, por lo cual la atención a las PPL es necesaria y urgente, más aún al considerar que en el marco del Buen Vivir, no hay espacio para la exclusión, así como en la era del conocimiento la verdadera inclusión es la inclusión en el conocimiento (Aguerrondo, 2008).

\section{Referencias bibliográficas}

Aguerrondo, I. (2008). Políticas de educación inclusiva. Conferencia Internacional de Educación (15-18). UNESCO.

Celis, R., \& Sepúlveda, C. (2012). Contra el despojo. Capitalismo, degradación ambiental y desplazamiento forzado. Bilbao: CEAR.

Constitución de la República del Ecuador. (2008). Ciudad Alfaro: Asamblea Constituyente.

Correa, R. (diciembre de 2008). Intervención conferencia magistral sobre el socialismo del siglo XXI. Recuperado de https://goo.gl/i9LDG2

Dias, J. (2008). Calidad, pertinencia y responsabilidad social de la universidad latinoamericana y caribeña. Tendencias de la Educación Superior en América Latina y el Caribe (87112). Cartagena: UNESCO.

Flores, P. (2005). Educación Superior y Desarrollo Humano. El caso de tres universidades tecnológicas. México: ANUIES - UIA.

INEA (2013). Educación para adultos en contexto de encierro. México: Instituto Nacional para la Educación de los Adultos.

Iturralde, C. (2005). Educación pública frente a educación privada en zonas urbano marginales de Guayaquil. Estudio de caso en Los Vergeles. Quito: FLACSO.

Larrauri, E. (1998). Criminología crítica: abolicionismo y garantismo. Lus et Praxis, 4(2), 27-64. Recuperado de https://goo.gl/wPBsqC

Ley Orgánica de Educación Superior (2010). Quito: Asamblea Nacional.

London, S., \& Formichella, M. (2006). El concepto de desarrollo de Sen y su vincula- ción con la Educación. Revista Economía y Sociedad, XI(17), 17-32. Recuperado de https://goo.gl/ulmZGT

Lutz, B. (2005). Reseña de 'Michel Foucault' y las prisiones de François Boullant. Revista Economía, Sociedad y Territorio, V(19), 659665. Recuperado de https://goo.gl/j1LNo3

Mandela, N. (1995). Un largo camino hacia la libertad. Madrid: Aguilar.

Messuti, A., Matus, J. P., Carrasco, E., Lagunas, C., Senesi, C., Eidem, M., y otros (2014). La rehabilitación social en el contexto latinoamericano. Quito: Ministerio de Justicia, Derechos Humanos y Cultos.

MJDHC (15 de mayo de 2015). Estado ecuatoriano promueve acceso a educación superior y técnica para PPL. Recuperado de https://goo.gl/tgkEfF

Nussbaum, M. (2006). Frontiers of justice. Disability, nationality, species membership. Londres: Belknap Press.

OAS (1948). Declaración Americana de los Derechos Humanos y Deberes del Hombre. Bogotá: OEA.

Obando, N., \& Ruiz, C. (2007). Determinantes socioeconómicos de la delincuencia: Una primera aproximación al problema a nivel provincial. Lima: CIES-CEDEP.

OEA (1988). Protocolo adicional a la Convención Americana sobre Derechos Humanos en materia de Derechos Económicos, Sociales y Culturales. Recuperado de https://goo.gl/fN2qVv

Parchuc, J. P. (2015). La Universidad en la cárcel: teoría, debates, acciones. Revista Redes de Extensión (1), 18-36. Recuperado de https://goo.gl/fs2Dyr

Pérez, C. (2013). Marcando al delincuente: estigmatización, castigo y cumplimiento del derecho. Revista Mexicana de Sociología, 75(2), 287311. Recuperado de https://goo.gl/gKJQyP

PIDESC (3 de enero de 1976). Pacto Internacional de Derechos Económicos, Sociales y Culturales. Recuperado de https://goo.gl/Fybgud

Ramírez, R. (2008). Igualmente pobres, desigualmente ricos. Quito: Ariel.

Scarfó, F. (2003). El derecho a la educación en las cárceles como garantía de la educación en derechos humanos. Revista IIDH, 36, 291 - 324. Recuperado de https://goo.gl/qADhGd

Scarfó, F. (2008). La educación pública en los establecimientos penitenciarios en Latinoamérica: garantía de una igualdad sustantiva. Educación 
en prisiones en Latinoamérica (111-142). Brasilia: UNESCO.

Sen, A. (2000). Desarrollo y libertad. Buenos Aires: Planeta.

SENPLADES (2012). ¡A (re)distribuir! Ecuador para todos. Quito: Secretaría Nacional de Planificación y Desarrollo.

SENPLADES (2013). Plan Nacional para el Buen Vivir 2013 - 2017. Quito: Secretaría Nacional de Planificación y Desarrollo.

UNESCO (14 de diciembre de 1960). Convención relativa a la Lucha Contra las Discriminaciones en la Esfera de la Enseñanza. Recuperado de https://goo.gl//ktb4AD

UNESCO (9 de marzo de 1990). Declaración Mundial sobre la Educación para Todos. Recuperado de https://goo.gl/Npa7e5

UNESCO (30 de marzo de 2007). Situación educativa de América Latina y el Caribe: Garantizando la Educación de Calidad para Todos. Recuperado de https://goo.gl/jDgiPP
UNESCO (10 de diciembre de 2008). Declaración Universal de Derechos Humanos. Recuperado de https://goo.gl/a7XLnH

UNESCO (2009). La nueva dinámica de la educación superior y la investigación para el cambio social y el desarrollo. Conferencia Mundial sobre la Educación Superior - 2009 (1-9). París: United Nations Educational, Scientificard and Cultural Organizations.

UNESCO (2015). La educación para todos, 2000 2015: logros y desafío. París: Organización de las Naciones Unidas para la Educación la Ciencia y la Cultura.

Urquijo, M. (2014). La teoría de las capacidades en Amartya Sen. Revista Edetania, 63-80. Recuperado de https://goo.gl/iGbXmr

Valenciano, G. (2009). Construyendo un concepto de educación inclusiva: Una experiencia compartida. En M. Sarto, \& M. Venegas, Aspectos clave de la educación inclusiva. 1ra. ed. (1324). Salamanca: INICO. 


\title{
Trayectoria de la Universidad Intercultural del Estado de Puebla (UIEP), México
}

\section{Trajectory of the Intercultural University of the State of Puebla (UIEP in Spanish), Mexico}

\begin{abstract}
Dr. Laurentino Lucas Campo es Docente investigador de la Universidad Intercultural del Estado de Puebla (México) (laurentino.lucas@uiep.edu.mx) (https://orcid.org/0000-0002-6912-2538)
\end{abstract}

Fanny Cruz García es profesora investigadora de la Universidad Intercultural del Estado de Puebla (México) (fanny.cruz@uiep.edu.mx) (https://orcid.org/0000-0002-8361-4424)

Recibido: 2017-08-03 / Revisado: 2017-09-12 / Aceptado: 2017-11-13 / Publicado: 2018-01-01

\section{Resumen}

Este escrito refiere al trabajo impulsado para brindar una opción de educación superior a la población que habita una de las regiones culturales representativas de México: el Totonacapan. En esa área cultural coexisten totonacos, nahuas y los denominados no indígenas y se ha establecido para todos ellos la Universidad Intercultural del Estado de Puebla (UIEP), la cual lleva diez años de camino andado. El objetivo de la presente comunicación es dar cuenta del funcionamiento de la UIEP para iniciar un análisis sobre qué tanto esta universidad ha logrado cumplir con el propósito para el cual fueron creadas las Universidades Interculturales (UI) en México. El abordaje del presente estudio se hace desde la reflexión y análisis de quienes pertenecen a la institución como profesores e investigadores de tiempo completo lo cual se ha derivado del trabajo colegiado en el que han colaborado en dicha institución. Los principales hallazgos que se presentan tienen estrecha relación con las tres funciones sustantivas o primordiales de las Ul's: La docencia, la investigación y la vinculación con la comunidad. Se concluye que tanto los avances, las contradicciones, los conflictos, así como las perspectivas del futuro inmediato abonan al crecimiento y desarrollo de la institución siempre y cuando no se pierda de vista su función educativa.

Descriptores: Educación, superior, intercultural, pueblos originarios, vinculación con la comunidad, México.

Forma sugerida de citar: Lucas Campo, L., y Cruz García, F. (2018). Trayectoria de la Universidad Intercultural del Estado de Puebla (UIEP), México. Alteridad, 13(1), 96-107. https://doi.org/10.17163/alt.v13n1.2018.07. 


\begin{abstract}
This paper refers to the work carried out to provide a higher education option to the population that inhabits one of the representative cultural regions of Mexico: the Totonacapan. In this cultural area the Totonacs, Nahuas and the denominated non-indigenous coexist. The Intercultural University of the State of Puebla (UIEP in Spanish) has been established for all of them, which has ten years of road traveled. The purpose of this written communication is to explain the operation of the UIEP to start an analysis of how much the intercultural universities $(\mathrm{UI})$ have managed to fulfill the purpose for which they were created in Mexico. The approach of the
\end{abstract}

\section{Introducción. La fundación de la UIEP en Huehuetla}

Desde principios del año 2000, la población totonaca y varias organizaciones demandaban una institución que brindara una educación considerando la especificidad lingüística y cultural de dicha población. ${ }^{1}$ Sin embargo, la exigencia de una institución de educación superior para los pueblos originarios en la sierra nororiental fue coyuntural con el impulso 'desde arriba' de la política de educación intercultural (Mateos y Dietz, 2013), con la creación de la Coordinación General de Educación Intercultural y Bilingüe (CGEIB) en el año 2001. Dicha instancia impulsó la creación de universidades interculturales en varias entidades federativas de la República Mexicana con el propósito de favorecer la inclusión de la población indígena (sic) en la generación del conocimiento (Casillas y Santini, 2009, p.39). En el estado de Puebla, a principios de la década del 2000 se tenía el dilema de dónde se instalaría la institución. El asunto se resolvió más por cuestiones de tipo político partidista, porque el grupo en el poder en aquellos años en el municipio de Huehuetla propuso su localidad de Lipuntahuaca para construir la UIEP (Mena, 2012, pp. 56-58).

El funcionamiento de la UIEP comenzó en el 2006. Durante sus primeros seis años tuvo resultados que pueden considerarse poco alentadores, por ejemplo tuvo baja eficiencia terminal present study is made from the reflection and analysis of those who belong to the institution as full-time professors and researchers, which has been derived from the collegial work in which they have collaborated within this institution. The main findings are closely related to the three substantive or primordial functions of IUs: teaching, research and community engagement. It is concluded that the advances, contradictions, conflicts, as well as the prospects for the immediate future contribute to the growth and development of the institution as long as its educational function is not lost.

Keywords: Education, superior, intercultural, indigenous peoples, community engagement, Mexico.

de sus egresados (64\% y $69 \%$ en las licenciaturas en Desarrollo sustentable y Lengua y Cultura, respectivamente). De esa manera, en el año 2013 se vivió una crisis en la universidad. Esto se debió a ciertas tensiones en las que se vio inmersa la institución. Existen versiones distintas del inicio de este conflicto, donde confluyeron razones políticas, académicas y estudiantiles. ${ }^{2}$

Derivado del conflicto, en 2013 se produjeron cambios en la dirección de la universidad. A partir de ese momento el representante de la rectoría y las áreas de dirección comenzaron una reestructuración y redefinición del rumbo de la institución. Resultado de ello, se han llevado a cabo distintas acciones como la apertura en agosto de 2015 de dos nuevas licenciaturas, lo que ha significado aumentar la matrícula escolar. Se construyeron nuevas instalaciones: dos edificios para residencias universitarias y dos edificios para el área de salud. Se vislumbra la creación de un programa educativo de maestría para 2018 y se ha logrado elevar el reconocimiento positivo de la institución a nivel regional, estatal y nacional.

Este trabajo presenta el estado del arte que se refiere a la investigación en educación superior con/por/para pueblos indígenas en América Latina; enseguida se describe el sustento metodológico del trabajo. Posteriormente, se aborda el funcionamiento de la UIEP en los rubros de docencia, investigación y vinculación con la 
comunidad para plantear la discusión y las conclusiones en torno a los retos y dificultades que tiene una institución de educación superior con las características de la UIEP.

\subsection{La educación superior para pue- blos indígenas}

La educación superior para indígenas, tema relativamente reciente, es un campo en el que se ha registrado un avance en el interés investigativo. En América Latina, los estudios más relevantes son los que han estado bajo la coordinación de Daniel Mato e impulsados por el Instituto Internacional para la Educación Superior en América Latina y el Caribe (IESALC-UNESCO). Los materiales generados y los distintos colaboradores dan cuenta de las perspectivas que se han abordado, si bien se pone en el centro de la discusión a la educación superior y los pueblos indígenas, también se entrecruzan con otros aspectos. En dichos materiales, se abordan desde las experiencias de educación superior existentes en ese momento (Mato, 2008); de la colaboración intercultural y desarrollo sostenible (Mato, 2009a) que refiere no únicamente la educación intercultural sino la formación de distintos profesionales; de los procesos de construcción, logros, innovaciones y desafíos de las instituciones interculturales de nivel superior (Mato, 2009b); acerca de las constituciones, leyes, políticas públicas y prácticas institucionales y experiencias tanto de indígenas como de afrodescendientes (Mato, 2012); y más recientemente de las experiencias (Mato, 2015) y los desafíos de tales tipos de instituciones (Mato, 2016) que se logran identificar en los países latinoamericanos.

En México las Universidades Interculturales (UI) son producto de varios procesos sociales así como de específicas políticas educativas nacionales como internacionales (Jablonska, 2010; Bastida, 2012). A una década de existencia de dicho modelo, ha llevado a ser analizadas como un campo temático particular relativa- mente nuevo (Dietz y Mateos, 2011; Mateos y Dietz, 2016). De las once UI's existentes, cada una ha tenido una trayectoria específica debido a las condiciones contextuales de la región y de la entidad federativa donde se ubican. En términos de investigación las UI están muy poco estudiadas. De los trabajos revisados que refieren la experiencia de México de sólo algunas instituciones de educación superior o instancias que llevan a cabo acciones en este ámbito, mencionamos las que hemos identificado: Universidad Intercultural de Chiapas (Fábregas Puig, 2008, 2009); Universidad Autónoma Indígena de México (UAIM) (Guerra García, 2008; Guerra García y Meza Hernández, 2009); Universidad Veracruzana Intercultural (Dietz, 2008; Meseguer, 2016); Universidad Intercultural Maya de Quintana Roo (Hernández Silva, 2012) Universidad Comunitaria de San Luis Potosí (Silva, 2009). Se identifica que hay sólo 4 casos abordados de universidades interculturales de México. Mientras que también se abordan experiencias de otras modalidades que se enfocan en la atención de pueblos originarios o de contextos rurales, como el Centro de Estudios Ayuuk-Universidad Indígena Intercultural Ayuuk (Estrada, 2008); políticas públicas de las instituciones y programas interculturales de educación superior en México (Bastida Muñoz, 2012); La Universidad Campesina Indígena en Red (UCIRED) (Hernández y Manjarrez, 2016); así como el Programa Universitario de Estudios de la Diversidad Cultural y la Interculturalidad (PUIC), de la Universidad Nacional Autónoma de México (UNAM) (Del Val Blanco, 2016).

En ese sentido, no existen muchos trabajos que las aborden como objeto de investigación o reflexión. Por lo que nos parece relevante presentar en esta entrega el caso de la Universidad Intercultural del Estado de Puebla (UIEP). De los trabajos que se centran en la UIEP identificamos el de Deance y Vázquez (2010) acerca de la lengua originaria. El de Mena (2012) centrado en el impacto del mode- 
lo intercultural en la etnogénesis de la identidad de los estudiantes. En el presente escrito se abordan los resultados del trabajo colegiado del profesorado que participa predominantemente en la licenciatura en Lengua y Cultura en la UIEP, la cual en 2016 ha cumplido diez años de estar en funcionamiento.

\section{Metodología}

Este trabajo deriva de una serie de reuniones colegiadas llevadas a cabo durante 2015 y 2016 por los integrantes de la Academia de la licenciatura en Lengua y Cultura la cual ha estado conformada en promedio por nueve profesores-investigadores de tiempo completo y dos profesores por asignatura. Se recuperan las opiniones y las experiencias de quienes están involucrados directamente en las diversas actividades académicas y administrativas de la institución. Algunos de estos actores se encuentran laborando en la universidad desde sus inicios, 2006 o 2007. Otros se encuentran laborando desde 2013 o 2015 entre ellos los autores de este trabajo. Quienes escriben este texto han sido partícipes de tales actividades. Además de que se reconocen parte de los pueblos originarios Tutunakú y Mixteco, respectivamente.

Las reuniones colectivas de las cuales se ha derivado el presente trabajo se han realizado para llevar a cabo, entre otras actividades, la "Evaluación y Actualización del Programa Educativo en Lengua y Cultura" y la creación del "Programa Educativo de nivel Maestría". Primeramente, la Evaluación del Programa Educativo en Lengua y Cultura se llevó a cabo con la participación de los profesores en 2015. Posteriormente, la Actualización del Programa Educativo en Lengua y Cultura se ha realizado a partir de enero de 2017 con la participación de todos los profesores que imparten clases predominantemente en la licenciatura mencionada. Asimismo, las reuniones de trabajo para impulsar la apertura de un Programa de nivel
Maestría también han sido una oportunidad de reflexión sobre el modelo educativo basado en la educación intercultural bilingüe. Estas oportunidades del trabajo colectivo corresponden a una metodología cualitativa para analizar la propia práctica de docencia, investigación y vinculación.

\section{Resultados}

A continuación se presentan algunos señalamientos que son el resultado de la reflexión del trabajo en las tres áreas sustantivas de las UI's: La docencia, la investigación y la Vinculación con la Comunidad. Primeramente, se plantea cómo se ha desarrollado la práctica docente y cómo ha incidido en la formación académica de los estudiantes. Después, se expone cómo se han trabajado los proyectos de investigación científica en el marco de las distintas actividades institucionales. Finalmente, se presenta una semblanza de cómo se ha llevado a cabo la Vinculación con la Comunidad los avances, retos y horizontes de posibilidad.

\subsection{La actividad docente y los requeri- mientos institucionales}

El aula no se ha convertido, totalmente, en un espacio para propiciar un diálogo de saberes en donde confluyan los conocimientos de los pueblos originarios y los conocimientos científicos. Las razones que no han permitido lograr ese propósito son variados. Uno de ellos es la excesiva carga de horas/clase de los docentes. Para atender el gradual aumento de la matrícula estudiantil, los docentes en ocasiones se han hecho cargo de impartir hasta seis asignaturas en un semestre. Además, han tenido que responsabilizarse de comisiones distintas a la docencia, que se les asignan, las cuales deben atender a veces en el inmediato o en el corto plazo. Esto ha hecho que la carga de trabajo de los docentes sea demasiada y que tales responsabilidades las tengan que 
atender incluso fuera del horario laboral establecido. El argumento de la autoridad universitaria es que las instancias estatales ni federales han autorizado mayor presupuesto para ampliar la contratación de más personal no sólo docente sino también administrativo.

Otro proceso que ha incidido en la práctica docente y en la formación profesional de los jóvenes es la difusión de la oferta educativa de la UIEP. Desde 2013 hasta el primer semestre de 2016, se organizaban visitas a los distintos bachilleratos ubicados en los municipios circundantes a la universidad. Se designaba a uno o dos profesores y en compañía de algunos estudiantes, de dos a cinco, de las diferentes carreras, se dirigían a los bachilleratos para dar a conocer la oferta educativa mostrar imágenes de las instalaciones y explicar los tipos de becas nacionales o internacionales con las cuales se pueden beneficiar los universitarios. De acuerdo al lugar a donde se fuera y según la distancia, el tiempo empleado iba de medio día hasta dos o tres días en una semana. Esto originaba distintas consecuencias: al no estar los docentes se interrumpían las clases, lo que derivaba en el retraso en el avance de la planeación didáctica del semestre escolar. Esta dinámica originó inconformidades en docentes y alumnos. Para remediar lo anterior, se planteó otra estrategia. A partir del segundo semestre de 2016 se programan en días y horarios específicos visitas de los bachilleratos existentes en la región a la UIEP. Por lo menos un docente de cada carrera profesional comparte la información necesaria de la carrera donde participa y los jóvenes conocen las instalaciones, equipos y servicios de la institución. La nueva estrategia ha significado que la difusión de la oferta educativa no sea una causa para propiciar la ausencia tanto de profesores como estudiantes ni la interrupción constante de clases.

En cuanto al trabajo colegiado de los docentes, por ejemplo las Academias, conformadas por profesores que imparten clases en la misma licenciatura, no se ha podido lograr un trabajo continuo y consistente, porque en muy pocas ocasiones pueden coincidir en horarios para trabajar en conjunto. Lo anterior ha ocasionado mucha dificultad para dar seguimiento puntual a diversas tareas institucionales y atender las necesidades académicas de los estudiantes en las distintas licenciaturas.

En materia de contratación laboral hasta 2013, se realizaba de manera semestral. Eso implicó mucha rotación de personal docente, lo cual incidió en que los procesos administrativos y académicos quedaran inconclusos o se vieran interrumpidos constantemente. Desde 2014 a la fecha 2017, aunque la contratación es anual sigue presente la inestabilidad laboral y la rotación del personal docente.

\subsubsection{La enseñanza de las lenguas originarias}

Las UI's promueven la enseñanza de las lenguas originarias como un eje central de su modelo educativo. Sin embargo, en la UIEP esta propuesta se encuentra en construcción. El manejo pedagógico de la enseñanza de la lengua originaria se vuelve un asunto de suma importancia pero también es un aspecto complejo en su abordaje en cuanto a los grados del dominio de la lengua originaria (Deance y Vázquez, 2010). Esto se debe a que algunos la hablan pero no la escriben o hay hablantes pasivos; es decir, los que la hablan poco o los que la entienden pero no la hablan.

Aproximadamente el $40 \%$ de los estudiantes de la UIEP hablan la lengua tutunakú. Asimismo los monolingües en español representan también un $40 \%$ y aproximadamente el 15\% habla náhuatl. El 10\% restante habla las demás lenguas existentes en el estado de Puebla (N'guiva, Ha shuta enima, Hñähñü, Nuu savi) (Informe Anual, 2016, p. 5).

En 2015, se trabajó para establecer en la universidad un criterio metodológico en la enseñanza de la lengua originaria. Por lo tanto, desde esa fecha y en la actualidad la matrícula escolar se divide en dos tipos de poblaciones: los hablantes 
de alguna lengua originaria para desarrollar la lecto-escritura y los que desean aprenderla como segunda lengua. Es en este segundo grupo donde se incluyen a los monolingües en español. De ese modo para la enseñanza de náhuatl o totonaco, se recurre a esta clasificación para hacer un manejo pedagógico más adecuado de la enseñanza de dichos idiomas. Los hablantes de N'guiva (popoloca), Ha shuta enima (mazateco), Hñähñü (otomí), Nuu savi (mixteco) forman un grupo los cuales trabajan con una metodología que reconoce su competencia lingüística de hablantes y reflexionan sobre los elementos gramaticales de su lengua para desarrollar su escritura.

Un reto para los profesores responsables de las clases de la lengua originaria es establecer los contenidos por semestre escolar para determinar cuáles serían los conocimientos y habilidades lingüísticas que deben alcanzar los estudiantes para medir su dominio de la lengua en nivel básico, intermedio y avanzado.

\subsubsection{El "diálogo de saberes" en la práctica docen- te: ¿realidad o aspiración?}

El modelo de la universidad intercultural promueve el reconocimiento de la diversidad cultural y epistémica, por lo que se plantea el 'diálogo de saberes' entre los conocimientos científicos en conjunción con los conocimientos tradicionales de los pueblos originarios para identificar o resolver las necesidades y problemáticas más apremiantes que tales pueblos padecen.

En el debate acerca de los conocimientos y saberes, autores distintos establecen la necesidad del diálogo de saberes (Leff, 2006) o el reconocimiento de otros conocimientos que regularmente han sido relegados y constituidos como 'no existentes' (Santos, 2012) reconociendo la existencia de distintos sistemas epistémicos que permitirían la explicación de los fenómenos y los problemas desde distintos ángulos y sobre todo, para atenderlos desde las distintas miradas, sustentadas en un pluralismo epistemológico.
Ante el planteamiento anterior, se identifica que la mayoría de la planta docente no logra percibir la especificidad del modelo de universidad intercultural, por lo que continúan reproduciendo sus prácticas docentes y académicas convencionales, además de los principios epistemológicos desde los cuales han sido formados en las áreas de conocimientos según sus perfiles profesionales.

Tanto en la formación de los estudiantes como en los trabajos de investigación se les continúa dando un peso muy fuerte a la perspectiva científica, por lo que se sigue reproduciendo una mirada donde los conocimientos que los pueblos originarios generan, ponen en práctica y reproducen quedan relegados en el proceso formativo de los jóvenes y futuros profesionales. Esto se debe a distintos factores, desde la formación profesional de los profesores que llegan a colaborar a la UIEP, como por la nula información sobre el modelo de educación superior de las universidades interculturales que se les puede compartir a los docentes en su inicial incorporación a la institución.

\subsection{La investigación: procesos discontinuos}

Las investigaciones en la UIEP carecen de financiamiento, por lo que instancias como el Programa para el Desarrollo Profesional Docente de tipo superior (PRODEP) o el Consejo Nacional de Ciencia y Tecnología (CONACYT) asumen ese papel. Por otra parte, las actividades de investigación son constantemente interrumpidas por distintos factores entre ellos la excesiva carga académica y administrativa asignada a los docentes, la rotación de personal en la universidad, el criterio para contratar al personal docente, el no reconocimiento del trabajo colegiado por Academias y el poco tiempo asignado y las dificultades para coincidir y realizar dicha actividad investigativa en conjunto en los Cuerpos Académicos. 
Por otra parte, también se decidió reemplazar de manera gradual a los perfiles docentes existentes en ese momento. Desde 2014 los perfiles docentes con el grado de doctorado se han incrementado significativamente. En el segundo semestre de 2016 el 50\% de la planta académica cuenta con grado de doctorado, mientras un 16\% está reconocido en el Sistema Nacional de Investigadores (SNI) (Informe anual, 2016, pp. 6-8). A pesar de ser contratados como docentesinvestigadores se les asignan muchas asignaturas y numerosas comisiones administrativas o de gestión que no les permiten realizar en condiciones idóneas su función docente, de investigación para la generación de conocimiento, así como la Vinculación con la Comunidad. Sólo hasta inicios del 2017 se ha logrado "descargar" de la excesiva docencia a los académicos, pero únicamente a los docentes que han sido reconocidos en el SNI. En tanto que a los demás profesores aún les son asignadas excesiva carga docente.

En la UIEP sólo se cuenta con dos Cuerpos Académicos (CA) reconocidos, ambos en el nivel de "En formación". ${ }^{3}$ Los miembros de tales colectivos, al tener que solventar los distintos asuntos de la institución, ya mencionados, no les ha sido posible lograr dar un impulso ni consolidar la actividad investigativa en conjunto. Si bien existen experiencias de proyectos de investigación financiados por PRODEP, seis en el año 20152016, y diez en 2016 de toda la planta docente, conformada por 32 profesores, sigue sin consolidarse un trabajo colectivo para la generación de conocimiento de manera continua y estable. En especial se han logrado impulsar los proyectos de investigación de docentes con doctorado y existe gran dificultad para que docentes con grado de maestría logren consolidar sus intereses intelectuales a través de proyectos de investigación, toda vez que PRODEP o CONACYT sólo otorgan financiamiento a los doctores. Por lo que los CA se vuelven el espacio idóneo para impulsar las líneas de investigación de académicos con maestría.

\subsection{La Vinculación con la Comunidad y su trompicado camino}

Otra de las funciones sustantivas de las universidades interculturales es la Vinculación con la Comunidad, la cual no cuenta con financiamiento por parte de la universidad. De acuerdo al documento para fundamentar el modelo de universidades interculturales, se establece que la finalidad de esta acción educativa es la de "impulsar acciones de vinculación con la comunidad que ofrezcan soluciones a los problemas y necesidades locales y regionales, y a sus procesos de gestión e innovación" (Casillas y Santini, 2009, p. 146). Se enfatiza este ejercicio como "un conjunto de actividades que implica la planeación, organización, operación y evaluación de acciones en que la docencia y la investigación se relacionan internamente en el ámbito universitario y externamente con las comunidades para la atención de problemáticas y necesidades específicas" (Casillas y Santini, 2009, p. 153). Debido a distintas circunstancias, no se cuentan con datos suficientemente veraces para reconstruir la manera en que se realizaba la Vinculación con la Comunidad entre 2006 y 2013, por lo que en este documento sólo se refiere lo que ha acontecido a partir de 2013.

En 2013 hubo un momento de transición, debido a que una nueva administración tomó a su cargo el rumbo de la UIEP, quienes decidieron hacer una pausa, donde nadie salió a realizar la vinculación comunitaria. Se rediseñó la estrategia y el criterio que la comenzó a orientar fue el de considerar los convenios que la UIEP había establecido o los que se acordaran a partir de ese momento con algunos gobiernos municipales de la región. Dichos convenios fortalecen una política de inclusión a la educación superior de jóvenes pertenecientes a pueblos originarios. Además se buscó garantizar por parte del $\mathrm{H}$. Ayuntamiento Municipal el apoyo de hospedaje y alimentación para los aspirantes interesados en ingresar a estudiar en la UIEP. En 2014, ese 
fue el criterio institucional para llevar a cabo la Vinculación con la Comunidad.

En cuanto a la participación de los estudiantes, anteriormente se conformaban brigadas multidisciplinarias, estudiantes de diferentes licenciaturas acudían a una comunidad, pero a partir de 2014 las brigadas fueron conformadas por licenciatura. Así, éstas se atomizaron, es decir, sólo se conformaron con integrantes de la misma licenciatura o ingeniería de distintos semestres con la finalidad de atender un requerimiento específico del ámbito de conocimiento de la licenciatura o ingeniería hecho por la autoridad municipal.

Tener el convenio con algún municipio en algunos casos ha permitido dar seguimiento constante al proyecto requerido. Algunos docentes han aprovechado esta estrategia institucional para innovar proyectos relacionados a su respectiva línea de investigación. De esa manera, son ellos los que le proponen o presentan al Ayuntamiento Municipal un proyecto. Así, en el segundo semestre del 2015 se realizaron varios proyectos acordes a las investigaciones de los docentes que incluso fueron apoyados por PRODEP y/o CONACYT. Realizada de este modo, la vinculación con la comunidad logra tener resultados significativos en la atención de los problemas sentidos por la comunidad social, a su vez se logra llevar a cabo investigación seria que puede desembocar en la propuesta de soluciones en conjunto con las comunidades donde se lleva a cabo dicha actividad.

Por otra parte, en varios municipios aún no se logra consolidar el quehacer de la universidad por lo tanto se han realizado proyectos "de última hora" lo cual ha desencadenado una logística de forma apresurada. Esto ha tenido como consecuencia que las brigadas estudiantiles no han encontrado sentido a la Vinculación con la Comunidad, lo que ha generado distintas problemáticas al interior de cada carrera y de la institución en general.

\section{Discusión}

La actual administración de la UIEP (2013-2017) ha logrado muchos cambios. Ha incrementado la matrícula estudiantil en la cual se han integrado jóvenes de otras culturas, ha aumentado la infraestructura, ha cambiado el perfil en la planta docente lo cual ha permitido el aumento de las posibilidades de investigación. Se están explorando nuevos horizontes para consolidar la vinculación con la comunidad. Sin embargo, no se ha logrado contrarrestar la excesiva rotación de personal académico lo cual tiene implicaciones en los procesos de enseñanza aprendizaje, al no poder dar continuidad a la formación de los estudiantes ni lograr que los docentes vislumbren proyectos de largo plazo ni de largo alcance en el desempeño académico. Aunado a ello, aún predomina la reproducción de la formación profesional "convencional" de la mayoría de los docentes, situación que no coadyuva a desarrollar el modelo educativo de la educación intercultural bilingüe.

La incipiente puesta en práctica de una metodología para la enseñanza de lenguas originarias en el modelo de UI tiene un largo camino que recorrer. No se aprovecha el potencial de los estudiantes como sujetos biculturales-bilingües. No se está aprovechando el aula escolar como un espacio ideal para desarrollar la interacción entre distintas culturas y lenguas; es decir no se hace fructífera la diversidad cultural y lingüística presente en el aula para experimentar y desarrollar la interculturalidad.

Por su parte, la investigación científica en la UIEP carece de financiamiento, en la mayoría de los casos, sigue siendo "convencional". Por lo tanto, la universidad aún no tiene grandes resultados para ampliar y abonar la discusión en torno a la epistemología de los pueblos originarios. En ese sentido aún falta generar criterios que permitan a las Universidades Interculturales, ser evaluados empero considerando su especificidad. 
En relación a la Vinculación con la Comunidad, aunque se ha modificado para reconocer y/o lograr resolver alguna necesidad o requerimiento que la autoridad municipal ha identificado aún se encuentra lejos de cumplir con el propósito de generar procesos mediante metodologías participativas donde se analicen los problemas o necesidades reales junto con la comunidad. Además, la vinculación comunitaria ha significado un ejercicio institucional, en el que una vez por semestre durante dos semanas tanto estudiantes como docentes "salen a vinculación”. Este lapso de tiempo es insuficiente para lograr resultados adecuados y aceptables. Por lo tanto, durante dos semanas en un semestre, o por cuatro semanas durante un año, no se logra concretar un modelo de vinculación con la comunidad donde se puedan conjuntar de forma equitativa los intereses de la comunidad, los intereses para la formación estudiantil, los objetivos institucionales y los intereses intelectuales de los docentes.

\section{Conclusiones}

En la revisión de la experiencia de la UIEP se ha logrado percibir que en el trabajo docente colegiado, queda pendiente fortalecer el trabajo de las Academias, que permitiría desarrollar una metodología de enseñanza de las lenguas originarias como primera o como segunda lengua de instrucción escolar. Otro reto es el de fortalecer la investigación de los distintos colectivos de profesores, de acuerdo a sus intereses intelectuales, tanto los que están realizando esfuerzos por ser reconocidos como colectivo dentro de los Cuerpos Académicos, como los que ya han sido reconocidos individualmente por instancias institucionales nacionales (PRODEP, SNI). Los procesos de fortalecimiento docente se han logrado de forma parcial, ya que continúa la rotación de personal, situación que lograría solventarse mediante la asignación de mayor presupuesto para las UI's.
En el "diálogo de saberes" se hace necesario que los docentes que se incorporan a laborar, incluso los que ya están en funciones, se les proporcione un curso introductorio acerca del enfoque del modelo de educación superior intercultural. Ello con la finalidad de comprender e impulsar la relación entre conocimientos científicos y los sistemas de conocimientos de los pueblos originarios, para procurar ese diálogo de saberes que potencialice los esfuerzos de docencia, investigación y la Vinculación con la Comunidad que atiendan las problemáticas de la sociedad a la cual sirven.

En lo que respecta a la investigación son aún incipientes los proyectos, por lo que uno de los retos a corto y mediano plazo es que puedan contar con financiamiento y se consoliden a nivel individual y colectivo. En estrecha relación con lo anterior, en cuanto al tema de la Vinculación con la Comunidad todavía hay un camino por recorrer para atender las necesidades reales y la participación más amplia y profunda de las comunidades de los pueblos originarios. Por otra parte, si miramos la Vinculación con la Comunidad como tema académico se ha ido delegando esta responsabilidad a cada docente, en la medida que en parte responde a su línea de investigación. Aunque se prioriza la Vinculación para atender los convenios establecidos con algunos municipios. El reto en esa función sustantiva de las universidades interculturales es consolidar una forma en que se cristalice la formación de los estudiantes de manera gradual, por un lado y por otro, acompañar a la comunidad para generar diagnósticos de necesidades sociales y gestionar recursos para que sean atendidas por las mismas comunidades donde pretende incidir la universidad.

En cuanto a los logros, desde la perspectiva de las actuales autoridades educativas, se ensalza la contratación del personal académico con altos perfiles. Se les da preferencia a los candidatos que tienen grado de doctorado o 
maestría. De ese modo este rubro de ser una debilidad ha pasado a ser una fortaleza. La planta académica gradualmente se consolida y está generando una dinámica de iniciales esfuerzos por concretar los procesos de docencia, de investigación, redefinición de la gestión y Vinculación con la Comunidad.

En este escrito se deja constancia de la experiencia de la Universidad Intercultural del Estado de Puebla. Se procuró dar cuenta de lo que se ha puesto en práctica durante los últimos 10 años en la Región Nororiental del estado de Puebla en México lo cual sirve para analizar que si bien se ha avanzado en dirigir una educación superior que considera la diversidad cultural y lingüística de la región aún falta mucho por reflexionar sobre cómo impulsar la inclusión del conocimiento de los pueblos originarios y caminar hacia el pluralismo epistémico.

\section{Notas}

1 Entrevista con miembros de la Organización Independiente Totonaca (OIT), en Huehuetla, Puebla el 20 de abril de 2015

2 La noticia salió publicada en el periódico La Jornada de Oriente, el día 13 de febrero de 2013, en el que se da cuenta de los motivos del conflicto. Información recuperada de la nota del periódico La Jornada de Oriente, el día 5 de mayo de 2016. www.lajorna dadeoriente.com.mx/.../tras-protesta-destituyen-al-rector-y-a

3 La instancia que da reconocimiento a los Cuerpos Académicos es PRODEP dependencia de la Secretaría de Educación Pública (SEP) en México.

\section{Referencias bibliográficas}

Bastida Muñoz, M. C. (2012). Políticas públicas de las instituciones y programas interculturales de educación superior en México. En D. Mato (Coord.), Educación superior y pueblos indígenas y afrodescendientes en América Latina. Normas, políticas y prácticas (275306). Caracas: UNESCO-IESALC.

Camacho Morfin, R., Guzmán Félix, C. E. y Díaz Hernández, J. (2009) Una experiencia intercultural a partir del conocimiento etnomédico [México]. En Daniel Mato (Coord.), Educación Superior, colaboración intercultural $y$ desarrollo sostenible/buen vivir. Experiencias en América Latina (65-86). Caracas: IESALC.

Casillas, Ma. L. y Santini Villar, L. (2009). Universidad Intercultural. Modelo Educativo. 2da. ed. México. [SEP-CGEIB]. Recuperado de: https://goo.gl/uM65Y9

Deance, I. y Vázquez Valdés, V. (2010). La lengua originaria ante el modelo intercultural en la Universidad Intercultural del Estado de Puebla. Cuicuilco, Nueva época, 17(48), (35-47).

Del Val Blanco, J. M. (2016). Equidad en la Educación Superior para un mundo culturalmente diverso. En Daniel Mato, Educación superior y pueblos indígenas en América Latina. Experiencias, interpelaciones y desafíos (243260). Buenos Aires: EDUNTREF.

Dietz, G. y Mateos, L. S (2011). Interculturalidad y educación intercultural en México. Un análisis de los discursos nacionales e internacionales en su impacto en los modelos educativos nacionales. México: SEP-CGEIB.

Dietz, G. (2008). La experiencia de la Universidad Veracruzana Intercultural. En Daniel Mato (Coord.), Diversidad cultural e interculturalidad en educación Superior. Experiencias en América Latina (359-370). Caracas: IESALC.

Estrada, G. (2008). Sobre la experiencia del Centro de Estudios Ayuuk-Universidad Indígena Intercultural Ayuuk. En Daniel Mato (Cooord.), Diversidad cultural e interculturalidad en educación Superior. Experiencias en América Latina (371-380). Caracas: IESALC.

Fábregas Puig, A. (2008). La experiencia de la Universidad Intercultural de Chiapas. En Daniel Mato (Cooord.), Diversidad cultural e interculturalidad en educación Superior. Experiencias en América Latina (339-348). Caracas: IESALC.

Fábregas Puig, A. (2009). Cuatro años de educación superior intercultural en Chiapas, México. En Daniel Mato (Coord.), Instituciones Interculturales de Educación Superior en América Latina. Procesos de construcción, logros, innovaciones y desafíos (251-278). Caracas: IESALC.

Guerra García, E. (2008). La experiencia educativa de la Universidad Autónoma Indígena de México. En Daniel Mato (Coord.), Diversidad cultural e interculturalidad en educación Superior. 
Experiencias en América Latina (349-358). Caracas: IESALC.

Guerra García, E. y Meza Hernández, M. E. (2009). El corto y sinuoso camino de la Universidad Autónoma Indígena de México (UAIM). En: Daniel Mato (Coord.), Instituciones Interculturales de Educación Superior en América Latina. Procesos de construcción, logros, innovaciones y desafíos (215-250). Caracas: IESALC.

Hernández Silva, I. P. (2016). La formación profesional en la sociedad maya contemporánea: el caso de la Universidad Intercultural Maya de Quintana Roo en México. En Daniel Mato, Educación superior y pueblos indígenas en América Latina. Experiencias, interpelaciones y desafíos (233-242). Buenos Aires: EDUNTREF.

Hernández Loeza, S. E. y Manjarrez Martínez, Y. (2016) La Universidad Campesina Indígena en Red (UCIRED). En Daniel Mato, Educación superior y pueblos indígenas en América Latina. Experiencias, interpelaciones y desafíos (261280). Buenos Aires: EDUNTREF.

Jablonska, A. (2010). La política educativa intercultural del gobierno mexicano en el marco de las recomendaciones de los organismos internacionales. En S. Velasco Cruz y A. Jablonska (Coords.), Construcción de políticas educativas interculturales en México: debates, tendencias, problemas, desafíos (25-62). México: UPN.

Leff, E. (2006). Aventuras de la epistemología ambiental. México: Siglo XXI.

Mateos Cortés, L. S. y Dietz, G. (2013). Universidades interculturales en México. En M. Bertely Busquets, G. Dietz, y M. G. Díaz Tepepa, Multiculturalismo y educación 2002-2011 (349-381). México: COMIE.

Mateos Cortés, L. S. y Dietz, G. (2016). Universidades interculturales en México. Balance crítico, Revista Mexicana de Investigación Educativa, 70(21), 683-690.

Mato, D. (Coord.) (2008). Diversidad cultural $e$ interculturalidad en educación Superior. Experiencias en América Latina. Caracas: IESALC.

Mato, D. (Coord.) (2009a). Educación superior, colaboración intercultural y desarrollo sostenible/
Buen vivir. Experiencias en América Latina. Caracas: IESALC.

Mato, D. (Coord.) (2009b). Instituciones interculturales de educación superior en América Latina. Procesos de construcción, logros, innovaciones $y$ desafíos. Caracas: IESALC.

Mato, D. (Coord.) (2012). Educación Superior y pueblos indígenas y afrodescendientes en América Latina. Constituciones, leyes, políticas públicas y prácticas institucionales. En Daniel Mato (Coord.), Educación Superior $y$ pueblos indígenas $y$ afrodescendientes en América Latina. Normas, políticas y prácticas (13-98). Caracas: IESALC.

Mato, D. (2013). Diversidad cultural, interculturalidad y educación superior en América Latina. Contextos, modalidades de colaboración intercultural, logros y desafíos. En S. E. Hernández Loeza, M. I. Ramírez Duque, Y. Manjarrez Martínez, y Rosas A. Flores (Coords.), Educación intercultural a nivel superior: reflexiones desde diversas realidades latinoamericanas (155-178). México: UIEP/ UCIRED/UPEL.

Mato, D. (2015). Educación superior y pueblos indígenas en América Latina. Contextos y experiencias. Buenos Aires: EDUNTREF.

Mato, D. (Coord.) (2016). Educación superior y pueblos indígenas en América Latina. Interpelaciones, avances, problemas, conflictos y desafíos. En Daniel Mato (Coord.), Educación superior y pueblos indígenas en América Latina. Experiencias, interpelaciones $y$ desafíos (21-47). Buenos Aires: EDUNTREF.

Mena Silva, N. (2012). Convergencias y divergencias en torno al impacto del Modelo Educativo Intercultural en los procesos de etnogénesis de estudiantes indígenas. El caso de la Licenciatura en Lengua y Cultura de la Universidad Intercultural del Estado de Puebla. (Tesis inédita de maestría). México: DIE-CINVESTAV-IPN.

Meseguer, S. (2016). Aportes y retos de las universidades interculturales mexicanas: reflexiones desde la Universidad Veracruzana Intercultural. En Daniel Mato, Educación superior y pueblos indígenas en América Latina. Experiencias, interpelaciones y desafíos (281-298). Buenos Aires: EDUNTREF. 
Silva Carrillo, S. (2009). Universidad Comunitaria de San Luis Potosí. En Daniel Mato (Coord.), Educación Superior, colaboración intercultural y desarrollo sostenible/buen vivir.
Experiencias en América Latina (163-182). Caracas: IESALC.

Universidad Intercultural del Estado de Puebla (2016). Informe anual de actividades. Septiembre 2015- octubre 2016. México: Autor. 


\title{
Capacitación docente: Pilar para la identificación y gestión de la violencia escolar
}

\section{Teacher training: Pillar for the identification and bullying management}

\begin{abstract}
Ramiro Andrés Andino Jaramillo es docente de la Unidad Educativa Nicolás Gómez Tobar (Ecuador) (raandinoj@gmail.com) (https://orcid.org/0000-0001-8547-8780)
\end{abstract}

Recibido: 2017-04-17 / Revisado: 2017-08-07 / Aceptado: 2017-11-01 / Publicado: 2018-01-01

\section{Resumen}

El presente trabajo se enfoca en explicar la mejora del proceso de identificación y gestión de la violencia escolar en los docentes de Educación General Básica de la Unidad Educativa "Nicolás Gómez Tobar", de la ciudad de Santo Domingo, período académico 2016-2017. La propuesta aplicada fue un módulo de capacitación que describe tipos de violencia escolar y modelos de gestión pacífica de conflictos entre estudiantes, que se pueden aplicar en el contexto educativo de la institución, ya que es necesario fortalecer la formación docente en gestión pacífica de casos de violencia escolar. La metodología del estudio se basó en la investigación explicativa y en un diseño cuasiexperimental, con la aplicación de un pretest, una intervención y un postest a una muestra de 22 docentes que imparten clases desde inicial hasta décimo grado en la institución. Las técnicas de investigación utilizadas fueron la encuesta y el análisis estadístico. Los resultados obtenidos con el estudio muestran que la capacitación mejora la identificación de casos de violencia escolar, de la misma manera, se plantea la posibilidad de aplicar uno o varios modelos de resolución pacífica de conflictos. En las conclusiones, se explica la importancia de la capacitación como parte del perfeccionamiento de la carrera docente en identificación y gestión de la violencia escolar, además se sintetizan los beneficios de concientizar a los docentes sobre este problema habitual en el contexto escolar.

Descriptores: Acoso escolar, capacitación, educación, docente, institución, violencia.

\begin{abstract}
This paper is focused on explaining the improving of the process of identification and management of school violence by teachers of primary education in the "Nicolás Gómez Tobar" school in Santo Domingo city during the period of 2016-2017. The applied proposal consisted of a training module which describes different types of school violence as well as models of pacific conflict management among students, which can
\end{abstract}

Forma sugerida de citar: Andino Jaramillo, R. A. (2018). Capacitación docente: Pilar para la identificación y gestión de la violencia escolar. Alteridad, 13(1), 108-119. https://doi.org/10.17163/alt.v13n1.2018.08. 
be applied in the educational context of the institution, ever since strengthen the pacific violence management is a real teacher's need. The methodology of this study was based on an explanatory research and quasi experimental design. With the application of a pretest, intervention and a posttest to a sample made up of twenty-two teachers, who teach from the initial to tenth grade. The applied research techniques were the survey and the statistical analysis. The results obtained through the research effectively show that training

\section{Introducción}

La violencia escolar es un problema cotidiano dentro de las aulas de clase, ya que se presenta de diferentes formas $y$, con una serie de víctimas y agresores diferentes. La Organización de las Naciones Unidas (ONU) considera a la violencia escolar como cualquier acto de agresión física o psicológica, lesiones, explotación, negligencia, omisión de denuncia que ocurre entre estudiantes, docentes y estudiantes, autoridades y estudiantes y contra la propiedad. Estos actos pueden ocurrir tanto dentro como fuera de la escuela, en la comunidad o barrio que está circundante con la institución, por redes sociales o cualquier tecnología de la información y la comunicación (Ministerio de Educación de Perú, 2014). Durante clases y fuera de ellas, los estudiantes experimentan una serie de conflictos, porque la institución educativa es un espacio social en el que conviven cientos de individuos con diferencias de todo tipo. Es inevitable considerar a la violencia escolar como un problema cotidiano de las instituciones educativas, ya que según López (2014) la violencia es una forma de resolver conflictos entre estudiantes, convirtiéndose así, en parte de la cotidianidad y convivencia de la comunidad educativa.

La violencia y las agresiones entre estudiantes se presentan de varias maneras en las instituciones educativas, forman parten de la cotidianidad de las aulas, por lo tanto, se debe considerar que la violencia se evidenciará en algún momento o situación; durante clases, improves school violence cases identification and also the possibility of applying one or several pacific conflict resolution models. The importance of teacher training on the violence identification and conflict management as part of the improvement of the teaching career is explained in the conclusions, as well as the benefits of making teachers aware of this habitual issue in the school context.

Keywords: Bullying, training, education, teacher, organization, violence.

recesos o en actividades escolares. Con respecto a lo mencionado, la Organización Mundial de la Salud (OMS) plantea que la violencia es el uso deliberado de la fuerza por medio de agresiones o la dominación, ya sea en forma de amenaza o hecho consumado, contra uno mismo, otras personas, un grupo o una comunidad. Este uso deliberado de fuerza por medio de agresiones, pueden causar muerte, lesiones, trastornos psicológico o de desarrollo madurativo (Piñero et al., 2014).

El problema de la violencia escolar se encarna en cada instancia de las instituciones educativas, por tanto es ineludible que no se generen conflictos en un espacio en el que se encuentran una diversidad de estudiantes con diferencias culturales y sociales. De esta manera, Piñero et al. (2014) en concordancia con la Organización Mundial de la Salud (OMS), considera que en la actualidad el problema de la violencia se reconoce como un problema social y de salud que produce un impacto nocivo en las condiciones de vida y estabilidad emocional de las personas, ya que la violencia se puede convertir en un factor generador de enfermedades a corto, medio o largo plazo, incluso provocar enfermedades crónicas.

Los primeros focos de atención y estudios científicos relacionados a la violencia escolar surgieron en los años 70, pero a partir de los años 80 en adelante se empezó a realizar investigaciones centradas en determinar los porcentajes de violencia que existían en las instituciones educativas y cómo afectaba a los estudiantes. En las pri- 
meras investigaciones sobre violencia escolar se centraba la atención sobre el individuo, es decir, el alumno y los efectos negativos que producen su contacto con algún tipo de violencia.

Esta perspectiva investigativa sobre el individuo tiene su origen en la gran influencia de las investigaciones realizadas por autores nórdicos que se centraban en factores o causas a nivel psicológico o familiar, enfocándose hacia aspectos netamente sociales y culturales (Colombo, 2011). A partir de esto, se plantearon algunas teorías que explicaban los efectos negativos de la violencia sobre las personas. La teoría del desarrollo por ejemplo, explicaba que los infantes que crecen en ambientes violentos, se adaptan a estos y desarrollan comportamientos agresivos que afectan su desarrollo emocional, social y psicológico (Rosser, Martínez \& Villegas, 2015).

Otro planteamiento fue la teoría del trauma que hacía énfasis en los cambios fisiológicos, el estrés y el desarrollo cerebral producto de la violencia experimentada por el individuo y cómo esto afectaba en gran medida el lenguaje, la memoria y la concentración. Las dos teorías antes mencionadas se centraban en contextos sociales fuera del hogar, por esa razón, se planteó la teoría de los sistemas familiares que consideran a la violencia escolar como resultado de la falta de apoyo que tenían los padres con respecto a infantes o adolescentes que eran agresivos dentro de las instituciones educativas.

Los resultados sobre violencia escolar en todos los países tienen porcentajes relativamente similares, en este sentido Cabezas \& Monge (2013) consideran que las conductas agresivas en las aulas de clase, se valoran alrededor de un $15 \%$, no obstante este porcentaje es variable de acuerdo a los estudios que se han realizado en diferentes contextos escolares, en otras palabras, la violencia dentro de las aulas de clase es una realidad presente en las instituciones educativas, aunque no sea evidente o se encubra, por esta razón, en América Latina y el Caribe se estima que entre un 50\% y $70 \%$ de estudiantes han sido testigos o víctimas de algún tipo de violencia, corroborando lo expuesto por el Ministerio de Educación del Ecuador (2014), el cual plantea que la violencia entre estudiantes se incrementa cada vez más en la región.

En 2004 se realizó una investigación científica a nivel nacional sobre violencia escolar en el Ecuador, a través del INNFA (Instituto Nacional de la Niñez y la Familia) en colaboración con el DNI (Defensa de Niños y Niñas Internacional). Con una muestra de niños y adolescentes se reveló los siguientes datos: El 32\% de los niños, niñas y adolescentes que hay en el Ecuador son golpeados o insultados "a veces" por compañeros de clase, de estos, el 22,6\% son niños y niñas entre edades de 6 a 11 años y, el 20,1\% son adolescentes entre 15 a 17 años de edad (McBride, 2012).

Otro informe con datos similares al anterior fue realizado en 2010 por el Observatorio de la Niñez y Adolescencia, revelando que el 63\% de los estudiantes en el Ecuador molesta a otros por ser diferentes; el $74 \%$ insulta o se burla de un compañero de clase; y el $53 \%$ sufre robos dentro y fuera de la institución (El Universo, 2014 , p. 1). Estos resultados demuestran cierta tendencia sobre el incremento progresivo de la violencia en las aulas de clase, a pesar de todas las propuestas o proyectos que se han realizado, y que aún continúan. Ante la masificación de la violencia y agresiones en el contexto escolar, el Ministerio de Educación del Ecuador ha pedido que los estudiantes, docentes, autoridades, padres de familia y la comunidad denuncien inmediatamente cualquier caso de acoso escolar (El Universo, 2014).

Son varias las explicaciones que se han dado para entender la violencia y las agresiones entre individuos, pero se desestima el hecho de que el maltrato entre iguales tiene un gran impacto en el contexto escolar, esto involucra agresiones y abusos sistemáticos dentro la relaciones interpersonales que se establecen entre estudiantes (Haro \& García, 2014), por esta razón, la violencia y agresiones dentro de las aulas de clase se presentan indistintamente dentro de las instituciones educativas, en sí, es un problema que atañe a toda la comunidad educativa, los legisladores y 
ciudadanos en general. Este trabajo enfoca el problema desde el planteamiento de Blásco \& Orgilés (2014), quienes afirman que la agresividad es una conducta que se aprende por medio de la observación de conductas agresivas que otros generan, siendo esto el estímulo para actuar de forma similar o con mayor brusquedad.

Como se lo ha mencionado, la violencia dentro de las aulas de clase es parte cotidiana de la convivencia escolar. Según varias investigaciones, los estudiantes y los docentes establecen relaciones interpersonales que pueden en algún momento convertirse en conflictivas, por lo tanto, parece ser claro que la capacitación docente es de importancia para gestionar los problemas que se puedan dar durante clases, y en mayor razón, si se trata de conflictos y agresiones entre estudiantes. De acuerdo a Martínez et al. (2007), los docentes son conscientes de los problemas emocionales, sociales, familiares y económicos de los estudiantes, y al no sentir ayuda o tener la capacitación necesaria para resolver situaciones precarias de sus discentes se generan estados emocionales de angustia, tristeza o frustración, provocando que estos cuestionen su desempeño docente, llegando incluso al escepticismo frente a nuevas iniciativas o propuestas en contra de la violencia en el contexto escolar.

La capacitación es parte del desarrollo profesional de los docentes, por el motivo que permite mejorar el proceso de enseñanza y aprendizaje. De acuerdo a Torrego, Monge, Pedrajas \& Martínez (2015) la formación del profesorado se la debe entender como un desarrollo profesional que mejora y dinamiza los procesos de aprendizaje, que constantemente están variando, por lo tanto, las prácticas profesionales deben desarrollarse en la misma manera que estos procesos. $\mathrm{La}$ perspectiva de estos autores valora a la capacitación como un medio de desarrollo profesional de los docentes, que en un sentido positivo, permite establecer mejores procesos de gestión de problemas observados en las aulas.

Son puntuales las investigaciones que proponen a la formación docente como medio para gestionar la violencia dentro de las aulas de clase, pese a ser una acción que no es de reciente planteamiento, sino más bien, forman parte de la mejora de los procesos de enseñanza y aprendizaje, además de fortalecer una convivencia escolar alejada de los conflictos, la violencia y otros problemas sociales. Sobre la base de lo mencionado, Gibbons \& Rossí (2015) consideran que los docentes deben promover experiencias significativas y relevantes para los estudiantes que estén en alguna situación de riesgo (violencia, exclusión, drogas, vandalismo, prostitución, etc.), en razón de que, las instituciones educativas que no dedican la atención necesaria para fomentar la convivencia pacífica, el liderazgo, la confraternidad, la colaboración, la cooperación y el empoderamiento; pueden acrecentar la violencia, la exclusión, el abuso y los conflictos dentro y fuera de las aulas de clase.

Mejorar la gestión de la violencia y los conflictos dentro del aula de clase es parte del perfil profesional que requieren los docentes. Como lo sostienen algunas investigaciones, la capacitación sobre violencia escolar, permite que los docentes brinden un mejor apoyo a los estudiantes que estén experimentado algún problema. De acuerdo a esto, Gibbons \& Rossí (2015) sostienen que los estudiantes con el apoyo necesario, pueden tener un cambio de actitud que permita ayudarlos a analizar situaciones cotidianas de forma distinta, impulsando el cambio de creencias, y de esta manera, desestimar a la violencia como parte funcional de la convivencia en la institución.

La capacitación de docentes sobre violencia escolar tiene la finalidad de prevenir y evitar actos violentos entre estudiantes, pero también es una forma de plantear mejores soluciones ante conflictos. Gibbons \& Rossí (2015) consideran que los objetivos de los programas de capacitación sobre violencia escolar no solo se deberían enfocar en prevenir la violencia y conflictos entre estudiantes, sino también en enseñar prácticas pacíficas de resolución de conflictos y toma de decisiones participativas que permitan fortalecer el clima positivo del aula y la convivencia armónica de todos los agentes de la comunidad educativa. 
Las investigaciones que se han realizado con respecto a la capacitación de docentes sobre violencia escolar, se enfocan no solo en la prevención de la violencia, sino también en mejores formas de gestionar el aula, para que no se generen conflictos agresivos entre estudiantes. Sobre la base de esto, Gibbons \& Rossí (2015) plantean que la formación docente en liderazgo y mediación forma parte de las decisiones a nivel individual y grupal para prevenir la violencia. El planteamiento de estos autores se relaciona con el rol de líder que debe tomar el docente ante conflictos y violencia entre estudiantes, para que cuando se tomen decisiones tengan un impacto positivo a nivel individual (docente o estudiante) como grupal (docentes y estudiantes, padres de familia, autoridades), y así solucionar la problemática abordada.

Distintos estudios que se enfocan en la capacitación docente en temas de violencia escolar, plantean que es posible la identificación de los tipos de violencia que se observan en el aula de clase como una medida para plantear estrategias de prevención y resolución pacífica de estos problemas. Martínez et al. (2007) sostienen que la identificación de los factores que generan o inhiben la agresión, podrían suministrar los procedimientos y acciones para diseñar estrategias de prevención e intervención para orientar políticas públicas que reduzcan el impacto de la violencia escolar, la cual se manifiesta precozmente en los niños y niñas.

De acuerdo a las perspectivas descritas, la violencia se presenta de forma frecuente en las aulas de clase, por esta razón, se han propuesto proyectos que ayudan a tratar este problema, que es una cuestión de interés para los docentes, estudiantes, padres de familia y la comunidad (Marchant, 2009). Sobre la base de la problemática identificada, se diseñó un módulo de capacitación con la finalidad de mejorar el proceso de identificación y gestión de la violencia escolar en los docentes de Educación General Básica de la Unidad Educativa "Nicolás Gómez Tobar", de la ciudad de Santo Domingo, período académico 2016-2017. La estructura del módulo contem- pla antecedentes de la violencia escolar a nivel internacional y nacional para situarla como un problema latente en la institución. La primera unidad del módulo tiene relación con las generalidades de la violencia; describiendo su tipología como es: violencia física, violencia psicológica, violencia sexual, violencia económica y violencia patrimonial, de la misma manera, se explican las modalidades en que se presenta la violencia, como son: intrafamiliar, institucional, laboral y violencia en contra de la naturaleza.

La segunda unidad aborda la violencia escolar, sobre la cual, se detalla y analiza casos de exclusión, hostigamiento, coacciones, intimidación y bullying (verbal, físico, gesticular, cibernético). De la misma manera, se describe el abstenimiento de la denuncia y los agentes que propician la violencia dentro de las instituciones educativas. La tercera unidad del módulo de capacitación tiene relación con los métodos de resolución pacífica de la violencia escolar. En este apartado temático se analiza y describe el modelo de técnica asertiva, el método Pikas, el círculo de amigos, la dinámica de mediación y el modelo relacional integrado. En este sentido, el trabajo presentado contempla la importancia de mejorar el proceso de identificación y gestión de la violencia escolar, que es una necesidad prioritaria en la formación de los docentes, porque en ciertos casos, estos no tienen los conocimientos ni teóricos, ni metodológicos para gestionar conflictos o agresiones dentro del aula de clase (Vijayan, Chakravarthi, Philips, 2016).

\section{Material y métodos}

El proceso metodológico aplicado en la investigación es poco común, ya que trabajos con temáticas similares al que se propone en este manuscrito, se centran en estudios de caso y otros diseños metodológicos no experimentales. Desde esta perspectiva, la propuesta investigativa tomó un diseño cuasiexperimental que considera resultados antes, durante y después de la intervención, para determinar los alcances y las 
limitaciones de la investigación. Sobre la base de la metodología aplicada y fundamentada en el enfoque mixto (cualitativo y cuantitativo), el alcance de la investigación abarcó de manera más amplia el problema de la violencia escolar en la institución, incluso permitió una mayor generalización de los resultados.

Como se lo mencionó en el párrafo anterior, el proceso metodológico del estudio se fundamentó en un enfoque mixto, debido a que se utilizó el enfoque cualitativo para analizar la experiencia docente con respecto a la capacitación. Del mismo modo, se aplicó el enfoque cuantitativo para el análisis estadístico de la mejora en la identificación y gestión de la violencia escolar, una vez concluida la capacitación. El diseño cuasiexperimental, según Hernández, Fernández \& Baptista (2010) es útil para la medición de variables sociales, considerando principalmente que se escogen grupos previamente formados, es decir no se emplea ningún tipo de selección aleatoria. En investigación educativa, este tipo de diseño permite alcanzar resultados para tendencias generales, porque las variables de estudio pueden ser comparadas antes, durante $y$ después, en un tiempo determinado.

Para el presente trabajo, el diseño cuasiexperimental se aplicó mediante un pretest, una intervención y un postest para una muestra intencional de 22 docentes de Educación General Básica que imparten clases desde inicial hasta décimo grado en la institución. En el pretest, se aplicó una encuesta de 20 preguntas relacionadas a casos de violencia escolar y modelos de gestión pacífica de conflictos. A partir de la encuesta, se propuso el módulo de capacitación con tres unidades que detallan los tipos de violencia escolar y modelos de gestión pacífica de conflictos que se pueden contextualizar con la realidad de la comunidad educativa. La capacitación se realizó durante quince días y dos horas de participación diaria. La estrategia metodológica fue participativa; por lo tanto, se realizó debates y mesas de trabajo para el análisis de las unidades temáticas y el desarrollo grupal de los talleres del módulo. El postest consistió en volver a aplicar la encuesta tomada en el pretest, y de esta manera, comparar estadísticamente los resultados alcanzados para determinar si hubo una mejora en el proceso de identificación y gestión de la violencia escolar.

\section{Análisis y resultados}

A continuación se describen y analizan los resultados de las preguntas generales y específicas de la encuesta sobre identificación y gestión de violencia escolar, aplicada a 22 docentes de Educación General Básica de la Unidad Educativa "Nicolás Gómez Tobar".

Tabla 1. Aspectos generales de los docentes de la institución

\begin{tabular}{|l|l|}
\hline \multirow{2}{*}{ Formación profesional } & Tercer nivel $(86,36 \%)$ \\
\cline { 2 - 2 } Formación pedagógica & Cuarto nivel (13,64\%) \\
\hline Capacitación en resolución pacífica de la violencia escolar & $100 \%$ \\
\hline \multirow{2}{*}{ Frecuencia de capacitación } & $86,36 \%$ \\
\hline Disposición para capacitación & Hace un mes (4,55\%) \\
\cline { 2 - 2 } & Hace un año (22,73\%) \\
\cline { 2 - 2 } Frecuencia de observación de conflictos & Hace más de dos años (72,73\%) \\
\hline & $100 \%$ \\
\hline
\end{tabular}

Fuente: elaboración propia, datos obtenidos de la encuesta sobre identificación y gestión de la violencia escolar. 
De acuerdo con los resultados, los docentes de la institución tienen una formación profesional de tercer nivel $(86,36 \%)$ y cuarto nivel $(13,64 \%)$, de la misma manera, todos tienen una formación pedagógica; por lo tanto, son profesionales formados para ejercer la docencia (ver tabla 1). En contraste con los resultados de la formación profesional, el 86, 36\% de los docentes indica que ha sido capacitado para resolver pacíficamente la violencia escolar; sin embargo, parece ser que existe un escaso proceso de capacitación; por el motivo que, el mayor porcentaje de docentes $(72,73 \%)$ indica que hace más de dos años ha recibido una capacitación en resolución pacífica de la violencia escolar (ver tabla 1).

A pesar de que se evidencia una escasa frecuencia de capacitación a docente, todos los encuestados están dispuestos a capacitarse en temas relacionados a la gestión de la violencia escolar (ver tabla 1). En contraste con los resultados obtenidos, se muestra que el $86,37 \%$ de los docentes observa semanalmente conflictos o agresiones entre estudiantes, de la misma manera, el 9,09\% indica que mensualmente observa actos violentos entre estudiantes. A diferencia de los docentes que observan actos violentos entre estudiantes, el $4,55 \%$ de encuestados indica que no observa ninguna agresión entre estudiantes (ver tabla 1); por lo tanto, parece ser que existe la posibilidad que haya docentes que no tienen la capacidad de identificar tipos de violencia escolar o, por el contrario, no son conscientes del problema observado por los demás docentes.

Tabla 2. Identificación de tipos de violencia escolar

\begin{tabular}{|c|c|c|c|}
\hline Tipo de violencia escolar & $\begin{array}{c}\text { Pretest } \\
\text { (correcta) }\end{array}$ & $\begin{array}{c}\text { Postest } \\
\text { (correcta) }\end{array}$ & Mejora \\
\hline Coacciones & $9,09 \%$ & $95,24 \%$ & $86,15 \%$ \\
\hline Intimidación & $36,36 \%$ & $95,24 \%$ & $58,87 \%$ \\
\hline Hostigamiento & $18,18 \%$ & $95,24 \%$ & $77,06 \%$ \\
\hline Bullying gesticular & $31,82 \%$ & $100 \%$ & $68,18 \%$ \\
\hline Bloqueo social & $54,55 \%$ & $100 \%$ & $45,45 \%$ \\
\hline Bullying verbal & $77,27 \%$ & $100 \%$ & $22,73 \%$ \\
\hline Ciberbullying & $72,73 \%$ & $100 \%$ & $27,27 \%$ \\
\hline Promedio de mejoras & & & $55,10 \%$ \\
\hline
\end{tabular}

Fuente: elaboración propia, datos obtenidos de la encuesta sobre identificación y gestión de la violencia escolar.

En concordancia con los resultados del pretest, se muestra que los docentes identifican en menor porcentaje las coacciones $(9,09 \%)$, el hostigamiento $(18,18 \%)$, el bullying gesticular $(31,82 \%)$ y la intimidación $(36,36 \%)$; por el contrario, los tipos de violencia escolar que identifican de mejor manera son el bullying verbal $(77,27 \%)$, el ciberbullying $(72,73 \%)$ y el bloque social $(54,55 \%)$ (ver tabla 2$)$.

Luego de la aplicación de la capacitación a los docentes, los resultados del postest indican que los docentes mejoraron la identificación de las coacciones, la intimidación y el hostigamiento en un $94,24 \%$ respectivamente. De la misma manera, los resultados indican un $100 \%$ de identificación en el bullying gesticular, bloqueo social, bullying verbal y ciberbullying (ver tabla 2). Al realizar una comparación de los porcentajes de identificación de tipos de violencia escolar en el pretest y el postest, se obtiene un promedio mejora del 55,10\% (ver tabla 2), que indica un incremento sustancial en la diferenciación y tipificación de tipos de violencia escolar. 
Tabla 3. Identificación y utilización de modelos de gestión de violencia escolar

\begin{tabular}{|l|l|l|l|}
\hline \multicolumn{1}{|c|}{ Gestión pacífica de violencia escolar } & \multicolumn{1}{c|}{$\begin{array}{c}\text { Pretest } \\
\text { (correcta) }\end{array}$} & \multicolumn{1}{c|}{$\begin{array}{c}\text { Postest } \\
\text { (correcta) }\end{array}$} & \multicolumn{1}{c|}{ Mejora } \\
\hline Método Pikas & $13,64 \%$ & $85,71 \%$ & $82,08 \%$ \\
\hline Modelo relacional integrado & $22,73 \%$ & $95,24 \%$ & $72,51 \%$ \\
\hline Círculo de amigos & $13,64 \%$ & $76,19 \%$ & $62,55 \%$ \\
\hline Dinámica de Mediación & $54,55 \%$ & $95,24 \%$ & $40,69 \%$ \\
\hline Modelo de Técnica Asertiva & $40,91 \%$ & $76,19 \%$ & $35,28 \%$ \\
\hline Promedio de mejoras & & & $58,62 \%$ \\
\hline
\end{tabular}

Fuente: elaboración propia, datos obtenidos de la encuesta sobre identificación y gestión de la violencia escolar.

Con relación a los resultados del pretest, se demuestra que el método Pikas (13,64\%), el círculo de amigos $(13,64 \%)$ y el modelo relacional integrado $(22,73 \%)$ son los modelos de que los docentes menos identifican o utilizarían para resolver conflictos o agresiones entre estudiantes (ver tabla 3 ); por otro lado, la dinámica de mediación $(54,55 \%)$ y el modelo de técnica asertiva $(40,91 \%)$ en el pretest, son los modelos que identifican y utilizarían los docentes para gestionar la violencia escolar (ver tabla 3).

Una vez realizada la capacitación, los resultados indican que los docentes tienen una mejor capacidad para identificar y proponer la utilización de los modelos propuestos en la capacitación (mayor al 76\%, ver tabla 3). La comparación entre el pretest y el postest indica un promedio de mejora del $58,52 \%$ en la identificación y utilización de los modelos propuestos (ver tabla 3). Sobre la base de la comparación entre el pretest y postest y las mejoras por cada modelo, se propone al modelo relacional integrado $(95,25 \%)$ como la alternativa que la mayoría de docentes utilizaría para gestionar conflictos en el aula de clase (ver tabla 3 ).

\section{Discusión}

Sobre la base de los resultados, se demuestra que los docentes tienen formación de tercer y cuarto nivel en formación pedagógica, pero su capacitación en resolución pacífica de violencia escolar es poco frecuente o inexistente, provocando que posiblemente los docentes se conviertan sin proponérselo en cómplices de la violencia, como lo sostienen Cabezas \& Monge (2013). De la misma forma, los docentes conocen y observan actos violentos dentro y fuera del aula; por lo tanto, parece ser que sienten la responsabilidad y necesidad de hacer algo para mejorar esta problemática, aunque no sepan cómo hacerlo. Con base a la necesidad de capacitación identificada y el conocimiento del problema de la violencia escolar que tienen los docentes, parece ser necesaria la mejora de los procesos de perfeccionamiento docente en temas de identificación de la violencia escolar, ya que según Gómez (2013), posiblemente los docentes se conviertan en espectadores pasivos de los conflictos entre estudiantes, dando como resultado un incremento de la violencia dentro y fuera de las aulas de clase.

Aunque se evidencia una poca o inexistente capacitación en resolución pacífica de la violencia escolar, los docentes parecen estar sintiéndose corresponsables de este problema, ya que de acuerdo a Lorente, Ramos \& Pérez (2016), los docentes son conscientes de los problemas emocionales, sociales, familiares y económicos de los estudiantes. Desde esta perspectiva Rodríguez (2014) plantea la importancia de la capacitación como un medio para mejorar las competencias docentes en resolución pacífica de la violencia escolar, tomando en consideración que los docentes son conscientes de las virtudes, nece- 
sidades y problemas de sus estudiantes; por lo tanto, la capacitación sería una de las herramientas para que los docentes acepten nuevas propuestas, pero también que tengan la capacidad de generar propuestas que se ajusten al contexto educativo y al conflicto observado y evaluado en cada aula de clases.

Si los docentes no se concientizan sobre la violencia que se genera en el contexto escolar, tampoco pueden concienciar a los estudiantes sobre esta problemática, que según Gairín, Armegol \& Silva (2013) puede aumentar la apatía e insolidaridad con respecto al sufrimiento de las víctimas, aumentando el riesgo de que existan en el futuro nuevos protagonistas directos de la violencia. Atendiendo a este planteamiento, Castro \& Regattieri (2012) consideran necesario fortalecer la solidaridad y tolerancia recíproca para equilibrar la vida social que se da dentro y fuera del aula de clases, porque la violencia no solo afecta a la víctima o al agresor, sino también a quiénes la observan y no la denuncian por miedo o por indolencia del conflicto que se produce.

La disposición y responsabilidad de los docentes por capacitarse es parte del proceso de mejora y solución de la violencia escolar; en razón de que, Ruiz (2014) considera que los docentes deben promover experiencias significativas para los estudiantes, además Gibbons \& Rossí (2015) plantean que las escuelas que no dedican atención a mantener la unidad, el liderazgo, la renovación y la colaboración, pueden acrecentar la violencia, la exclusión y los conflictos entre estudiantes y docentes. De acuerdo con la explicación de los autores, resulta importante que cada docente sea un promotor de mecanismos para resolver pacíficamente conflictos y, sobre la base de propuestas cercanas a la realidad del contexto escolar, plantear situaciones significativas que sean de provecho para los estudiantes y una posible solución del problema de la violencia escolar.

Otro aspecto relevante de la disposición y responsabilidad de los docentes por mejorar los procesos educativos, lo consideran Gibbons \& Rossí (2015), los cuales sostiene que si los estu- diantes cuentan con el apoyo suficiente, pueden cambiar su actitud, además de ayudarlos a analizar de diferente manera las situaciones diarias a las que se enfrentan, que de una u otra manera, podría dar paso a un cambio de creencia sobre la violencia. Con base a la perspectiva planteada, parece ser que el módulo de capacitación aportó en la concienciación de los docentes sobre la violencia escolar que existe en la institución, ya que hubo mejoras en la identificación y propuesta de solución ante esta problemática; por lo tanto, se viene a demostrar que el conocimiento de los tipos de violencia escolar por parte de los docentes de la Unidad Educativa "Nicolás Gómez Tobar" incide positivamente en la identificación y el reconocimiento de conflictos o actos violentos dentro de las aulas de clase.

La concienciación de la violencia escolar por parte de los docentes, surge del conocimiento e identificación de su tipología en el contexto escolar, porque según Gibbons \& Rossí (2015) la capacitación sobre violencia escolar no solo se enfoca en prevenir este problema, sino también en enseñar mejores estrategias para la solución de conflictos y la toma de decisiones para mejorar la comunicación y relaciones interpersonales entre estudiantes y docentes. Efectivamente, de acuerdo con Martínez et al. (2007) la identificación de los factores que generan la violencia, podría proporcionar las pautas para mejorar, plantear y desarrollar estrategias de intervención y políticas públicas que se orienten a la lucha en contra de de la violencia dentro y fuera de las aulas de clase.

A partir de que los resultados muestran una responsabilidad de los docentes con respecto a la violencia, también hay una aceptación unánime de los mismos por capacitarse en resolución pacífica de la violencia escolar; por lo tanto, parece ser que el modelo relacional integrado con respecto a los otros métodos de resolución pacífica de la violencia escolar, tiene una mayor posibilidad de aplicación en la institución, ya que, los docentes y estudiantes están dispuestos a participar en la mejora de la situación. Aunque los resultados muestran una mayor posibilidad 
de aplicación del modelo relacional integrado, es necesario resaltar que el método Pikas, el círculo de amigos, el modelo de técnica asertiva y la dinámica de mediación son métodos que se pueden aplicar positivamente, de acuerdo al caso de violencia escolar que se identifique.

En respuesta a la predisposición de los docentes y al cambio de creencias de los estudiantes, se plantea el modelo relacional integrado como un método adecuado para el contexto educativo de la institución, porque traslada la resolución pacífica de la violencia escolar a todos los actores de la comunidad educativa, esto quiere decir que, desde la propia iniciativa o animados por los docentes y padres de familia, los estudiantes resuelven conflictos y agresiones por medio del diálogo pacífico y la conciencia sobre el impacto de la violencia dentro y fuera del aula de clase. De este modo, parece ser que existe una posibilidad latente de llevar a cabo este modelo de resolución pacífica de violencia escolar en la institución, pues los docentes y estudiantes han expuesto su interés en participar en la resolución pacífica de esta problemática que aún parece ser una muy radical para todos los actores de la comunidad educativa, encontrándose por otro lado, habituada en el contexto educativo.

En definitiva, la capacitación docente en temas relacionados a la identificación y gestión de la violencia escolar permite cambiar la perspectiva del problema; de modo que, da la posibilidad de proponer estrategias que coadyuven en la lucha de la violencia escolar. A partir de la capacitación de los docentes, se evidencia mediante los resultados una mejora en la identificación de tipos de violencia escolar, pero también parece ser que existe la posibilidad de ejecutar modelos participativos de gestión pacífica de la violencia escolar, como es el caso del modelo relacional integrado, el cual fue mayormente aplicado por los docentes luego de haber concluido con la capacitación. Con base a esta apertura positiva de los docentes, se puede resumir que la capacitación es una herramienta que a más de concientizar al docente sobre el problema de la violencia, le permite tomar un rol de líder con respecto a propuestas que ayuden a mitigar la violencia escolar en cada aula de clase.

\section{Conclusiones}

En términos generales, la capacitación de los docentes con respecto a la resolución pacífica de la violencia escolar es poco frecuente o inexistente, provocando que los conflictos y agresiones entre estudiantes sean poco identificados o controlados en la institución. Esta arista del problema determinada en el estudio se relaciona con la necesidad de perfeccionamiento de la carrera docente, ya que es claro que los docentes están dispuestos a capacitarse en resolución pacífica de conflictos y agresiones entre estudiantes; por lo tanto, existe la posibilidad de aplicar modelos integrales de participación de la comunidad educativa, tal es el caso del modelo relacional integrado, el método Pikas, modelo de técnica asertiva, el círculo de amigos y la dinámica de mediación. Estas posibles soluciones para el problema de la violencia escolar no surgen de manera espontánea, sino que son el resultado de un proceso de concienciación y formación del docente para expandir y proponer modelos que se contextualicen con la realidad escolar en la que se suscitan conflictos y agresiones entre estudiantes.

Con respecto a la aplicación del módulo de capacitación, se observó un cambio de actitud de los docentes, ya que en primer lugar, hubo una aceptación positiva de la capacitación, y en segundo lugar, los docentes identificaban específicamente y con mayores resultados los tipos de violencia escolar que se producía en sus aulas de clase, además, procedimentalmente proponían el modelo de gestión pacífica de violencia escolar que mejor se contextualizara con las características del conflicto identificado. Este cambio de creencias y procedimientos de los docentes es reflejo de la capacitación en identificación de tipos de violencia escolar y modelos de gestión pacífica de conflictos, que indudablemente 
forma parte del proceso de perfeccionamiento de la carrera docente.

Es claro que la capacitación sobre violencia escolar es un elemento necesario para desarrollar conciencia en los docentes sobre este problema cotidiano entre estudiantes. De acuerdo con lo planteado, es posible fomentar una cultura de prevención y tratamiento de conflictos mediante la capacitación a docentes en temas relacionados con la identificación de tipos de violencia escolar y los métodos para gestionarla de manera pacífica. En este sentido, existe la posibilidad de mejorar esta problemática, porque a partir de la capacitación los docentes poseen los conocimientos y procedimientos necesarios para gestionar la violencia escolar que observen dentro de sus aulas de clase.

En definitiva, la oportunidad que se establece con respecto a la capacitación docente, permite desde cualquier perspectiva un aspecto positivo en la mejora del proceso educativo que se da en la institución educativa. La formación docente es un proceso inacabado que requiere de un perfeccionamiento progresivo mediante un proceso de capacitación que se adecue a las necesidades del profesional de la educación y, de acuerdo a los resultados de mejora obtenidos con el estudio, la capacitación sobre identificación y resolución pacífica de la violencia escolar es un elemento trascendental en la lucha de habituación de la violencia, en una sociedad cada vez más inconsciente de problemas fundamentales que coartan la convivencia, la interculturalidad, el cambio y la paz. En definitiva, el módulo de capacitación sobre identificación y gestión de la violencia escolar resultó ser efectivo en el contexto escolar de la institución y se adecuó a las necesidades del profesorado que labora en cada uno de los grados de Educación General Básica.

\section{Referencias bibliográficas}

Blasco, M. \& Orgilés, M. (2014). Agresividad en menores de 18 años jugadores de fútbol: Diferencias en función del sexo y la edad y en comparación con los jugadores de baloncesto.
Cuadernos de Psicología del Deporte, 14(2), 21-26. Recuperado de https://goo.gl/r1jPyd

Cabezas, H. \& Monge, M. (2013). Violencia escolar, un problema que aumenta en la escuela primaria costarricense. Actividades Investigativas en Educación, 13(2), 1-20. Recuperado de https://goo.gl/LmrCre

Castro, J. \& Regattieri, M. (2012). Interacción Escuela familia. Brasilia: UNESCO. Recuperado de https://goo.gl/hcX7m3

Colombo, G. (2011). Violencia escolar y convivencia escolar: Descubriendo estrategias en la vida cotidiana escolar. Revista Argentina de Psicología, 8-9(15-16), 81-104. Recuperado de https://goo.gl/nkysJR

El Universo (2014). El acoso escolar se torna más violento en las aulas de Ecuador. Recuperado de https://goo.gl/7zA4DU

Gairín, J., Armengol, C., \& Silva, B. (2013). El 'bullying' escolar. Consideraciones organizativas y estrategias para la intervención. Educación XXI, 16(1), 17-38. Recuperado de https://goo.gl/prHYZi

Gibbons, M. \& Rossí, M. (2015). Evaluación de Impacto de un Programa de Inclusión Social y Prevención de Violencia Estudiantil. Washington: BID. Recuperado de https://goo.gl/qKbHq6

Gómez, A. (2013). Bullying: El poder de la violencia. Una perspectiva cualitativa sobre acosadores y víctimas en escuelas primarias de Colima.Revista Mexicana de Investigación Educativa, 18 (58), 839-870. Recuperado de https://goo.gl/tWKT5s

Haro, I. \& García, B. (2014). Variables emocionales y sociomorales asociadas con el tipo de rol que asumen los alumnos y alumnas en el maltrato entre iguale. Apuntes de Psicología, 32(1), 15-23. Recuperado de https://goo.gl/Zg6cAV

Hernández, R., Fernández, C. \& Baptista, M. (2010). Metodología de la investigación. 5ta. ed. México: Mcgraw-Hill.

López, V. (2014). Convivencia escolar. Santiago: UNESCO. Recuperado de https://goo.gl/U2ZZ7M

Lorente, L., Ramos, G., \& Pérez, A. (2016). Las prácticas docentes y el desarrollo de las competencias emocionales en estudiantes de educación primaria. Aula de Encuentro, 18 (1), 129-154. Recuperado de https://goo.gl/guJolG 
Marchant, C. (2009). Sobre reformas, integración inclusión y exclusión educativa. Reflexiones a partir de la experiencia española. Revista Latinoamericana de Educación Inclusiva, 3(2), 15-25.

Martínez, J., Muñoz, L., Duque, A., Castrillón, D., Rojas, C. \& Tovar, J. (2007). Percepciones y creencias de los docentes de algunas escuelas públicas de Pereira sobre el comportamiento agresivo de los niños. Revista Investigaciones Andina, 9(14), 5-25. Recuperado de https://goo.gl/JEKgC1

McBride, C. (2012). Bullying en el Ecuador. Quito: USFQ.

Ministerio de Educación de Perú (2014). Paz escolar, estrategia nacional contra la violencia escolar. Lima: MINEDU. Recuperado de https://goo.gl/qSjQQ3

Piñero, E., Arense, J., López, J. \& Torres, A. (2014). Incidencia de la violencia y victimización escolar en estudiantes de educación secundaria obligatoria en la Región de Murcia. Revista de Investigación Educativa, 32(1), 223-241. Recuperado de https://goo.gl/RMPjhy

Rodríguez, D. (2014). La mediación escolar: claves de interpretación desde una mirada politi- co-educativa. Tandil: NEES. Recuperado de https://goo.gl/Vq9rFy

Rosser, A., Martínez. R. \& Villegas, E. (2015). La exposición a violencia de género y su repercusión en la adaptación escolar de los menores. Bordón, 67(2), 117-129. Recuperado de https://goo.gl/DD5oJV

Ruiz, M. (2014). Liderazgo y responsabilidad educativa: el necesario liderazgo de directores y profesores en la educación. Revista Fuentes, 1 (14), 85-104. Recuperado de https://goo.gl/mbvR3A

Torrego, J., Monge, C., Pedrajas, M. \& Martínez, C. (2015). Formación del profesorado en aprendizaje cooperativo y alumnos con altas capacidades: un enfoque inclusivo. Revista Latinoamericana de Educación Inclusiva, 9 (2), 91-110. Recuperado de https:/goo.gl/9jc2DT

Vijayan, P., Chakravarthi, S. \& Philips, J. (2016). The Role of Teachers' Behaviour and Strategies in Managing a Classroom Environment. International Journal of Social Science and Humanity, 6(3), 208-215. Recuperado de https://goo.gl/yYpcxh 


\title{
Desempeño académico y experiencias de estudiantes universitarios mayas en Yucatán, México
}

\section{Performance academic and experiences of Mayan university students on Yucatan, Mexico}

\begin{abstract}
Rubi Surema Peniche Cetzal es docente de CONACYT-Universidad Autónoma de Aguascalientes (México) (rupeniche81@gmail.com) (http://orcid.org/0000-0003-0105-6471)
\end{abstract}

Cristóbal Crescencio Ramón Mac es docente de la Universidad Autónoma de Yucatán (México) (ccrmac@gmail.com) (http://orcid.org/0000-0003-3732-5717)

Recibido: 2017-07-25 / Revisado: 2017-08-28 / Aceptado: 2017-11-01 / Publicado: 2018-01-01

\section{Resumen}

Esta investigación fue realizada bajo una metodología cualitativa, empleando el estudio de caso colectivo. Se describen las experiencias académicas que han tenido los estudiantes universitarios mayas caracterizados con un desempeño académico sobresaliente, enfatizando en sus dificultades y las estrategias empleadas para sopesar tales situaciones. Los participantes fueron tres estudiantes universitarios mayas de una universidad pública en Yucatán, México. Se utilizó la entrevista semiestructurada y el diario de campo como técnicas de recolección. Al parecer, los tres casos se enfrentan al asunto económico como principal problema ante su formación profesional; la dificultad para emplear los equipos y recursos tecnológicos, la crítica a la imagen por parte de los demás, y la falta de apoyo y credibilidad por parte de los padres para formarse profesionalmente fueron otros obstáculos identificados. A pesar de ello, los estudiantes consideran que una correcta organización del tiempo, una adecuada comunicación con los profesores, una autogestión personal, así como el empleo frecuente de la tutoría institucional y los programas de becas a la excelencia, les permiten aminorar las dificultades y conseguir buenos resultados como universitarios. Mucho de los hallazgos fueron similares a la literatura que había sido reportada en años anteriores siendo lamentable observarlos en la actualidad.

Descriptores: Educación superior, desempeño académico, desigualdad social, pobreza, vulnerabilidad social,Yucatán, México.

\section{Abstract}

This research was performed under a qualitative methodology, using the collective case study. It describes the academic experiences that have been characterized with outstanding academic performance, college

Forma sugerida de citar: Peniche Cetzal, R. S. y Ramón Mac, C. C. (2018). Desempeño académico y experiencias de estudiantes universitarios mayas en Yucatán, México. Alteridad, 13(1), 120-131. https://doi.org/10.17163/alt.v13n1.2018.09. 
students emphasizing their difficulties and strategies used to weigh such situations. The participants were three Mayan University students of a public University in Yucatan, Mexico. The semi-structured interview and the field journal as data collection techniques was used. Apparently, all three cases is facing economic issue as a main problem in their vocational training; the difficulty of using the equipment and technological resources, criticism of the personal appearance by others, and the lack of support and credibility by parents for prepare professionally were identified like obstacles. Despite this,

\section{Introducción}

En América Latina creció el porcentaje de estudiantes entre 18 y 24 años de edad inscritos en educación superior de $21 \%$ en 2000 a $40 \%$ en 2010, en particular entre grupos de ingreso bajo y medio, en promedio, el 50\% más pobre de la población representaba el $16 \%$ de los alumnos de educación superior en 2000 y esta cifra creció alrededor de 25\% en 2013 (Banco Mundial, 2017), sin embargo y a pesar de los avances, en México se siguen observando amplias diferencias de cobertura en los contextos rural y urbano (Giorguli y Angoa, 2016; Solís, 2010) así como desigualdades de género para el acceso en varios estados del país, ya que las mujeres no han equiparado sus niveles de logro escolar respecto a los hombres, de acuerdo al censo de 2010, la brecha se hace más patente en el acceso a la universidad incluso en la capital cuando un $25 \%$ de hombres terminan su universidad completa respecto a un $18 \%$ de las mujeres que la concluyen (Brunet, 2016).

En la Educación Superior (ES) en México, sólo el 20\% de los jóvenes más pobres en el plano nacional acceden a la enseñanza superior, mientras aquellos con los ingresos más altos tienen una probabilidad cuatro veces mayor de cursar una carrera universitaria, desigualdad que evidencia la incapacidad del país para impedir que el origen de clase condicione el destino educativo, social y laboral de dicho sector (Peñaloza, 2011). En la educación se fundan los cimientos de la igualdad de oportunidades, siendo en México students considered that a proper organization of the time, a proper communication with professors, personal self-management, as well as the frequent use of the institutional mentoring and scholarship programs it excellence, allow them to lessen the difficulties and achieve good results as University students. Many of the findings were similar in the literature that had been reported in previous years and it is regrettable to still observe today. Keywords: Higher education, academic performance, social inequality, poverty, social vulnerability, Yucatan, Mexico.

esta desigualdad la que marca profunda y persistentemente las brechas sociales (Saraví, 2015). Las poblaciones vulnerables se ven afectadas por factores sociales como la pobreza que impiden ver a la escuela como un instrumento de mejora en la sociedad, la experiencia educativa se ve acotada por actividades como el trabajo infantil o adolescente que finalmente afectan el desempeño escolar; de igual manera, contribuye a las divisiones sociales mediante el acceso selectivo a las instituciones, según el origen socioeconómico de los alumnos como mencionó Tuirán (2011).

En México, el 10\% de la población pertenece a una de las 68 agrupaciones lingüísticas, que se encuentran localizadas principalmente en el centro, sur y sureste de México, geográficamente, los estados que pertenecen a esta zona, cuentan con índices bajo de desarrollo social y económico (Monroy, 2010) y estadísticamente las mujeres hablantes de lengua indígena alcanzan en promedio menos de 6 años de primaria (5.2 años), las brecha de género en los indígenas son muchos más grandes que las brechas étnicas. En particular, entre los hablantes de lengua indígena, los hombres tienen casi tres años en promedio más de asistencia a la escuela que las mujeres (Vázquez, 2016); del 27\% en jóvenes indígenas mayores de 15 años, únicamente el $1 \%$ de los indígenas que cursan la primaria acceden al nivel superior, de los cuales uno de cada cinco estudiantes egresa (Schmelkes, 2013) frente a los retos de acceso, permanencia y conclusión que implica realizar estudios universitarios (CONEVAL, 2011), de igual manera, que 
en el nivel educativo anterior no se han definido los parámetros mínimos sobre desempeños escolares y académicos (Zorrilla, 2010). Por otro lado, se ignora la cifra de estudiantes indígenas matriculados en educación superior, ya que las instituciones que no sean universidades indígenas e interculturales no reportan el origen étnico del estudiante (Didou, 2014).

El rezago educativo se vive en cada estudiante indígena que desea continuar con sus estudios y migra a las ciudades para tener acceso a una buena educación; la marcada brecha de calidad educativa debido a la inaccesibilidad geográfica, falta de servicios, oportunidades limitadas, así como la falta de recursos familiares arrastra marcadas deficiencias académicas (CONEVAL, 2011), con estas condiciones es casi inevitable que los resultados de aprendizaje sean muy pobres y por debajo de lo razonablemente esperable (Saraví, 2015), estos factores repercuten en el desempeño académico y se demuestra en los resultados desfavorables que presentan los estudiantes indígenas en pruebas estandarizadas como EXCALE, ubicándose en los niveles más bajos I y II, (INEE, 2010) frente a sus compañeros de ciudad que tienen trayectorias educativas diferentes, como lo indica Abiedi (2015), la pobreza limita el potencial de los estudiantes y eso impacta en el aprovechamiento académico. Además de la situación académica, el estudiante indígena tiene que enfrentarse a nuevos problemas que afectan su desempeño escolar por tener una cultura diferente a la de sus compañeros, el cambio de contexto de su lugar de origen a la ciudad que puede representar para la familia una pérdida importante, la incertidumbre por mantener los costos de traslado y manutención que genera el estudiar la educación superior y los factores discriminatorios que sufren quienes buscan y les atraen nuevas oportunidades de superación (Carnoy, Santibañez, Maldonado y Ordorika, 2002).

El acceso a la educación superior en México, es un privilegio que no todos los jóvenes mexicanos pueden presumir y quiénes logran ingresar hacen frente a factores que afectan su paso por este nivel educativo (Tuirán, 2011); factores como la homogenización social, la infraestructura pedagógica y la calidad educativa reproducen las desigualdades en el sistema educativo, las características sociales de los estudiantes en el este nivel educativo hacen de segmentación entre los estudiantes (Savarí, 2015). A pesar de ello, actualmente existen programas de apoyo destinados a jóvenes que cursan la educación superior para que continúen con sus estudios y disminuir las desventajas externas del nivel superior. A pesar de las oportunidades para continuar sus estudios, persisten problemas que afectan la finalización de los estudios, problemas, que contribuyen a reproducir la estratificación social (Blanco, 2014).

Específicamente, en el estado de Yucatán se han identificado ciertas causas sociales de rezago educativo a los estudiantes maya hablantes: la discriminación social principalmente por hablar su idioma nativo y los rasgos indígenas que poseen, así por la vestimenta tradicional; la familia de los estudiantes son otra causa de rezago, ya que al no contar con estudios, no ven la educación como un instrumento para tener mejores oportunidades y mejor calidad de vida; los medios de comunicación a los que acceden a través de la televisión, les parecen más atractivos que el asistir a la escuela; estas causas principalmente ocasionan que no puedan concluir la educación básica y llegar a la educación superior (Mijangos, 2009).

\section{Establecimiento del problema}

En México, al igual que en otros países de América Latina, es un privilegio el tener acceso a la educación superior y para la población indígena resulta ser más difícil por las pocas oportunidades de desarrollo, a pesar de estas contrariedades es esencial que los indígenas accedan a este nivel educativo (Schmelkes, 2003) que les permita tener una mejor calidad de vida y equidad social (Silas, 2010). 
Para acceder a las instituciones de educación superior, los aspirantes realizan un examen de admisión estandarizado y quienes logran incorporarse forman grupos heterogéneos de estudiantes y entre ellos se encuentran los estudiantes indígenas que han librado un obstáculo frente a la cultura dominante que hasta algunos años resultaban invisibles para las instituciones de educación superior (Carmona, 2013), si los estudiantes mestizos tienen diferencias académicas importantes, los estudiantes universitarios indígenas se encuentran en desventaja frente a los primeros que gozan al tener una madre lengua en español y una formación académica más consistente que se requiere para desarrollar estudios de nivel superior (Ortelli y Sartorello, 2011). Dubet (2005) identifica que una vez dentro de las instituciones de educación superior, los estudiantes universitarios se enfrentan a varios obstáculos en su experiencia escolar que tiene que ver con el tipo de organización universitaria, el contenido de los estudios, la finalidad de los estudios, las interacciones con sus compañeros $\mathrm{y}$ otros factores que influyen para permanecer o abandonar sus estudios.

Con base en lo anterior, Schmelkes (2003) menciona que los pocos estudiantes indígenas que logran ingresar a una institución de educación superior, consiguen desempeñarse exitosamente a pesar de las desventajas que tienen con respecto a sus compañeros que han tenido una mejor preparación. Savarí (2015) identifica dos dimensiones que viven los estudiantes por su paso por la escuela, la primera se refiere a la inclusión del individuo dentro de un grupo al que tiene que adaptarse y responder a la estructura establecida, el autor lo menciona como la experiencia del rol; la segunda dimensión se refiere a la experiencia particular en la trayectoria individual, es decir la propia experiencia biográfica.

Por ello, que surge el interés de conocer más sobre la vida escolar de los estudiantes universitarios mayas con desempeño académico sobresaliente, para saber cómo experimentan, significan e incorporan sus realidades en el nivel educativo que están estudiando, las situaciones y estrategias a las que se han enfrentado para permanecer en la universidad. Considerando que la población maya son jóvenes que provienen de familias maya hablante, hablan o entienden el idioma maya, en algunos casos provienen de comunidades rurales, tienen dificultades para acceder a la educación de nivel superior y que pocos son los que ingresan a la universidad, surge el planteamiento del problema de investigación con la siguiente pregunta:

¿Cuáles son las experiencias académicas que han tenido los estudiantes universitarios mayas caracterizados con un desempeño académico sobresaliente?

Ante la cuestión planteada, se presentan los siguientes objetivos que direccionan este reporte de investigación.

- Determinar los principales obstáculos que ha enfrentado el estudiante universitario maya con desempeño académico sobresaliente.

- Determinar las estrategias empleadas por los estudiantes universitarios mayas para obtener un desempeño académico sobresaliente.

Es importante comentar que el presente estudio formó parte de un proyecto macro de investigación que refirió a estudio de casos, pertenecientes a instituciones de educación superior ubicadas en el estado de Yucatán, México, y que se enfocó determinar las condiciones de desigualdad en ES en el Estado. Los casos de éxito identificados durante el estudio macro, dieron lugar al interés de este reporte con el fin de compartir los hallazgos, considerando que los sujetos de estudio fueron escasos, o que irónicamente convierte en relevante el estudio en su esencia.

\section{Fundamentación teórica}

La educación ha sido considerada como uno de los principales mecanismos de movilidad social y, por tanto, como uno de los instrumentos idóneos para combatir la desigualdad y mejorar la cali- 
dad de vida de los jóvenes mayas que están en la universidad (Gallart y Henríquez, 2006), sin embargo, en contraste se observan desigualdades para acceder en el sistema educativo mexicano que parecieran manifestar que el acceder al conocimiento es privilegio para los mejores posicionados, negando la posibilidad de desarrollo personal y social (OEI, 2010) y que de acuerdo a los enfoques sociológicos, pareciera que la escuela es únicamente un escenario para encaminar la reproducción de la estratificación (Zorrilla, 2010). Es interesante resaltar que los países más atrasados en el logro de la escolaridad universal para sus niños y adolescentes son precisamente los que tienen mayor proporción de población indígena (Ibarrola, 2014).

Desde mediados de la década de 1990, hubo un incrementó en la matrícula de educación superior de los países de América Latina, cabe mencionar que la tasa de atención fue desigual al interior de cada país en función a desigualdades económicas, culturales y entre los grupos de población (Ibarrola, 2014). Aun cuando los estudiantes mayas no tienen las mismas posibilidades de acceder a una institución de educación superior, hay algunos que logran ingresar a la universidad y permanecer hasta egresar con un desempeño académico sobresaliente pese a las dificultades sociales y económicas que enfrentan en su estancia en dicha institución (Rodríguez y Valdivieso, 2008). En una investigación realizada por los anteriores autores encontraron que el contexto social, económico y cultural en que vive un estudiante indígena tiene una influencia determinante en sus posibilidades de obtener un desempeño académico sobresaliente, que en la mayoría de las veces influyen positivamente en la autoestima del estudiante por mejorar cada día. Con base en lo anterior, los estudiantes mayas asimilan que unos ganan y otros pierden y que las recompensas, como las buenas calificaciones, las merecen sólo los que se han esforzado. Es por ello que aprenden la relación entre desempeño y gratificación, porque es una retribución, que premia el esfuerzo y la dedicación que el estu- diante obtuvo durante su estancia en la universidad (Ramírez, Devia y León, 2011).

El Estado le apuesta a la creación de programas que beneficien a los estudiantes mayas para permanecer en la educación superior y concluir una carrera universitaria. Un ejemplo es la creación del Programa Beca Manutención que ayuda al acceso y permanencia del estudiante en la universidad cuyo fin es brindar los recursos económicos para que el estudiante asista a la universidad y concluya sus estudios superiores; tiene como requisito que el alumno tenga un buen promedio y lo mantenga hasta finalizar sus estudios universitarios (Gallart y Henríquez, 2006). Cuando el estudiante de comunidades indígenas ingresa a la universidad cambia su comportamiento, su forma de vestir, actuar, su lenguaje, entre otros aspectos. Esto se debe a que al ingresar convive con personas de diferentes culturas y nivel socioeconómico diferente a la suya, sin embargo, algunos estudiantes, como los mayas, conservan su identidad cultural; en cambio, algunos jóvenes mayas adoptan nuevas ideologías de la cultura dominante para ser aceptados y que su estancia en la universidad sea más placentera, a lo que Edgardo Lander denomina como La colonialidad del saber (Schmelkes, 2003).

En su momento, Carnoy, Santibañez, Maldonado y Ordorika (2002) identificaron cinco obstáculos que sufren los estudiantes universitarios indígenas y que mantienen resistencia para permanecer en este nivel educativo. Estos obstáculos, tienen que ver con la distancia geográfica al no contar con instituciones de educación superior cerca de las comunidades ya que estas se encuentran en las capitales estatales, lo que obliga a emigrar; las barreras culturales, catalogada como una de las más importantes por ser una brecha de "choque migratorio" con problemas de adaptación y las propias barreras del lenguaje llegar a causar confusión en el sistema de comunicación y por lo tanto los pone en desventaja en el sistema educativo; las barreras económicas que impiden a las familias lidiar con el financiamiento de transporte, hospedaje, libros, alimentación, colegiaturas requeridos 
para estudiar la educación superior; la baja calidad educativa que recibieron en los niveles anteriores los pone en desventaja cuando realizan los exámenes de admisión para ingresar a la educación superior y lo factores de discriminación por su origen provoca problemas de interacción con los compañeros mestizos.

Algunos estudiantes universitarios, pertenecientes a zonas más urbanizadas, a pesar de contar con buenas condiciones materiales, un capital cultural adecuado y códigos culturales ampliados, no tienen desempeño académico sobresaliente en la escuela y, en el otro extremo, los estudiantes mayas universitarios que, a pesar de estudiar en las condiciones más desfavorables, obtienen un desempeño académico sobresaliente (Ramírez, Devia y León, 2011). Al respecto, Rodríguez y Valdivieso (2008), encontraron que los factores más importantes para que el estudiante universitario maya obtenga un desempeño académico sobresaliente no se deben al maestro, ni al currículo, ni al aparato escolar, sino a las condiciones del contexto familiar, aspecto que está fuera del ámbito de acción de las autoridades educativas. De forma adicional, identifican a la pobreza y al género como factores clave que mantienen a los estudiantes vulnerables, alejados de la escuela.

Frente a estos desafíos, los estudiantes indígenas con rendimiento académico sobresaliente instrumentan estrategias para permanecer y terminar exitosamente su carrera profesional, ya que refrendan el compromiso que adquieren con la familia al decidir estudiar fuera de su lugar de origen y valorar el esfuerzo de las familias que sacrifican la economía para que estudien (Chávez, 2008).

\section{Metodología}

El trabajo de investigación se realizó bajo el enfoque cualitativo, ya que ayudó a comprender la naturaleza de un problema, en este caso, las experiencias de estudiantes mayas con desempeño académico sobresaliente, para que los individuos puedan comprender su realidad. Se llevó a cabo un estudio de caso de tipo colectivo (Stake, 2005). Para este estudio los participantes fueron tres estudiantes universitarios mayas con desempeño académico sobresaliente de tres diferentes licenciaturas (enfermería, educación y contaduría) de una universidad pública ubicada en el oriente del estado de Yucatán, México; para la selección se establecieron características específicas: que los estudiantes estén inscritos en alguna de las tres licenciaturas antes mencionadas; que se encuentren en el rango de edad de 18 a 24 años; que tengan un promedio académico general en el rango de 90 a 100 y que sean estudiantes universitarios de origen maya.

Para obtener información para este estudio se utilizó la entrevista, debido a que busca entender el mundo desde la perspectiva del interesado y desmenuzar los significados de sus experiencias (Álvarez-Gayou, 2003). Otra técnica empleada fue el diario de campo (Flick, 2004), que se utilizó para obtener información actualizada y fue redactada por los sujetos de investigación durante cuatro meses, un reporte por semana, en el semestre agosto-diciembre de 2015. El tratamiento de los datos fue realizado mediante el análisis de contenido, que permitió el agrupamiento de las respuestas emitidas por los participantes en categorías específicas, para su posterior interpretación, como lo propone Creswell (2009). Para validar y verificar los datos obtenidos se utilizó una estrategia de triangulación metodológica: la entrevista, la revisión de la entrevista por parte de los entrevistados y el diario de campo, los cuales en conjunto complementan la recolección de los datos (Denzin citado por Flick, 2004).

\section{Resultados}

Considerando los objetivos del estudio, los resultados se reportan con base en cada uno de los tres casos, empleando pseudónimos para cuidar el anonimato y confidencialidad de los mismos. 


\section{Caso 1. Carlos}

\section{PRINCIPALES OBSTÁCULOS}

El obstáculo al que se ha enfrentado Carlos es al manejo y contacto con la tecnología, pues afecta su desarrollo en la universidad, más en el uso de la paquetería office al realizar las tareas escolares, lo que repercute en sus calificaciones; al parecer, cuando los estudiantes no están familiarizados con la tecnología se les dificulta adaptarse a los aparatos tecnológicos que se utiliza en su Institución de Educación Superior. Lo anterior se comprueba con el siguiente comentario:

Cuando entré a la escuela, yo sabía muy poquito usar las computadoras, y cuando me pedía tareas me ponía nervioso; creo que las hacía muy lento. Veía a mis compañeros y no les pasaba eso; el internet me costó mucho trabajo, el asunto de la búsquedas específicamente (Yucatán. Noviembre, 2015).

El asunto económico fue otra barrera para desarrollar sus estudios, ya que al carecer de recursos económicos no le permitió cubrir sus necesidades personales y académicas como estudiante universitario. De igual manera, se ha enfrentado al tiempo respecto del traslado desde su lugar de origen hacia la ciudad donde se encuentra la Universidad; al no contar con los recursos económicos para hospedarse en la ciudad donde se encuentra la universidad, tiene que viajar todos los días y, por ello, pierde tiempo que puede invertir en tareas académicas.

\section{Estrategias empleadas}

Carlos cree que una verdadera organización del tiempo puede ser la clave para obtener un nivel académico sobresaliente, debido a que aprovecha su tiempo seleccionando los espacios para estudiar, así como en terminar sus tareas académicas en tiempo y forma. Al parecer, este estudiante aprovecha las oportunidades que se le presentan en su vida universitaria está muy pendiente de las convocatoria que se publican, ya sea para concursar en eventos culturales (oratoria, maratones) o para evento académicos locales y nacionales (intercambios, veranos de investigación). Cree que es necesario tener trayectoria, relacionarse y hacer contactos en el campo profesional.

\section{Caso 2. Guadalupe}

\section{PRINCIPALES OBSTÁCUlos}

Al parecer, Guadalupe se ha enfrentado también al factor económico, pero referido más a tener que lidiar con asuntos de salud que con los escasos recursos monetarios que tiene no le permiten acudir a un médico especialista; ello le ha causado dificultades en la asistencia de clases y de tareas entregadas a destiempo. Aunado a ello, esta alumna tiene que trabajar en una papelería de su comunidad por lo que le cuesta tener tiempo suficiente para estudiar, pero es una necesidad imperante para obtener ingresos. Comentó:

...he tenido problema de gastritis y con el estrés se me empeora. A veces necesito comprar mis medicamentos pero no me alcanzan. Voy al servicio médico de mi universidad pero ahí solo me dan cosas remediales... el tiempo casi no me alcanza para hacer las tareas como quisiera, pero debo trabajar (Yucatán. Septiembre, 2015).

Por otro lado, Guadalupe considera como obstáculo el autoconcepto y autoimagen que se tenga, así como las creencias e influencia social externas que surgen por el hecho de ser de origen maya; lo anterior influye en la relación con los demás y de la inclusión al grupo. En ciertas ocasiones, algunos compañeros le comentan que habla con una acentuación maya muy marcada, y hasta en ocasiones le sugieren modificar su manera de vestir para actividades escolares o sociales.

\section{Estrategias empleadas}

Ante los obstáculos manifestados por la alumna, ella cree que una correcta organización de agenda 
le permite aprovechar los tiempos, incluso cuando tiene que trabajar de tiempo parcial. Cree que cuando se desea la superación, se busca cualquier espacio para cumplir las actividades y compromisos. De igual manera, mantener una comunicación estrecha con los profesores y expresar las dificultades es una adecuada estrategia para que los otros comprendan sus necesidades; aprender a negociar, hablar y trabajar en equipo le ha permitido avanzar a lo largo de los semestres.

Respecto de su identidad, esta universitaria trabaja todos los días con su autoconcepto; ha descubierto que posee un gran valor, pues sus compañeros le manifiestan su admiración y acuden frecuentemente por su ayuda ante las tareas. Lo anterior le permitido cierta fortaleza antes las críticas hacia su persona. Considera que no ha sido un camino fácil, y que en algún momento pensó en abandonar la carrera, pero ha descubierto mucho futuro viéndose como una profesional.

\section{Caso 3. Raquel}

\section{PRINCIPALES OBSTÁCULOS}

El principal obstáculo que ha enfrentado Raquel ha sido la falta de apoyo y credibilidad de sus padres y familia respecto de cursar una carrera profesional. Al parecer, la familia manifiesta que no es necesario estudiar tanto tiempo y no lograr un trabajo "bueno". A lo anterior se añade el rechazo hacia una carrera universitaria por el hecho de ser mujer, pues se ha de gastar tiempo y dinero en una formación que ni se ejercerá, al final la alumna seguro acabará casada y con hijos. Todo esto desgasta a Raquel, prefiriendo ignorar los comentarios y evitando compartir muchos de sus logros escolares.

Desde que inicié la carrera sabía que nadie me apoyaría, pero yo confío que valdrá la pena. Mi mamá piensa que no acabaré la carrera y que seguro estaré embarazada de algún fulano del pueblo. Yo le he dicho que no, pero no lo creen (Yucatán. Octubre, 2015).
Al igual que los anteriores casos, esta alumna se enfrenta todos los días a problemas económicos, pues debe trasladarse de un pueblo que se encuentra a 40 minutos del municipio además de los gastos que la propia carrera le exige. Lo más complicado es no contar con el apoyo económico de sus padres considerando la postura que ellos tienen y que ha sido descrito al inicio del caso.

\section{Estrategias empleadas}

Raquel considera que levantarse todos los días con una actitud propositiva es una buena estrategia para mantenerse de pie ante tanto obstáculo. Sabe que su condición de vulnerabilidad la hacen estar en desventaja ante sus compañeros pero cree firmemente que puede lograr la carrera. Intenta mantener una relación cercana con los profesores, pues ellos continuamente le dan consejos y le comparten materiales de lectura o productos que le proveen aprendizajes adicionales.

Aprovechando el programa institucional de Tutoría, esta estudiante confía en los beneficios de dicho sistema; cree que un adecuado acompañamiento le permite sopesar las dificultades diarias; en su caso, su tutora está muy pendiente de ella y continuamente revisan su expediente para establecer e implementar técnicas de estudio, en algunos casos se ha tenido que recurrir a la atención psicológica.

Adicionalmente, Raquel procura mantener la beca de manutención, a través de los programas del gobierno federal, que le proporciona un ingreso mensual; ello le permite cubrir sus necesidades básicas de la escuela.

\section{Discusión}

A pesar de las adversidades que enfrenta el estudiante maya en la universidad, algunos logran obtener un desempeño académico sobresaliente el cual es descrito como poseedor de conocimientos y habilidades con suficiencia y promoción que destaca del resto de su grupo de estudio (Erazo, 
2011). Siguiendo la misma línea del autor citado, para que un alumno tenga un desempeño académico ejemplar no basta con que salga bien, en un examen o en un curso, debe tener una conducta más o menos permanente, sistemática y recurrente, que le permita interiorizar las normas de la institución escolar, estudiar y "salir bien" de acuerdo con los parámetros de la escuela. Para ello debe tener la disciplina, los hábitos y el interés para dedicarse al estudio, por lo cual el alumno interioriza una actitud perseverante, debido a que sólo la capacidad intelectual no sería suficiente para sobresalir en el ámbito escolar.

Analizando los tres casos que conformaron esta investigación, se puede concluir que el asunto económico, escases de recursos monetarios, es un factor inevitable en el caminar de todo estudiante universitario, y mucho mayor en el caso de aquellos que vienen de comunidades rurales con el sueño de lograr una formación profesional. Muchos de ellos se enfrentan a la dificultad de adquirir materiales didácticos, alimentos durante su estancia en la jornada académica, pago del transporte desde su lugar de origen hasta la universidad, así como escasa o nula asistencia médica especializada; es entendible que al ser originario de una comunidad rural, la familia se dedica a actividades del campo y los ingresos son, en mayor parte, para cubrir las necesidades básicas del hogar; por ello, estos estudiantes difícilmente pueden obtener grandes apoyos monetarios por parte de sus padres o familiares. A pesar de lo anterior, en los tres casos se ha mostrado entereza para lograr mantenerse en su programa educativo, y con un desempeño sobresaliente. Aunado a lo anterior, Mijangos (2009) manifestó años atrás que la escasez de recursos económicos de las familias indígenas repercute directamente en los deseos de superación de jóvenes en el nivel superior. Esto queda claro, donde al parecer los programas gubernamentales no son suficientes en la cobertura o solvencia de esta necesidad. Parece necesario revisar qué es lo que se sigue haciendo, con un propósito claro de evaluación de políticas y programas sociales.
Respecto del limitado tiempo que tienen los estudiantes para realizar sus actividades académica, ya sea por trabajar de manera parcial o por el traslado de su comunidad al municipio principal, al parecer, una buena organización del tiempo y compromiso para ello permite obtener resultados óptimos, siendo similar a lo que Rodríguez y Valdivieso (2008) declararon. De igual manera, estos estudiantes consideran que ante el caso de sentirse agobiados ante su realidad, procuran mantener una actitud positiva y enfocada al futuro que los mantiene firmes antes los obstáculos.

A pesar que en la teoría reportada respecto que las mujeres indígenas se ven más limitadas para formarse profesionalmente según Brunet (2016), en la universidad a la que pertenecen los tres casos analizados en este estudio, dos fueron mujeres que mostraron desempeños académicos de gran reconocimiento en comparación de sus compañeros de aula no indígenas; ellas no solo tienen que enfrentarse a los típicas barreras de todo estudiante de comunidad rural, sino también a la falta de credibilidad de la familia y sociedad; al parecer, han roto esquemas y podrían convertirse en gestoras para la motivación de futuras generaciones, o agentes cambio. Relacionado a ello, parece ser que el profesor tiene un papel preponderante en el desempeño y crecimiento de los estudiantes, pues en los casos estudiados se mencionó que la relación y comunicación cercana con los maestros le permiten al alumno obtener conocimientos adicionales a los transmitidos en el aula, lo que indica que las interacciones con los formadores pueden motivar con mayor fuerza el interés de los jóvenes hacia la superación (Rué, 2009).

Vale pena considerar, que mucho de estas situaciones descritas como dificultades en la formación profesional, tiene que ver bastante con el proceso de adaptación que todo estudiantes enfrenta al iniciar los estudios superiores (Ferreyra, Avitabile, Botero, Haimovich, y Urzúa (2017), considerando que para algunos que se encuentran en condiciones de vulnerabilidad 
estas dificultades se potencializan por el simple hecho de venir de comunidades rurales o de formación académica previa con niveles deficientes, que incluyen no solo el poco manejo de las tecnologías, si no la misma interacción social.

\section{Conclusiones}

Es claro que este estudio no es generalizable a las poblaciones con condiciones similares, pero ante este fenómeno que es escasamente estudiado en el contexto, puede significar una contribución al trabajo científico y propuestas hacia la política educativa.

Ante lo anterior, las autoridades educativas deberían diseñar en las IES programas o proyectos que se enfoquen en los estudiantes universitarios indígenas, y en su caso con desempeño académico sobresaliente, para que desarrollen todas sus potencialidades y adquieran experiencias para su desarrollo profesional, buscando su motivación continua. Estos programas deben ser diseñados considerando las necesidades del contexto, con la participación de profesores y administrativos que vayan hacia la consecución de los mismos objetivos. Vale la pena mencionar, que al hablar de programas hacia una población específica no se está determinando la discriminación de la misma, lo que se pretende es que se atiendan ciertas necesidades que no son generalizables a toda la comunidad estudiantil por sus propias condiciones, incluso se esperaría que también pueda trabajarse en una cultura de inclusión dentro de la organización educativa. Parecería inherente la participación del sistema de educación media superior, por lo que debería invitársele al programa o proyecto que permita, desde sus funciones de formación, identificar estudiantes que se encuentren en las aulas y que cuenten con las características similares a los de este estudio; de esta manera, se podría anticipar casos que requieren de atención y promoción para concluir sus estudios de educación media y continuar así hacia la superior.
Respecto de los programas de apoyo o subsidio de estudiantes, es necesaria una revisión oportuna de la asignación y cantidad de recursos a aquellos alumnos que lo requieran, acompañado de un seguimiento efectivo de los mismos (Schmelkes, 2007). Es importante hacer a un lado, la concepción simple de que estos programas gubernamentales cumplen su función por el simple hecho de formar parte de políticas públicas, se requiere de campañas para una cultura de valorización que integra a la familia, sociedad y escuela. Trabajar hacia una equidad educativa en educación superior, es un terreno de gran amplitud (Köster, 2016); se debe comenzar con identificar la situación actual en el escenario educativo para determinar estrategias particulares que permitan una efectiva permanencia del alumnado.

Estudios como el descrito permiten mostrar el gran terreno que es necesario de atender a gran magnitud y con poblaciones mucho más amplias; es un espacio abierto a la comunidad científica para continuar el desarrollo de estudios que profundicen con otro tipo de diseños y técnicas para obtener información, desde perspectivas sociológicas y educativas.

\section{Referencias bibliográficas}

Abiedi, J. (2015). Student academic achievement and poverty. En W. Tierney, Rethinking education \& poverty (28-53). Baltimore: Johns Hopkins.

Álvarez-Gayou, J. (2003). ¿Cómo hacer investigación cualitativa?: Fundamentos y metodología. México: Paidós Educador.

Banco Mundial (Mayo, 2017). La educación superior se expande en América Latina y el Caribe, pero aún no desarrolla todo su potencial. México: BM. Recuperado de https://goo.gl/h39Tpd

Blanco, E. (2014). Interrupción de la asistencia escolar: desigualdad social, institucional y curso de vida. En E. Blanco, P. Solís, y H. Robles (Coords.), Caminos desiguales. Trayectorias educativas y laborales de los jóvenes en la Ciudad de México (39-70). México: COLMEX.

Brunet, N. (2016). Dejar la escuela en perspectiva longitudinal micro-macro: marcas biográ- 
ficas y contextuales. En M. Coubés, P. Solís, y M. Zavala (Coords.), Generaciones, cursos de vida y desigualdad social en México (339367). México: COLMEX.

Carmona, A. L. (2013). Las condiciones y estilos de vida de los estudiantes indígenas en la ciudad. Los universitarios en Xalapa. (Tesis de maestría). Xalapa: Universidad Veracruzana.

Carnoy, M., Santibañez, L., Maldonado, A., \& Ordorika, I. (2002). Barrera de entrada a la educación superior y a oportunidades profesionales para la población indígena mexicana. Revista Latinoamericana de Estudios Educativos, 32(3), 9-43.

Chávez, M. (2008). Ser indígena en la educación superior ¿desventajas reales o asignadas? Revista de la Educación Superior, 4(18), 31-55.

CONEVAL (2011). Informe de evaluación de la política de Desarrollo Social en México en materia de rezago educativo 2011. México: CONEVAL

Creswell, J. (2009). Research Design. Qualitative, Quantitative, and Mix Methods Approaches. Los Ángeles: SAGE.

Didou, S. (2014). Educación superior, afianzamiento de la identidad indígena y compromisos étnicos en México. Entre diversidades. Revista de Ciencias Sociales y Humanidades, 3, 17-49.

Erazo, O. (2011). Rendimiento académico, un fenómeno de múltiples relaciones y complejidades. Vanguardia psicológica, 2(2), 144-173. Recuperado de https://goo.gl/trCvCn

Flick, U. (2004). Introducción a la investigación cualitativa. Madrid: Morata.

Gallart, M., \& Henríquez, C. (2006). Indígenas y educación superior: algunas reflexiones. Universidades, 32, 27-37. Recuperado de https://goo.gl/YgvgRq

Giorguli, S., \& Angoa, M. (2016). Trayectorias migratorias y su interacción con los procesos educativos. En M. Coubés, P. Solís, y M. Zavala (Coords.), Generaciones, cursos de vida y desigualdad social en México (369-402). México: COLMEX.

Ferreyra, M., Avitabile, C., Botero, J., Haimovich, F., \& Urzúa, S. (2017). Momento decisivo: La educación superior en América Latina y el Caribe. Washington: Grupo del Banco Mundial.

Ibarrola, M. (2014). Una nueva educación para América Latina en el siglo XXI: desafíos, tensiones y dilemas. México: ANUIES.
INEE (2010). México en PISA 2009. México: INEE.

Köster, A. J. (2016). Educación asequible, accesible, aceptable y adaptable para los pueblos indígenas en México: Una revisión estadística. Alteridad. Revista de Educación, 11(1). https://goo.gl/7Bwn51

Mijangos, J. (2009). La lucha contra el rezago educativo. En el caso de los mayas de Yucatán. México: Unas letras.

Monroy, P. (en prensa) (2010, 28 de febrero). Educación en México, cada vez más pobre y desigual. Contralínea: Periodismo de investigación. Recuperado de: https://goo.gl/C1qgXC

OEI (2010). Metas educativas 2021: Desafíos y oportunidades. Informe sobre tendencias sociales en América Latina 2010. Buenos Aires: UNESCO-IIPE.UNESCO.

Ortelli, P., \& Sartorello, S. (2011). Jóvenes universitarios y conflicto cultural. Estudiantes indígenas y mestizos en San Cristóbal de las Casas, Chiapas. Perfiles educativos, 33, 115-128.

Peñaloza, P. (2011). El ocaso de la superstición punitiva. Revista el Cotidiano. 170, 39-48. Recuperado de https://goo.gl/yWFBhB

Ramírez, M., Devia, R., \& León, R. (2011). Pobreza y rendimiento escolar: estudio de caso de jóvenes con alto rendimiento. Educere, 52(15), 663-672. Recuperado de https://goo.gl/q2xC2v

Rodríguez, C., \& Valdivieso, A. (2008). El éxito escolar de alumnos en condiciones adversas. Estudios educativos, 38(1-2), 81-106. Recuperado de https://goo.gl/VkMBRY

Rué, J. (2009). El aprendizaje autónomo en educación superior. Madrid: Narcea.

Savarí, G. (2015). Juventudes fragmentadas. Socialización, clase y cultura en la construcción de la desigualdad. México: FLACSO, CIESAS.

Schmelkes, S. (noviembre, 2003). Educación superior intercultural el caso de México. Conferencia dictada en el Encuentro Internacional Intercambio de Experiencias Educativas: Vincular caminos a la educación superior. Recuperado de https://goo.gl/NHREY8

Schmelkes, S. (2007). El impacto del programa Oportunidades sobre la educación de la población indígena. Una exploración con base en estadísticas oficiales. En: $X$ Congreso Nacional de Investigación educativa, área 12: 
multiculturalismo y educación. Recuperado de https://goo.gl/F82cdC

Schmelkes, S. (1 de abril de 2013). Educación y pueblos indígenas: problemas de medición. Presentación en el panel sobre Vulnerabilidad educativa en el Seminario internacional Medición de grupos vulnerables. México: UNAM e INEGI.

Silas, J. (2010). Iniciativas para el acceso de la población indígenas a la educación superior en México. Pequeños pasos en un largo camino. Ponencia presentada en el $X$ Congreso Nacional de Investigación Educativa.

Solís, P. (2010). La desigualdad de oportunidades y las brechas de la escolaridad. En A. Arnaut, y S. Giorguli (Eds.), Los grandes problemas de México: educación (599-622). México: COLMEX.

Stake, R. (2005). Investigación con estudio de casos. 3a Ed. Madrid: Morata.

Tuirán, R. (2011). La educación superior en México: avances, rezagos y retos. Suplemento Campus Milenio. 27 de febrero.

Vázquez, G. (2016). Poblaciones indígenas urbanas en México. En M. Coubés, P. Solís, y Zavala, M. (Coords.), Generaciones, cursos de vida y desigualdad social en México (109-137). México: COLMEX.

Zorrilla, J. (2010). El bachillerato mexicano: un sistema académicamente precario. Causas y consecuencias. México: IISUE. 


\section{Juego de Arena y Escrituras de Sí: revelando los itinerarios ecoformativos de una profesora}

\section{The Sandplay and the Written of Itself: revealing the eco-formative journey of an teacher}

Luciane Schulz postdoctoranda en el Programa de Post Graduación en Educación de la Universidad Regional de Blumenau (Brasil) (luciane.schulz19@gmail.com) (http:/orcid.org/0000-0003-1662-6633)

Recibido: 2017-08-01 / Revisado: 2017-10-09 / Aceptado: 2017-11-06 / Publicado: 2018-01-01

\section{Resumen}

Los estudios apuntan que el foco central que permea los cursos de formación de profesores está en una concepción esencialmente intelectual/conceptual. Por otro lado es necesario dar voz a este profesor en formación, con la creación de un ambiente pedagógico que favorezca la autoría, la autoconstrucción y la autorreflexión en el sentido de su subjetividad. Este artículo parte del referencial (auto)biográfico que se caracteriza como la búsqueda de la comprensión de sí mismo y de sus relaciones con el saber y tiene como objetivo presentar el itinerario de la ecoformación de la autora, por medio de la descripción y el análisis del Juego de Arena (Sandplay) y de las escrituras de sí. La metodología consistió en talleres que se realizaron en el Programa de Postgrado de Maestría y Doctorado del Centro de Educación de la Universidad Federal de Rio Grande do Norte, Brasil, culminando con la confección de escenarios imaginarios de los elementos agua, fuego, aire y tierra por medio del Juego de Arena y de las escrituras de sí. Esta apertura dada para la investigación (auto)biográfica y el Juego de Arena como recursos metodológicos autorreflexivos nos hizo tomar conciencia de que la ecoformación ha sido el motor inductor de toda nuestra trayectoria personal, docente y académica. Por lo tanto, el Juego de Arena y las escrituras de sí, son recursos metodológicos ecoformativos esenciales para la formación del profesor.

Descriptores: Búsqueda (auto)biográfica, ecoformación, Escrituras de sí, formación del profesor, Juego de arena (Sandplay), profesora.

\begin{abstract}
Some studies point out that the central focus that permeates teacher training courses is in an essentially intellectual / conceptual conception. On the other hand, it is necessary to give voice to this teacher in formation, with the creation of an educational environment that favors authorship, self-construction and self-reflection in the sense of their subjectivity. This article starts with the (Auto)biographic referential that
\end{abstract}

Forma sugerida de citar: Schulz, L. (2018). Juego de Arena y Escrituras de Sí: revelando los itinerarios ecoformativos de una profesora. Alteridad, 13(1), 132-145. https://doi.org/10.17163/alt.v13n1.2018.10. 
is characterized as the search for the understanding of oneself and for its relations with the knowledge and aims to present the author's eco-formative journey through the description and analysis of the Sandplay and the Written of itself.The methodology consisted of workshops that were carried out in the Postgraduate Program of the Education Center of the Universidade Federal do Rio Grande do Norte, culminating in the creation of imaginary scenarios of water, fire, air

\section{Introducción}

En programas de formación de profesores, se percibe la ausencia de la dimensión personal, que es una cuestión frecuentemente señalada por algunos estudiosos e investigadores del área educacional (Gatti, 2003; Placco, 2002; Nóvoa, 2009). El enfoque central que está presente en tales estudios es la visión orientada esencialmente por los aspectos intelectuales y conceptuales de gran parte de esos cursos de formación.

O sea, tales estudios parten del presupuesto de que cuánto más grande es la oferta de informaciones y contenidos, más grandes serán los cambios en sus posturas y formas de actuar, a partir del dominio de nuevos conocimientos. Los profesores, por otra parte, no son percibidos por sus subjetividades, ${ }^{1}$ las cuales los constituyen como individuos frente a los múltiples efectos de las dinámicas de sus condiciones sociales y afectivas, sus pensamientos y sus emociones. Según Gatti (2003) y Scoz (2011), esa situación puede ser una de las razones por las cuales tantos programas de formación inicial y continuada de docentes, que buscan cambios cognitivos, de metodologías y de posturas, se revelan insatisfactorios, sin resultados eficientes.

Es necesario poner más atención a las concepciones metodológicas presentes en esos cursos de formación. O sea, es necesario entender la importancia de que se creen espacios sanos, que valoren y discutan el rol de la emoción y de los sentimientos. Como indica Maturana y VerdenZöller (2011), espacios donde se corrija el hacer, y no el ser, donde se contemplen metodologías de and earth elements through the Sandplay and the Written of itself. This openness given through these methodological resources has made us aware that eco-formation has been the motto of our entire personal, academic and academic trajectory. Therefore, the Sandplay and the written of itself, are eco-formative methodological resources essential for teacher training. Keywords: Autobiographic Research, eco-formation, Sandplay, teacher training, Written of itself, teacher.

autorreflexividad que conduzcan a su proceso de (auto-hetero-eco)formación ${ }^{2}$ (Pineau, 2008a).

En la búsqueda por esas experiencias de formación o aún por esos ambientes de ecoformación, ya sean formales, informales o no formales, nos apoyamos en la investigación (Auto) biográfica, considerando que "Autos es la identidad, lo yo que es consciente de sí mismo, Bios es la vida simplemente vivida y la Grafia es el medio para un nuevo nacimiento del yo, refiriéndose al arte profesional de tejer una figura pública de sí" (Passeggi, 2008, p. 28). En otras palabras, se caracteriza como la búsqueda de la comprensión de sí mismo y de sus relaciones con el saber.

La metodología de ese estudio se creó en el "Seminário Expressividade e Corporeidade", realizado en la BACOR ("Base de Pesquisa da Corporeidade") del PPGE (el Programa de Postgrado en Educación) de la Universidad Federal del Rio Grande do Norte, ${ }^{3}$ con alumnos de los programas de maestría y doctorado en el año de 2009. Sus objetivos eran profundizar los estudios de la Pedagogia Vivencial Humanescente (Cavalcanti, 2010). El punto culminante de ese coloquio fue la creación de escenarios imaginarios tridimensionales de los elementos agua, fuego, aire y tierra a través del Juego de Arena y de las escrituras de sí. ${ }^{4}$

El Juego de Arena, defendido en investigaciones realizadas por Ammann (2004), Cavalcanti (2010), Scoz (2011) y Schulz (2014), es una herramienta que estimula los juegos durante su ejecución, asociados al proceso de creación, desarrollando de esta forma la autorreflexividad de los participantes de la actividad. Las 
escrituras de sí (Passeggi, 2010), por su parte, son un dispositivo que produce el autorreflexión, la expresión y la resignificación de lo que se siente, de lo que se hace y de lo que se piensa a través de lo que se escribe.

En conformidad con el cuadro expuesto, el objetivo de este artículo es presentar la trayectoria ecoformativa de la autora a través de la investigación (Auto)biográfica y del Juego de Arena, respectivamente en cuanto recursos epistemológico y metodológico autorreflexivos. Utilizaremos como base para este trayecto los cuatro elementos de la naturaleza (agua, fuego, tierra y aire), apoyándonos en Bachelard (2001; 2003; 2008; 2013).

\section{Investigación (auto)biográfica y las Escrituras de Sí}

Para pensar y escribir dentro de un enfoque epistemológico y metodológico de la investigación (auto)biográfica, que por su parte contribuye con el movimiento de las escrituras de sí, de las historias de vida, del caminar hacia uno mismo, de la (auto-hetero-eco) formación, utilizamos como base los estudios de Gaston Pineau, en Canadá, Marie-Christine Josso, en Suiza, y António Nóvoa, en Portugal (Passegi, 2010).

Al llevar a alguien que escribe a reflexionar, a expresar y a resignificar lo que siente, lo que hace y lo que piensa, tenemos en las propias escrituras de sí un dispositivo que posibilita el enriquecimiento del repertorio de la "persona común", redimensionando el rol atribuido al sujeto. O sea, tenemos un lugar de reconstrucción del saber profesional y de identidad. (Passeggi, 2010).

Según la autora (2008), hay tres etapas que forman las escrituras de sí: la primera es la evocación de los recuerdos; la segunda es un momento intermediario de reflexión, en el cual el narrador se interroga y toma conciencia de las experiencias formadoras; en la tercera, reconoce a sí mismo como un otro y por el otro, el punto de llegada de una nueva partida.
Los docentes, cuando escriben sobre su vida, ejercitan el saber analizar y el analizarse. De esta forma, reflexionan y son desafiados a "reconstruir el conocimiento profesional a partir de una reflexión práctica y deliberada" (Nóvoa, 2002 , p. 27), porque es imposible separar la dimensión personal de la profesional. Eso exige un "análisis interpretativo de los acontecimientos en el contexto de su ocurrencia y la ecología de sus relaciones" (Nóvoa, 2002, p. 41), visto que el ejercicio de la profesión ocurre no solamente a través del cúmulo de saberes y competencias, sino también a través de la forma como son aplicados en una determinada situación pedagógica para promover un aprendizaje significativo.

El desarrollo de la dimensión personal en programas de formación de profesores otorga voz a los protagonistas acerca de la acción educativa. En contrapartida, existe la concepción específicamente orientada por los aspectos intelectuales y conceptuales de la mayoría de esos cursos de formación, con énfasis en el enfoque tecnicista de enseñar y también fragmentada al discutir la relación del individuo con los conocimientos producidos para su (hetero-eco) formación y con él mismo para su (auto)formación. Por eso es importante contemplar las escrituras de sí para la investigación de las relaciones establecidas entre la experiencia y el proceso de formación inicial y continuada del profesor, construyendo un conocimiento de sí mismo que surge del conocimiento en cuanto profesional que no se completa solamente con enfoques de carácter técnico y científico.

\section{Juego de Arena (Sandplay): un recurso tecnológico reflexivo}

El Juego de Arena (Ammann, 2004; Cavalcanti, 2010; Scoz, 2011) es un recurso de carácter investigativo que tuvo como su pionera, entre los años 1954 y 1956, a la analista suiza junguiana Dora Kalff (1980). Según Ammann (2004) es un método basado en la creación práctica y creativa en la 
caja de arena. Para la realización del juego, hay una caja con arena que forma el campo concreto. Su tamaño es de aproximadamente 17x50x07 $\mathrm{cm}$, para que esté dentro del campo visual del participante sentado frente a la caja.

Para la construcción de los escenarios imaginarios, o sea, uno de los productos del Juego de Arena, se ofrece una colección de miniaturas de varios materiales, como arcilla, madera, plástico, fibras naturales, entre otros, como se puede observar en la Figura 1A. Para intentar condensar y enriquecer los valores, los temas de problematización aplicados al Juego de Arena, las miniaturas son lo más variadas posible, obedeciendo a demandas universales y multiculturales (Cavalcanti, 2010; Schulz, 2014). No obstante, en caso de que no sea posible encontrar todas las figuras que se deseen para la simbolización, no hay problema, visto que eso es lo que estimula la creación del propio participante. Así que, a través de diversos objetos y miniaturas que incluyen representaciones realistas de animales, materiales de profesiones, medios de transporte, construcciones, árboles, flores, figuras humanas, entre otros, ocurre el encuentro simbólico, desvelando experiencias y descubiertas significativas, visto que "los que juegan en la caja de arena, ya sean adultos o niños, crean varias imágenes tridimensionales en la arena, involucrándose en ese proceso en cuerpo, alma y espíritu" (Ammann, 2004, p. 11). Las miniaturas deben ser de buena calidad para que sean atractivas y estimulen el sentido estético y creativo del sujeto de la investigación.

Para Weinrib (1993, p. 37), el concepto de "espacio libre y protegido" es el aspecto central del Juego de Arena, que tiene dimensiones tanto físicas como psicológicas, puesto que, por un lado, hay la posibilidad de crear lo que se desee en la caja de arena, pero, por otro lado, su tamaño y el número de miniaturas, aunque sean variados, son limitados y "constrictivos". Así se crea una situación segura y protegida.

El punto de partida surge a partir de una pregunta-problema. Los sujetos de la investiga- ción, sentados en círculo, como se puede observar en la Figura 1B, crean en la caja de arena escenarios imaginarios tridimensionales que respondan a la pregunta-problema. En ese momento, "predomina la acción y se habla poco, principalmente de modo no inmediato o de manera racional e interpretativa" (Ammann, 2004, p. 23), y al componer el escenario, lo que se ofrece es un constante retrato del estado emocional en un claro espejo de su desarrollo analítico (Weinrib, 1993), puesto que son representadas figuras y paisajes del mundo interior y exterior.

En la segunda etapa de la actividad, hay la descripción oral por parte del sujeto de la simbología de cada parte del escenario, momento en el cual ocurre la reflexión sobre el proceso creativo, porque "primero se vive, se experimenta, se elabora y después se nombra y se proclama" (Gadotti, 2000, p. 94). El objetivo de esta etapa es establecer conexiones con uno mismo (autoformación), con el otro (heteroformación) y con los saberes del mundo (ecoformación). Los participantes forman un círculo porque, según Tuan (2012), el círculo es el símbolo junguiano que otorga reconciliación de los opuestos para que se obtenga la totalidad y la harmonía.

Según Weinrib (1993), en esa segunda etapa de exhibición y explicación individual del escenario, es posible concretizar más la experiencia con el inconsciente, porque el impacto sobre el participante que socializa provoca reflexiones y cambios. De la misma forma, los participantes que escuchan son afectados, reconociendo las conexiones de los significados simbólicos de los escenarios con ellos mismos. Para futura análisis y manejo de los datos que surgen durante la vivencia a través del habla reflexiva de los participantes, son importantes los registros en forma de audio, producido durante la socialización de cada escenario, y en forma imaginaria, a través del registro fotográfico de las imágenes creadas, produciéndose posteriormente un archivo que debe ser organizado en forma de portafolio con las representaciones más significativas del momento. 
a) Miniaturas ofrecidas

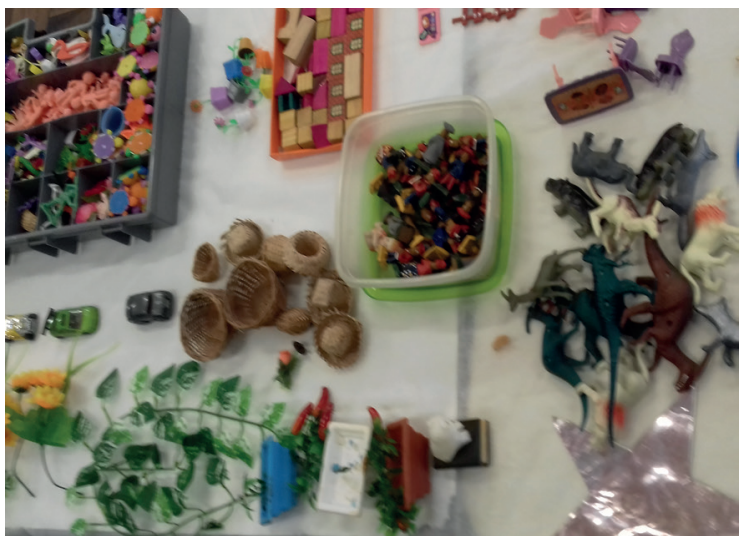

b) Momento vivencial en el Juego de Arena

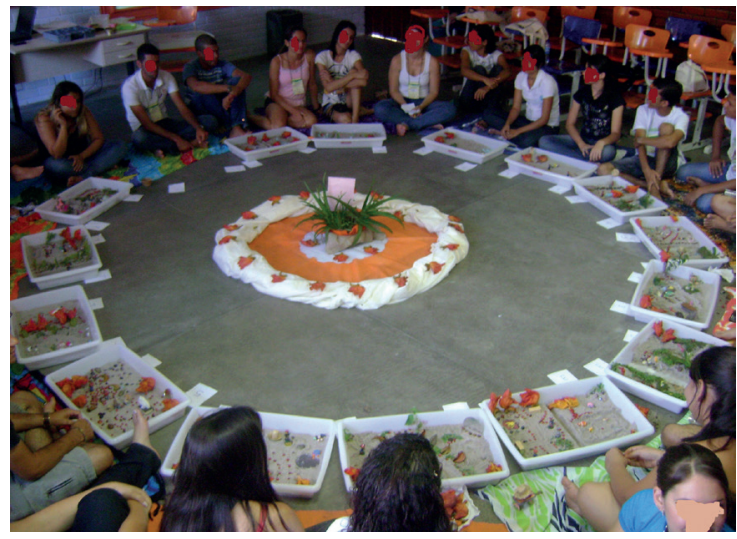

\section{Trayecto Ecoformativo a través del Juego de Arena y de las Escrituras de sí}

Al iniciar una investigación que terminaría en la defensa de la tesis de doctorado intitulada "Pedagogía Ecovivencial Ambiental -por una Educación Ambiental Emancipatoria" (Schulz, 2014), sentimos la necesidad de reflexionar sobre nuestra propia existencia. Durante nuestro desarrollo, desde de la infancia hasta la edad adulta, ya sea en el campo personal o profesional, el proceso ecoinformativo ha sido estimulado, despertando la inquietud para la investigación y la profundización de esa temática. Pero la toma de conciencia de ese trayecto ecoinformativo ocurrió con la participación como alumna con vinculación especial de la BACOR, en 2009.

El punto culminante de ese coloquio fue la creación de escenarios imaginarios tridimensionales de los elementos agua, fuego, aire y tierra a través del Juego de Arena, representados en las Figuras 2, 3, 4 e 5, siendo la pregunta problematizadora para cada encuentro la siguiente: ¿Cuál es el recuerdo más destacado de mi relación con los elementos agua, fuego, tierra y aire? El coloquio estuvo dividido en secciones que contemplaban un elemento a la vez.

Ahora, de acuerdo con el referencial adoptado en este texto, el cual discute las escrituras de sí en cuanto un recurso de la investigación (Auto)biográfica, describiremos nuestro trayecto ecoformativo. Con el auxilio del Juego de Arena, muchos recuerdos afloraron, y con ellos las marcas, algunas buenas y otras ni tanto, que han contribuido para nuestro proceso de ecoformación.

Por haber vivido en una casa con patio en un medio urbano, pero que tenía características campesinas, nuestros aspectos cognitivos, afectivos y emocionales eran estimulados, en un proceso ecoformativo (Pineau, 2004; 2008a; 2008b, 2010, 2012), visto que podía disfrutar libremente de ese ambiente. Esa ecovivencialidad ${ }^{5}$ (Schulz, 2014) ha posibilitado, desde la infancia, la percepción de nuestro entorno ambiental por sus diversas formas de expresión, como: los sonidos de los árboles provocados por la lluvia; el crepúsculo por detrás de la montaña; el canto de los pájaros al amanecer.

Compartía ese ambiente ecoformador con personas creadas con ecovivencias y saberes del campo, una familia urbana, pero con esencia campesina. Así, la biodiversidad estaba presente 
bajo la forma de canes, gallinas, diversos tipos de pájaros, árboles frutales y un huerto, que enseñaban a mantenerse sano y en conexión y harmonía con la tierra. Y todas las mañanas observábamos la vida que se renovaba mientras caminábamos por ese "patio encantado", 6 estimulando todos nuestros sentidos a través de colores, sonidos, olores y sabores. Era un aprendizaje constante poder vivenciar esa realidad concreta, en el sentido de la ecoformación en conformidad con las lecturas de mundo propuesta por Freire (2012).

Al compartir con un grupo de amigos un entretenimiento en común, buscando renovar las energías en otros "patios encantados" durante la juventud, hacíamos largas caminatas por el bosque. Veíamos lindas cascadas, y ahí nos bañábamos, porque el agua tiene el poder de llevarnos, de arrullarnos, de adormecernos (Bachelard, 2013).
Al buscar los recuerdos lúdicos de la adolescencia con el elemento agua, nos valemos de Bachelard (2013, p. 9) y sus devaneos afirmando que "no puedo sentarme cerca de un regato sin que se produzca en mí un devaneo profundo, sin que contemple mi fortuna".

La práctica del Juego de Arena permite una expresión tangible tridimensional de los contenidos incipientes e inconscientes, puesto que, como podemos percibir, la preparación del escenario es, en sí misma, un acto simbólico, y los símbolos son representados por las construcciones, que por su parte representan figuras y paisajes del mundo interior y exterior. Así, "al bañarse en agua fresca para renacer renovado" (Bachelard, 2013, p. 151), una vez que asomaron los símbolos, se produjeron emociones relacionadas a los diferentes recuerdos junto a ese elemento, como se puede observar en la Figura 2.

Figura 2: Escenario intitulado "Agua es vida" - A) simbolización de personas; B) simbolización del ambiente marino C) simbolización de la biodiversidad.

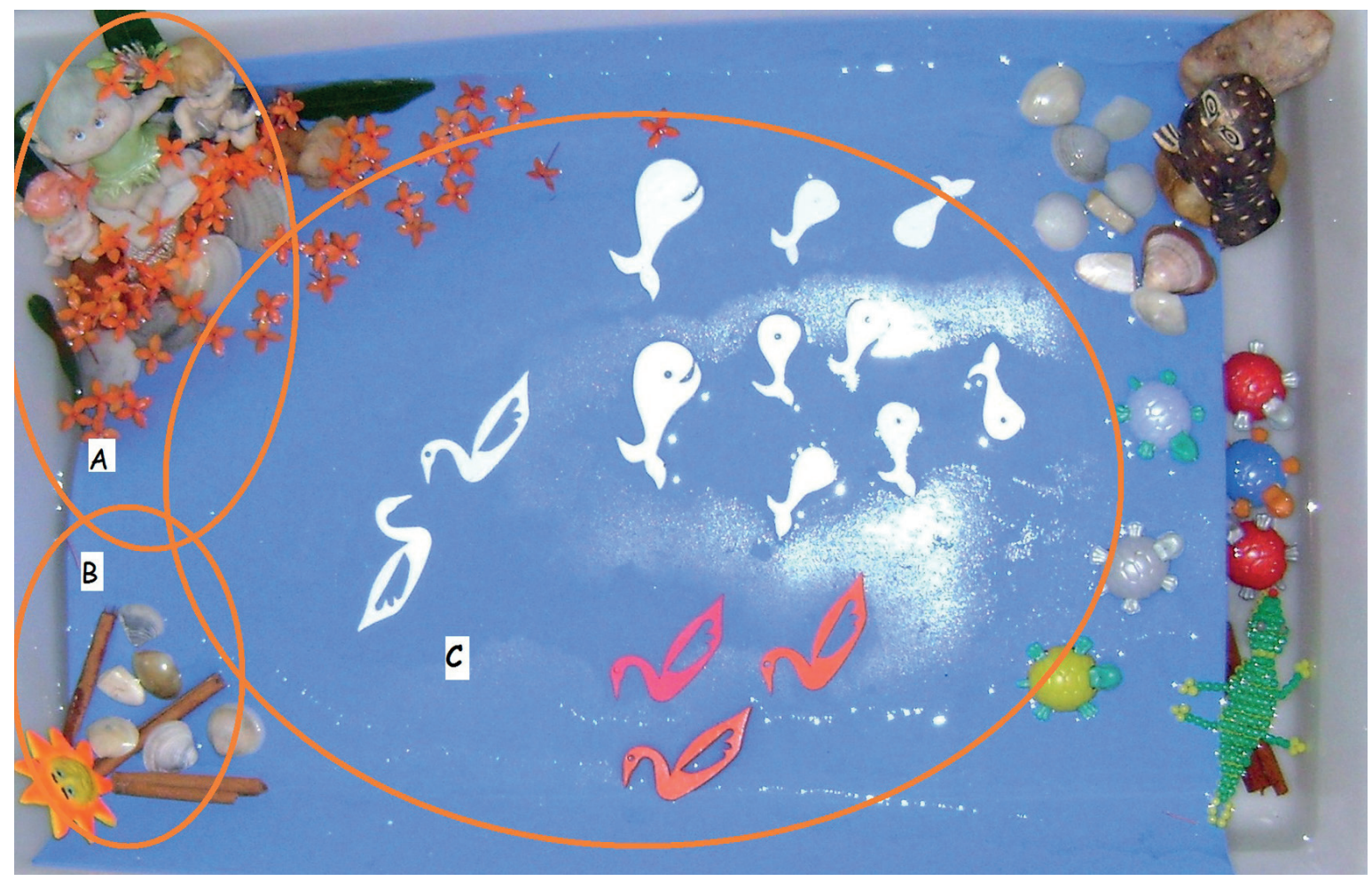

Fuente: archivo de la investigación. 
Con el paso de los años, al empezar la juventud/vida adulta, frente a las nuevas y cada vez más consciente lecturas mundo (Freire, 2012), frente a las relaciones que se establecían entre naturaleza/sociedad/ambiente (Loureiro, 2011), era perceptible la discriminación con respecto a los individuos con comportamientos típicos de los campesinos, tanto los que vivían como los que no vivían en regiones rurales. Ellos, por su parte, siempre que posible, negaban y ocultaban sus raíces campesinas, porque el comportamiento y los valores aceptados en esta sociedad urbanizada se relacionaban mucho más con la modernidad, debido al modelo de desarrollo adoptado en Brasil. De esta forma, se establecieron nuevas relaciones con la tierra, fuertemente orientadas por el consumo y el descarte, provocando una ceguera ambiental (Guattari, 2012).

Pero el destino encuentra formas sutiles de actuar y mostrar caminos, y durante el desarrollo profesional, escogimos algo que nos traía el mismo placer que se sentía en los "patios encantados" de las ecovivencias de la infancia y de la adolescencia. Así, elegimos la docencia de Ciencias y Biología. La Figura 3 muestra ese ardor presente en el llamado de la vocación, en el cual "una chispa que salta del humo es suficiente para impulsarnos a nuestro destino" (Bachelard, 2008, p. 28). Según el autor, el fuego hace que intuiciones personales y experiencias científicas se confundan por ser un objeto inmediato y con valor fenomenológico al actuar en una zona objetiva impura.

Figura 3: Escenario intitulado "La llama de la educación”. A): la energía, que simboliza la Heteroformación; B) el búho, que simboliza la Autoformación; C) las velas, que simbolizan la Ecoformación

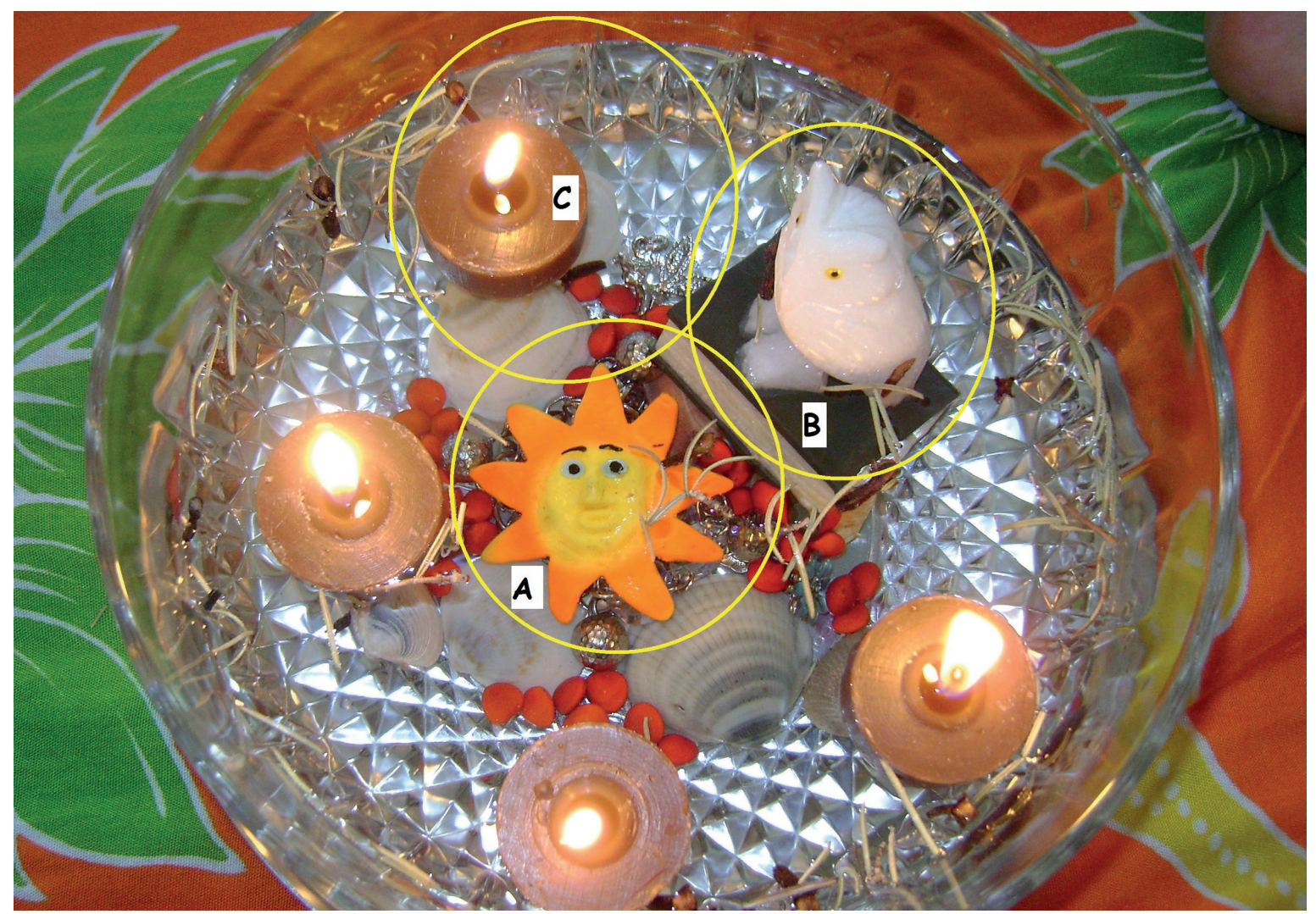

Fuente: archivo de la investigación. 
En los primeros años de docencia, prevaleció la forma 'artesanal' (Pimenta, Lima, 2004), pero sabía que era necesario superar los varios espacios en blanco que existían para ejercer reflexivamente la profesión. Entonces buscamos soporte epistemológico y metodológico para transponer nuestra forma 'artesanal' y alcanzar una práctica educacional reflexiva, porque "en la naturaleza, todo se encuentra en perpetuas oscilaciones de dilatación y contracción debido a la acción del fuego sobre los cuerpos" (Bachelard, 2008, p. 121). Iniciamos el contacto con varios cursos de corta y larga duración, tanto lato-sensu como stricto-sensu, consciente de que la formación no se construye solamente con el acúmulo de cursos, conocimientos y técnicas, como indica Nóvoa (2009). Así que, al profundizar los estudios acerca de la Educación Ambiental (EA) y, más específicamente, sobre su vertiente crítica (EAC), ${ }^{7}$ al percibir tales cambios en nuestra trayectoria como profesora de Ciencias Biológicas, había la premisa de transmitir a los estudiantes conocimientos basados no solo en los aspectos cognitivos, inherentes a esa área de enseñanza. Buscábamos también estimular las lecturas de mundo, dirigidas hacia el habitar sostenible, con la toma de decisiones y acciones corresponsables. En suma, era necesario desarrollar en los estudiantes aspectos de la autoformación, de la heteroformación y de la ecoformación (Pineau, 2008a).

Un nuevo espacio, también 'encantado', empezó a crearse, dado que que "en el trayecto que nos hace regresar a los orígenes, hay primeramente el camino que nos hace volver a la infancia, a nuestra infancia soñadora" (Bachelard, 2003, p. 94). Así, a los pocos las ecovivencias sobresalientes de la fase infantil y de la juventud pudieron ser experimentadas nuevamente en un ambiente escolar, ahora bajo la condición de profesora. Utilizando como referencias el lenguaje de la naturaleza de Capra (2012), la ecopedagogía de Gutiérrez e Prado (2008), la biología del amor de Maturana (2011) y la concepción libertaria de la Educación de Freire (2011), varios proyectos educacionales han sido creados y ecovivenciados, como se puede ver en la Figura 4, lo que está simbolizado a través del elemento tierra. Las clases, por su parte, traspasaban los límites de las cuatro paredes de un aula. Cualquier espacio era lugar para el aprendizaje significativo, según la concepción de la transgresión de espacios apuntada por Espírito Santo (1996), ya sea tal espacio formal o informal.

Los recuerdos fluían libremente con el Juego de Arena y las Escrituras de sí, desvelando reminiscencias y nuevas percepciones de ese proceso de ecoformación. Estaban en conformidad con Pineau (2008a, p. 52) cuando este afirmó que "el habitar no es solamente formado por hábitos que son más o menos un reflejo del alojarse; habitar exige nuevos aprendizajes y se convierte en una competencia individual y colectiva para construir y aprender". Por lo tanto, ya no observábamos la harmonía en el entorno ambiental como la habíamos ecovivenciado en la infancia. Lo que veíamos entonces era el crecimiento de un gran centro urbanizado e industrializado ${ }^{8}$, pero sin una planificación sostenible que fuera suficiente para las demandas de infraestructura de una población cada vez más grande. Tanto con respecto al cinturón de pobreza de las periferias, privado del debido saneamiento básico y sin una solución adecuada para que se descarten los desechos sólidos y orgánicos producidos, como con relación a las áreas de protección como nacientes, manglares y bosques de galería, e incluso con relación al descarte en el aire de cuerpos hídricos de residuos industriales no biodegradables.

Con la criticidad cada vez más latente de mi desarrollo en cuanto docente, entendía que el proceso educacional ocurría, como indica Freire (2011), cuando se comparten varios saberes oriundos de todos aquellos involucrados, tanto estudiantes como familiares, gestores y docentes, con la construcción de espacios sanos para un aprendizaje significativo. Pero la realidad observada era otra, caracterizada por la rigidez espacial de los ambientes pedagógicos, reafirmando en los estudiantes una ceguera ambiental. La ecovivencialidad (Schulz, 2014), 
la creatividad, la sensibilidad y la expresividad, además de la emancipación que buscaba la autoformación (Pineau, 2008b), no tenían un espacio ni recibían una valoración adecuados. Las relaciones entre esos estudiantes, que tenían como objetivo la heteroformación (Pineau, 2008a), eran marcadas por la falta de respeto, por la competencia y por la falta de solidaridad. De la misma forma, sus relaciones con el medio más inmediato, con su entorno, lo que objetivaba su ecoformación (Pineau, 2008a), no eran diferentes, porque eran orientadas por la lógica mercantilista-exploratoria, por la tendencia al consumo y al descarte.

Figura 4: Escenario intitulado "Las semillas de la educación”. A) simbolización de la escuela; B) simbolización de la comunidad escolar; C) simbolización del árbol-madre y sus semillas; D) simbolización de las mudas del nuevo plantío

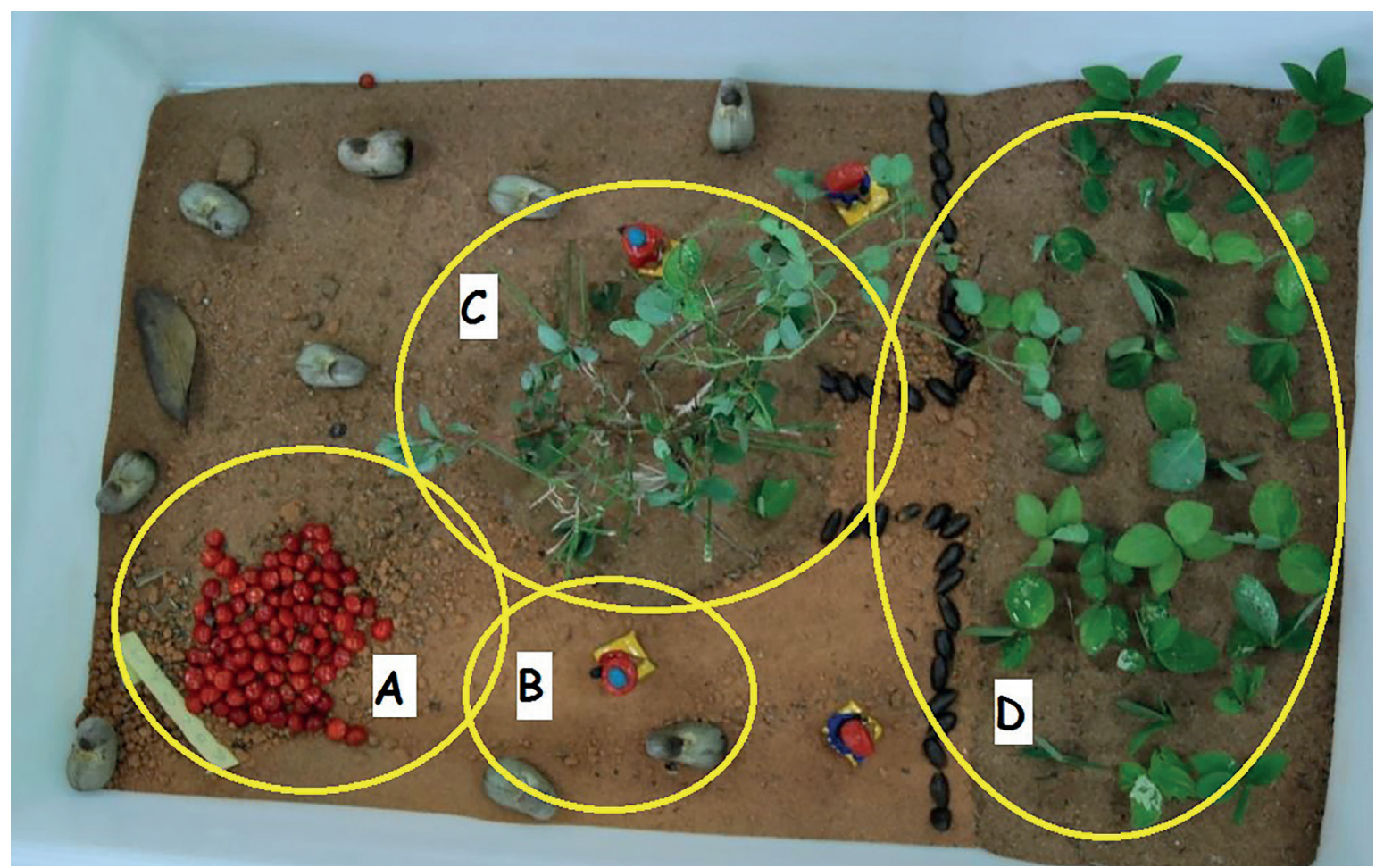

Fuente: archivo de la investigación.

La EA, por su parte, cuando era abordada por los docentes y gestores, tanto en el ambiente interno como en el ambiente externo de la institución, era limitada y poco eficiente, ya que no hacía que se examinaran cuestiones y valores sociales. No estimulaba la capacidad crítica, dado que que estaba concentrada en el objetivo de comunicar a la sociedad su eficiencia y preocupación ambiental según una lógica neoliberal y productivista (Gentili, 1995). Por lo tanto, era practicada como si el ser humano no fuera parte del ambiente, como si no fuera un ser natural, no ofreciendo intervenciones socioambientales. En otras palabras, la EAC no era contemplada.

Durante las clases con las ecovivencias, había otras observaciones inquietantes. Entre ellas, la desconexión de los alumnos urbanos con la tierra, con ambientes naturales, teniendo en cuenta que ellos evitaban tocar la tierra para no 'ensuciarse'. En las caminatas por el bosque, mostraban falta de equilibrio y de coordinación motriz, ansiedad y miedo, no logrando que- 
darse en silencio o apreciar los sonidos, olores y colores del 'nuevo ambiente'. Si habían sido creados en lugares planos, 'limpios', con aspecto de modernidad, ¿cómo iban a sentir y manifestar placer y desenvoltura en la interacción con un 'patio encantado'? Por otro lado, observábamos el comportamiento de los hijos de campesinos de las áreas rurales dentro de la ciudad, que demostraban, además de tranquilidad, cuidado, cariño $y$ afecto en esas ecovivencias con relación al medio y a los demás. Esas observaciones estaban en conformidad con Tuan (2012) y el principio de la topofilia. Para el autor, ese término es un neologismo que incluye todos los vínculos de afectividad de los seres humanos con su entorno más inmediato, o sea, con su medio ambiente.

Frente a esas inquietudes, durante tal trayectoria en cuanto docente, varios retos han surgido, retos que estimulaban a crear un lugar de ecovivencias, de reconexión, donde fuera posible para los participantes el reencantamiento con los 'patios encantados' de nuestra infancia y que dialogarán con los saberes académicos científicos de la EAC. Se sentía la necesidad de seguir profundizando los estudios, asociando la enseñanza de Ciencias y Biología, la EAC y las relaciones Ecoformativas. Esa intención fue simbolizada en la Figura 5: "gracias al método del Juego de Arena, las dimensiones espiritual y psicológica no son solamente consteladas en el individuo, sino que al mismo tiempo se les da una forma concreta a través del trabajo manual" (Ammann, 2004, p. 11). Ese es el potencial que contiene el espacio simbólico de la caja de arena ( $\mathrm{Scoz}$, 2011). Así que era necesario provocar nuevas polinizaciones en nuevos aires, y así elegimos el colibrí para tal simbolización, para ese encuentro entre sujeto y objeto, entre emoción y pensamiento, entre consciente e inconsciente.

Nos mudamos de Santa Catarina, estado de la región Sur de Brasil, y nos trasladamos a la otra extremidad del país, a la capital del estado de Rio Grande do Norte, la ciudad de Natal. En ese nuevo 'patio', el ambiente observado es un poco diferente en varios aspectos: por su biodiversi- dad, con sus dunas; por la expresión cultural, con sus creencias y valores; o aún por el modo cómo se relacionan las personas con ellas mismas y con su medio. "Desraizar exige violencia, provocaciones, gritos", como afirma Bachelard (2003, p. 229). Así que, en conformidad con Pineau (2008a, p. 55) cuando nos dice que "es necesario mucho tiempo y energía para encontrar un otro lugar para re-enraizarse", estábamos conscientes de que sería necesario recomenzar todo nuevamente en un 'patio' que no conocíamos, que era extraño para nosotros.

$\mathrm{Y}$ en ese proceso de creación de nuevas raíces, observábamos también en los habitantes de la nueva ciudad comportamientos de estigmatización y desprecio con relación a las familias oriundas del campo, más precisamente del "semiárido potiguar" (la región semiárida del Rio Grande do Norte), una región que sufre constantemente con la falta de lluvias y que tiene un bajo régimen pluviométrico. Esas impresiones nos hacían volver a los recuerdos de nuestra región y a la marginalización que también ocurría con nuestros estudiantes del campo. Además, era necesario resignificar las ideas que fueran incorporadas a lo largo de la vida, de que el suelo de la región Noreste del país sería infértil $^{9}$, y con ese objetivo probamos a sembrar un huerto en esa nueva y diferente tierra. Como elemento de deconstrucción, hemos percibido una latente fertilidad, dado que en poco tiempo surgieron los primeros brotes.

La necesidad de investigar la Enseñanza de Ciencias y Biología, la EAC y las relaciones Ecoformativas aún nos intrigaban, llevándonos a buscar sitios e investigaciones que dialogaran con nuestra problemática. En el grupo de investigación BACOR-PPGE-UFRN, encontramos el primer espacio académico, con estudios e investigaciones que consolidan este artículo. Con enfoque en la corporeidad y la expresividad, la línea de investigación elegida también se ocupaba de la importancia atribuida al enfoque vivencial humanitario (Cavalcanti, 2010) utilizando como recursos el Juego de Arena y las Escrituras 
de sí. De esta forma, se ofrecía una nueva metodología para incorporarse al proceso de formación de los profesores-investigadores. Esta perspectiva educacional invierte en la formación a partir del propio sujeto y su vivencia, que se apoya en los estudios acerca de los fenómenos humanos de la creatividad, de la implicación, de la autorreflexión y de la sensibilidad para que se incorporen a los nuevos saberes y a las nuevas prácticas educacionales (Cavalcanti, 2010).

Figura 5: Escenario intitulado 'Vida nueva, nuevos aires'. En (A), simbolización de la apertura para nuevas investigaciones. En (B), simbolización de encuentro con el colibrí

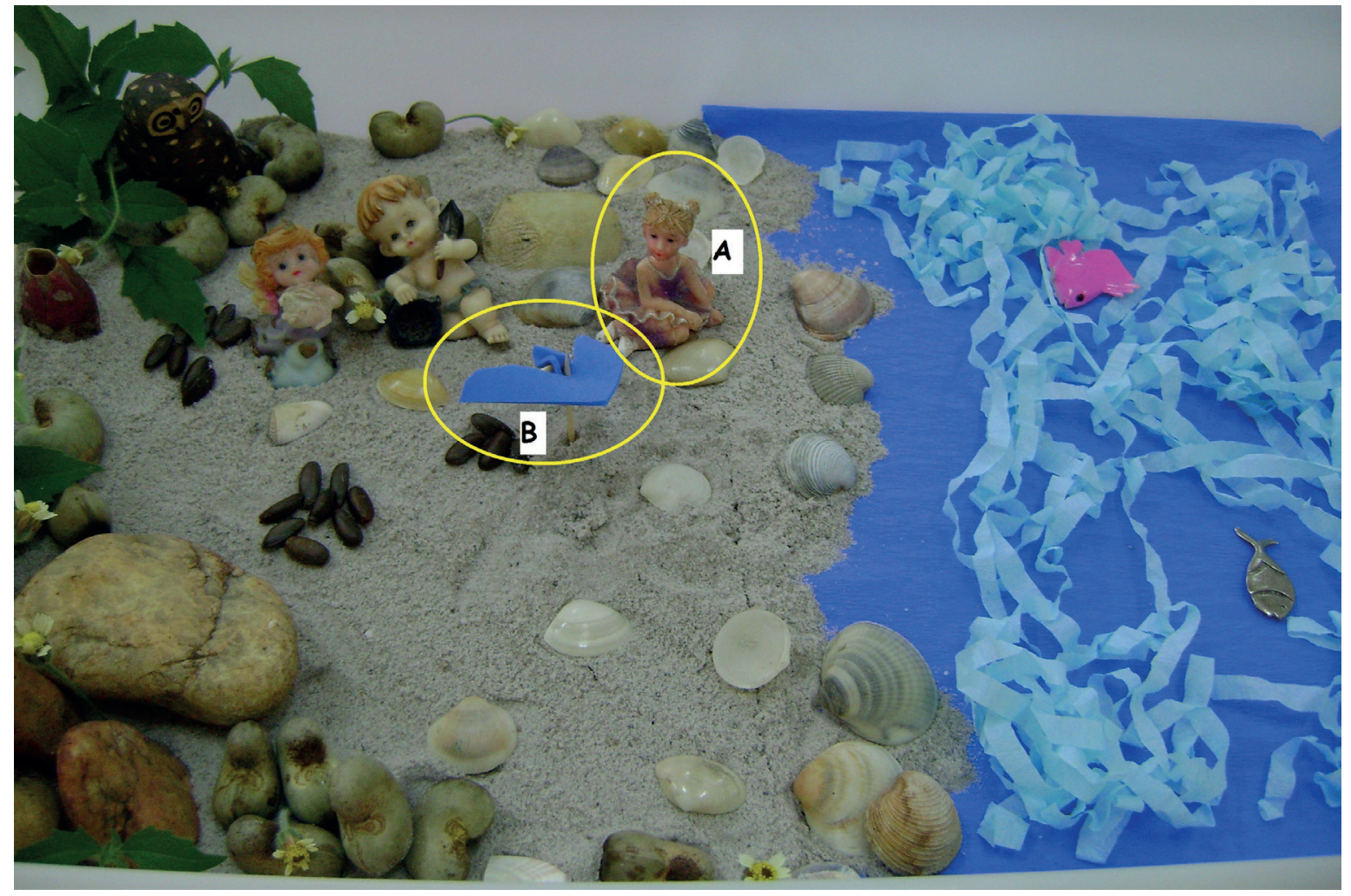

Fuente: archivo de la investigación.

Frente a todo ese trayecto ecoformativo, al final del 2014, materializamos parte de nuestras inquietudes, porque según Bachelard (2013, p. 120), "cuando amamos una realidad con toda el alma, es porque nuestra realidad es ya un alma”. Así, defendimos la tesis intitulada 'Pedagogia Ecovivencial: por uma Educação Ambiental Emancipatória', (Schulz, 2014) convalidada como estrategia pedagógica de EAC. Tal propuesta se apoya sobre tres ejes fundadores: el epistemológico, el ontológico y el metodológico. Para el eje epistemológico, la propuesta fue fundada con los siguientes aportes teóricos: la Biología del Amor (Maturana, 2010, 2011), sobre la cual se basó la vertiente de la afectividad, la Ecopedagogía (Gutiérrez; Prado, 2008), sobre la cual se basó la ecovivencialidad, y la Concepción Crítica y Libertaria de la Educación (Freire, 2011, 2012), sobre la cual se basó la vertiente de la emancipación, de la criticidad. El eje metodológico se basó en los aspectos conceptuales, procedimentales y actitudinales (Coll et al., 2000) inherentes al proceso de enseñanzaaprendizaje, fundamentales para la formación integral. Finalmente, el eje ontológico se basó en el proceso (auto-hetero-eco)formativo de Pineau 
(2008a). Por fin, con el objetivo de seguir con ese proceso de materialización, esperamos difundir esta propuesta pedagógica, ofreciéndola para aplicaciones en otros públicos para que pueda ser probada, criticada y corregida a través de diálogos provechosos entre nosotros, educadores, en busca de la EAC que queremos.

\section{Consideraciones finales}

Asociar conocimientos de la investigación (Auto)biográfica y del Juego de Arena, o "Sandplay", en cuanto recursos metodológicos autorreflexivos fue fundamental para comprender mejor el sentido de nuestra ecoformación. El Juego de Arena posibilitó el flujo de emociones y sentimientos represados con la creación de imágenes internas. A través de las escrituras de sí, fuimos llevados a reflexionar, a expresar y a resignificar lo que sentimos, lo que hacemos, lo que pensamos y hacia dónde caminamos.

Además, el reto de escribir este ensayo nos hizo conscientes de que la ecoformación ha sido el hilo conductor de toda nuestra trayectoria personal, docente y académica. Nos hizo ver que estamos en un punto privilegiado de nuestra trayectoria, en el cual la intuición encontró los fundamentos teóricos necesarios para actuar de forma madura y global. Nuestras frecuentes visitas a las playas del Rio Grande do Norte nos hicieron recordar, entre baños de mar, la clásica explicación de Bourdieu (1998) sobre el capital cultural. Ese capital que, diferente de los capitales financiero y económico, no se puede obtener rápidamente, por herencia o ganando en la lotería, por ejemplo. Al contrario, así como un bronceado de verano, surge lentamente, inscribiendo sobre la piel un nuevo color, capa sobre capa. Sentimos que ese bronceado alcanzó su punto ideal, sentimos ese nuevo capital cultural y así empezamos a apropiarnos de él.

Esperamos, entonces, que este texto, cuyo referencial metodológico es el Juego de Arena y las Escrituras de sí, termine por promover discusiones fundamentales y amplíe el debate en la comunidad, estimulando la autoformación, la heteroformación y la ecoformación para que se obtenga una EAC ecovivenciada, amorosa y emancipadora.

\section{Notas}

1 Adoptamos las contribuciones de González Rey (1997) sobre el concepto de subjetividad, el cual, según el autor, se compone de la psique en el sujeto individual, formándose también de procesos y estados que son inherentes a ese individuo en sus actividades de acción social.

2 La formación humana, según Pineau, ocurre de forma tripolar: entre la acción del individuo con sí mismo (autoformación), del individuo con los demás (heteroformación) y del individuo con el medio ambiente (ecoformación).

3 "Base da Corporeidade" (BACOR) del Programa de Posgrado en Educación de la Universidad Federal del Rio Grande do Norte.

4 Todos los registros eran hechos por medio de un portafolio con las Escrituras de sí que evidenciaban marcas acerca de los procesos de ecoformación de la autora.

5 La ecovivencialidad deriva de dos palabras: "oikos" (que en griego significa "casa") y "vivencialidad", que se refiere a la vivencia y significa sentir o experimentar algo con intensidad.

6 Decimos "patios encantados" |"quintais encantados", en el original) a los sitios con potencial ecoformador.

7 La Educación Ambiental Crítica (EAC) es parte de la macrotendencia crítica propuesta por Layrargues y Lima (2014), reuniendo corrientes de la Educación Ambiental Popular, Emancipadora, Transformadora y en el Proceso de Gestión Ambiental.

8 La ciudad de Joinville (SC), durante los 70 y los 80, presentó un rápido proceso de industrialización, pasando a ser conocida como la "Manchester Catarinense", en referencia a la gran ciudad industrializada de Inglaterra.

9 Maknamara (2012) apunta que, históricamente, hay una red de discursos que han estado contribuyendo para la incorporación de ciertas ideas acerca de la región Noreste de Brasil, y entre ellas está la idea de la infertilidad del suelo.

\section{Bibliografía}

Ammann, R. (2004). A terapia do jogo de areia: imagens que curam a alma e desenvolvem a personalidade. Tradução de Marion Serpa. $2^{\text {a }}$. ed. São Paulo: Paulus.

Bachelard, G. (1985). O novo espirito científico. Tradução de Juvenal Hahne Junior. 2a ed. Rio de Janeiro: Tempo Brasileiro.

Bachelard, G. (2001). O ar e os sonhos: Ensaio sobre a imaginação do movimento. Tradução de 
Antonio de Pádua Danesi. 2a ed. São Paulo: Martins Fontes.

Bachelard, G. (2003). A Terra e os Devaneios do Repouso - ensaio sobre as imagens da intimidade. Tradução de Paulo Neves. S. Paulo: Martins Fontes.

Bachelard, G. (2008). A psicanálise do fogo. Tradução de Paulo Neves. 3a ed. São Paulo: Martins Fontes.

Bachelard, G. (2013). A água e os sonhos - Ensaio sobre a imaginação da matéria. Tradução de Antonio de Pádua Danesi. 2a ed. São Paulo: Martins Fontes.

Bourdieu, P. (1998). Os três estados do capital cultural. In: Nogueira, Maria Alice; Catani, Afrânio (Org.). Escritos de educação (265-270). 2 da. ed. Petrópolis: Vozes.

Capra (2012). A Teia da Vida. 13a ed. São Paulo: Cultrix.

Cavalcanti, K. B. (2010). O jogo de Areia como obra de arte da vida. In Cavalcanti, K. B. (Orgs.), Jogo de Areia: uma abordagem transdisciplinar para a Educação (19-48). Natal, RN: EDUFRN.

Coll, C. et al. (2000). Os conteúdos na reforma. Porto Alegre: Artmed.

Espírito Santo, R. C. (1996).Pedagogia da Transgressão: um caminho para o autoconhecimento. $10^{\mathrm{a}}$ ed. São Paulo: Ágora.

Freire, P. (2011). Pedagogia do Oprimido. 50. ed. Rio de Janeiro: Paz e Terra.

Freire, P. (2012). À Sombra desta Mangueira. 10a ed. Rio de Janeiro: Civilização Brasileira.

Gadotti, M. (2000). Pedagogia da Terra. 3. ed. São Paulo: Peirópolis.

Guattari, F. (2012). As três ecologias. 21 a edição. São Paulo: Papirus.

Gatti, B. (2003). Formação continuada e professores: a questão social. Cadernos de Pesquisa, 119, (191-204).

Gentili, P. (1995). Como reconhecer um governo neoliberal? Um breve guia para educadores. In Silva, L. H.; Azevedo, J. C. (Orgs.), Reestruturação curricular: teoria e prática no cotidiano da escola (128-137). Petrópolis: Vozes.

González Rey, F. (1997). Epistemología cualitativa y subjetividad. São Paulo: Educ.

Gutiérrez, F., \& Prado, C. (2008). Ecopedagogia e Cidadania Planetária. 4a ed. São Paulo: Instituto Paulo Freire.
Kalff, D. M. (1980). A psychotherapeutic approach to the psyche. 2a ed. Boston: Sigo.

Layrargues, P. O. \& Lima, G. F. C. (2014). As macrotendências político-pedagógicas da Educação Ambiental brasileira. Ambiente \& Sociedade, XVII(1), 23-40.

Loureiro, C.F. (2011). Educação ambiental e os movimentos sociais na construção da cidadania ecológica e planetária. In Loureiro, C. F; Layrargues, P. P.; Castro, R. S. (Orgs.), Educação Ambiental: repensando o espaço da cidadania (73-103). São Paulo: Cortez.

Maknamara, M. (2012). Educação ambiental e Nordestinidade: Desafios à práxis ecologista. Revista Brasileira de Educação Ambiental, (10-17). Rio Grande, Número Especial.

Maturana, H. (2010). A árvore do conhecimento: as bases biológicas da compreensão humana. São Paulo: Palas Athena.

Maturana, H., Zoller, G. V. (2011). Amar e Brincar: fundamentos esquecidos do humano. Tradução Humberto Mariotti e Lia Diskin. 3. ed. São Paulo: Pala Atenas.

Nóvoa, A. (2002). Formação de professores e trabalho pedagógico. Lisboa: Educa.

Nóvoa, A. (2009). Professores: imagens do futuro presente. Lisboa: Educa.

Passeggi, M. C. (2008). Memoriais auto-bio-gráficos: a arte profissional de tecer uma figura pública de si. In Passeggi, M. C., Barbosa, T. M. N. (Org.). Memórias, memoriais: pesquisa e formação docente. 1ra. ed. São Paulo: Paulus; EDUFRN.

Passeggi, M. C. (2010). Narrar é humano! Autobiografar é um processo civilizatório. In Passeggi, M. C., Silva, V. B. (Org.), Invenções de vidas, compreensão de itinerários e alternativas de formação (103-130). São Paulo: Cultura Acadêmica.

Pimenta, S. G.; Lima, M. S.L. (2004). Estágio e Docência. São Paulo: Cortez.

Pineau, G. (2004). Temporalidades na formação: rumo a novos sincronizadores. São Paulo: Triom.

Pineau, G. (2008a). Aprender a habitar a Terra: ecoformação e autobiografias ambientais. In Passeggi, M. C. Souza, E. C. S. (Org.), (Auto) biografia: formação, territórios e saberes (4766). São Paulo: Paulus. 
Pineau, G. (2008b). O "gaio saber" do amor à vida. In Souza, E. C.; Mignot, A. C. V. (Orgs), Histórias de vida e formação de professores (17-38). Rio de Janeiro: Quartet.

Pineau, G. (2010). A autoformação no decurso da vida: entre a hetero e a ecoformação. In Nóvoa, A.; Finger, M. (orgs): O método (auto) biográfico e a formação (98-118). São Paulo: Paulus.

Pineau, G., \& Le Grand, J. (2012). As histórias de vida. Tradução Carlos Eduardo Galvão Braga e Maria da Conceição Passeggi. Natal: EDUFRN.

Placco, V.M.N.S. (2002). Relações interpessoais na sala de aula e desenvolvimento pessoal. Em Almeida, L.R. e Placco, V.M.N.S. (Eds.), As relações interpessoais na formação de professores (7-19). São Paulo: Loyola.

Schulz, L. (2014). Pedagogia Ecovivencial: por uma educação ambiental emancipatória. Tese (Doutorado) - Programa de Pós-Graduação em Educação. Universidade Federal da Paraíba, João Pessoa.

Scoz, B. J. L. (2011). Identidade e subjetividade de professores - sentidos do aprender e do ensinar. Petrópolis/RJ: Vozes.

Tuan, Y. (2012). Topofilia: um estudo da percepção, atitudes e valores do meio ambiente. Londrina/ PR: EDUEL.

Weinrib, E.L. (1993). Imagens do self: o processo terapêutico na caixa-de-areia. Tradução de David Gilbert Aubert. São Paulo: Summus. 



\section{Normas Editoriales}

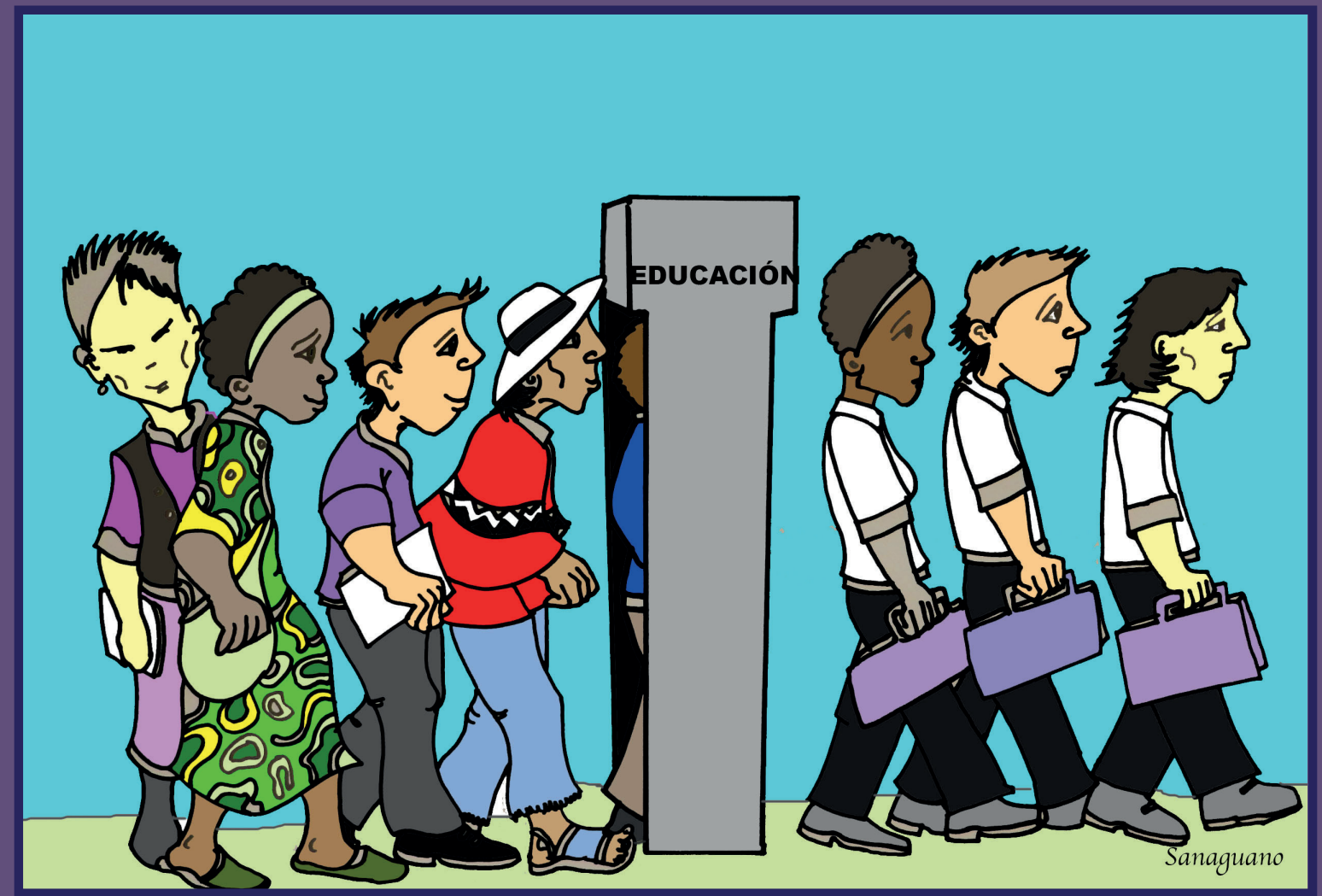




\section{Alteridad. Revista de Educación http://alteridad.ups.edu.ec/ p-ISSN:1390-325X / e-ISSN:1390-8642}

\section{Normas de Publicación en "Alteridad"}

\section{Información general}

"Alteridad" es una publicación científica bilingüe de la Universidad Politécnica Salesiana de Ecuador, editada desde enero de 2006 de forma ininterrumpida, con periodicidad fija semestral, especializada en Educación y sus líneas transdisciplinares como Didáctica, Políticas Públicas, Gerencia de Centros Escolares, Educomunicación, TIC, entre otras.

Es una revista científica arbitrada, que utiliza el sistema de evaluación externa por expertos (peerreview), bajo metodología de pares ciegos (dobleblind review), conforme a las normas de publicación de la American Psychological Association (APA). El cumplimiento de este sistema permite garantizar a los autores un proceso de revisión objetivo, imparcial y transparente, lo que facilita a la publicación su inclusión en bases de datos, repositorios e indexaciones internacionales de referencia.

"Alteridad" se encuentra indexada en el directorio y catálogo selectivo del Sistema Regional de Información en Línea para Revistas Científicas de América Latina, el Caribe, España y Portugal (Latindex), en el Sistema de Información Científica REDALYC, en el Directorio de Revistas de Acceso Abierto DOAJ y en repositorios, bibliotecas y catálogos especializados de Iberoamérica.

La revista se edita en doble versión: impresa (ISSN: 1390-325X) y electrónica (e-ISSN: 1390-8642), en español e inglés, siendo identificado además cada trabajo con un DOI (Digital Object Identifier System).

\section{Alcance y política}

\subsection{Temática}

Contribuciones originales en materia de Educación, así como áreas afines: Didáctica, Políticas Públicas, Gerencia de Centros Escolares, Educomunicación, TIC... y todas aquellas disciplinas conexas interdisciplinarmente con la línea temática central.

\subsection{Aportaciones}

"Alteridad" edita preferentemente resultados de investigación empírica sobre Educación, redactados en español y/o inglés, siendo también admisibles informes, estudios y propuestas, así como selectas revisiones de la literatura (state-of-the-art).

Todos los trabajos deben ser originales, no haber sido publicados en ningún medio ni estar en proceso de arbitraje o publicación. De esta manera, las aportaciones en la revista pueden ser:

- Investigaciones: 5.000 a 6.500 palabras de texto, incluyendo título,a resúmenes, descriptores, tablas y referencias.

- Informes, estudios y propuestas: $5.000 \mathrm{a}$ 6.500 palabras de texto, incluyendo título, resúmenes, tablas y referencias.

- Revisiones: 6.000 a 7.000 palabras de texto, incluidas tablas y referencias. Se 
valorará especialmente las referencias justificadas, actuales y selectivas de alrededor de unas 70 obras.

"Alteridad" tiene periodicidad semestral (20 artículos por año), publicada en los meses de enero y julio y cuenta por número con dos secciones de cinco artículos cada una, la primera referida a un tema Monográfico preparado con antelación y con editores temáticos y la segunda, una sección de Misceláneas, compuesta por aportaciones variadas dentro de la temática de la publicación.

\section{Presentación, estructura y estilo de los manuscritos}

Los trabajos se presentarán en tipo de letra Arial 10, interlineado simple, justificado completo y sin tabuladores ni espacios en blanco entre párrafos. Solo se separarán con un espacio en blanco los grandes bloques (título, autores, resúmenes, descriptores, créditos y epígrafes). La página debe tener 2 centímetros en todos sus márgenes.

Los trabajos deben presentarse en documento de Microsoft Word (.doc o docx), siendo necesario que el archivo esté anonimizado en Propiedades de Archivo, de forma que no aparezca la identificación de autor/es.

Las Normas de publicación se basan en APA 6 (https://goo.gl/x4PyFw).

\subsection{Estructura del manuscrito}

Para aquellos trabajos que se traten de investigaciones de carácter empírico, los manuscritos seguirán la estructura IMRDC, siendo opcionales los epígrafes de Notas y Apoyos. Aquellos trabajos que por el contrario se traten de informes, estudios, propuestas y revisiones podrán ser más flexibles en sus epígrafes, especialmente en Material y métodos, Análisis y resultados y Discusión y conclusiones. En todas las tipologías de trabajos son obligatorias las Referencias.
1. Título (español) / Title (inglés): Conciso pero informativo, en castellano en primera línea y en inglés en segunda. Se aceptan como máximo 80 caracteres con espacio. El título no solo es responsabilidad de los autores, pudiéndose proponer cambios por parte del Consejo Editorial.

2. Resumen (español) / Abstract (inglés): Tendrá como extensión máxima 230 palabras, primero en español y después en inglés. En el resumen se describirá de forma concisa y en este orden: 1) Justificación del tema; 2) Objetivos; 3 ) Metodología y muestra; 4) Principales resultados; 5) Principales conclusiones. Ha de estar escrito de manera impersonal "El presente trabajo analiza...". En el caso del abstract no se admitirá el empleo de traductores automáticos por su pésima calidad.

3. Descriptores (español) / Keywords (inglés): Se deben exponer 6 descriptores por cada versión idiomática relacionados directamente con el tema del trabajo. Será valorado positivamente el uso de las palabras claves expuestas en el Thesaurus de la UNESCO.

4. Introducción y estado de la cuestión: Debe incluir el planteamiento del problema, el contexto de la problemática, la justificación, fundamentos y propósito del estudio, utilizando citas bibliográficas, así como la literatura más significativa y actual del tema a escala nacional e internacional.

5. Material y métodos: Debe ser redactado de forma que el lector pueda comprender con facilidad el desarrollo de la investigación. En su caso, describirá la metodología, la muestra y la forma de muestreo, así como se hará referencia al tipo de análisis estadístico empleado. Si se trata de una metodología original, es necesario exponer las razones que han conducido a su empleo y describir sus posibles limitaciones.

6. Análisis y resultados: Se procurará resaltar las observaciones más importan- 
tes, describiéndose, sin hacer juicios de valor, el material y métodos empleados. Aparecerán en una secuencia lógica en el texto y las tablas y figuras imprescindibles evitando la duplicidad de datos.

7. Discusión y conclusiones: Resumirá los hallazgos más importantes, relacionando las propias observaciones con estudios de interés, señalando aportaciones y limitaciones, sin redundar datos ya comentados en otros apartados. Asimismo, el apartado de discusión y conclusiones debe incluir las deducciones y líneas para futuras investigaciones.

8. Apoyos y agradecimientos (opcionales): El Council Science Editors recomienda a los autor/es especificar la fuente de financiación de la investigación. Se considerarán prioritarios los trabajos con aval de proyectos competitivos nacionales e internacionales. En todo caso, para la valoración científica del manuscrito, este debe ir anonimizado con XXXX solo para su evaluación inicial, a fin de no identificar autores y equipos de investigación, que deben ser explicitados en la Carta de Presentación y posteriormente en el manuscrito final.

9. Las notas (opcionales) irán, solo en caso necesario, al final del artículo (antes de las referencias). Deben anotarse manualmente, ya que el sistema de notas al pie o al final de Word no es reconocido por los sistemas de maquetación. Los números de notas se colocan en superíndice, tanto en el texto como en la nota final. No se permiten notas que recojan citas bibliográficas simples (sin comentarios), pues éstas deben ir en las referencias.

10. Referencias: Las citas bibliográficas deben reseñarse en forma de referencias al texto. Bajo ningún caso deben incluirse referencias no citadas en el texto. Su número debe ser suficiente para contextualizar el marco teórico con criterios de actualidad e importancia. Se presentarán alfabéticamente por el primer apellido del autor.

\subsection{Normas para las referencias}

\section{Publicaciones periódicas}

Artículo de revista (un autor): Valdés-Pérez, D. (2016). Incidencia de las técnicas de gestión en la mejora de decisiones administrativas [Impact of Management Techniques on the Improvement of Administrative Decisions]. Retos, 12(6), 199-213. https://doi. org/10.17163/ret.n12.2016.05

Artículo de revista (hasta seis autores): Ospina, M.C., Alvarado, S.V., Fefferman, M., \& Llanos, D. (2016). Introducción del dossier temático "Infancias y juventudes: violencias, conflictos, memorias y procesos de construcción de paz" [Introduction of the thematic dossier "Infancy and Youth: Violence, Conflicts, Memories and Peace Construction Processes"]. Universitas, 25(14), 91-95. https:// doi.org/10.17163/uni.n25.\%25x

Artículo de revista (más de seis autores): Smith, S.W., Smith, S.L. Pieper, K.M., Yoo, J.H., Ferrys, A.L., Downs, E.,... Bowden, B. (2006). Altruism on American Television: Examining the Amount of, and Context Surronding. Acts of Helping and Sharing. Journal of Communication, 56(4), 707-727. https://doi. org/10.1111/j.1460-2466.2006.00316.x

Artículo de revista (sin DOI): Rodríguez, A. (2007). Desde la promoción de salud mental hacia la promoción de salud: La concepción de lo comunitario en la implementación de proyectos sociales. Alteridad, 2(1), 28-40. (https:// goo.gl/zDb3Me) (2017-01-29).

Libros y capitulos de libro

Libros completos: Cuéllar, J.C., \& MoncadaParedes, M.C. (2014). El peso de la deuda externa ecuatoriana. Quito: Abya-Yala.

Capítulos de libro: Zambrano-Quiñones, D. (2015). El ecoturismo comunitario en Manglaralto y Colonche. En V.H. Torres (Ed.), Alternativas de Vida: Trece experiencias de desarrollo endógeno en Ecuador (175-198). Quito: Abya-Yala. 


\section{Medios electrónicos}

Pérez-Rodríguez, M.A., Ramírez, A., \& GarcíaRuíz, R. (2015). La competencia mediática en educación infantil. Análisis del nivel de desarrollo en España. Universitas Psychologica, 14(2), 619-630. https://doi.org.10.11144/ Javeriana.upsy14-2.cmei

Es prescriptivo que todas las citas que cuenten con DOI (Digital Object Identifier System) estén reflejadas en las Referencias (pueden obtenerse en http://goo.gl/gfruh1). Todas las revistas y libros que no tengan DOI deben aparecer con su link (en su versión on-line, en caso de que la tengan, acortada, mediante Google Shortener: http:// goo.gl) y fecha de consulta en el formato indicado.

Los artículos de revistas deben ser expuestos en idioma inglés, a excepción de aquellos que se encuentren en español e inglés, caso en el que se expondrá en ambos idiomas utilizando corchetes. Todas las direcciones web que se presenten tienen que ser acortadas en el manuscrito, a excepción de los DOI que deben ir en el formato indicado (https://doi.org/XXX).

\subsection{Epígrafes, tablas y gráficos}

Los epígrafes del cuerpo del artículo se numerarán en arábigo. Irán sin caja completa de mayúsculas, ni subrayados, ni negritas. La numeración ha de ser como máximo de tres niveles: 1. / 1.1. / 1.1.1. Al final de cada epígrafe numerado se establecerá un retorno de carro.

Las tablas deben presentarse incluidas en el texto en formato Word según orden de aparición, numeradas en arábigo y subtituladas con la descripción del contenido.

Los gráficos o figuras se ajustarán al número mínimo necesario y se presentarán incorporadas al texto, según su orden de aparición, numeradas en arábigo y subtituladas con la descripción abreviada. Su calidad no debe ser inferior a 300 ppp, pudiendo ser necesario contar con el gráfico en formato TIFF, PNG o JPEG.

\section{Proceso de envío}

Los manuscritos deben ser enviados única y exclusivamente a través del OJS (Open Journal System), en el cual todos los autores deben darse de alta previamente. No se aceptan originales enviados a través de correo electrónico u otra interfaz. Deben remitirse simultáneamente dos archivos:

1. Portada y Carta de presentación (usar el modelo oficial), en la que aparecerán:

- Título (español) / Title (inglés): Conciso pero informativo, en castellano en primera línea y en inglés en segunda. Se aceptan como máximo 80 caracteres con espacio. El título no sólo es responsabilidad de los autores, pudiéndose proponer cambios por parte del Consejo Editorial.

- Nombre y apellidos completos de cada uno de los autores, organizados por orden de prelación; seguido por la categoría profesional, centro de trabajo, correo electrónico de cada autor y número de ORCID. Es obligatorio indicar si se posee el grado académico de doctor (incluir Dr./Dra. antes del nombre).

- Resumen (español) / Abstract (inglés).

- Descriptores (español) / Keywords (inglés).

- Se incluirá además una declaración (Cover letter) de que el manuscrito se trata de una aportación original, no enviada ni en proceso de evaluación en otra revista, confirmación de las autorías firmantes, aceptación (si procede) de cambios formales en el manuscrito conforme a las normas y cesión parcial de derechos a la editorial.

2. Manuscrito totalmente anonimizado, conforme a las normas referidas en precedencia.

Todos los autores han de darse de alta, con sus créditos, en la plataforma OJS, si bien uno solo de ellos será el responsable de correspondencia. Ningún autor podrá enviar o tener en revisión dos manuscritos de forma simultánea, estimándose una carencia de cuatro números consecutivos (2 años). 


\section{Alteridad. Revista de Educación http://alteridad.ups.edu.ec/ p-ISSN:1390-325X / e-ISSN:1390-8642}

\section{Publication guidelines in "Alteridad"}

\section{General information}

"Alteridad" is a bilingual scientific publication of the Universidad Politécnica Salesiana of Ecuador, published since January 2006 in an uninterrupted manner, with a fixed biannual periodicity, specialized in Education and its transdisciplinary lines such as Didactics, Public Policies, Management of Schools, Educomunication, ICT, among others.

It is scientific journal, which uses the peer-review system, under double-blind review methodology, according to the publication standards of the American Psychological Association (APA). Compliance with this system allows authors to guarantee an objective, impartial and transparent review process, which facilitates the publication of their inclusion in reference databases, repositories and international indexing.

"Alteridad" is indexed in the directory and selective catalog of the Regional Online Information System for Scientific Journals of Latin America, the Caribbean, Spain and Portugal (Latindex), in the Scientific Information System REDALYC, in the Directory of Journals of Open Access DOAJ and in repositories, libraries and specialized catalogs of Latin America.

The journal is published in a double version: printed (ISSN: 1390-325X) and digital (e-ISSN: 1390-8642), in English and Spanish, each work being identified with a DOI (Digital Object Identifier System).

\section{Scope and policy}

\subsection{Theme}

Original contributions in Education, as well as related areas: Didactics, Public Policies, Management of Schools, Edu-communication, ICT... and all interdisciplinary disciplines related to the central theme.

\subsection{Contributions}

"Alteridad" preferably publishes results of empirical research on Education, written in Spanish and / or English, as well as reports, studies and proposals, as well as selected state-of-the-art literature reviews.

All works must be original, have not been published in any medium or be in the process of arbitration or publication.

- Research: 5,000 to 6,500 words of text, including title, abstracts, descriptors, charts and refer- ences.

- Reports, studies and proposals: 5,000 to 6,500 words of text, including title, abstracts, charts and references.

- Reviews: 6,000 to 7,000 words of text, including charts and references. Justified references, would be specially valued. (current and selected from among 70 works) 
"Alteridad" has a biannual periodicity (20 articles per year), published in January and July and counts by number with two sections of five articles each, the first referring to a Monographic topic prepared in advance and with thematic editors and the second, a section of Miscellaneous, composed of varied contributions within the theme of the publication.

\section{Presentation, structure and style of the manuscripts}

Texts will be presented in Arial 10 font, single line spacing, complete justification and no tabs or white spaces between paragraphs. Only large blocks (title, authors, summaries, descriptors, credits and headings) will be separated with a blank space. The page should be 2 centimeters in all its margins.

Papers must be submitted in a Microsoft Word document (.doc or docx), requiring that the file be anonymized in File Properties, so that the author/s identification does not appear.

These publication guidelines are based on the standards of APA 6: (http://www.apastyle.org/).

\subsection{Structure of the manuscript}

For those works that are empirical investigations, the manuscripts will follow the IMRDC structure, being optional the Notes and Supports. Those papers that, on the contrary, deal with reports, studies, proposals and reviews may be more flexible in their epigraphs, particularly in material and methods, analysis, results, discussion and conclusions. In all typologies of works, references are mandatory.

1. Title (Spanish) / Title (English): Concise but informative, in Spanish on the first line and in English on the second. A maximum of 80 characters with spaces are accepted. The title is not only the responsibility of the authors, changes being able to be proposed by the Editorial Board.
2. Abstract (Spanish) / Abstract (English): It will have a maximum extension of 230 words, first in Spanish and then in English. : 1) Justification of the topic; 2) Objectives; 3 ) Methodology and sample; 4) Main results; 5) Main conclusions. It must be impersonally written "This paper analyzes ... In the case of the abstract, the use of automatic translators will not be accepted due to their poor quality.

3. Descriptors (Spanish) / Keywords (English): 6 descriptors must be presented for each language version directly related to the subject of the work. The use of the key words set out in UNESCO's Thesaurus will be positively valued.

4. Introduction and state of the issue: It should include the problem statement, context of the problem, justification, rationale and purpose of the study, using bibliographical citations, as well as the most significant and current literature on the topic at national and international level.

5. Material and methods: It must be written so that the reader can easily understand the development of the research. If applicable, it will describe the methodology, the sample and the form of sampling, as well as the type of statistical analysis used. If it is an original methodology, it is necessary to explain the reasons that led to its use and to describe its possible limitations.

6. Analysis and results: It will try to highlight the most important observations, describing, without making value judgments, the material and methods used. They will appear in a logical sequence in the text and the essential charts and figures avoiding the duplication of data.

7. Discussion and conclusions: Summarize the most important findings, relating the observations themselves with relevant studies, indicating contributions and limitations, without adding data already mentioned in other sections. Also, the 
discussion and conclusions section should include the deductions and lines for future research.

8. Supports and acknowledgments (optional): The Council Science Editors recommends the author (s) to specify the source of funding for the research. Priority will be given to projects supported by national and international competitive projects. In any case, for the scientific evaluation of the manuscript, it should be only anonymized with XXXX for its initial evaluation, in order not to identify authors and research teams, which should be explained in the Cover Letter and later in the final manuscript.

9. The notes (optional) will go, only if necessary, at the end of the article (before the references). They must be manually annotated, since the system of footnotes or the end of Word is not recognized by the layout systems. The numbers of notes are placed in superscript, both in the text and in the final note. The numbers of notes are placed in superscript, both in the text and in the final note. No notes are allowed that collect simple bibliographic citations (without comments), as these should go in the references.

10. References: Bibliographical citations should be reviewed in the form of references to the text. Under no circumstances should references not mentioned in the text be included. Their number should be sufficient to contextualize the theoretical framework with current and important criteria. They will be presented alphabetically by the first last name of the author.

\subsection{Guidelines for references}

\section{Periodic publications}

Journal article (author): Valdés-Pérez, D. (2016). Incidencia de las técnicas de gestión en la mejora de decisiones administrativas [Impact of Management Techniques on the Improvement of Administrative Decisions]. Retos, 12(6), 199-2013. https://doi. org/10.17163/ret.n12.2016.05

Journal Article (Up to six authors): Ospina, M.C., Alvarado, S.V., Fefferman, M., \& Llanos, D. (2016). Introducción del dossier temático "Infancias y juventudes: violencias, conflictos, memorias y procesos de con- strucción de paz"[Introduction of the thematic dossier"Infancy and Youth:Violence, Conflicts, Memories and Peace ConstructionProcesses"]. Universitas, 25(14),91-95.

https://doi.org/10.17163/uni.n25.\%25x

Journal article (more tan six authors): Smith, S.W., Smith, S.L. Pieper, K.M., Yoo, J.H., Ferrys, A.L., Downs, E.,... Bowden, B. (2006). Altruism on American Television: Examining the Amount of, and Context Surronding. Acts of Helping and Sharing. Journal of Communication, 56(4), 707-727. https:// doi. org/10.1111/j.1460-2466.2006.00316.x

Journal article (without DOI): Rodríguez, A. (2007). Desde la promoción de salud mental hacia la promoción de salud: La concepción de lo comunitario en la implementación de proyectos sociales. Alteridad, 2(1), 28-40. (https:// goo.gl/zDb3Me) (2017-01-29).

\section{Books and book chapters}

Full books: Cuéllar, J.C., \& Moncada-Paredes, M.C. (2014). El peso de la deuda externa ecuatoriana. Quito: Abya-Yala.

Chaprter of book: Zambrano-Quiñones, D. (2015). El ecoturismo comunitario en Manglaralto y Colonche. En V.H. Torres (Ed.), Alternativas de Vida: Trece experiencias de desarrollo endógeno en Ecuador (175-198). Quito: Abya-Yala.

\section{Digital media}

Pérez-Rodríguez, M.A., Ramírez, A., \& GarcíaRuíz, R. (2015). La competencia mediática en educación infantil. Análisis del nivel de desarrollo en España. Universitas Psychologica, 14(2), 619-630. https://doi. org.10.11144/ Javeriana.upsy14-2.cmei 
It is prescriptive that all quotations that have DOI (Digital Object Identifier System) are reflected in the References (can be obtained at http://goo.gl/gfruh1). All journals and books that do not have DOI should appear with their link (in their online version, if they have it, shortened by Google Shortened: http://goo.gl) and date of consultation in the indicated format.

Journal articles should be presented in English, except for those in Spanish and English, in which case it will be displayed in both languages using brackets. All web addresses submitted must be shortened in the manuscript, except for the DOI that must be in the indicated format (https://doi.org/XXX).

\subsection{Epigraphs, Figures and Charts}

The epigraphs of the body of the article will be numbered in Arabic. They should go without a full box of capital letters, neither underlined nor bold. The numbering must be a maximum of three levels: 1. / 1.1. / 1.1.1. A carriage return will be established at the end of each numbered epigraph.

The charts must be included in the text in Word format according to order of appearance, num- bered in Arabic and subtitled with the description of the content.

The graphics or figures will be adjusted to the minimum number required and will be presented incorporated in the text, according to their order of appearance, numbered in Arabic and subtitled with the abbreviated description. Their quality should not be less than $300 \mathrm{dpi}$, and it may be necessary to have the graph in TIFF, PNG or JPEG format.

\section{Submission process}

Manuscripts must be submitted only and exclusively through the OJS (Open Journal System), in which all authors must previously register. Originals sent via email or other interfaces are not accepted. The following two files must be sent together:

1. Title page and Cover letter (use official model), in which will appear:

- Title (Spanish) / Title (English): Concise but informative, in Spanish on the first line and in English on the second. A maximum of 80 characters with spaces are accepted. The title is not only the responsibility of the authors, changes being able to be proposed by the Editorial Board.

- Full name and surnames: Of each of the authors, organized by priority. Next to the names must follow the professional category, work center, email of each author and ORCID number. It is mandatory to indicate if you have the academic degree of doctor (include Dr. / Dra. before the name).

- Resumen (Spanish) / Abstract (English).

- Descriptores (Spanish) / Keywords (English).

- A statement that the manuscript is an original contribution, not sent or being evaluated in another journal, with the confirmation of the signatory authors, acceptance (if applicable) of formal changes in the manuscript in accordance with the rules and partial transfer of rights to the publisher.

2. Manuscript totally anonymized, according to the guidelines referred in precedence.

All authors must register with their credits on the OJS platform, although only one of them will be responsible for correspondence. No author can submit or have in review two manuscripts simultane- ously, estimating an absence of four consecutive numbers (2 years). 
